NASACONTRACTOR REPORT
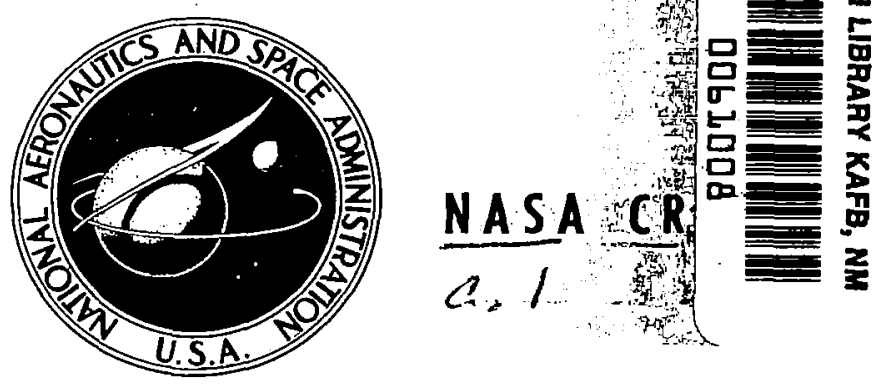

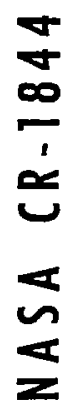

LOAN COPY: RETURN TO AFWL (DOUL) KURTLAND AFB, N. M.

\title{
THE DEVELOPMENT OF
}

A SONIC BOOM SIMULATOR

WITH DETONABLE GASES

by R. T. Strugielski, L. E. Fugelso, L. B. Holmes,

and $W . J$. Byrne

Prepared by

GENERAL AMERICAN RESEARCH DIVISION

Niles, Ill. 60648

for Langley Research Center

NATIONAL AERONAUTICS AND SPACE ADMINISTRATION - WASHINGTON, D. C. - NOVEMBER 197I 
पObLOवB

1. Report No. NASA CR-1844

4. Title and Subtitle

THE DEVELOPMENT OF A SONIC BOOM SIMULATOR WITH DETONABLE GASES

7. Author(s)

R. T. Strugielski, L. E. Fugelso, L. B. Holmes and W. J. Byrne

9. Performing Organization Name and Address

General American Transportation Corporation General American Research Division Niles, Mlinois

12. Sponsoring Agency Name and Address National Aeronautics and Space Administration Washington, D. C. 20546

2. Government Accession No.

3. Recipient's Catalog No.

5. Report Date

November 1971

6. Performing Organization Code

8. Performing Organization Report No.

10. Work Unit No.

$133-61-15-01$ )

11. Contract or Grant No.

NAS1 - 9252

13. Type of Report and Period Covered Contractor Report

14. Sponsoring Agency Code

15. Supplementary Notes

16. Abstract

A sonic boom pressure profile was simulated in the far-field by detonation of a methaneoxygen mixture contained in a slender, shaped mylar envelope. Ideal $N$-waves were synthesized with peak overpressures from two to five psf and durations of 30 to 75 milliseconds. The detonation of the gas mixture was initiated by a single Primacord strand running the length of balloon. The $\mathrm{N}$-wave producing balloon was synthesized as a composite structure, utilizing experimental pressure profiles obtained from the detonations of slender, axisymmetric balloons with elementary, non-cylindrical shapes.

17. Key Words (Suggested by Author(s))

Sonic Boom

N-Wave

Simulator

Detonable Gases
18. Distribution Statement

Unclassified - Unlimited
19. Security Classif. (of this report).

Unclas sified
20. Security Classif. (of this page) Unclassified
21. No. of Pages 177
22. Price* $\$ 3.00$

For sale by the National Technical Information Service, Springfield, Virginia 22151 

FOREWORD

The General American Research Division (GARD) in cooperation with the National Aeronautics and Space Administration (NASA/Langley) has conducted a program to develop a method whereby pressure signatures generated by supersonic aircraft may be readily and economically simulated with detonable gas explosions. Program efforts were directed towards two primary objectives: 1) formulation of a rational basis which enables the design of experiments which will produce a desired pressure signature, and 2) demonstration of the simulation of this pressure signal.

The program was sponsored by the Federal Aviation Administration through Mr. J. K. Power of the Office of Noise Abatement and administered by the National Aeronautics and Space Administration under Contract No. NASI-9252 entitled The Development of a Sonic Boom Simulator with Detonable Gases. The period of performance was 12 June 1969 through 19 June 1970.

GARD personnel were responsible for the design of the experiments, reduction, analysis and interpretation of data. Deployment and loading of the balloon specimen were functions of GARD personnel. NASA/Langley personnel were responsible for the instrumentation and data recording systems. Installation and operation of the detonating ignition system was the function of the NASA/Langley Explosives Crew. Overall responsibility and control of directing the experimental field operation was vested in NASA/Langley personnel.

The cooperation of Messrs. H. B. Pierce, R. H. Rhyne, G. F. Black, and R. N. Barnes of Langley Research Station contributed to the successful completion of the program. Their aid and assistance is gratefully acknowledged.

Major technical and administrative program direction was provided by Dr. W. J. Byrne, Group Leader, Applied Mechanics. The assistance in program planning and fielding of the experiments provided by Mr. R. J. Klima during the program commencenent phase is sincerely appreciated. Successful completion of the program was greatly aided by the efforts of $\mathrm{Mr}$. R. S. Koike of GARD. His invaluable contributions to the fielding of the experiments and the drawing of the figures in this report are acknowledged.

All of the experiments were performed on the Sonic Boom Simulation range at NASA/Langley. The experiments were organized on the basis of four independent test groups, each group consisting of approximately ten specimens. 
FOREWORD................................... ii

INTRODUCTION............................. I

Problem Definition........................ I

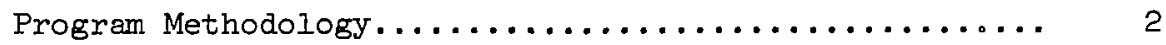

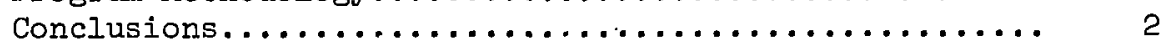

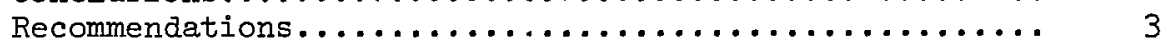

PROGRAM RATIONALE AND PROCEDURE................... 4

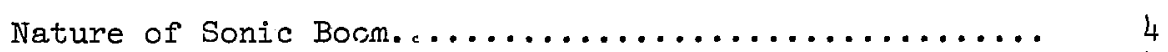

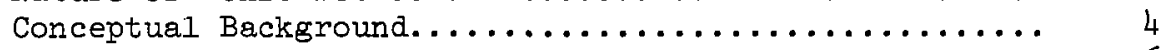

Program Organization....................... 6

EXPERIMENTAL TECHNIQUE..................... 8

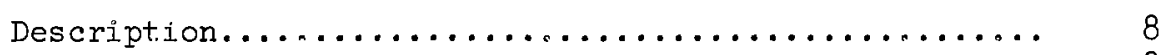

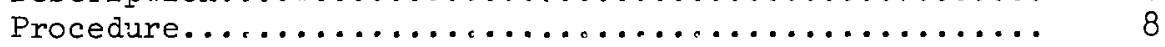

Special Considerations........................ 9

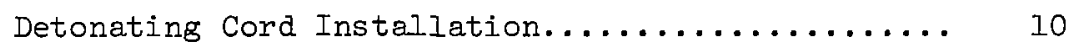

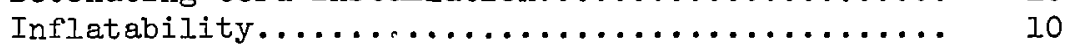

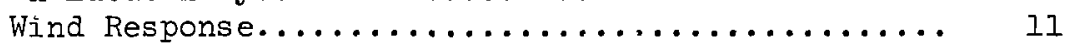

Typical Detonation........................ Il

$\mathbb{N}$-WAVE SYNTHESIS. . . . . . . . . $\ldots \ldots \ldots \ldots \ldots \ldots \ldots \ldots$

Pertinent Experimental Data.................... 15

Properties of Pressure Profiles............. 16

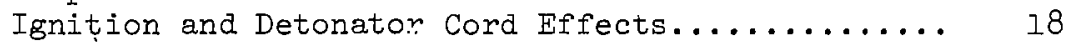

Shape Effects......................... 20

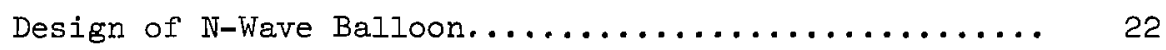

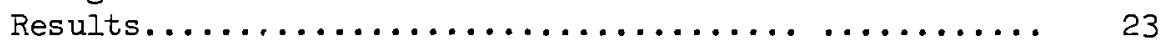

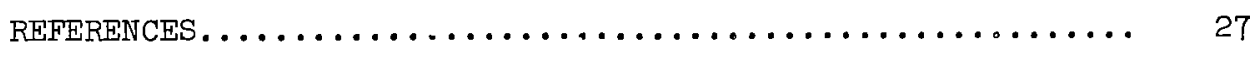

APPENDIX I - EXPERIMENTAL PARTICULARS.............. 28

APPENDIX II - EXPERIMENTAL RESULTS............... 35 
TABLE I PEAK OVERPRESSURE AND TIME DURATION

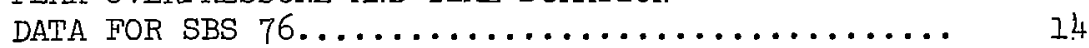

TABLE II SUMMARY OF PRESSURE AND DURATION DATA

MEASURED FOR THE DETONATIONS OF THE

N-WAVE BALLOONS........................ 24

TABLE III(a) SPECIMEN DESIGNATION - TEST SERIES I.......... 38

TABLE III(b) SPECIMEN POSITIONING - TEST SERIES I.......... 39

TABLE III(c) SPECIMEN IGNITION - TEST SERIES I............ 40

TABLE IV(a) SPECIMEN DESIGNATIONT - TEST SERIES II.......... 41

TABLE IV(b) SPECIMEN POSITIONING - TEST SERIES II.......... 42

TABLE IV(c) SPECIMEN IGNITION - TEST SERIES II........... 43

TABLE V $(a)$ SPECIMEN DESIGNATION - TEST SERIES III......... 44

TABLE $v(b)$ SPECIMEN POSITIONING - TEST SERIES III......... 45

TABLE $V(c)$ SPECIMEN IGNITION - TEST SERIES III.......... 46

TABLE VI(a) SPECIMEN DESIGNATION - TEST SERIES IV.......... 47

TABLE VI(b) SPECIMEN POSITIONING - TEST SERIES IV.......... 48

TABLE VI(c) SPECIMEN IGNITION - TEST SERIES IV........... 49

TABLE VII PEAK PRESSURE AND DURATION DATA -

TEST SERIES I........................ 50

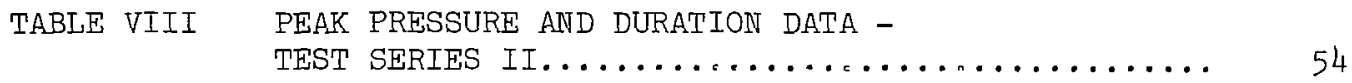

TABLE IX PEAK PRESSURE AND DURATION DATA -

TEST SERIES III...................... 58

TABLE $X$ PEAK PRESSURE AND DURATION DATA -

TEST SERIES IV....................... 62 
THE DEVELOPMENT OF A SONIC BOOM STMULATOR

WITH DETONABLE GASES

\author{
R. T. Strugielski, I. E. Fugelso, I. B. Holmes, and W. J. Byrne \\ General American Research Division
}

INTRODUCTION

Problem Definition

\begin{abstract}
The advent of supersonic aircraft to the field of commercial transportation is accompanied by several significant problems. Foremost along these are the effects of the moving pressure field generated by the high speed flight of these aircraft on objects, both animate and inanimate. A typical sonic-boom waveform at ground level consists of a leading shock, a decay to pressures below ambient followed by a tail shock which returns the pressure to ambient. The magnitudes and durations are dependent upon aircraft configuration, aircraft operational characteristics and atmospheric conditions.
\end{abstract}

The complex nature of the real problem precludes detailed theoretical analysis of sonic-boom response. For this reason an experimental program is the most reasonable means for any response studies.

Actual aircraft utilization in an experimental program is not always possible as over-flights at supersonic speed affect large areas outside the primary test regions and the costs of extensive testing utilizing supersonic aircraft for statistical analysis of atmospheric effects and response of structures are high. Several sonic boom simulation techniques are already in existence, however, their signal generation capability is somewhat limited in terms of signal overpressures and durations (ref. I). These limitations preclude full scale signal. reproduction which in turn limit evaluation of the effects of full scale signals on objects be they existing structures or living beings. Therefore development of a reliable, low cost experimental technique for the reproduction of full-scale sonic booms is highly desirable.

One such technique is the generation of weak air-shock waves by the detonation of detonable-gas mixtures contained in thin plastic or mylar balloons. In order to develop an $\mathrm{N}$-wave generating capability with balloons filled with detonable gases, the balloon geometries which produce $\mathrm{N}$-waveforms must be determined. Once they are determined, an efficient experimental procedure must be devised such that field deployment is accomplished with ease and acceptable cost. These two aspects, namely, determining the family of $\mathrm{N}$-wave generating balloons and detonation of said balloons, have given impetus to the subject program. 


\section{Program Methodology}

The objectives of this program are twofold: 1) to develop procedures that will permit the design of a gas-filled envelope, whose subsequent detonation will produce an $\mathbb{N}$-wave, 2) to successfully design this balloon and demonstrate the $\mathrm{N}$-wave.

To accomplish these aims a primarily experimental program was undertaken in four broad phases. Basic information on the detonation of gas-filled balloons and the ensuing pressure-profiles, was measured in the initial phase. The effects of various ignition devices and their positioning, of augmenting the gas-detonation with detonating cord, and of tethering effects on the balloon were the subjects of the second experimental phase. Investigation of the effect of balloon shape on the far field pressure signal for a variety of elementary balloon shapes comprised the next phase. Utilizing the information gathered in these three phases, a shaped balloon capable of yielding an $\mathrm{N}$-wave was designed, fabricated and tested in the final experimental phase.

\section{Conclusions}

A pressure profile in the form of an $\mathbb{N}$-wave can be generated by the detonation of a shaped, slender gas-filled balloon. A family of such balloons exists which can produce $N$-wave profiles of any desired duration and peak overpressure. The pressure profiles which have been experimentally generated in this program simulate the pressure signals characterizing sonic booms. Signal durations of up to 75 milliseconds were recorded at distances less than 800 feet from the point of balloon detonation. Peak overpressures in the range 3 to 15 psf were obtained.

The balloon configuration required to obtain $\mathrm{N}$-waves having durations on the order of 75 milliseconds at a range of 800 feet is a composite shape, 60 feet long, consisting of two truncated cones and a cylindrical segment, the cones abuting either end of the cylinder. The cone section toward the observation point deviates only slightly from a cylindrical segment, while the other cone has a greater slope. The balloon, when filled with the detonable gas mixture, is suspended from a cable and tethered in a horizontal position 20 feet above the ground. The gas mixture, consisting of a methane and oxygen in the mol.ar ratio of one to two, is detonated by a Primacord strand which lies along the cylindrical axis of the balloon. The Primacord, necessary for stabilization of the resulting pressure signal, is ignited by a conventional detonator at the end of the balloon nearest to the observation point such that the ensuing Primacord detonation propagates away from the observation point. The method, similar in concept to a multiple strand Primacord technique developed by Hawkins and Hicks (ref.2) has a signal which is characteristically devoid of high frequency noise or "hash", typical of air shocks generated by solid explosives. 
Field deployment is simple and safe. A five man crew is required to provide a cycle time of two hours per experiment. The balloon suspension system requires nothing more than a catenary cable with a minimum vertical height above grade of 25 feet which can be provided by two lightweight portable stanchions. The sonic boom simulation technique described in this report is mobile and can be emplaced in any desired locale.

To summarize, the advantages of using detonable gas envelopes in simulating sonic boom environments are: 1) the capability to produce distinct, clear, noise-free pressure wave shapes, 2) the variety of possible wave shapes, 3) site mobility, 4) safety and 5) economy.

\section{Recommendations}

The detonations of gas-filled, slender, shaped balloons of the particular seometry tested in this project yield an $\mathrm{N}$-wave at moderate ranges from the source. These balloon detonations could be used directly as pressure signal inputs to a number of sonic boom effect studies. Response studies of structures such as existing buildings and full scale building components, for example, an exterior wall specimen containing windows and window casements, can be readily and inexpensively tested compared to overflight testing. Since the balloons can be fabricated to any desired size scale, model studies can also be performed. Certain physiological testing might also be considered as this technique generates a signal which does not have much high frequency noise superposed on the signal, a characteristic similar to sonic booms not exhibited by solid explosive simulation.

In order to allow for more versatility of balloon deployment in terms of sonic boom studies at particular geographical sites and/or high altitude testing, several alternate balloon suspending and launching systems have been conceived. The experience gained during the subject program also allowed for the conceptual evolution of a detonable gas loading system which conforms to the gambit of requirements for an efficient, safe, and versatile gas loading system. 


\section{PROGRAM RATIONALE AND PROCEDURE}

\section{Nature of the Sonic Booms}

A distinctive pressure pattern is generated by aircraft moving at speeds greater than the speed of sound. A rotationally symmetric shock is generated from the front end of the craft and a second shock is generated near the tail of the craft. (See Figure 1.) Other shocks may emanate from additional surface features of the aircraft. At points far away from the craft the pressure-time history at any point in the flow field takes on a characteristic shape. (See Figure 2.) The first shock wave generates rapid rise of pressure to a peak value, after which there is an almost linear decay, always to pressure below ambient. The second shock then follows, after which there is a decay to ambient conditions.

This subject study is concerned with sonic booms generated by conventional use of supersonic aircraft in level flight and the simulation of the pressure profiles at ground level. For these conditions the magnitude of the first shock is of the order of 4 psf. The pressures are distributed over a region bounded by a hyperbola which represents the intersection of a cone and a plane parallel to the generator of the cone.

\section{Conceptual Background}

The simplest method for generating sonic booms is the operation of supersonic aircraft at flight conditions which will generate the appropriate disturbance. This process is normally expensive and the effects cover a large area. The full-scale generation is also limited to currently available aircraft and by prevailing weather conditions.

Methods for simulating the pressure distribution in time and/or space on a smaller scale allow for weather contingencies, desired overpressure, duration, and wave shape. The undesirable effects of disturbing whole inhabited areas during testing are eliminated. Also, sonic boom effects that might be expected from as yet unflown and untested craft may be evaluated.

The use of distributed explosives to generate shock waves in air to simulate the pressure profiles expected in a sonic boom was demonstrated by Hawkins and Hicks. (ref. 2,3). They noted that the pressure profile along the extension of the axis of a linear string of Primacord detonated from one end was in the form of a positive pressure pulse followed at some delay by a negative pulse. The arrival of the first pressure pulse corresponded to an acoustic pulse propagating from the near end of the explosive line, while the beginning of the negative phase corresponded to a pulse propagating from the far end. Figure 3 shows a schematic drawing of the pressure pulse obtained from detonating a single strand of Primacord. The observation point is along the extension of the axis of the cord. The duration between the positive and negative pulses is proportional to the length of the explosive charge. Hawkins and Hicks suggested superposing several uniform line charges of different lengths and weights to generate a pressure profile 
approximating that expected in a sonic boom. Figure 4 shows schematically the superposition procedure that they used to construct a typical $N$-wave.

Hawkins and Hicks constructed and detonated multiple strand weaves, experimentally realizing blast profiles approximating the sonic boom pulse. There was a great deal of high-frequency "hash"; i.e., small amplitude noise, superposed upon the main signal. In their later experiments, closer agreement of the main signal to the sonic boom profile was obtained by modifications of the overall explosive loading density per lineal foot of the Primacord array.

That detonable gas explosions can be used to generate air blast waves that will simulate the blast from surface and high altitude nuclear explosions has been demonstrated in a sequence of programs by Balcerzak (ref. 4) and associates. Detonation of a propane-oxygen mixture in a 125 foot hemispherical balloon generated an air blast which effectively simulated a high yield nuclear surface burst. Also experimentally studied was a detonation of a tethered methane-oxygen sphere to simulate aerial bursts. Detonation of envelopes of methane-oxygen in reduced atmospheric pressures were conducted in the BRL spherical blast chamber to simulate very high altitude nuclear blast. Comparison of blast waves generated by gas explosives and solid chemical explosives was afforded for the propane hemisphere and tethered methane explosions. In these configurations, the air blast generated by the gas explosions had much less high-frequency noise and the pressure profile at large distances from the source attained the same shape as those generated by either HE or ruclear blasts. The profile is approximately described by a function of the form

$$
p(x, t)=P(x)\left(1-\left(\frac{t-t_{a}}{t_{1}}\right)\right) \exp \left(-\left(t-t_{a}\right) / t_{2}\right) I\left(t-t_{a}\right)
$$

where $P(x)$ is the peak overpressure, which is a function of the range, $t_{a}$ is the time of arrival of the blast front, $t_{1}$ and $t_{2}$ are parameters and $l(x)$ is the unit step function.

For moderate ranges of overpressures, the air blast from the gas explosions and from $H E$ have the same pressure profile and amplitude range behavior. This suggested that if a detonable gas mixture could be dispersed in a long, approximately cylindrical envelope, the ensuing detonation of this mixture could drive an air shock which would have features similar to that of the sonic boom. Variation of the shape of the pressure profile could be made by varying the diameter of the balloon along its length.

The concept is illustrated in Figure 5. Here a thin plastic envelope in the shape of two truncated cones joined at their bases contain a detonable gas mixture. Primacord is placed along the axis of the envelope. Ignition of the Primacord will cause the gas mixture to detonate, thus producing a timedependent pressure field in the external atmosphere. The characteristics of the pressure profiles are directly related to the geometrical properties of the plastic envelope and the initial conditions of the detonable gas mixture. 
The principle advantages of using detonable gases in simulating the sonic boom environment are their versatility and capability to produce distinct, clear pressure wave shapes. The detonation pressure can be varied by controlling the particular constituents of the detonable gas mixture or the relative proportion of each gas in the mixture. By proper design of the envelope which initially confines the detonable gas mixture, the pressure history or signature may be tailored to whatever wave shape is desired.

\section{Program Organization}

The overall program was divided into four main phases, each phase having definite goals and objectives. These phases, briefly mentioned previously, are elaborated below.

\section{Phase I - Basic Properties of the Gas-Filled Balloon Detonation}

In this series of ten experiments, detonations of gas-filled cylinders were performed to obtain basic information on the quantitative and qualitative aspects of the pressure regimes and experimental procedures. Specifically 1) detonations of cylinders with length equal to diameter, detonated by a single igniter, centrally placed;2) detonations of $20^{\prime}$ long cylinders with varying diameters from $1^{\prime}$ to $3^{\prime}$, having a Primacord strand to augment the detonation and ignited at the end of the balloon nearer the microphone array; and 3) detonations of $50^{\prime}$ and $100^{\prime}$ long balloons, diameter $1^{\prime}$, ignited similarls to the $20^{\prime}$ balloons were performed. The purposes of these detonations were: 1 ) to establish the field operational procedure, 2) to determine the pressurerange character, and 3) to establish the effect of $I / D$ ratio on the shape of the pressure signal.

Phase II - Effect of Ignition Placement and Tethering

Ten detonations were performed to examine the effects of: 1) placement of the detonator, 2) presence of a detonating cord, 3) type of igniter and 4) mode of tethering the balloon on the pressure signal. All balloons tested il this phase were 50' long and $I^{\prime}$ in diameter. Three balloons were tested with gas alone, the detonator being near the microphone array, at the center, or at the far end. Similarly two balloons were tested with Primacord strands running the length of the balloon, ignition occurring at either end. A fourth gas only balloon was detonated with a different load patch spacing, this being done to examine the effects of tethering. In addition, balloons were ignited with either match squibs or a Primacord augnented detonator to investigate the effect of initiation mode on the subsequent detonation. A final balloon configuration used Pyrocore ingtead of Primacord to drive the detonation.

Phase III - Effect of Balloon Shape

Ten $30^{\prime}$ long balloons of various shapes were tested in this phase using a single method of ignition. The method of ignition was chosen from considerations of the results of the previous test series. Optimum detonations were obtained when they had a Primacord strand along the axis and were detonated from the microphone end of the balioon. The shapes included truncated cones and composite cylinder-cone structures. 
Phase IV - N-Wave Synthesis

The results of Phases I, II and III were utilized to design a balloon whose detonation will yield an N-wave. Five balloons, with similar shapes, ranging in length from $30^{\prime}$ to $60^{\prime}$ were constructed. One $30^{\prime}$ long balloon, a variant in detail, was also constructed. Additional balloons, fabricated to match the explosive density of the Hawkins-Hicks (ref. 3) experiment were also tested.

Appendix II contains detailed descriptions of all the balloons tested under these four series. 


\section{EXPERIMENTAL TECHNIQUE}

\section{Description}

Figure 6 presents a pictorial illustration of the test site employed during the program. Suspension of a balloon envelope was accomplished by attaching the balloon to the catenary cable, which was suspended from two towers, with nylon cords. Position stabilization of the balloon was provided by nylon cord tethering lines attached to the balloons and ground stakes. The catenary cable could be raised and lowered by hand.

The gas loading system consisted of an array of gas cylinders with associated flow control valves and pipes located near the balloon envelope. Remote control operation of the gas loading system was provided through a cable attached to control apparatus located in the vicinity of an instrumentation trailer which also provided the requisite electrical power sources.

The pressure transducer system consists of six high performance microphones. The microphones, identical at each section of the array, had a flat response up to $8 \mathrm{kilohertz}$ in the overpressure range measured ( 1 to $60 \mathrm{psf}$ maximum). One microphone was placed 200 feet from the balloon center along a line normal to the axis of the balloon. The remaining five microphones were aligned along a ground line parallel to the longitudinal axis of the specimen, nominally, 200 feet, 350 feet, and 500 feet from the balloon center. The plan views of the microphone array used in the four experimental test series are shown in Figures 7 through 10. All of the microphones were cable connected to automatic magnetic tape recording and paper reproducing systems located in the instrumentation trailer.

Two Fastex motion picture cameras were located 200 feet from the center of the balloon along a line normal to the specimen longitudinal axis. The cameras were operated at 4000 frames per second. The photographs were in color and black/white.

The detonation ignition system consisted of an ignition device, such as an electrical detonator, typically an EB-106, wired by a firing cable to a firing programmer located in the instrumentation trailer. An arming circuit provided the requisite margin of safety against accidental or inadvertent firing.

Details of balloon construction, employed gas loading systems, and instrumentation are presented in Appendix $I$.

\section{Procedure}

Figure 6 succinctly illustrates the catenary method of balloon suspension, the discussion that follows presents the procedure used in the field for preparing the balloon and documents procedures which field experience has shown to be best. 
The first stage in the sequence leading up to the detonation is the proper positioning of the balloon. The catenary and vertical tether lines must be attached and positioned properly. The location on the catenary cable for each tethering line to the corresponding load patch on the balloon is established. The gas loading and pressure monitoring tubes are attached to the catenary, as are the vertical nylon tethering cords, which are cut to the appropriate lengths. The remaining tethering lines are attached to anchors emplaced in the ground.

Once the catenary cable is adjusted and the vertical tethering lines attached to the cable, the next step is the attachment and suspension of the balloon. The catenary cable is lowered and the deflated balloon is unfolded upon a canvas ground cover. Electrical ground connections are attached to the metallized mylar conduit at both ends of the envelope, this being done to prevent accidental premature detonation by the discharge of static electricity which could build up on the balloon surface. A Primacord strand of sufficient length is cut and attached to a length of nylon cord. This cord, which is already strung through the conductive mylar conduit, is then pulled through until the Primacord replaces the nylon cord within the envelope. Tubing is attached to the envelope loading duct on the balloon and the balloon is sealed. The other end of the tubing leads to the gas cylinders. The detonator is taped to the Primacord and also to the catenary cable, this latter procedure for structural security. The tethering lines are attached to the envelope and the catenary cable is raised into firing position.

The detonable gas mixture is injected into the balloon form precharged cylinders of methane and oxygen. Both gases are loaded simultaneously, to insure proper mixing of the gases. When the balloon filling is complete, the cylinder valves are closed by remote control.

During the time period that the catenary and balloon were prepared the instrumentation system for initiating and recording the event was prepared. The preparation included static calibration of the microphones, readying the Ampex tape recorder, loading and positioning the Fastex cameras, and readying the timing and firing programmer. The latter is an electrical device which actuates the recording and photographic systems before the initiation of the event and initiates the event.

Immediately after the event the recorded signals were reproduced from the magnetic tape on paper records, the paper records subsequently used in data reduction.

\section{Special Considerations}

Three facets of experimentation are of great consequence, namely, installation of the detonating cord such that upon balloon inflation the cord aligns itself along the longitudinal axis of the balloon, overpressure in the balloon such that it takes the desired designed shape, and wind response of the uninflated and inflated balloon. The narrative that follows presents the recommendations as to these three experimental facets as obtained from program field experience. 
Detonating cord installation. - A most important detail of an experiment performed with the subject simulation technique is installation of the detonating cord such that upon balloon inflation the cord aligns itself along the longitudinal axis of the balloon without sagging. Photographic coverage of the subject experiments has shown that when the cord does align itself along the axis the detonation wave front takes the classical wedge shape, but when the cord sags, the produced wave front is somewhat non-symmetrical. Figure II illustrates a particularly poor cord installation in that the cord lies on the bottom of the inflated balloon.

Early in the sequence of experimentation the problem of "detonating-cord sag" became apparent. The initial solution was to tape the cord to the balloon nozzle at one end. Then holding the taped end, attempt to pull the cord taut while simultaneously pulling the balloon, and attempt to extend it to full length, and while maintaining the tautness of both the cord and the balloon, tape the cord to the remaining balloon nozzle. This procedure proved of limited success. A variation of the procedure was tried in that instead of attempting to extend the balloon to full length, the balloon was gathered with slack along the length and then taped to the taut cord at the second balloon nozzle, i.e., say the balloon being tested is 50 feet long, tape both balloon nozzles at a distance of 49' " $^{\prime \prime}$ along the cord such that upon inflation the balloon itself would elongate the cord thereby causing a slight tension in the cord which causes the alignment of the cord along the balloon axis with minimal sag between the interior conduit supports. This procedure functioned satisfactorily with long, slender balloons, however, for short, stocky balloons proved ineffective.

A third procedure for cord installation was implemented for SBS-lll and 112 which were short, stocky balloons. The procedure is essentially the variational procedure described except that after threading the cord through the conduit and taping the cord to one nozzle, the balloon is lifted five feet above grade and the cord pulled by hand with sufficient tension such that it is taut and then taped to the balloon at the second nozzle, the balloon again slack along the length by 4 inches as previously described. This procedure, was successful and although somewhat more time consuming is the procedure that should be followed in subsequent testing.

Inflatability. - During the course of the program, balloons were inflated with gauge overpressures varying from a minimum of 3 inches to a maximum of 9 inches of water. Overpressures of 3 inches proved unsatisfactory since balloon shapes were extremely poor; for example, SBS-74 and SBS-75. Overpressures of 5 inches proved marginal for uncomplicated shapes and in the case of complicated composite shapes, such as the tri-diameter cylinder of SBS-96, proved unsatisfactory. Overpressures greater or equal to 7 inches proved satisfactory even for complicated composite shapes, consequently it is recommended that, henceforth, all balloons be pressurized to 8 inches of water gauge.

An additional advantage accrues from pressurizing to 8 inches with regard to detonating cord tautness. Field experience has shown that overpressures less than 5 inches do not pressurize the balloon sufficiently to cause tensioning 
of the cord. Consequently, the cord has unacceptable sag in between the conduit supports. However, field observation of balloons pressurized to 8 inches provides excellent cord positioning. During the inflation process it has been observed that the cord initially sags badly in between the conduit supports. Such sagging continues to an overpressure of 5 inches. When the overpressure approaches 6 inches the cord instantaneously snaps into a position coincident with the longitudinal axis of the balloon. Continued pressurization to 8 inches tensions the cord tending to alleviate any local sags which the cord might have.

Wind response. - A variety of tethering spacings were used during the course of the program. Several balloons were tested in high velocity, gusty wind conditions; SBS-88 and 89 are typical. Both balloons were cylinders, 1 foot in diameter and 50 feet long. SBS-88 had five tethers at a 12.5 foot spacing while SBS-79 had three tethers at a 25 foot spacing. The balloons were tested within an hour with high gusting winds peaking at approximately 25 knots.

With both balloons in position, but uninflated, some 20 feet above grade level, the winds violently whipped the envelope about. However, both envelopes sustained no damage and inflated well. Upon completion of inflation, both to gauge overpressures of 3 inches of water, SBS-88 with the 12.5 foot spacing maintained acceptable stability; however, SBS-89 with the 25 foot spacing, oscillated violently in a vibrational mode shape with nodes at the balloon quarter points. The maximum nodal displacement was approximately 1.5 feet. The shot had to be delayed until the wind dissipated.

Both balloons, however, inflated to good cylindrical shapes. SBS-88 oscillated as a rigid body, while SBS-89 oscillated in a beam mode shape, leading observers to conclude that when testing in high wind states spacings should be 10 feet, while for conditions of mild but gusting winds, 25 foot spacings will cause flexural oscillations of the balloon.

The experience obtained from SBS-88 and SBS-89 was incorporated in Test Series III and IV by limiting tether spacings to a maximum of 15 feet. Deployment of Test Series III and IV balloons, several in high gusting winds, prevented flexural oscillations of the balloons from occurring with excellent uninflated and inflated balloon stability.

\section{Typical Detonation}

The detonation and related phenomena for a typical experimental run are shown in some detail in this section. Thirty-eight gas-filled balloons were detonated during the course of this project and the physical sequences in all successful detonations were essentially similar in their gross features. The refined details, such as the exact shape of the pressure profile for distant stations, of course varied from experiment to experiment. The differences in the pressure profiles, their discrimination and control are discussed in later paragraphs. 
The detonation selected for detailed exposition is SBS-76, a $1^{\prime} \mathrm{x} 20^{\prime}$ cylinder, detonated at the end near the main microphone array. The detonation is augmented by a single strand of Primacord, centered on the axis of symmetry of the balloon and running the length of the balloon. The balloon was filled with methane and oxygen, with a composition of 1.5 moles of oxygen to each mole of methane. The excess pressure of the contained mixture over the ambient pressure was 5 inches of water. The volume of the balloon was 15.7 cubic feet and the gas mixture contained is energetically equivalent to 1.65 pounds of TNT. The balloon was essentially rigid at the initial overpressure. The shape of the balloon maintained prior to the detonation departed slightly from the ideal as there was a slight kink in the center, caused by tethering the center too high. The misalignment of the two cylindrical axes was $5^{\circ}$. The center of the balloon was $20^{\prime}$ from the ground.

Figure 12 shows the pictorial sequence of the detonation as recorded by a Fastex camera. The framing rate was $.25 \mathrm{msec} /$ frame and the sequence shown covers the first $13 \mathrm{msec}$ of the detonation. The progression of the detonation front, excited by the detonation of the Primacord strand is shown in the first five frames. The later frames show the maturing and decay of the fireball.

A plot of the growth and decay of the fireball is shown in Figure 13. The abscissa represents position along the cylinder measured from the ignition end while the ordinate represents time in milliseconds. The fireball is composed of two regions, an intensely luminous region which contains hot, burnt gas mixtures and a less luminous region created when these gas mixturescool, the regions differentiated by visual inspection of the detonation photographs. Two irregular lines are shown, the solid line represents the boundary separating the intensely luminous and less luminous areas while the dashed line represents the boundary separating the less luminous from the clear areas. If the effects of thermal conduction are ignored the intensely lunimous regions denote high pressure burnt gas which creates and drives the far-field pressure signature. The double dashed line represents the rate of Primacord ignition. At any position, the fireball starts when the Primacord detonation wave passes. At the microphone end there is a spherical fireball. The fireball first loses intensity at the single intermediate tethering. Then the spherical fireball separates from the longer cylindrically shaped portions of spent gases. The termination of the peaks of the intense fireball appears to propagate from the tower end of the balloon at a velocity of $1400 \mathrm{ft} / \mathrm{sec}$, which is slightly in excess of the ambient sound velocity.

Figure 14 illustrates the time-displacement history of the fireball in the radial and axial directions for the near and far ends of the specimen, the near end being that end at which the detonator is located while the far end that opposite the detonator location. The theoretical fireball velocity, shown in the figure as a dashed line, is the contact surface velocity between the air and the burnt gas residue of the detonable gas mixture evaluated at the original contact surface. 
Figure 15 shows the pressure histories at the six microphones. The microphone designated as A is placed 190' laterally from the axis. B, C, $D$ and $F$ are in the vertical plane containing the axis, and $200^{\prime}, 200^{\prime}, 350^{\prime}$ and 500' from the center of the balloon. All microphones are at ground level, $20^{\prime}$ below the horizontal plane containing the balloon axis. Table I shows the peak overpressures and the time duration data obtained for this experiment. Figure 16 illustrates the parameters defining an $\mathrm{N}$-wave as used throughout this report. 
TABIE I

PEAK OVERPRESSURE AND TIME DURATION DATA FOR SBS 76

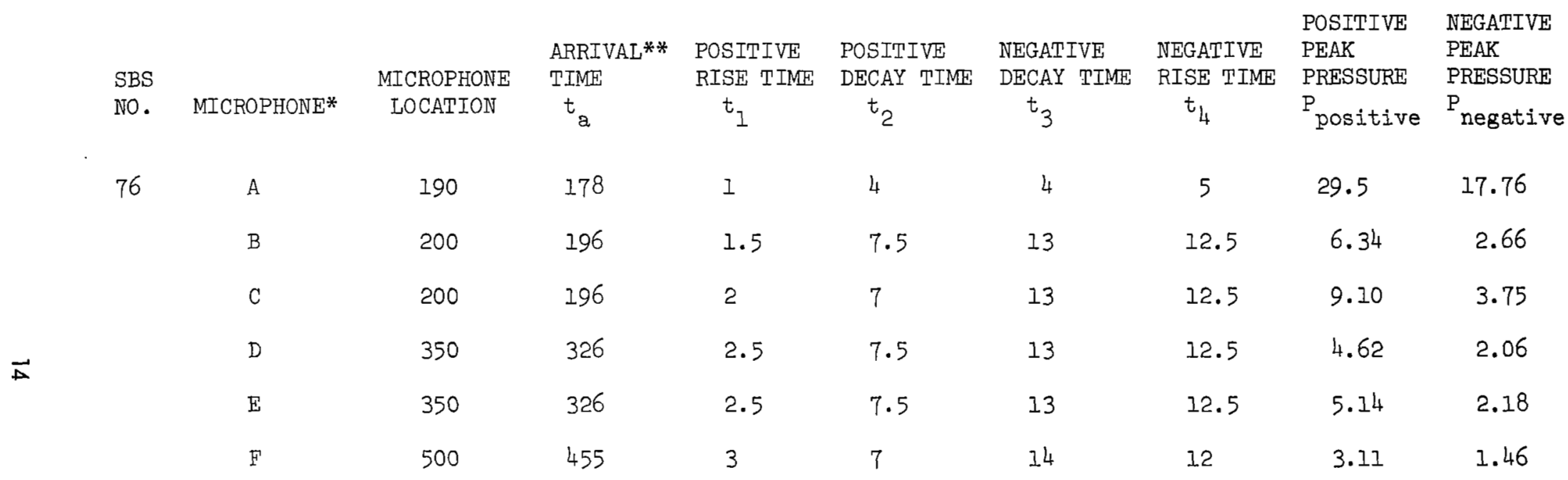

* See Figure 7 for placement of microphone array.

** See Figure 16 for definition of parameters describing the N-wave. 
N-WAVE SYNTHESIS

\section{Pertinent Experimental Data}

The experimental studies of the first three phases were designed to obtain information on several aspects of the detonations and the far-field pressure signals. To reiterate, the first phase of experimentation was to obtain basic information on detonation of gas-filled cylinders. The second phase was the investigation of the effects of positioning the ignition device and the effects of driving the detonation along the length of the cylinder with detonating cord. At the same time, effects of tethering and other miscellany were also examined. The third phase investigated balloons with different shapes and the attendant far-field pressure signals. The fourth phase was the fabrication of a balloon which, when detonated, would generate an $\mathrm{N}$-wave. The experimental results of the first three phases are discussed in this section. The next section will show the utilization of this material to design a shaped balloon whose detonation will result in an N-wave.

All the detonations carried out in all series of the program were in methane-oxygen gas mixtures at a nominal initial pressure of one atmosphere and at ambient temperature. The actual initial pressures at which the gas mixture was maintained prior to detonation exceeded this nominal value slightly for increased stability of the balloon configuration. The chemical composition of the detonable gas mixture was methane and oxygen, with a molar ratio of $\mathrm{O}_{2}$ to $\mathrm{CH}_{4}$ of 1.5 in the first two test series and of 2 for the last two test series. Theoretical detonation parameters for methane-oxygen mixtures at various compositions, initial pressures and temperatures can be computed by the methods presented by Lewis and Von Elbe. (ref. 5) For an initial pressure one atmosphere, an initial temperature of $300^{\circ} \mathrm{K}\left(81.6^{\circ} \mathrm{F}\right)$ and $\mathrm{O}_{2} / \mathrm{CH}_{4}=$ 1.5 , the detonation pressure (Chapman-Joguet pressure) is 451.1 psi or 30.70 times the initial pressure. The detonation velocity is estimated at 8410 $\mathrm{ft} / \mathrm{sec}$. Initial density of the mixture is $0.0693 \mathrm{lbs} / \mathrm{cu}$. ft. The parameters for $\mathrm{O}_{2} / \mathrm{CH}_{4}=2.00$ are: I) the detonation pressure equals $423.3 \mathrm{psi}$, 2) the pressure ratio is $28.78,3$ ) the detonation velocity is $7970 \mathrm{ft} / \mathrm{sec}$ and 4 ) the initial mixture density is $0.0676 \mathrm{lbs} / \mathrm{cu}$. ft. Within the ranges of temperature, initial pressures and actual loading compositions experienced during this program, variation of the detonation pressure, detonation velocity and energy release is quite small, i.e., of the order of $1 \%$ or less.

The peak overpressure and negative peak overpressure versus range data, obtained for each shot and for selected groups of detonations, is exhibited in an expression of the form

$$
P=K R^{n} D^{m}
$$

where $K, n$ and $m$ are constants. For the peak overpressures, $D$ refers to the diameter of the balloon at the end nearer the microphone array, while for the negative peak overpressures it denotes the diameter of the end away from 
the array. When these diameters are different, the former is denoted by $D_{7}$ and the latter by $D_{2}$. For the peak overpressure data, $R$ is the distance from the near end of the balloon to the microphone array, and for the negative peak overpressures, it denotes the distance from the far end, which is equal to $R+L$. The constants $K, n$, and $m$ are determined by a least squares fit to the logarithmic form of equation (2).

$$
\text { In } P=\ln K+n \ln R+m \ln D
$$

assuming that all the experimental error is in the measurement of $P$. The measurement of balloon diameter and microphone position relative to the balloon was accomplished with much greater accuracy than the pressure measurements.

The total of the overpressure-range data is quite extensive and indiscriminate plotting of the data does not readily yield information about the overpressure decay. To illustrate this point, the peak overpressure versus range data for all cylindrical balloon detonations in all phases is shown in Figure 17. Rather than trying to make a definitive statement about the fit to the composite of the data at this time, the analysis of the data will follow the outline given by the various phases.

Appendix II contains the details of the experimental results on all phases of the program. The specifications of all balloon shapes and test conditions are recorded there. Tabular listing of the peak overpressures, negative peak overpressures and time durations are presented. Finally, the pressure-time histories measured at all stations for all the detonations are graphically displayed (Figures 68-112).

Properties of the pressure profiles. - The pressure signals at the farfield positions have a typical profile as described previously. The pressurerange behavior and the duration data for several cylinder detonations will be examined in some detail.

The first part of the Test Series I set of experiments was the determination of the response of the cylinders filled with gas only. Ignition of these cylinders was effected by a single 8-grain detonator located in the center. Figure 18 shows the experimental observations of overpressure versus reduced range (i.e., R/D) for these three detonations (SBS-73, 74 and 75), while Figure 19 shows the experimentally determined negative peak overpressure. Also included in these two graphs is the data for the detonation of a $I^{\prime} \mathrm{x} 50^{\prime}$ cylinder filled with a gas mixture only and ignited by the same type detonator placed 4 feet from the end of the balloon away from the microphone array (SBS86). Inclusion of this shot for these peak overpressure versus range curves was done because the interaction of the initial detonation wave with the end of the balloon near the microphone has the same structure for this case as for the other three. A similar reason is invoked for its inclusion in the presentation and analysis of the negative peak overpressure data. The 
fit to all four shots for the peak overpressure is, in the case where the independent variable is constrained to be $R / D$,

$$
P=4540(R / D)^{-1.23} \text { psf }
$$

The slope for the individual detonations ranges from -1.15 to -1.39 with a mean of -1.25 . If we consider $R$ and $D$ as independent variables, the fit is

$$
P=5250 \mathrm{D}^{1.00} \mathrm{R}^{-1.22} \mathrm{psf}
$$

The spread of this data indicates little preference between forms (4) and (5). Since the former satisfies elementary scaling considerations, based on geometrical similarity, this form will be preferred.

The negative peak overpressure was analyzed similarly, with the resulting approximations

or

$$
\begin{aligned}
& P_{n}=-1740\left(\frac{R+L}{D}\right)^{-1.15} \text { psf } \\
& P_{n}=-467 D^{1.25}(R+L)^{-0.94} \text { psf }
\end{aligned}
$$

Detonations of cylinders, whose detonation is driven by a Primacord strand running the length of the cylinder and which are ignited initially near the microphone end, form another set whose overpressure data should be directly comparable. Shots from Test Series I, II and III fall into this set, comprising experiments SBS-76,77,78, 79, 80 and 99 . Since the data from the latter shot had a different composition of detonable gas than the others, its overpressure data was corrected by a factor equal to the ratio of the detonation pressures of the initial mixtures. Figures 20 and 21 show the peak overpressure and negative peak overpressure data, respectively. Station B points for shots SBS-76, 77 and 78 and the station C points for SBS- 77 and 78 were deleted from the least squares determination of the fit.* The entire set of data points of SBS-79 was deleted from the analysis of the negative peak overpressure as the later stage of the detonation in that experiment degenerated into a deflagration. For the peak overpressure, the following fit was obtained.

$$
P=5080(R / D)^{-1.17} \text { psf }
$$

For the negative peak overpressure,

$$
P_{n}=-944\left(\frac{R+L}{D}\right)^{-1.04} \text { psf }
$$

This series of shots was also examined on the basis of other scaling laws. In particular, one possible scaling law is based on making the characteristic

* Microphones $B$ and $C$ on these particular shots records data which was questionable. 
length proportional to the cube root of the energy released. This variant of scaling results in identical curves for SBS-73, 74 and 75 . In this present case, the cube root scaling completely spreads the data points for SBS-76, 77 and 78 and no valid linear fit can be made. It becomes apparent that the key scaling factor is the diameter at either end and no further attempts to invoke scaling based solely on energy will be made.

The durations of the signal obtained increase with distance from the balloon, the rate of increase being larger for the larger diameter balloons. The duration data for the detonations listed above cannot be readily distinguished, so the data is presented in one set of graphs. The duration between the arrival of the peak overpressure and the negative peak overpressure can be decomposed in the single expression:

$$
T=T_{0}+t+t^{\prime}
$$

$T$ is the duration expected from the length of the balloon and is computed according to elementary acoustic theory; that is, the source of the peak overpressure is at the end of the balloon nearer the microphones and the source of the negative peak overpressure comes from the far end. Numerically it is equal to $L / C$ where $(L)$ is the length of the balloon and $(C)$ the local velocity of sound. $t$ is the contribution to the duration arising from the finite time interval between ignition of either end, and is dependent on the detonation velocity of the gas or of the detonating string, if the detonation is thus augmented. This quantity is also dependent on the sequence and positioning of ignition. Numerically it is equal to $\mathrm{L} / \mathrm{d}$ where (d) is the velocity of detonation of the particular detonating propagating media. The remaining term, $t$ ', is due to the spreading of the pulse. This anomaly is attributed to the convection in the flow field. This term is expected to be larger when the amount of explosive is larger and the effects are noticeable even out to ranges where the peak overpressures are of the order to 5 psf.

Figure 22 shows the anomalous factor in the duration plotted as a function of reduced range, $R / D$. $t$ ' shows a slight increase with range. The development of the negative phase that propagates to long distances, which by acoustic theory should be a rarefaction wave for the far end of the balloon, shows strong interaction with the flow field of hot burnt gases in the source area, thus producing this result.

Ignition and detonator cord effects. - Under the experimental program of Test Series II, comparative experiments were conducted to investigate the effects of point of ignition, of the presence or absence of a Primacord strand, of the size of the igniter and of the method of tethering on the subsequent pressure wave. Figures 23 and 24 show the peak overpressure and negative peak overpressure for three Primacord-driven shots; one ignited at the tower end, i.e., away from the microphone array, the second ignited in the center ard the third ignited at the end near the microphones. For both graphs, overpressures generated by microphone end ignition were largest, followed by center ignition and, finally, by the tower end ignition. The mean exponent of $R / D$ of the peak overpressure versus range curves is -1.10 , while that for 
the negative peak is -0.85 . Apart from the small magnitude difference, the qualitative character of the pressure-time signal at the microphones is different when the incremental portion of the detonation, responsible for the incremental portion of the signal, is being driven toward or away from the microphone array. When the direction of propagation is away, the signal is smooth. When the conditions are reversed, there is a significant sinusoidal signal superposed on the overall mean pressure signal. The period of this sinusoidal wobble is about $10 \mathrm{msec}$.

Figures 25 and 26 show the overpressures in the same sequence as before, this time comparing gas-only detonations, ignited at either end, and Primacorddriven detonations, again ignited at either end. For the peak overpressure, the largest signal. is generated by a gas-only explosion ignited at the microphone end. Next in magnitude, about $10 \%$ lower, is the detonation of gas augmented by Primacord, again ignited at the microphone end. Significantly lower are the detonations initiated at the tower end. For these two, relative order of gas-only and Primacord-driven is intexchanged. Similar order and relative magnitudes occur for the negative peak overpressures. Approximate values of the exponents of $(R / D)$ for the two graphs again are -1.10 and -0.85 , respectively. The pressure signal from the gaswonly detonation has the oscillatory character indicated previously for the tower-end-ignited Primacorddriven shot.

The effects of igniter size and of load patch spacing are shown in Figures 27 and 28 . SBS- 88 and 89 were gas-only detonations with SBS-88 being ignited by solely an EBI06 detionator while SBS-89 was ignited by an EBI06 detonator augmented with a three-quarter inch piece of Primacord. Reference to Figures 87 and 88 which present the pressure-time histories of SBS-88 and 89, respectively, indicates no difference in signal shape and little difference in peak overpressures and durations. These results prompted use of unaugmented EBI06 detonators throughout the remainder of the program since unaugmented detonators are safer and simpler to install and also since augmented detonators have little or no effect on signal shape and durations. Differences in these factors have practically no effect on the peak overpressure or negative peak overpressure. When the load patch spacing is altered for a gas-only detonation, the period of the superposed oscillation on the farmfield pressure signal is changed in direct proportion to the change in spacing. Observations of the pictures of the gas-only detonations show the development of large vortices immediately after passage of the detonation front, and the initial location of these vortices lying bet;ween successive load patches.

At this point it is appropriate to mention one miscellaneous effect observed. In one of the gas-only detonations, a large black, circular paint spot was applied to the balloon for visual identification purposes. When this balloon was detonated, the characteristic vortex structure was again generated, with an added node at the site of the paint circle. In subsequent testing it is recommended that some other means of photographic identification be used. 
AlI of the detonating cord driven experiments employed Primacord manufactured by the Ensign Bickford Company which had an i.gnition propagation velocity of 23000 fps except for SBS-I05 which employed DuPont Company L/A Pyrocore which has an ignition propagation velocity of $8500 \mathrm{fps}$. The Pyrocore specimen underdrove the detonation resulting in a deflagration. Since the detonating velocity of the detonable gas mixture is $8400 \mathrm{fps}$ it is concluded that only detonating cords having ignition propagating velocities considerably in excess of that of the gas mixture, such as Primacord, cause complete detonation of a balloon envelope.

The results obtained during Test Series II indicate that the following specimen ignition procedure will generate the best results. The specimen, when filled with the detonable gas mixture, is suspended from a cable and tethered in a horizontal position 20 feet above the ground. The gas mixture, consisting of methane and oxygen in the molar ratio of one to two, is detonated by a Primacord strand which lies along the cylindrical axis of the balloon specimen. The Primacord necessary for stabilization of the resulting pressure signal, is ignited by a conventional EB 106 detonator at the end of the specimen nearest to the microphone array such that the ensuing Primacord detonation propogates away from the microphone array. This procedure was found to generate a stable, hash free signal.

Shape effects. - Phase III experiments determined the response to shaped balloons, driven by Primacord initiated at the microphone end.

The shapes considered in this phase were truncated cones, and composite structures of truncated cones joined either to cylinders or other truncated cones. The conical shape was chosen primarily for converience of manufacture. Three truncated cones were investigated. Two identical balloons of this shape were detonated, first with the small end near the microphones and then with the large end near the microphones, had a larger slope. Six balloons with composite cylinder-truncated cone structures were then detonated to investigate the resulting pressure field. The conical portions were always at the ends of the structure. The several shapes were chosen to give a wide representation of cone parameters, with tke conical. sections at both the microphone end and the tower end. Figure 29 shows the shapes of the balloon investigated in this section.

The scaling used for analyzing the prior measurements used the diameter of the balloon; however, in this series, the diameter is more specifically indicated as the diameter of the near end for the peak overpressures and of the far end for the negative peak overpressures. Trie data for this series is plotted in Figures 30 and 31. The fits for the corresponding cylinder data are also plotted and are seen to provide a lower bound to the data.

An attempt to further resolve the pressuremrange data is made by pragmatically invoking convection. The theory of the propagation of weak shock waves by Whitham (ref. 6) indicates that the shock front will be degraded faster than $l / r$ by a rarefaction wave overtaking the shock. Figure 32 shows 
schematically this situation. Thus the signal at the shock front, here synonymous with the peak overpressure signal, starts not from the end of the balloon, but from a point some distance from the end of the balloon. The flow velocity at the front is known from the Rankine-Hugoniot jump conditions, thus the location of the shock front and the intercepting characteristics can be approximated. For the weak shock in this problem, the shock velocity was approximated as the average of the characteristic velocity, $u+c$, behind the shock, and, $c$, in front of the shock. Furthermore, $c$, the local sound velocity, was taken as a constant. The signal. at the front, at the range of interest here, originated at a point from 4 to 8 feet from the end of the balloon with a mean of abcut 5 feet. When the balloon has a strong taper, the strength of the shock relative to that predicted from the end is larger. Taking $D_{1}$ as the diameter 5 feet from the microphone end, the data in Figure 30 for the overpressures is replotted in Figure 33. Similarly for the negative peak overpressure, $D_{2}$ is approximated by the diameter 5 feet inboard from the end away from the tower (Figure 34). The correlation is more distinct.

Hawkins and Hicks (Ref。3) have developed woven Primacord simulators which produce 100 and 200 millisecond $N$-waves with designations Mk. I Simulant and Mk.2 Simulant, respectively. Both simulators are characteized by similar charge density functions along their lengths, namely, a monotonically increasing "saw-tooth" Iine to a constant value, the constant value being maintained for approximately the inner $50 \%$ of simulator length, followed by a monotonically decreasing "saw-tooth" line. (See Figure 35.)

Early in the program it was hypothesized that if balloons were manufactured which duplicated the charge densities of the Hawkins and Hicks Simuliants, that $\mathrm{N}$-waves mi.ght be produced upon detonation of the balloons. Given the nature of an inflatable membrane it is impossible to reproduce ihe "saw-tooth" charge densities. Consequently, i.t. was decided to manufacture balloons which produced charge densities which followed the average line drawn through the "saw-tooth" line. (See Figure 35.) Due to program requirements of desired signal durations and peak overpressures as well. as constructional restrictions of balloon manufacture it was impossible to exactly duplicate either of the Hawkins and Hicks Simulants.

However, balloons were designed which produced charge densities which were linear and thus simulated the average line drawn through the "saw-tooth" line exhibited by the Hawkins and Hicks Simuiants. It was found that; in order for a balioon specimen to produce a linear charge density function, that the radii of the balloon must follow a relation involving the square root of balloon length. Two such bal.loons were manufactured, namely, SBS-.107 and SBS-1.09. In order to assess the effect on signal generation of these balloons which have radii following the square root of lengtin two compariton specimens were fabricated, namel.y, SBS-j.06 and SBS-108. SBS-106 and SBS-107 are matched as are SBS-108 and SBS-109 in the sense that: the firstin the two arrays have radi-i which are linear functions of balloon length while the second have radii which are square roct functions of balloon length. Both balloons of a particular array have the same segment: lengths and diameters. 
Figure 35 presents the normalized axial charge densities of the 20.4 foot segments of SBS-106 and 107 illustrating the differences between a linear radii function and a square root radii function. Also illustrated is the normalized average line for the "saw-tooth" charge density of the Hawkins and Hicks Simulants. The purpose of the illustration is to show to what extent the two balloon radii functions approximate the average line. It is readily seen that balloons with radii being a square root function of length is the best approximation.

Detonation of these Hawkins and Hicks-simulating specimens did not generate a signal resembling an $\mathbb{N}$-wave indicating that detonable gas explosions cannot be directly designed from solid explosive data. Little difference was discerned between the signals generated by the matched balloons sets, that is, between the one which radii are linear functions of length and the other where radii are square root functions of length. (See Figures 103 and 104.)

\section{Design of the $N$-Wave Balloon}

After the first three experimental test series were completed, the next step was the design of a balloon configuration which would yield an $N$-wave upon detonation. From the results of Test Series I and Test Series II, the balloon would have a Primacord strand running the length of the balloon, this being required to ensure stability of the pressure signal. Further the detonation of the Primacord strand would progress from the microphone end.

The pressure profile records from Phase III were examined at the $200^{\prime}$ stations. From these a composite record, consisting of the first half of shot SBS-93 and the second half of SBS-98, produced a wave which was almost an $\mathbb{N}$-wave. See Figure 36. The lead spike was just slightly larger. However, examination of the same records at the $350^{\circ}$ and $500^{\prime}$ stations showed that this would decay slightly faster than the negative phase and further that small, favorable changes in shape would occur. The $\mathbb{N}$-wave balloon configuration was thus the front half of SBS-93 joined with the back half of SBS-98. (See Figure 37.) The length of this balloon was taken as 30\%. Larger balloons of the same shape were also fabricated. Scaling considerations indicated that an $\mathbb{N}$-wave of longer duration should be attainable by simple cube root scaling of the balloon, maintaining a geometrically similar shape. An alternate $\mathbb{N}$-wave balloon, a slight modjfication of the previous design, was also prepared (Figure 38). The major difference was that the midale section was slightiy larger in that region of the balloon near the center barely on the microphone side. This augmentation was made to fill in the decay from the peak overpressure.

To further take advantage of the change of the front part of the profile as the pressure wave propagates, the range over which measurements were taken was extended to $800^{\text {? }}$. 
Five-detonations on Phase IV were designed to generate an $\mathrm{N}$-wave. These five, SBS-102, 103, 104, 108 and 112 are geometrically similar, having differend lengths. An $\mathrm{N}$-wave was generated. Figure 39 shows the pressure profile for SBS-102 at a microphone 767 feet from the center of the balloon. At the closer ranges the decay from the peak overpressure to the negative peak overpressure shows a break in the slope about halfway between peaks. This break in slope becomes progressively smaller and finally vanishes. Figure $4 \theta$ shows the pressure profiles at same microphone station for the other three $\mathbb{N}$-wave balloons tested. The duration of the pulses, i.e. peak-to-peak, is approximately proportional to the length of the balloon. Table II lists the peak pressure and durations of $t_{1}, t_{2}, t_{3}$ and $t_{4}$ for these tests.

Figure 41 shows the comparison of the experimental influence function obtained previously from combination of best features of SBS-.93 and 98 (see Fig。 36), with the measured composite structure response. The close agreement of the predicted and measured pressure profiles is indicative that the definite possibility exists that the method described of obtaining $\mathrm{N}$-wave generating balloons can be used to design balloons which can be expected to generate any desired wave form. However, further develofment of the method is required so as to establish the general and repetitive validity of the method.

The peak overpressure and negative peak overpressure versus reduced range are plotted in Figures 42 and 43. Corresponding points for SBS-103, a variant of the $\mathrm{N}$-wave configuration design, are also plotted. The peak over pressure versus range for the $\mathbb{N}$-wave configuration detonations has the fol.lowing approximate equation:

$$
P=6970\left(R / D_{1}\right)^{-1.11} \mathrm{psf}
$$

The negative peak overpressure has the formula:

$$
\mathrm{P}_{\mathrm{n}}=-2330\left(\frac{\mathrm{R}+\mathrm{L}}{\mathrm{D}_{2}}\right)^{-1.1 .5} \mathrm{psf}
$$

Figure 44 shows the duration of the N-wave versus balloon lengths for these balloons as determined from the obtained data. The expression shown on the figure agrees well with durations predicted from Expression 10 on page 17 .

The pressure profile matures into an ideal $\mathrm{N}$-wave as it propagates down range and becomes fully developed when the peak overpressure becomes less than 5 psf. Maturing of $\mathrm{N}$-waves for peak overpressure less than 5 psf can be seen by examining Figure 40 in that below this value of peak overpressure signal hash becomes less exaggerated and the signal. smoother. Thus, for a 
TABLE II

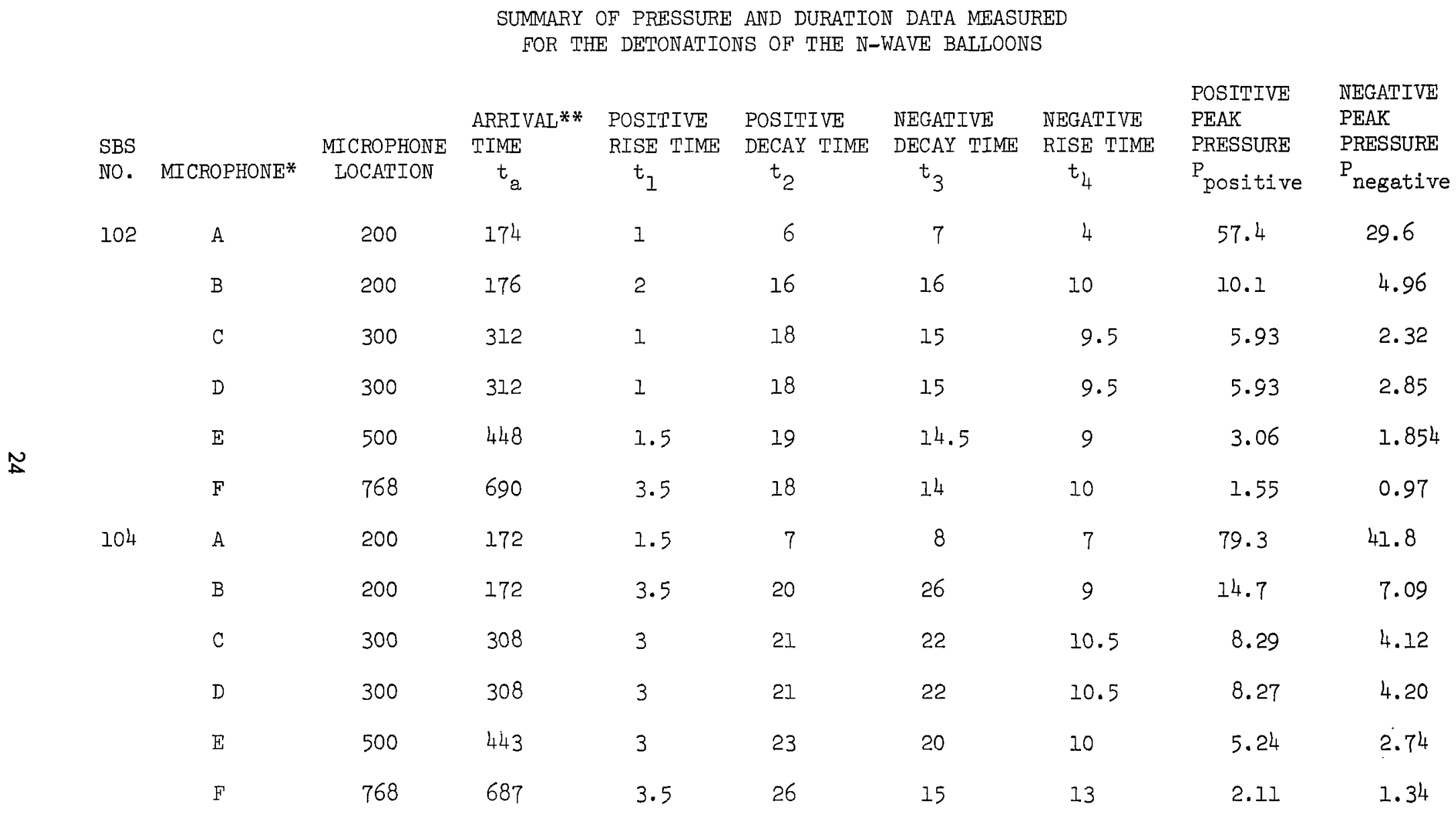

* Microphone array as for Phase IV, see Figure 10.

* See Figure 16 for definition of parameters describing the N-wave. 
TABLE II (CONT.)

\begin{tabular}{|c|c|c|c|c|c|c|c|c|c|}
\hline & & & ARRIVAL & POSITIVE & POSITIVE & NEGATIVE & NEGATIVE & $\begin{array}{l}\text { POSITIVE } \\
\text { PEAK }\end{array}$ & $\begin{array}{l}\text { NEGATIVE } \\
\text { PEAK }\end{array}$ \\
\hline SBS & & MICROPHONE & $\begin{array}{l}\text { TIME } \\
\text { TIM }\end{array}$ & RISE TINE & DECAY TIME & DECAY TIME & RISE TIME & PRESSURE & PRESSURE \\
\hline No. & MICROPHONE & LOCATION & $t_{a}$ & $t_{1}$ & $t_{2}$ & $t_{3}$ & $t_{4}$ & $\mathrm{P}_{\text {positive }}$ & $\mathrm{P}_{\text {negative }}$ \\
\hline 108 & A & 200 & 64 & 1 & 8 & 1 & 5 & 100.1 & 57.7 \\
\hline & B & 200 & 67 & 5 & 32 & 15 & 9 & 21.6 & 9.96 \\
\hline & c & 300 & 302 & 5 & 34 & 16 & 9 & 12.75 & 5.98 \\
\hline & D & 300 & 302 & 4 & 33 & 16 & 9 & 12.5 & 6.2 \\
\hline & $E$ & 500 & 437 & 4 & 33 & 17 & 9 & 8.0 & 4.07 \\
\hline & $F$ & 768 & 680 & 5 & 33 & 16 & 9 & 5.2 & 2.54 \\
\hline 112 & A & 200 & 168 & 1 & 11 & 13 & 6 & 106.3 & 55.6 \\
\hline & B & 200 & 159 & 1 & 27 & 35 & 6 & 23.4 & 10.3 \\
\hline & $\mathrm{c}$ & 300 & 291 & 2 & 26 & 35 & 4 & 12.82 & 4.7 \\
\hline & D & 300 & 291 & 2 & 26 & 35 & 4 & 13.0 & 5.56 \\
\hline & $\mathrm{E}$ & 500 & 423 & 2 & 28 & 34 & 7 & 9.36 & 3.66 \\
\hline & $F$ & 768 & 659 & 5 & 28 & 31. & 8 & 5.31 & 2.74 \\
\hline
\end{tabular}


given balloon length, the minimum range at which an $\mathrm{N}$-wave is developed can be determined, i.e., R/D, must be greater than 700 . Figure 45 presents a design nomograph from which an $\mathbb{N}$-wave generating balloon can be designed. The nomograph is applicable only to balloons which are geometrically similar to the balloon illustrated in Figure 37. Figure 45 enables estimation of the required range at which an $\mathbb{N}$-wave of specified duration and peak overpressure will be generated. The duration desired is used to estimate the length of the balloon as well as the range requirement for a specified peak overpressure. Figure 42 and 44 may be used to estimate the degree of scatter that might be expected in peak overpressure and duraition from a ballocn obtained on the basis of Figure 45. The two figures indicate that a balloon designed on the basis of Figure 45 when exploded will produce actual overpressures and durations varying from those predicted by about $+15 \%$ as there is some spread in the pressure-range data for the N-wave simulation at the lower range of pressures. (N.B. This range figure is the distance from the end of the balloon to that point where the $N$ wave will be observed. It is measured along an extension of the balloon.) Iarger peak pressures from the detonation occur in the lateral direction. See Figure 46, where the peak overpressure versus $r / L$, where $r$ is the lateral distance, is plotted. 
1. Warren, C. H. E.: The Simulation of Sonic Bangs. AGARD Aircraft Engine Noise and Sonic Boom; May, 1969; N70-1313703-02.

2. Hawkins, S. J.; and Hicks, J. A.: Sonic Bang Simulation by a New Explosives Technique. Nature, 211, No. 5055, 1966, pp. 1244-1245.

3. Hawkins, S. J.; and Hicks, J. A.: Sonic Bang Simulation by Explosives. Explosives Research and Development Establishment, Ministry of Technology, Waltham Abbey, Essex, England.

4. Balcerzak, M. J.; and Johnson, M. R.: Use of Detonable Gas Explosions for Blast and Shock Studies. The Shock and Vibration Bulletin, Bulletin 37, Part 4, Jan. 1968, pp. 199-211.

5. Lewis, B.; and Von Elbe, G.: Combustion, Flames and Explosion of Gases. Academic Press, 1961.

6. Whitham, G。 B.: The Propagation of Spherical Blast, Proc. Roy. Soc. London, Ser. A, 203, 1950-B, pp. 571-581. 


\section{APPEINDIX I}

\section{EXPERIMENTAL PARTICULARS}

The narrative presents detailed information of the several facets of the experimental process. Specimen manufacture, specimen field suspension, gas loading systems, and instrumentation systems will be dealt with。

\section{BALIOON FABRICATION}

The sonic boom specimens are balloon envelopes constructed of mylar film. The film material for Test Series I, II, and III was I mil thick while for Test Series IV the mylar film was 2 mils thick. Tearing strengths were $20 \mathrm{lb} / \mathrm{in}$ and $60 \mathrm{lb} /$ in for the $1 \mathrm{mil}$ and $2 \mathrm{mil}$ material, respectively。 Inflatable strengths of the balloon envelopes are greater than 15 inches of water (gauce) pressure for the thinner film and significantly higher for the thicker film. During the course of all the experimental work no inflation failures occurred which verifies the inflational integrity of the employed mylar films. Figure 47 presents the constructional details of a typical balloon. Peculiar aspects of balloon fabrication are discussed in the following sub-sections.

\section{Cylinder End Gathering}

Detail A of Figure 47 illustrates the method employed in closing balloon ends so as to form cylinder end closures. Stability experiments were performed to assess the contribution to shape integrity of the illustrated system of radial tape stiffeners as compared to the same end gathering without the tape stiffeners. It was found that the tape stiffeners added little shape integrity but increased the cost of the balloon by some 30\% due to the consumed labor in their application. Consequently, the tape stiffening system was dispensed with. Figure 48 illustrates a typical end gathering used on all specimens.

An additional benefit accrued from the end gathering method of cylinder closure in that the wrapping could be formed into a gas loading nozzle. Detail B of Figure 47 illustrates the nozzle configuration used throughout the program. The left hand side of the balloon illustrated in Figure 48 shows the hand swirling nozzle forming operation. Once the swirling operation is completed, the nozzle is taped for permanency,

\section{Detonating Cord Conduit, and Support Detail}

A metallized mylar conduit was provided for all specimens which employed detonating cord. The conduit was installed such that upon balloon inflation the conduit aligned itself along the longitudinal axis of the specimen. Conduit supports internal to the balloon were provided at select locations, The supports consisted of three nylon cord strands, $120^{\circ}$ apart, one end of any particular cord being attached to a center rubber bushing through which the conduit passed; the remaining end being attached to the mylar envelope. with taped D-ring connections. Section XX of Figure 47 illustrates the conduit support detail. The conduit has an intemal nylon cord running the 
full length of the balloon so as to facilitate installation of detonating cord by the simple expedient of first attaching the cord to the nylon cord and then pulling the cord through the balloon.

\section{Tethering Detail}

The tethering detail is illustrated in Section $\mathrm{XX}$ of Figure 47. The tethering system consists of three D-rings taped to the exterior surface of the balloon at intervals of $120^{\circ}$ with one always being placed in the vertical plane of balioon symmetry。

\section{Fabrication Schedule}

For a cylindrical specimen having a nominal diameter of less than 3 feet two pieces of mylar sheet material are cut to the proper length and propex width such that upon final seaming the requisite cylindrical shape results. The length of the cut sheet material is approximately the nominal length plus the additional length required for cylinder end wrapping. The width of the two sheets is $\pi$ times the nominal diameter plus $12^{\prime \prime}$ in order to allow for two seams, each seam overlapping three inches. The two sheets are then heat seamed together along the length and the taped conduit D-rings attached in the proper locations on the interior film surface. The tethering taped D-rings are attached to the exterior film surface at the requisite locations.

A separate assembly is simultaneously prepared, namely, the conduit assembly. Metallized mylar, again $1 \mathrm{mil}$ thick, is formed into a cylinder with a single seam. The conduit is fitted with the proper number of rubber bushings in the proper locations along the conduit so as to conform to the required conduit support spacing. The rubber bushings having been previously fitted with the three nylon cord strands.

The completed conduit assembly is attached to the taped conduit D-rings previously installed. The balloon closure seam is now made along the length of the mylar film. The ends are gathered, the nozzle wrapped and taped, and the nozzles securely taped to the exposed conduit.

If the nominal diameter of a cylindrical specimen is larger than 3 feet, three longitudinal seams rather than two are requlred. Shapes which have longitudinal tapers, such as frustrums of cones, generally require more than two seams regardless of the diameter in order to obtain acceptable inflated shapes. The completed balloon is then accordion folded allowing entrapped air to escape and packaged in a secure cardboard box for shipment.

\section{Cost Optimum Balloon}

The optimum unit, from a fabrication standpoint, is a cylinder with gathered ends. It has three tethering patches located every fifteen feet and three conduit supports every ten feet. A one inch diameter conductive tube of metallized mylar extends the full length of the cylinder and has an internal nylon cord for installation of the detonating cord. 


\section{Balloon Economics}

During the course of the program thirty-eight mylar balloons were fabricated. The shapes were primarily regular cylinders, conical cylinders, and unsymmetric tri-diameter cylinders. Nearly all the balloons were of a one-of-a-kind nature. Prices per unit have therefore been comparatively high. By reducing the number of envelope types and sizes and increasing order quantities prices can be significantly lowered. Figure 49 is a graph illustrating cost of the three primary types of balloon shapes in quantities from 10 to 70 units. It should be noted that the most significant factor is quantity not shape. The costs presented in Figure 49 are for a complete field deployable balloon which is 80 feet long and has a maximum diameter of 2 feet with the requisite number of tethering patches and conduit supports.

\section{GAS IOADING AND ASSOCIATED SYSTEMS}

\section{Gas Loading System}

Figure 50 illustrates the gas loading system as essentially used throughout the program. Nitrogen, oxygen, and methane were purchased in commercial gas cylinders. Predetermined portions of oxygen and methane were injected simultaneously into the balloon specimen to form the detonable gas mixture. Nitrogen, an inert gas, was always available to act as either a purging device for expelling a detonable mixture from a leaking deployed balloon or a balloon bursting device if the deployed balloon maintained seal integrity in abort situations.

The figure denotes two types of gas cylinders for methane and oxygen, storage and precharge cylinders. In the context of this report a storage cylinder is a cylinder laden with a particular gas to pressures of approximately 1500 psi and served as the source of gas quantities. A precharge cylinder, on the other hand, is a cylinder of a particular gas at atmospheric ambient. pressure denoted generally as an "empty cylinder". For a particular balloon envelope, knowing the balloon volume and requisite balloon superpressure upon inflation, the precharge cylinders were charged with gas from the storage cylinder to predetermined pressures such that upon release from the now charged "precharged" cylinders the detonable gas would occupy the balloon volume at the required superpressure. The pressure to which the precharge cylinder must be pressurized to fulfill a set of balloon inflation parameters is readily calculable in the manner that follows.

\section{Basis of Precharge Computations}

If we consider a gas mixture mole ratio of oxygen to methane of $1.5\left(\mathrm{O}_{2} / \mathrm{CH}_{4}=1.5\right)$, the precharged cylinder pressures are determined as follows:

The total number of moles in a mixture is defined as

$$
\mathrm{M}=\mathrm{M}_{2}+\mathrm{M}_{\mathrm{CH}}
$$


Substituting the equation of state for a gas into the above results in;

$$
\mathrm{pV} / \mathrm{R}_{\mathrm{O}} \mathrm{T}=\mathrm{P}_{\mathrm{O}_{2}} \mathrm{~V}_{\mathrm{O}_{2}} / \mathrm{R}_{\mathrm{O}} \mathrm{T}_{\mathrm{O}_{2}}+\mathrm{P}_{\mathrm{CH}_{4}} \mathrm{~V}_{\mathrm{CH}_{4}} / \mathrm{R}_{0} \mathrm{~T}_{\mathrm{CH}}
$$

If we now assume each component exerts the mixture pressure while occupying only a partial volume of the mixture,

$$
\mathrm{p}=\mathrm{P}_{\mathrm{O}_{2}}=\mathrm{P}_{\mathrm{CH}_{4}} \text { and } \mathrm{T}=\mathrm{T}_{\mathrm{O}_{2}}=\mathrm{T}_{\mathrm{CH}_{4}}
$$

therefore;

$$
\mathrm{V}=\mathrm{V}_{2}+\mathrm{V}_{\mathrm{CH}_{4}}
$$

The partial volume is related to the mole fraction $\left(\mathrm{n}_{i}\right)$ as follows:

$$
\mathrm{P}_{2} \mathrm{~V}_{\mathrm{O}_{2}} / \mathrm{pV}=\mathrm{n}_{\mathrm{O}_{2}} \mathrm{R}_{\mathrm{O}} \mathrm{T}_{2} / \mathrm{nR} \mathrm{T}
$$

therefore;

$$
\mathrm{V}_{\mathrm{O}_{2}} / \mathrm{V}=\mathrm{n}_{\mathrm{O}_{2}} / \mathrm{n}
$$

Thus the partial volume and mole fraction are proportional and the partial volume can be used to establish the gas mixture mole ratio.

\section{Typical Precharge Computation}

Consider a cylindrical volume two feet in diameter and two feet long. The volume of the cylinder is $6.28 \mathrm{ft}^{3}$. If the balloon is pressurized to five inches of water, the volume of air at one atmosphere is $6.28 \times 1.0112$ or $6.35 \mathrm{ft}^{3}$. A gas mixture having a mole ratio of $\mathrm{O}_{2} / \mathrm{CH}_{4}=i_{.5}$ requires volumes
corresponding to the mole fraction, i.e.,

$$
x_{\mathrm{O}_{2}}=\frac{\mathrm{n}_{2}}{\mathrm{n}_{\mathrm{O}_{2}}+\mathrm{n}_{\mathrm{CH}_{4}}} \text { and } x_{\mathrm{CH}_{4}}=\frac{\mathrm{n}_{\mathrm{CH}_{4}}}{\mathrm{n}_{2}+\mathrm{n}_{\mathrm{CH}_{4}}}
$$

and,

$$
\mathrm{V}_{\mathrm{O}_{2}}=\mathrm{x}_{\mathrm{O}_{2}} \quad \mathrm{~V}_{0}
$$


where,

$$
\mathrm{x}_{\mathrm{O}_{2}}=0.60 \text { and } \mathrm{x}_{\mathrm{CH}_{4}}=0.40
$$

therefore,

$$
\mathrm{V}_{\mathrm{O}_{2}}=3.82 \mathrm{ft}^{3} \text { and } \mathrm{V}_{\mathrm{CH}_{4}}=2.54 \mathrm{ft}^{3}
$$

Standard commercial gas cylinders have a typical liquid volume of 1.75 cubic feet. The pressures required to compress the above gas volumes to the volume of the precharged cylinder volume is computed as follows:

Assume the balloon envelope is evacuated, i.e., collapsed, and the volume of the gas in the tubing is negligible. The precharge pressure is given by:

$$
\mathrm{P}_{\mathrm{T}} \mathrm{V}_{\mathrm{T}}=\mathrm{P}_{0} \mathrm{~V}_{\mathrm{O}}
$$

where

$$
\begin{aligned}
\mathrm{P}_{\mathrm{T}} & =\text { precharge pressure, psia } \\
\mathrm{V}_{\mathrm{T}} & =\text { tank volume, } \mathrm{ft}^{3} \\
\mathrm{P}_{0} & =\text { atmospheric pressure, psia } \\
\mathrm{V}_{0} & =\text { gas volume at atmospheric pressure } \\
\mathrm{P}_{\mathrm{T}}= & \frac{14.7}{1.75} \mathrm{X} \quad\left(\mathrm{V}_{\mathrm{O}}+\mathrm{V}_{\mathrm{T}}\right) \\
= & \frac{14.7}{1.75} \mathrm{X} \quad(3.82+1.75)=46.6 \mathrm{psia} \\
= & 46.6-14.7=31.9 \mathrm{psig}
\end{aligned}
$$

The compressibility effects of the gases can be ignored if the pressures in the precharged bottles are kept relatively low. The compressibility effect on gases at high pressures can be determined from the compressibility factor, Z

where

$$
\mathrm{pv}=\mathrm{ZRT}
$$

The factor $Z$ is an empirical correction factor to align observed data into the form of a simple equation. It can be determined from plots of $z$ versus 
reduced properties of $p$ and $t$. The critical points of oxygen and methane are:

$$
\begin{array}{ll}
\text { Oxygen } & \text { Methane } \\
\mathrm{P}_{\mathrm{c}}=49.7 \mathrm{~atm} . & \mathrm{P}_{\mathrm{c}}=45.8 \mathrm{~atm} . \\
\mathrm{T}_{\mathrm{c}}=-182.1 \circ^{\circ} & \mathrm{T}_{\mathrm{c}}=-116.1{ }^{\circ} \mathrm{F}
\end{array}
$$

The reduced properties at $T=70^{\circ} \mathrm{F}$ and $\mathrm{P}=15$ atm. are:

$$
\begin{array}{lll}
P_{r}=P / P_{c}=15 / 49.7-0.302 & \text { for } \quad P_{r}=15 / 458=0.328 & \begin{array}{l}
\text { for } \\
\mathrm{CH}_{4}
\end{array} \\
T_{r}=T_{C}=\frac{460+70}{460-182.1} & 0_{2} & =1.87 \quad T_{r}=\frac{460+70}{460-116.1}=1.51
\end{array}
$$

therefore, from experimental data;

$$
\mathrm{Z}_{\mathrm{O}_{2}}=0.99 \quad \mathrm{Z}_{\mathrm{CH}_{4}}=0.97
$$

Thus the error is one percent for oxygen at pressures up to 220 psia and three percent for methane. The compressibility effects can therefore be ignored without serious error for pressures below 15 atmospheres.

\section{Schematic Description of Systems}

Figure 51 schematically illustrates the substance of the gas loading, pressure monitoring, and associated electrical control systems.

Test Series I employed remotely controlled ball valves. The ball valves did not permit fine regulation of gas flow. Consequently, in Test Series II the ball valves were replaced with solenoid valves. The solenoid valves functioned satisfactorily in that the system not only permitted fine regulation of the gas flow but also permitted instantaneous control of the flow. The only difference in the gas loading systems of Test Series I and II is the replacement of the ball valves with the solenoid valves. Test Series III and IV employed the solenoid valves.

The balloon internal pressure monitoring system initially designed for Test Series I and II proved insensitive and a high performance pressure transducer was calibrated and integrated into the existing pressure monitoring system for Test Series III and IV. The redesigned system performed satisfactorily. The incorporation of the new balloon internal pressure transducer freed the pressure transducer previously used as the internal pressure transducer. This transducer was used as the oxygen feed line pressure monitor in Test Series III and IV. During Test Series I and II only the methane feed line pressure was monitored. Figure 51 schematically illustrates the evoluation of the gas loading, pressure monitoring, and associated electrical control systems. 


\section{INSTRUMENTATION SYSTEM}

NASA/Langley provided and operated the pressure transducer system as well as the photographic system. The systems were developed by NASA/Langley prior to the present program and are extremely well suited to measure the generated signals and photographically record the progression of balloon detonation.

The pressure transducer system provided pressure-time-histories and arrival. time data of the shock front at various locations. An array of six transducers were available. One of the transducers was always positioned such that it was at a point 200 feet distant from the balloon on a line normal to the longitudinal axis of the balloon and coincident with the balloon center. The remaining five transducers were positioned at various points on a line parallel with the longitudinal axis of the balloon. Figures 7 through 10 present precise transducer locations for the four test series. Accumulated data was instantaneously recorded on magnetic tapes and played back through a system which reproduced the data on paper records.

The photographic system consisted of two Fastex cameras which operated at 4000 frames per second. The films were used to obtain visual air shock records as well as data to determine the uniformity of the detonations. All events involving balloons were film recorded except for SBS-70, 71 , and 72 . 


\title{
APPENDIX IT
}

\author{
APPENDIX II
}

EXPERIMENTAI RESUTIS

DESCRIPTION OF SBS ARRAY

Tables III through VI present an information array for the specimens tested in Test Series I, II, III, and IV respectively. The array is organized on the following basis.

Tables III(a) through VI(a) associate the NASA/Langley Sonic Boom Simulation (SBS) Number with the test conditions. Figures 52 through 66 present the balloon configuration associated with a particular SBS Number. The tables define the purpose of a shot as well as the volume of detonable gas and associated TNT equivalent.

Tables III(b) through VI(b) summarize field data and observations relative to balloon positioning and balloon inflatability. The column denoted by $(H)$ indicates the height above the ground of the horizontal centerline of a particular specimen immediately prior to ignition. The column dencted by (C) indicates the distance from the specimen's longitudinal min-point to ground-zero (see Figures 7 through 10 for definition of groundzero and transducer positions during the four test series). $6 \mathrm{R}$ means that the specimen mid-point was 6 feet to the right of ground-zero while $4 \mathrm{~L}$ means that the specimen mid-point was 4 feet to the left of ground-zero. The column denoted by (Positioning Comments) refers to a general qualitative evaluation of specimen deployment vis-a-vis the t.ransducer array. The column denoted by (Overpressure) refers to the actual balloon overpressure in guage inches of water immediately prior to specimen detonation. The column denoted by (Inflatability Comments) refers to a general qualitative evaluation of the balloon shape after inflation, $i_{\circ} e$, if the specimen was to be a cylinder, did it appear to be a cylinder upon inflation.

Tables III(c) through VI(c) document the ignition mode, type of ignition device, presence or absence of detonating cord, type of detonating cord, detonating cord position, and field comments which include any anomalies and visual-audic evaluations of the events.

The only non-self-descriptive parameter in Tables III through VI is the sclid explosive equivalent, denoted by (TNT Equivo). The basis of the equivalence computation is described in the following section.

\section{Detonable Gas Mixture Equivalence}

In order to employ the vast amount of information available pertaining to solid explosive blast phenomena it is desirable to obtain solid explosive equivalents for mixtures of detonable gases. GARD, through the years of experience with detionable gases has found that the most reliable method of obtaining solid explosive equivalents is on the basis of equating energy release. Typically, knowing that 1 gram of TNT releases 1000 calories of energy and also 
being able to conpute the energy release of a detonable gas under any conditions, a TNT equivalent is readily computable as follows. The parameters which are necessary to compute TNT equivalents are defined in the following tabulation:
a) Nominal volume of inflated specimen in cubic feet, $V$.
b) mole ratios of methane and oxygen, $x_{m}$ and $x_{0}$, respectively.
c) balloon guage overpressure in inches of water, $\mathrm{p}_{\mathrm{H}}$.
d) reaction energy release of gas mixture in $f t-l b / l b, e_{R}$.

The formulation sequence is as follows:

i) Compute the specific volume of the gas mixture, $v_{0} f^{3} / 1 b$

$$
\mathrm{V}_{\mathrm{O}}=\frac{\mathrm{RT}}{\mathrm{p}}
$$

where $R=$ mixture gas constant, $f t-1 b_{F} / 1 b_{M}-O_{R}$

$\mathrm{T}=$ temperature, degrees Rankine

$p=$ absolute pressure of mixture, psf

and $\quad \mathrm{R}=$

$$
\frac{R_{0}}{x_{m} M_{m}+x_{0} M_{0}}
$$

where $R_{0}=$ universal gas constant

$$
\begin{aligned}
& M_{m}=\text { molecular weight of methane } \\
& M_{O}=\text { molecular weight of oxygen }
\end{aligned}
$$

ii) Compute the weight of the gas mixture, $W_{G}$, from:

$$
W_{G}=\frac{V}{V_{0}}
$$

iii) Compute the energy release, $E_{R}$, when the gas mixture is dedetonated from:

$$
\mathrm{E}_{\mathrm{R}}=\mathrm{e}_{\mathrm{r}} \mathrm{W}_{\mathrm{G}}
$$

iv) Compute the solid explosive equivalent, $W_{T N T}$, from:

$$
\mathrm{W}_{\mathrm{T} N \mathrm{NT}}=\mathrm{E}_{\mathrm{R}} / 1.4 \times 10^{6}
$$

where $1.4 \times 10^{6} \mathrm{ft}-1 \mathrm{~b} / \mathrm{lb}$ is the energy released from one pound of TNT. 
PEAK PRESSURE AND DURATION DATA

Tables VII through $\mathrm{X}$ tabulate the sum total of all quantitative data. obtained during the program. Figures 16 and 67 define the data tabulated with reference to a typical pressure signature in the firm of a ciassical $\mathrm{N}$-wave. The microphone arrays for a particular series are as previously indicated in Figures 7 through 10 .

\section{EXPERIMENTAL PRESSURE SIGNALS}

Figure 69 through 110 present the experimentally measured pressuretime signals. Figure 68 provides a key as to interpretation of the signals. 
TABLE. III (a)

SPECIMEN DESIGNATION - TEST SERIES I

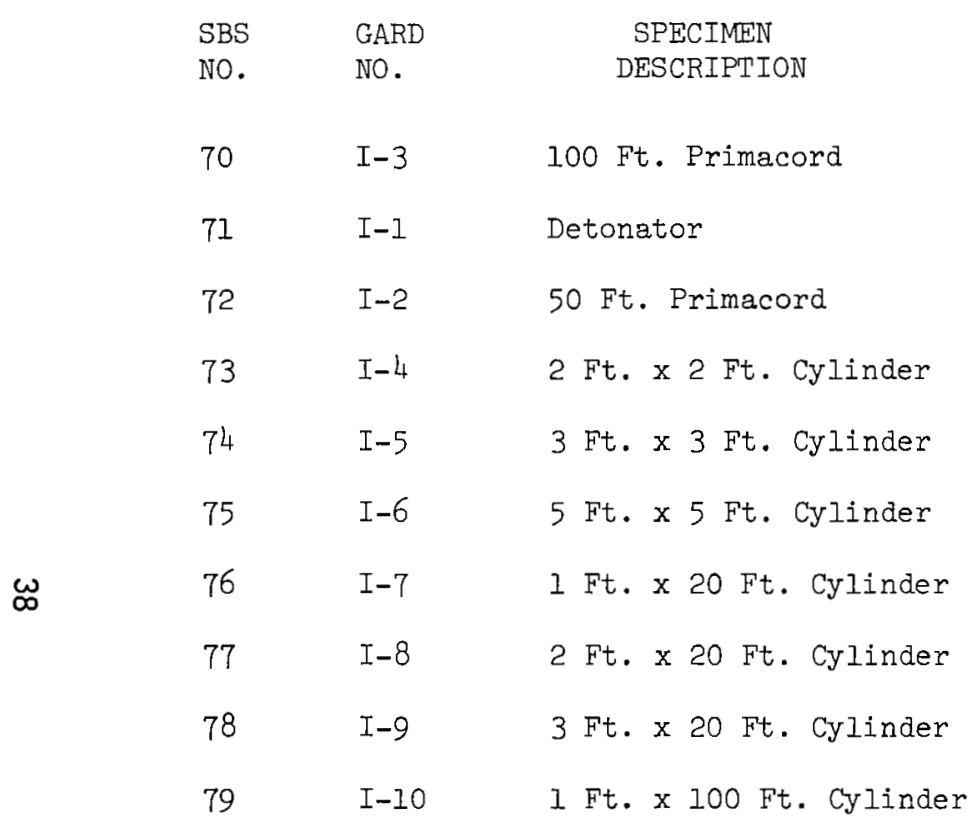

PURPOSE
Ignition Disturbance Effect
Ignition Disturbance Effect
Ignition Disturbance Effect
Point Source Investigation
Point Source Investigation
Point Source Investigation
Effect of Length and Diameter
Effect of Length and Diameter
Effect of Length and Diameter
Effect of Length

$\begin{array}{ll}\text { NOMINAL } & \text { TNT EQUIV. } \\ \text { VOL. }\left(\mathrm{Ft}^{3}\right) & (\text { Lbs })\end{array}$

-- $\quad 0.257$

-- $\quad 0.0014$

$--\quad 0.128$

$6.28 \quad 0.66$

$21.21 \quad 2.22$

$98.20 \quad 10.29$

$15.70 \quad 1.65$

$62.84 \quad 6.62$

$141.34 \quad 14.90$

$78.54 \quad 8.23$ 
TABLE III (b)

SPECIMEN POSITIONING - TEST SERIES I

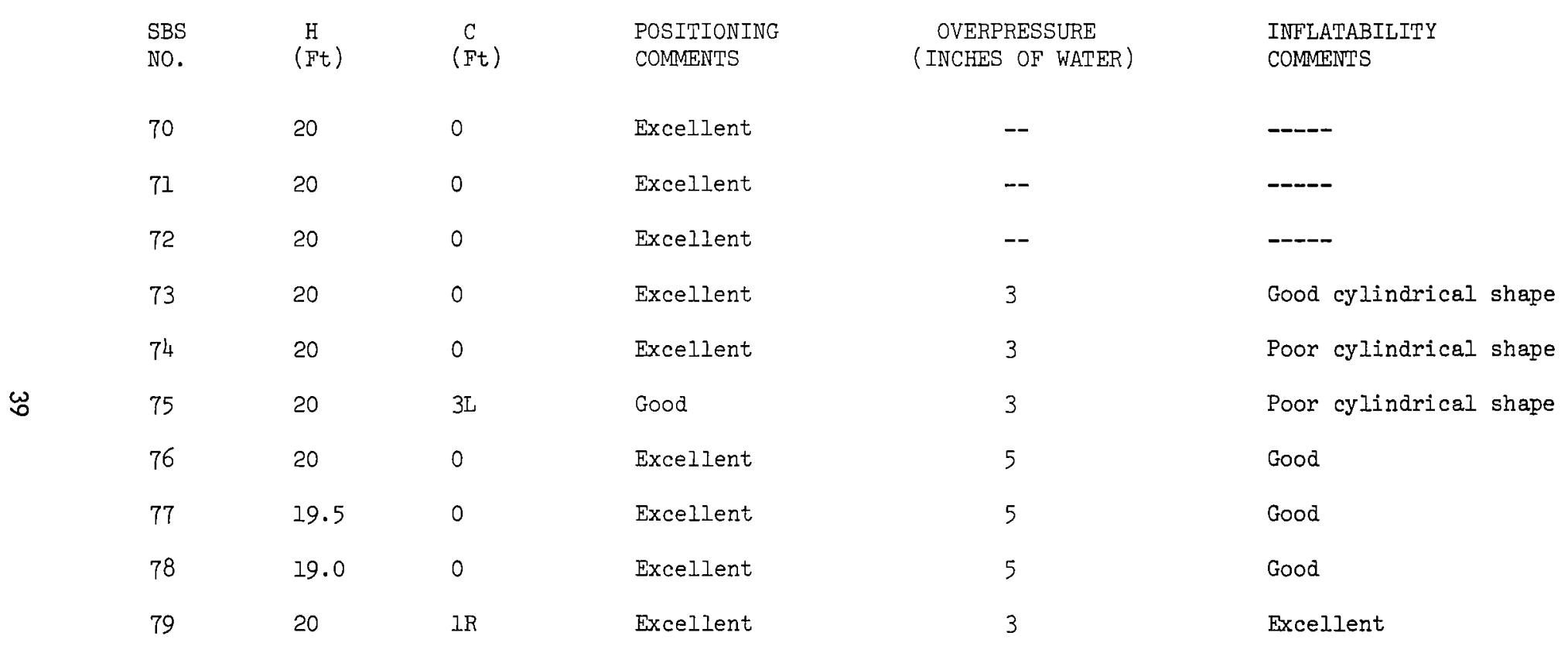


TABLE III (c)

SPECIMEN IGNITION - TEST SERIES I

\begin{tabular}{|c|c|c|c|c|}
\hline \multirow{3}{*}{$\begin{array}{l}\text { SBS } \\
\text { NO. }\end{array}$} & \multirow{2}{*}{\multicolumn{2}{|c|}{ DETONATOR }} & \multicolumn{2}{|l|}{ DETONATING CORD } \\
\hline & & & DETONATION VELOCITY & DETONATING CORD \\
\hline & TYPE & LOCATION & (FPS) & POSITIONING \\
\hline 70 & EB106 & $\begin{array}{l}\text { Microphone } \\
\text { End }\end{array}$ & 23000 & Excellent \\
\hline 71 & $\mathrm{~EB} 106$ & $\begin{array}{l}\text { Over Range } \\
\text { Center }\end{array}$ & NONE & Excellent \\
\hline 72 & EB106 & $\begin{array}{l}\text { Microphone } \\
\text { End }\end{array}$ & 23000 & Excellent \\
\hline 73 & EBI06 & $\begin{array}{l}\text { Over Range } \\
\text { Center }\end{array}$ & NONE & --- \\
\hline 74 & EB106 & $\begin{array}{l}\text { Over Range } \\
\text { Center }\end{array}$ & NONE & -- \\
\hline 75 & EB106 & $\begin{array}{l}\text { Over Range } \\
\text { Center }\end{array}$ & NONE & --- \\
\hline 76 & EB106 & $\begin{array}{l}\text { Outboard Micro- } \\
\text { phone End }\end{array}$ & 23000 & Good \\
\hline 77 & EB106 & $\begin{array}{l}\text { Outboard Micro- } \\
\text { phone End }\end{array}$ & 23000 & Poor \\
\hline 78 & EB106 & $\begin{array}{l}\text { Outboard Micro- } \\
\text { phone End }\end{array}$ & 23000 & Poor \\
\hline 79 & EB106 & $\begin{array}{l}\text { 4-foot Inboard } \\
\text { Microphone End }\end{array}$ & 23000 & Excellent \\
\hline
\end{tabular}

\section{COMMENTS}

Sharp crack report, shot successful.

Sharp crack report, shot successful.

Sharp crack report, shot successful.

Sharp crack report, spherical fireball, shot succesful.

Sharp crack report, spherical fireball, shot successful.

Sharp crack report spherical fireball, shot successful.

Shot successful.

Shot successful.

Microphone end $10 \mathrm{ft}$. detonated better than tower end $10 \mathrm{ft}$.

indicative of poor gas mixing in tower end $10 \mathrm{ft}$. section.

Last $10 \mathrm{ft}$. section at tower end did not detonate well. Debris from this $10 \mathrm{ft}$. section was not pulverized but in the form of $5 \mathrm{ft}$. $x 3$ in. strands. Indicative of poor mixing in tower end

$10 \mathrm{ft}$. section. 
SPECIMEN DESIGNATION - TEST SERIES II

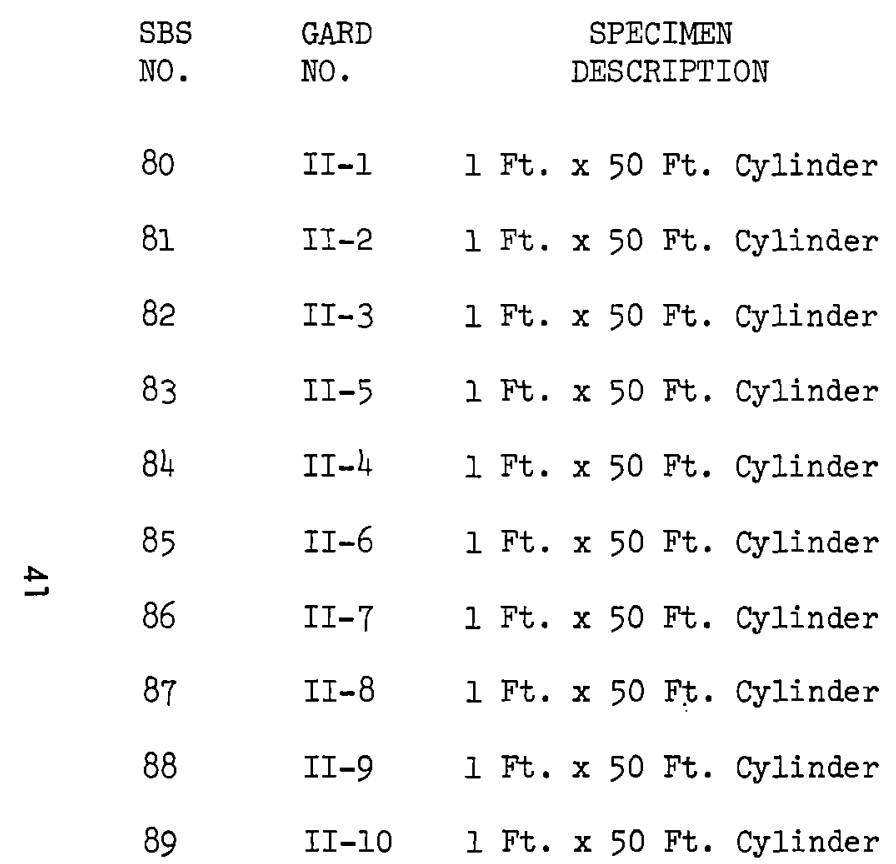

\begin{tabular}{lll}
\multicolumn{1}{c}{ PURPOSE } & $\begin{array}{l}\text { NOMINAL } \\
\text { VOL. }\left(\mathrm{Ft}^{3}\right)\end{array}$ & $\begin{array}{c}\text { TNT EQUIV } \\
\text { (Lbs) }\end{array}$ \\
Ignition Effects & 39.27 & 4.11 \\
Ignition Effects & 39.27 & 4.11 \\
Ignition Effects & 39.27 & 4.13 \\
Ignition Effects & 39.27 & 4.13 \\
Ignition Effects & 39.27 & 4.11 \\
Ignition Effects & 39.27 & 4.13 \\
Ignition Effects & 39.27 & 4.13 \\
Ignition Effects & 39.27 & 4.13 \\
Load Patch Effect & 39.27 & 4.13 \\
Load Patch and Primacord & 39.27 & 4.13 \\
Augmented Detonator Effects & &
\end{tabular}


TABLE IV (b)

SPECIMEN POSITIONING - TEST SERIES II

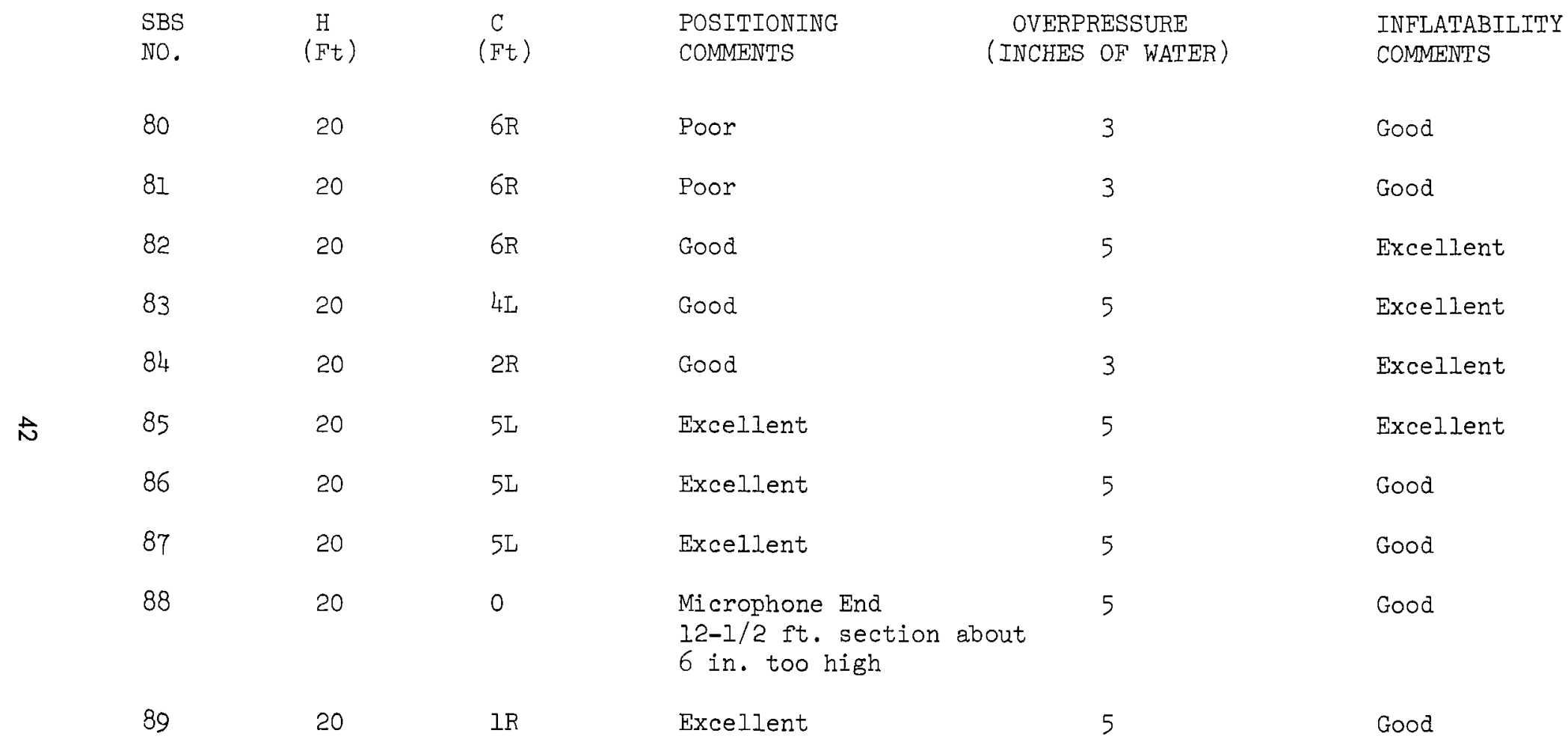


TABLE IV (c)

SPECIMEN IGNITION - TEST SERIES II

DETONATING CORD

\begin{tabular}{|c|c|c|c|c|}
\hline \multicolumn{3}{|c|}{ DETONATOR } & \multirow{2}{*}{$\begin{array}{c}\text { DETONATION VELOCITY } \\
\text { (FPS) }\end{array}$} & \multirow{2}{*}{$\begin{array}{r}\text { DETONATI } \\
\text { POSITI }\end{array}$} \\
\hline No. & TYPE & LOCATION & & \\
\hline 80 & EB106 & $\begin{array}{l}4 \mathrm{ft} \text {. inboard } \\
\text { from micro- } \\
\text { phone end }\end{array}$ & 23000 & Good \\
\hline 81 & EB106 & $\begin{array}{l}4 \mathrm{ft} \text {. inboard } \\
\text { from tower end }\end{array}$ & 23000 & Good \\
\hline 82 & EB106 & Center & 23000 & $5000^{2}$ \\
\hline 83 & $\begin{array}{l}\text { Match } \\
\text { Squib }\end{array}$ & Center & NONE & \\
\hline 84 & $\begin{array}{l}\text { Match } \\
\text { Squib }\end{array}$ & $\begin{array}{l}4 \mathrm{ft} \text {. inboard } \\
\text { from micro- } \\
\text { phone end }\end{array}$ & NONE & \\
\hline 85 & $\begin{array}{l}\text { Match } \\
\text { Squib }\end{array}$ & $\begin{array}{l}4 \mathrm{ft} \text {. inboard } \\
\text { from tower end }\end{array}$ & NONE & \\
\hline 86 & EB106 & $\begin{array}{l}4 \mathrm{ft} \text {. inboerd } \\
\text { from tower end }\end{array}$ & NONE & \\
\hline 87 & EB106 & $\begin{array}{l}4 \mathrm{ft} \text {. inboard from } \\
\text { microphone end }\end{array}$ & NONE & \\
\hline 88 & EB106 & $\begin{array}{l}\text { I ft. inboard from } \\
\text { microphone end }\end{array}$ & NONE & \\
\hline 89 & $\begin{array}{l}\text { EBI06 } \\
\text { augmented } \\
\text { with } 3 / 4 " \\
\text { primacord }\end{array}$ & $\begin{array}{l}\text { I ft. inboard from } \\
\text { microphone end }\end{array}$ & NONE & \\
\hline
\end{tabular}

COMAENTS

Shot successful.

Shot successful.

Extremely loud report and

visually excellent detonation.

Shot successful.

Shot successful.

Shot successful.

Shot successful.

Shot successful.

Shot successful. See page 11 for wind response discussion.

Shot successful. See page 11 for wind response discussion. 
TABLE V (a)

SPECIMEN DESIGNATION - TEST SERIES III

\begin{tabular}{|c|c|c|c|c|c|}
\hline $\begin{array}{l}\text { SBS } \\
\text { NO. }\end{array}$ & $\begin{array}{l}\text { GARD } \\
\text { NO. }\end{array}$ & $\begin{array}{l}\text { SPECIMEN } \\
\text { DESCRIPTION }\end{array}$ & PURPOSE & $\begin{array}{l}\text { NOMINAL } \\
\text { VOL. }\left(\mathrm{Ft}^{3}\right)\end{array}$ & $\begin{array}{l}\text { TNT EQUIV. } \\
\text { (IDS) }\end{array}$ \\
\hline 90 & III-I & $\begin{array}{l}\text { Truncated Cone, l. ft. dia. } \\
\text { towards microphone }\end{array}$ & Shape Effect & 34.24 & 3.44 \\
\hline 91 & III-2 & $\begin{array}{l}\text { Truncated Cone, } 1 \mathrm{ft} \text {. dia. } \\
\text { towards tower }\end{array}$ & Shape Effect & 34.24 & 3.44 \\
\hline 92 & III-4 & $\begin{array}{l}\text { Symmetric Irregular } \\
\text { Cylinder }\end{array}$ & Shape Effect & 34.24 & 3.44 \\
\hline 93 & III-5 & $\begin{array}{l}\text { Unsymmetric Irregular } \\
\text { Cylinder ( } 15 \mathrm{ft} .), 0.50 \\
\text { ft. dia. toward microphones }\end{array}$ & Shape Effect & 34.51 & 3.46 \\
\hline 94 & III-6 & $\begin{array}{l}\text { Unsymmetric Irregular } \\
\text { Cylinder (10 ft.), } 0.50 \\
\text { ft. dia. towards microphones }\end{array}$ & Shape Effect & 38.40 & 3.86 \\
\hline 95 & III-3 & $\begin{array}{l}\text { Truncated Cone, } 1 \text { ft. dia. } \\
\text { towards microphones }\end{array}$ & Shape and Size Effect & 54.97 & 5.53 \\
\hline 96 & III-1I & $\begin{array}{l}\text { Tri-diameter Cylinder } \\
10 \text { ft. section towards } \\
\text { microphones }\end{array}$ & Shape Effect & 62.52 & 6.30 \\
\hline 97 & III-7 & $\begin{array}{l}\text { Unsymmetric Irregular } \\
\text { Cylinder (10 ft.), } 1.4 \mathrm{ft} \text {. } \\
\text { dia. towards microphones }\end{array}$ & Shape Effect & 38.40 & 3.86 \\
\hline 98 & III-9 & $\begin{array}{l}\text { Symmetric Irregular } \\
\text { Cylinder }\end{array}$ & Shape Effect & 42.20 & 4.25 \\
\hline 99 & III-10 & $\begin{array}{l}\text { Regular Cylinder } \\
1.4 \mathrm{ft} . \mathrm{x} 30 \mathrm{ft} .\end{array}$ & $\begin{array}{l}\text { Control Specimen for } \\
\text { Test Series III }\end{array}$ & 46.17 & 4.60 \\
\hline
\end{tabular}


TABLE V (b)

SPECIMEN POSITIONING - TEST SERIES III

\begin{tabular}{|c|c|c|c|c|c|}
\hline $\begin{array}{l}\text { SBS } \\
\text { NO. }\end{array}$ & $\begin{array}{l}\mathrm{H} \\
(\mathrm{Ft})\end{array}$ & $\begin{array}{l}\mathrm{C} \\
(\mathrm{Ft})\end{array}$ & $\begin{array}{l}\text { POSITIONING } \\
\text { COMMENTS }\end{array}$ & $\begin{array}{c}\text { OVERPRESSURE } \\
\text { (INCHES OF WATER) }\end{array}$ & $\begin{array}{l}\text { INFLATABILITY } \\
\text { COMMENTS }\end{array}$ \\
\hline 90 & 20 & 0 & Excellent & 7.4 & Excellent \\
\hline 91 & 20 & $I R$ & Excellent & 7.5 & Excellent \\
\hline 92 & 20 & IR & Excellent & 8 & Excellent \\
\hline 93 & 20 & IR & Excellent & 7 & Excellent \\
\hline 94 & 20 & 0 & Excellent & 8 & Excellent \\
\hline 95 & 20 & 0 & Excellent & 8 & Excellent \\
\hline 96 & 20 & 0 & Good & 4 & Poor \\
\hline 97 & 20 & 0 & Excellent & 8 & Excellent \\
\hline 98 & 20 & 0 & Excellent & 8 & Excellent \\
\hline 99 & 20 & 0 & Excellent & 4 & Excellent \\
\hline
\end{tabular}


TABLE V (c)

SPECIMEN IGNITION - TEST SERIES III

DETONATING CORD DETONATION VELOCITY

(FPS)

23000

23000

23000

23000

23000

23000

23000

23000

23000

23000
DETONATING CORD

POSITIONING

COMMENTS

Excellent

Excellent

Excellent

Excellent

Excellent

Excellent

Excellent

Excellent

Excellent

Excellent

Excellent

Excellent

Excellent

Sagging in last section nearest tower
Excellent

Good, see pagell for wind response discussion.

Excellent

Excellent

Good 
TABLE VI (a)

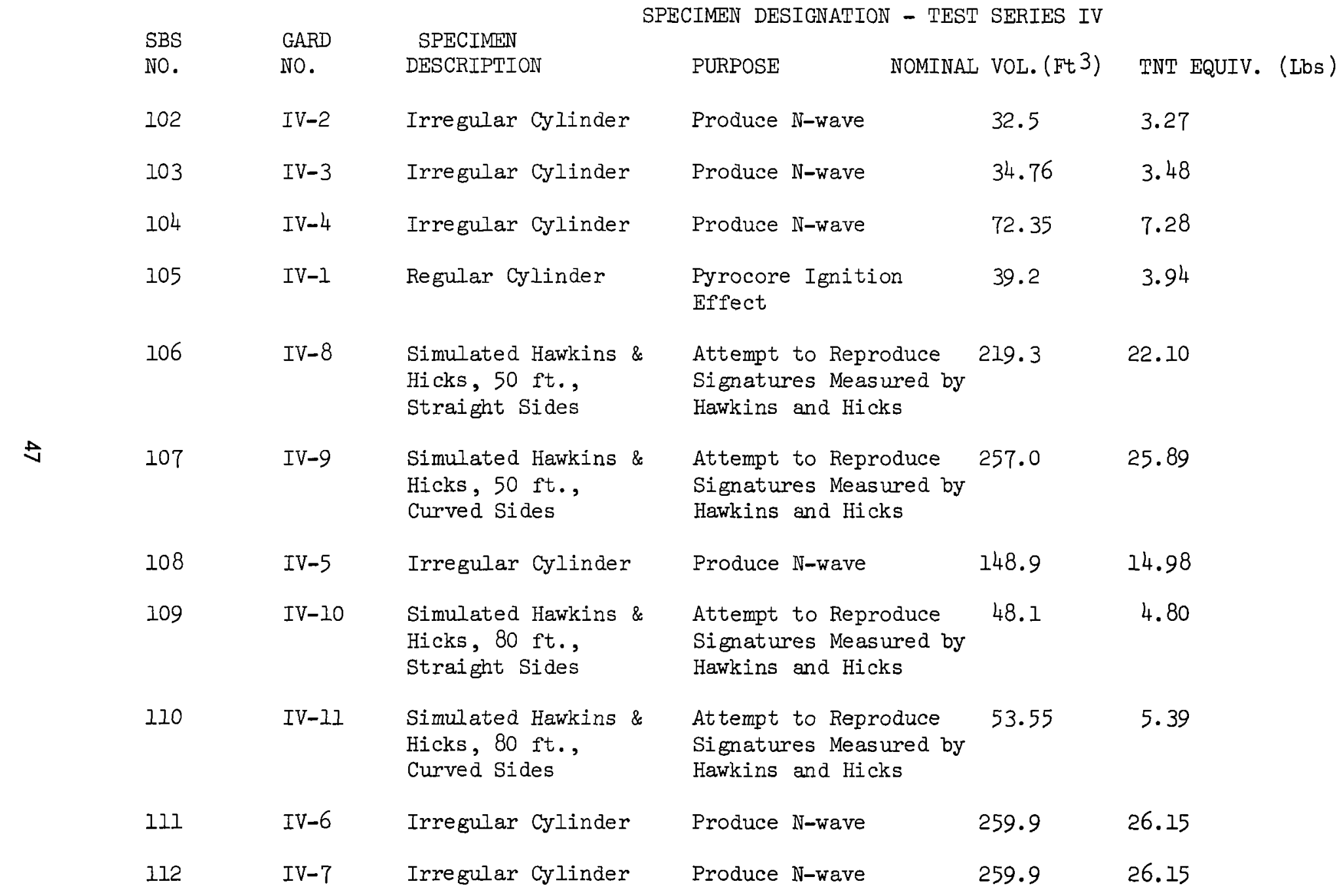


TABLE VI (b)

SPECIMEN POSITIONING - TEST SERIES IV

$\begin{array}{lll}\text { SBS } & \mathrm{H} & \mathrm{C} \\ \text { NO. } & (\mathrm{Ft}) & (\mathrm{Ft}) \\ 102 & 17 & 0 \\ 103 & 17 & 2 \mathrm{~L} \\ 104 & 17 & 0 \\ 105 & 15 & 1 \mathrm{~F} \\ 106 & 15.33 & 2 \mathrm{~L}\end{array}$

$\stackrel{+\infty}{\infty}$

$\begin{array}{llll}107 & 15.33 & 2 L & \begin{array}{l}\text { Tower end of balloon } \\ \text { is } 6 \text { in. too high }\end{array} \\ 108 & 15.17 & 0 & \begin{array}{l}\text { Microphone end of } \\ \text { balloon is } 1 \mathrm{ft} . \\ \text { too high }\end{array} \\ 109 & 15.5 & 0 & \begin{array}{l}\text { Excellent } \\ 110\end{array} \\ 15.5 & 0 & \text { Excellent } \\ 111 & 15.5 & 0 & \text { Excellent } \\ 112 & 15.5 & 0 & \text { Excellent }\end{array}$

Tower end of balloon

\section{OVERPRESSURE INFLATABILITY (INCHES OF WATER) COMMENTS}

Excellent

8

Excellent

Excellent

6

Excellent

Good

$10 \mathrm{ft}$. section near-

est microphones is

$1 \mathrm{ft}$. too high, $10 \mathrm{ft}$. section nearest tow$e r$ is 6 in. too low

Excellent

8

Excellent

Excellent

Excellent

Good

Excellent 
TABLE VI (c)

SPECIMEN IGNITION - TEST SERIES IV

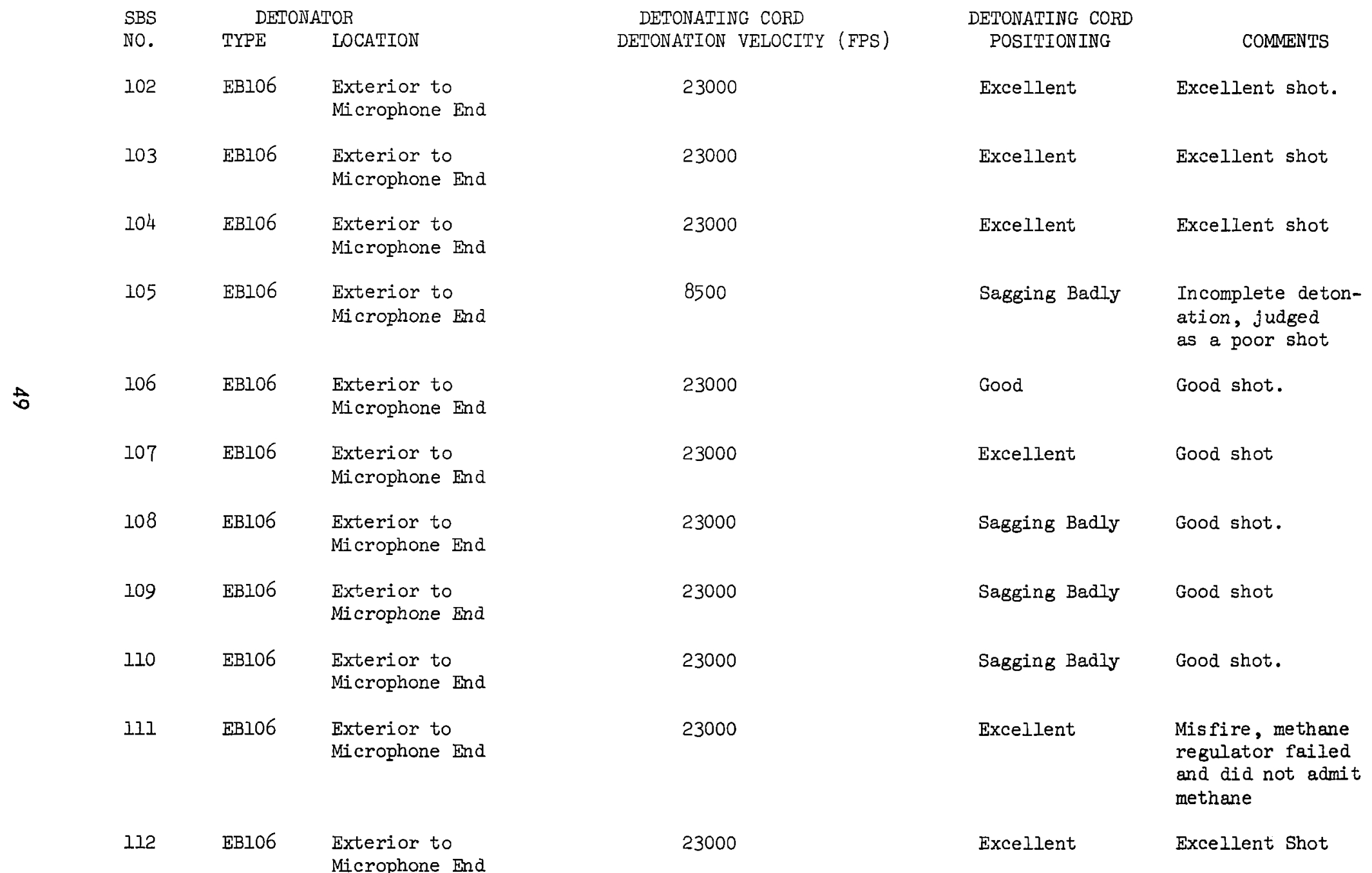


TABLE VII

PEAK PRESSURE AND DURATION DATA*

TEST SERIES I

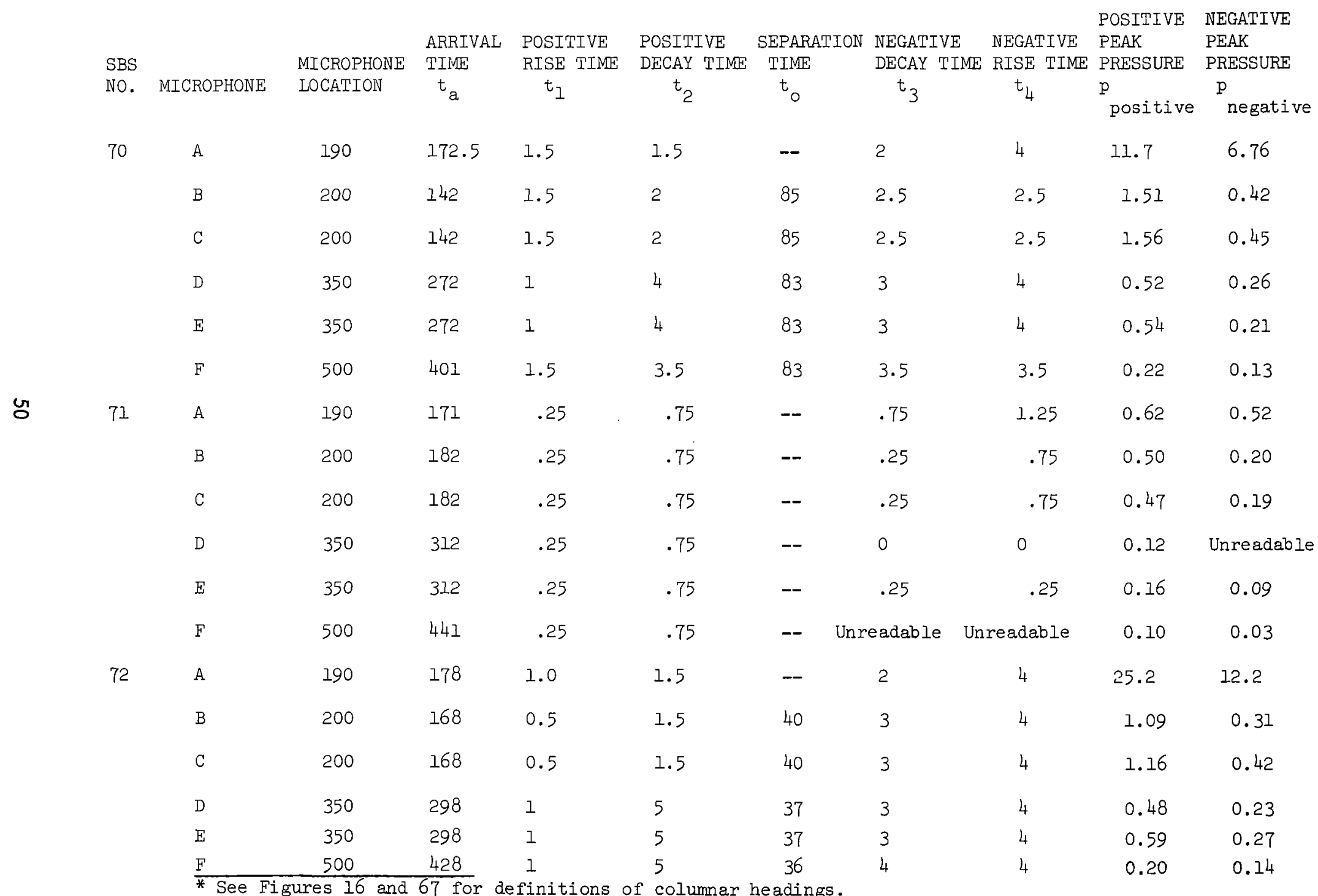




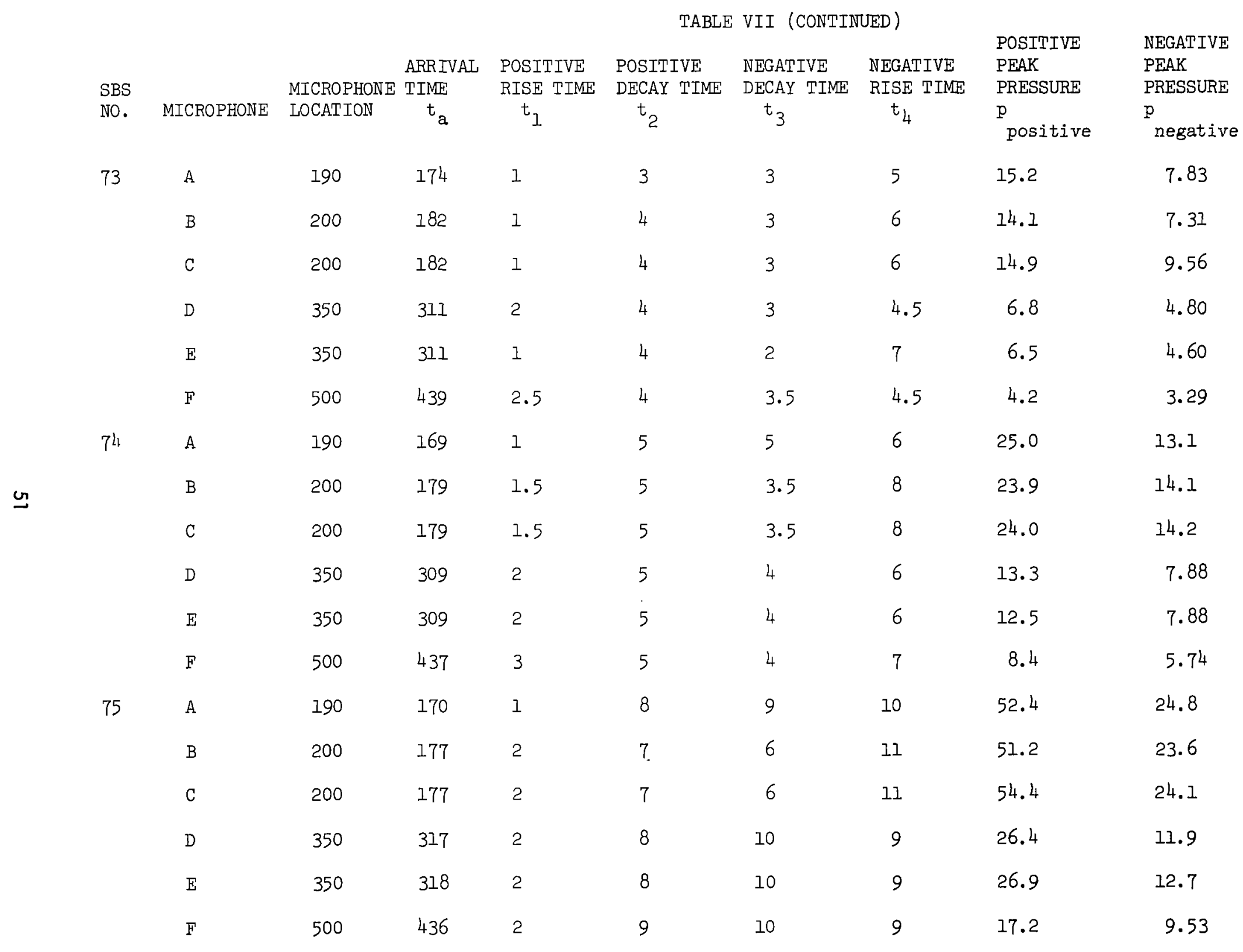


TABLE VII (CONTINUED)

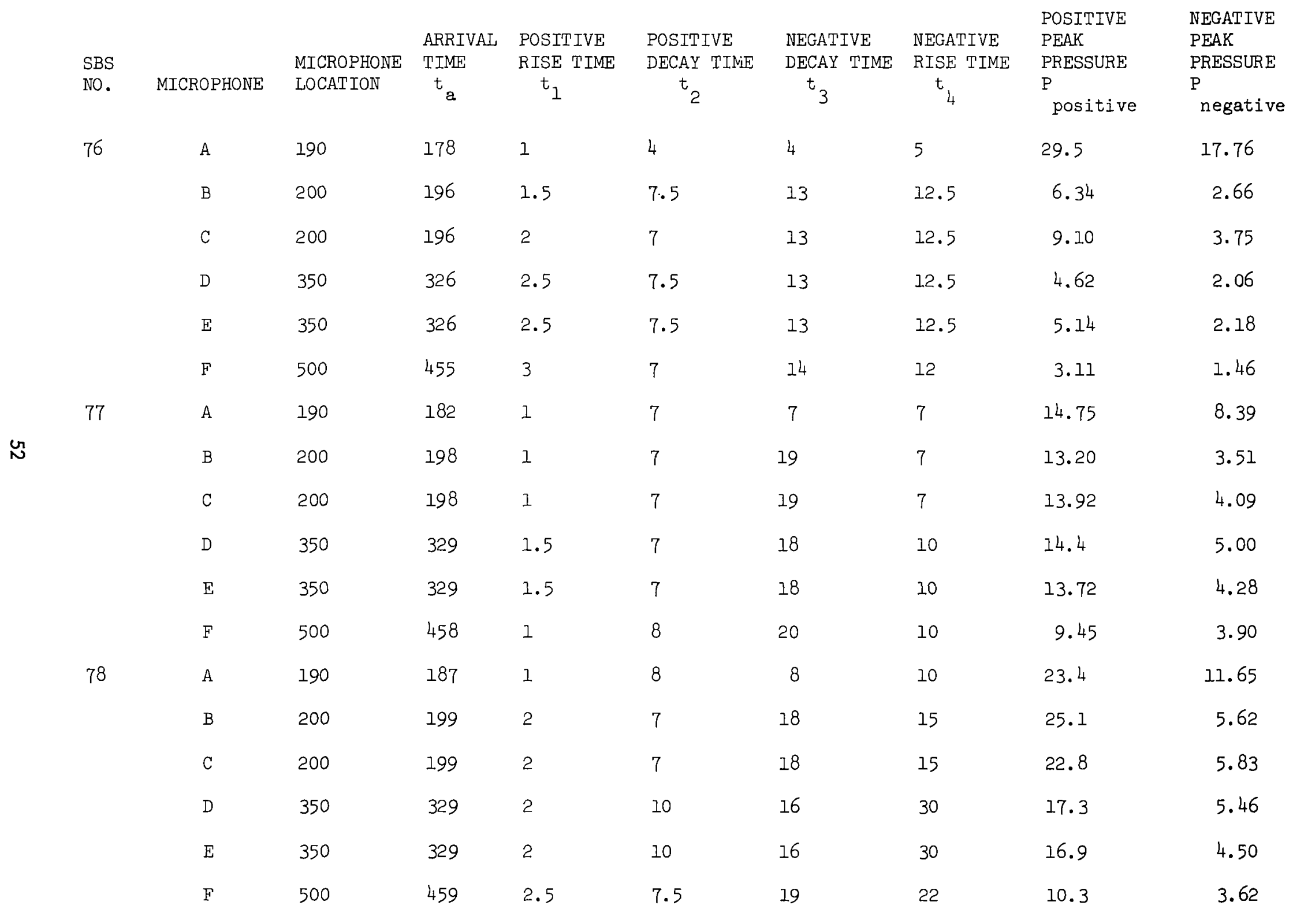


TABLE VII (CONTINUED)

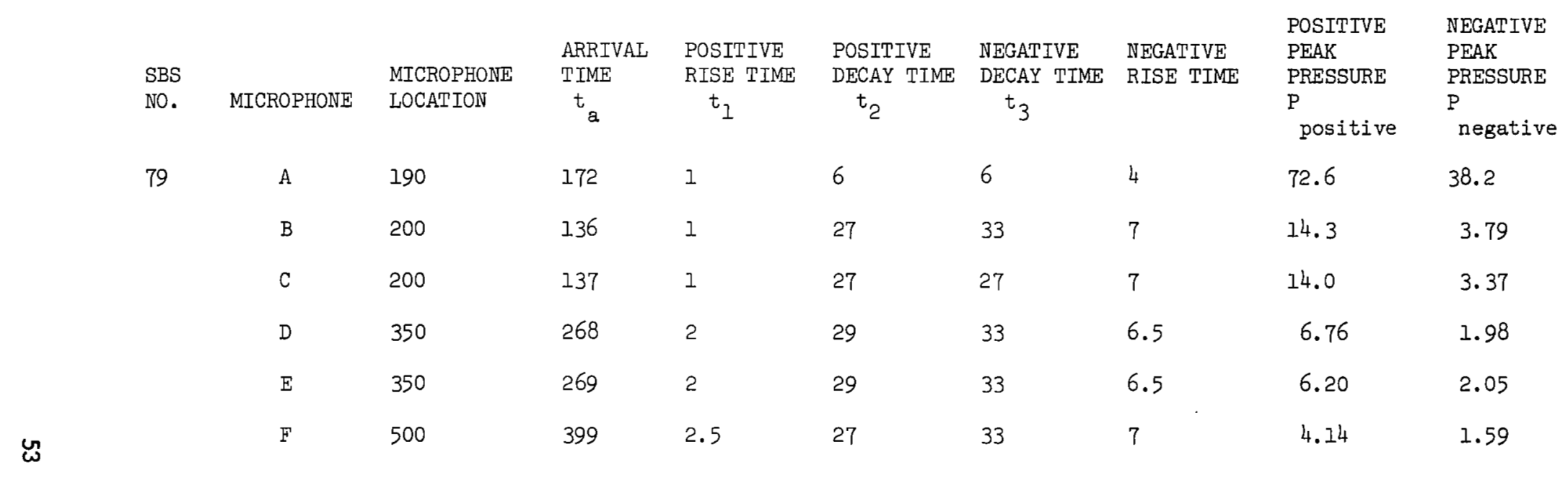


TABLE VIII

PEAK PRESSURE AND DURATION DATA TEST SERIES II

\begin{tabular}{|c|c|c|c|c|c|c|c|c|c|}
\hline & & & ARRIVAL & POSITIVE & POSITIVE & NEGATIVE & NEGATIVE & $\begin{array}{l}\text { POSITIVE } \\
\text { PEAK }\end{array}$ & $\begin{array}{l}\text { NEGATIVE } \\
\text { PEAK }\end{array}$ \\
\hline SBS & & MICROPHONE & TIME & RISE TIME & DECAY TIME & DECAY TIME & RISE TIME & & PRESSURE \\
\hline NO. & MICROPHONE & LOCATION & $t_{a}$ & $\mathrm{t}_{1}$ & $t_{2}$ & $t_{3}$ & $t_{4}$ & $\begin{array}{l}\mathrm{P} \\
\text { positive }\end{array}$ & $\mathrm{P}$ negative \\
\hline \multirow[t]{6}{*}{80} & A & 200 & 169 & 1 & 6 & 6 & 6 & 55.9 & 21.6 \\
\hline & B & 200 & 166 & 2 & 15 & 35 & 6 & 10.8 & 3.21 \\
\hline & $\mathrm{C}$ & 200 & 167 & 2 & 15 & 35 & 6 & 11.9 & 3.24 \\
\hline & D & 350 & 298 & 2 & 16 & 33 & 6 & 6.14 & 2.08 \\
\hline & $\mathrm{E}$ & 350 & 298 & 2 & 16 & 33 & 6 & 5.53 & 2.05 \\
\hline & $F$ & 500 & 428 & 2.5 & 16 & 34 & 6 & 3.90 & 1.47 \\
\hline \multirow[t]{6}{*}{81} & A & 200 & 170 & 1 & 5 & 5 & 6 & 66.7 & 31.4 \\
\hline & B & 200 & 170 & 1 & 31 & 12 & 11 & 8.60 & 2.62 \\
\hline & $\mathrm{C}$ & 200 & 170 & 1 & 31 & 12 & 11 & 8.23 & 2.62 \\
\hline & D & 350 & 302 & 2.5 & 31 & 13 & 10 & 4.37 & 1.30 \\
\hline & E & 350 & 302 & 2.5 & 31 & 13 & 10 & 4.19 & 1.76 \\
\hline & $F$ & 500 & 432 & 3 & 31 & 13 & 11 & 2.79 & 1.29 \\
\hline \multirow[t]{6}{*}{82} & A & 200 & 169 & 1 & 5 & 5 & 6 & 56.8 & 27.4 \\
\hline & B & 200 & 168 & 1 & 35 & 13 & 11 & 10.30 & 2.86 \\
\hline & C & 200 & 168 & 1 & 35 & 13 & $I I$ & 10.72 & 2.62 \\
\hline & D & 350 & 299 & 2 & 34 & 12 & 13 & 5.00 & 1.73 \\
\hline & $E$ & 350 & 299 & 2 & 34 & 12 & 13 & 4.36 & 1.78 \\
\hline & $F$ & 500 & 430 & 2 & 36 & 11 & 12 & 3.16 & 1.42 \\
\hline
\end{tabular}




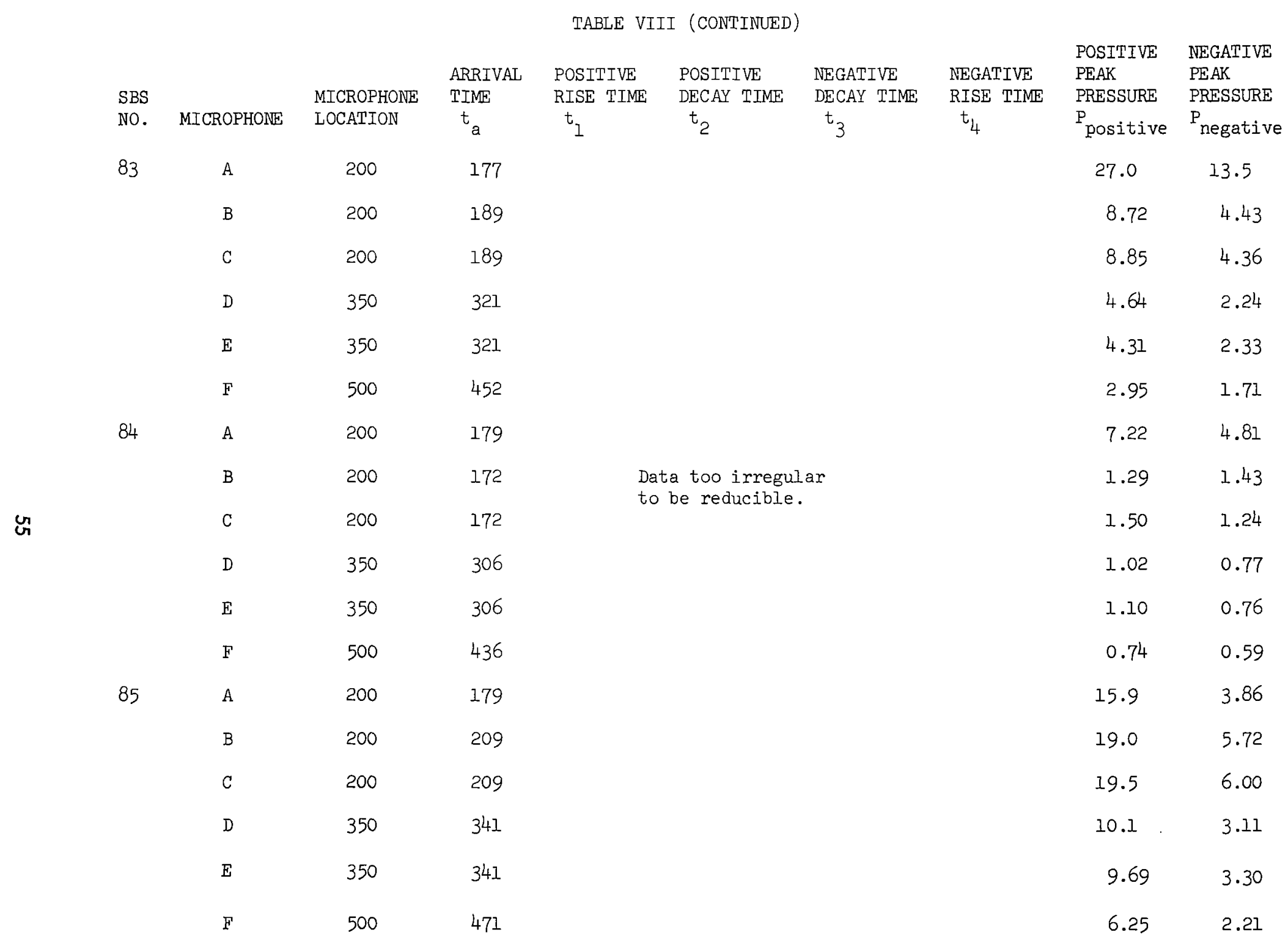




\begin{tabular}{|c|c|c|c|c|c|c|c|c|c|}
\hline & \multicolumn{9}{|c|}{ TABLE VIII (CONIINUED) } \\
\hline & & & ARRIVAL & POSITIVE & POSITIVE & NEGATIVE & NEGATIVE & $\begin{array}{l}\text { POSATIVE } \\
\text { PEAK }\end{array}$ & $\begin{array}{l}\text { NEGATIVE } \\
\text { PEAK } \\
\text { PPFCSIRF }\end{array}$ \\
\hline SBS & & MICROPHONE & TIME & RISE TIME & DECAY TIME & DECAY TIME & RISE TIME & PRESSURE & \\
\hline No. & MICROPHONE & LOCATION & $\mathrm{t}_{\mathrm{a}}$ & $t_{1}$ & $t_{2}$ & $t_{3}$ & $t_{4}$ & $\mathrm{P}_{\text {positive }}$ & ${ }^{\mathrm{P}}$ negative \\
\hline 86 & A & 200 & 171 & 1.5 & 5 & 7 & 6 & 57.5 & 24.1 \\
\hline & B & 200 & 172 & 1 & 18 & 18 & 2 & 7.87 & 2.86 \\
\hline & C & 200 & 172 & 1 & 18 & 18 & 2 & 7.86 & 2.54 \\
\hline & D & 350 & 302 & 2 & 18 & 18 & 2 & 3.77 & 1.70 \\
\hline & E & 350 & 302 & 2 & 18 & 18 & 2 & 3.72 & 1.69 \\
\hline & $F$ & 500 & 433 & 2 & 18 & 18 & 2 & 2.27 & 1.36 \\
\hline 87 & A & 200 & 169 & 1 & 6.5 & 9 & 2 & 42.4 & 24.1 \\
\hline & B & 200 & 168 & 3.5 & 7 & 42 & 3 & 13.4 & 3.58 \\
\hline जू & $\mathrm{C}$ & 200 & 168 & 3.5 & 7 & 42 & 3 & 13.3 & 3.24 \\
\hline & D & 350 & 299 & 2 & 9 & 42 & 4 & 7.40 & 2.04 \\
\hline & E & 350 & $29 y$ & 2 & 9 & 42 & 4 & 7.36 & 1.86 \\
\hline & $F$ & 500 & 429 & 4 & 8 & 42 & 5 & 4.90 & 1.24 \\
\hline 88 & A & 200 & 170 & 2 & 5 & 9 & 2 & 42.7 & 29.1 \\
\hline & B & 200 & 164 & 2 & 9 & 44 & 2 & 15.6 & 2.80 \\
\hline & C & 200 & 164 & 2 & 9 & 44 & 2 & 15.9 & 2.66 \\
\hline & D & 350 & 297 & 2.5 & 7 & 47 & 4 & 7.65 & 1.63 \\
\hline & $\mathrm{E}$ & 350 & 297 & 2.5 & 7 & 47 & 4 & 7.71 & 1.66 \\
\hline & $\mathrm{F}$ & 500 & 429 & 3 & 7 & 45 & 3 & 5.28 & 1.27 \\
\hline
\end{tabular}




\begin{tabular}{|c|c|c|c|c|c|c|c|c|c|}
\hline & & & & TABLE VII & (CONTINUED) & & & & \\
\hline & & & ARRIVAL & POSITIVE & POSITIVE & NEGATIVE & NEGATIVE & $\begin{array}{l}\text { POSITIVE } \\
\text { PEAK }\end{array}$ & $\begin{array}{l}\text { NEGATIVE } \\
\text { PEAK }\end{array}$ \\
\hline SBS & & MICROPHONE & TIME & RISE TIME & DECAY TIME & DECAY TIME & RISE TIME & PRESSURE & PRESSURE \\
\hline No. & MICROPHONE & LOCATION & $t_{a}$ & $t_{1}$ & $t_{2}$ & $t_{3}$ & $t_{4}$ & $\mathrm{P}_{\text {positive }}$ & $\mathrm{P}_{\text {negative }}$ \\
\hline 89 & A & 200 & 164 & 3 & 6 & 8 & 8 & 39.8 & 20.4 \\
\hline & B & 200 & 163 & 3 & 5 & 43 & 7 & 15.9 & 3.70 \\
\hline & C & 200 & 163 & 3 & 5 & 43 & 7 & 16.1 & 3.93 \\
\hline & D & 350 & 294 & 3 & 5 & 43 & 7 & 8.18 & 1.92 \\
\hline & $E$ & 350 & 293 & 3 & 5 & 43 & 7 & 7.35 & 1.70 \\
\hline & $F$ & 500 & $42 b$ & 3 & 5 & 43 & 7 & 5.19 & 1.30 \\
\hline
\end{tabular}


TABLE IX

PEAK RRESSURE AND DURATION DATA - TEST SERIES III

91.

$\begin{array}{lllll} & & & & \\ \text { ARRIVAL } & \text { POSITIVE } & \text { POSITIVE } & \text { NEGATIVE } & \text { NEGATIVE } \\ \text { TIME } & \text { RISE TIME } & \text { DECAY TIME } & \text { DECAY TIME } & \text { RISE TIME } \\ t_{a} & t_{1} & t_{2} & t_{3} & t_{4}\end{array}$

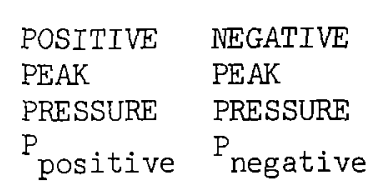

90

$\begin{array}{ll}\text { A } & 200 \\ B & 200 \\ C & 200 \\ D & 350 \\ \text { E } & 350 \\ \text { F } & 500\end{array}$

$\begin{array}{ll}172 & 1.0 \\ 173 & 1.5 \\ 173 & 1.1\end{array}$

5.5

7.5

5.9

12.2

18.3

4.8

7.0

309

2.0

16.0

$$
22.0
$$

7.0

18.4

15.5

$$
18.3
$$

6.6

309

2.3

16.5

18.2

5.3

9.6

9.6

9.0

10.2

12.7

5.9

15.2

15.2

15.8

14.8

15.4

$440 \quad 1.1$

500

$$
6.4
$$

25.5

25.4

25.7

23.5

22.5

7.0

16.6

16.8

16.2

16.4

16.7

$$
7.5
$$$$
7.3
$$

6.1

8.4

8.6

8.5

10.6

$$
9.0
$$

2.4

9.6

9.6

10.1

10.7

10.1
59.6

12.4

11.5

6.83

6.37

4.30

57.4

16.8

17.2

9.54

8.77

5.67

51.0

12.1

12.1

6.52

5.93

4.37
29.0

7.06

6.46

3.87

3.69

2.75

29.2

3.68

3.31

2.02

1.79

1.54

27.2

4.71

4.71

2.79

2.60

1.95 
TABLE IX (CONTINUED)

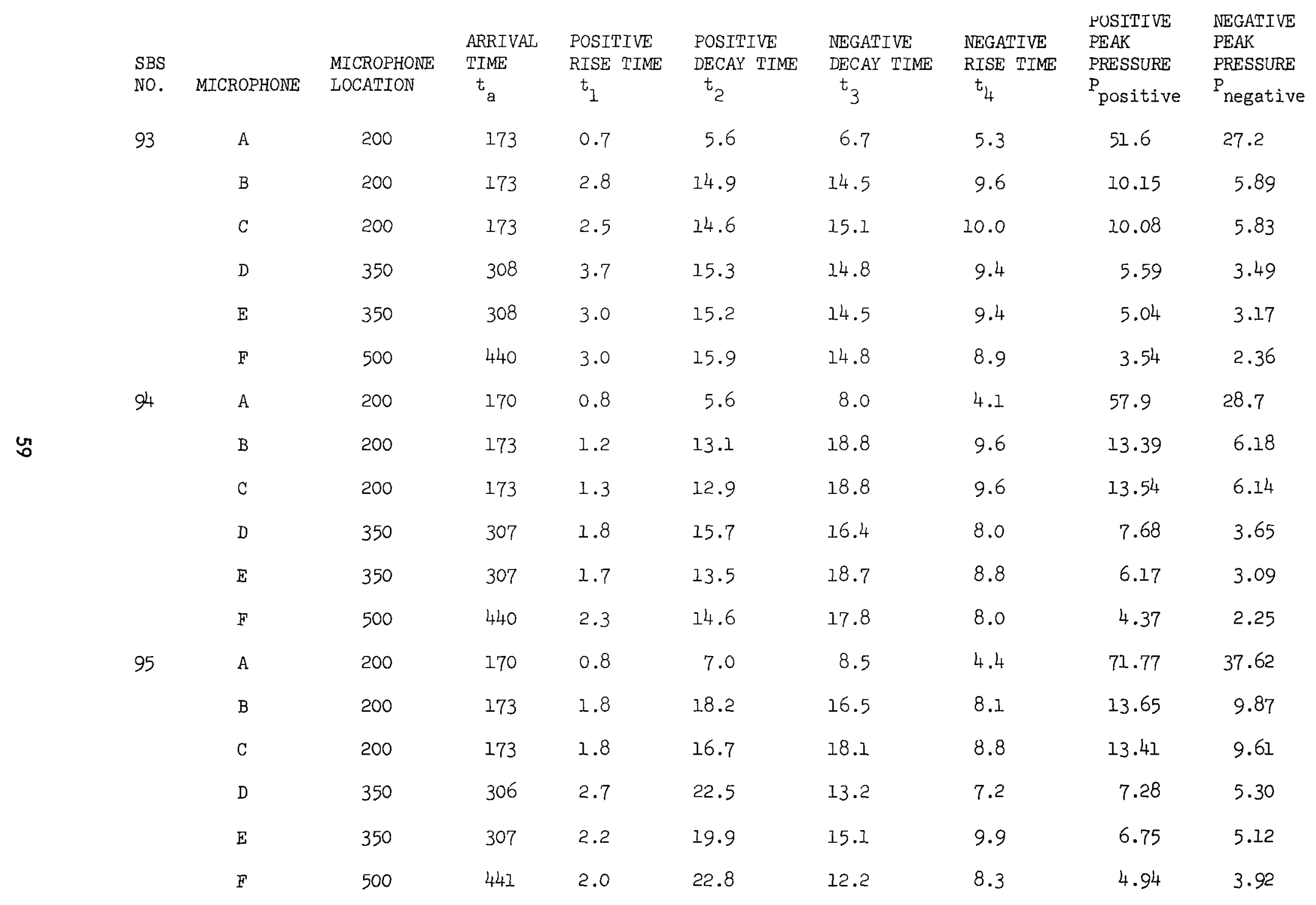




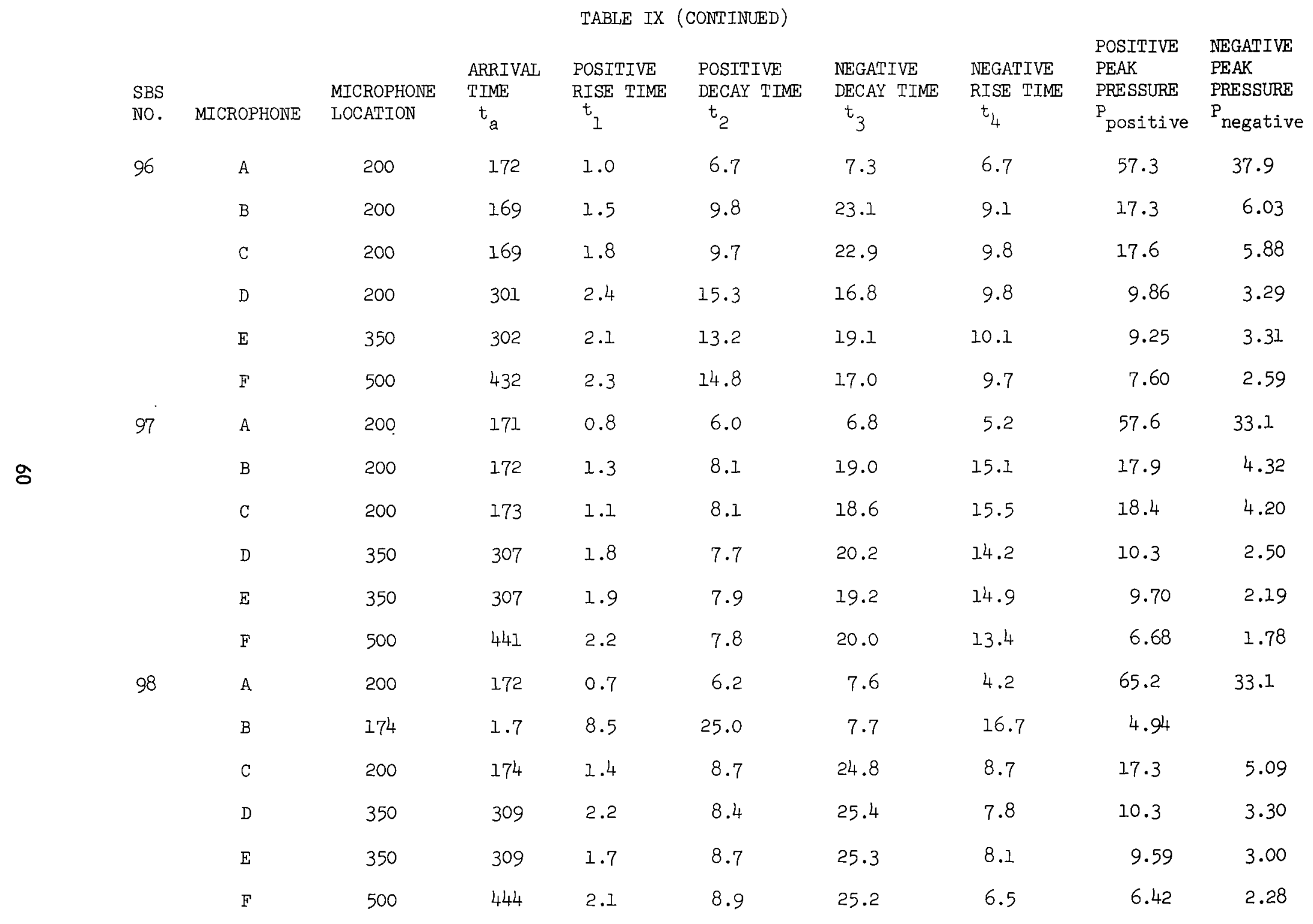


TABLE IX (CONTINUED)

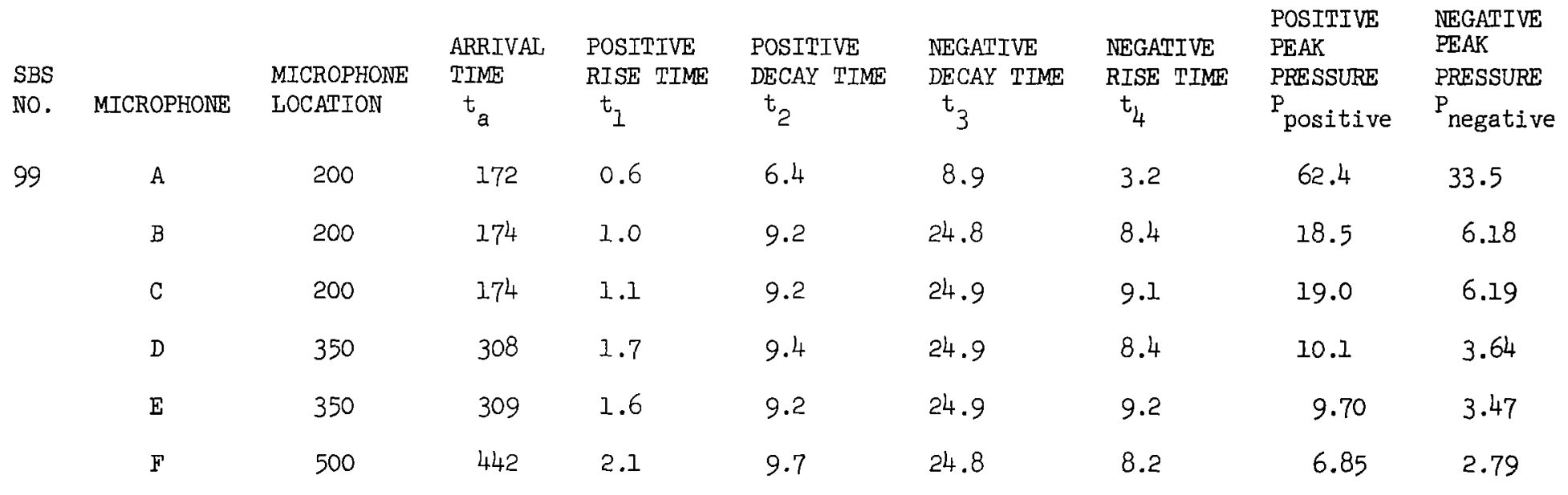


TABLE $X$

PEAK PRESSURE AND DURATION DATA - TEST SERIES IV

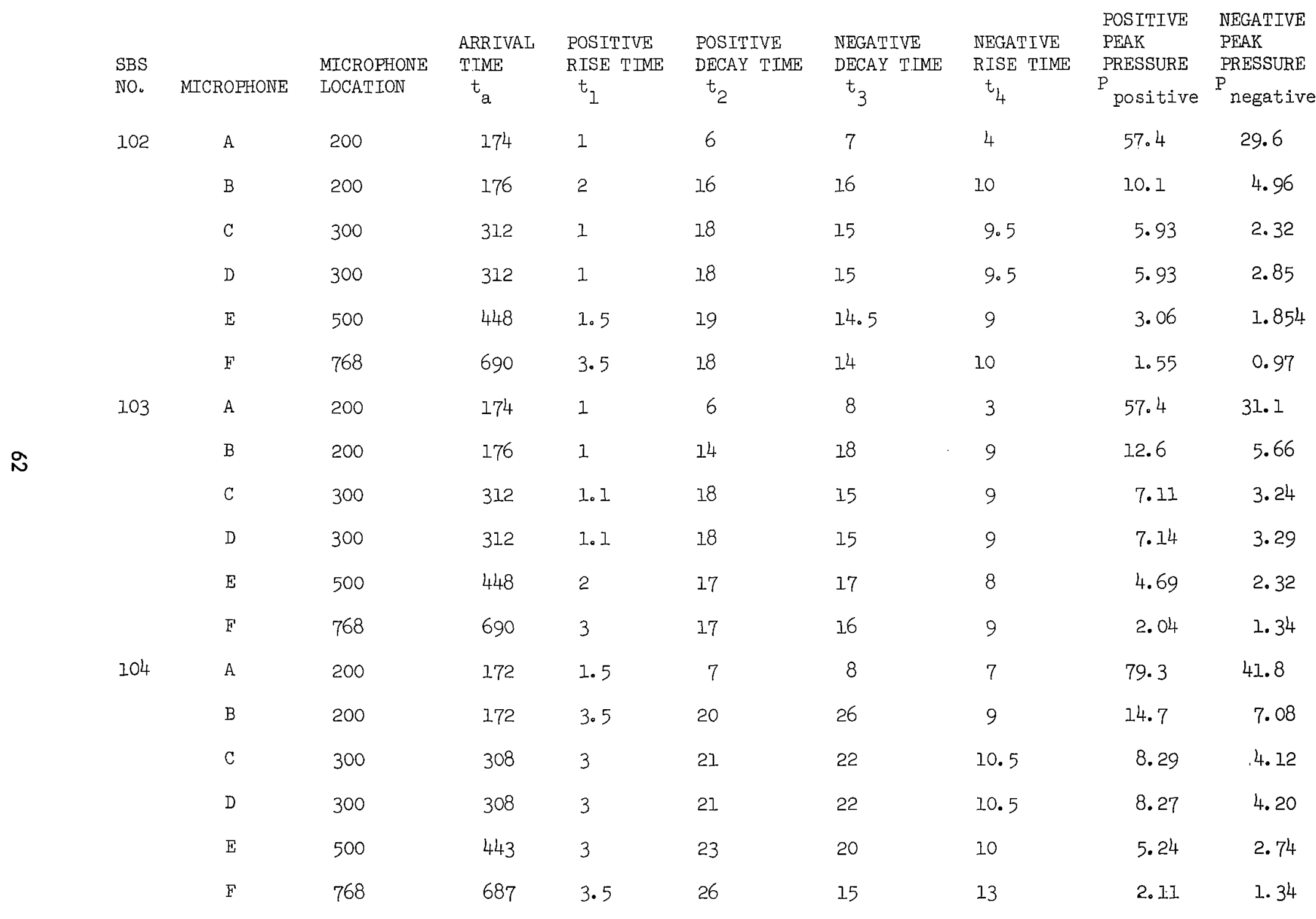


TABLE X (CONTINUED)

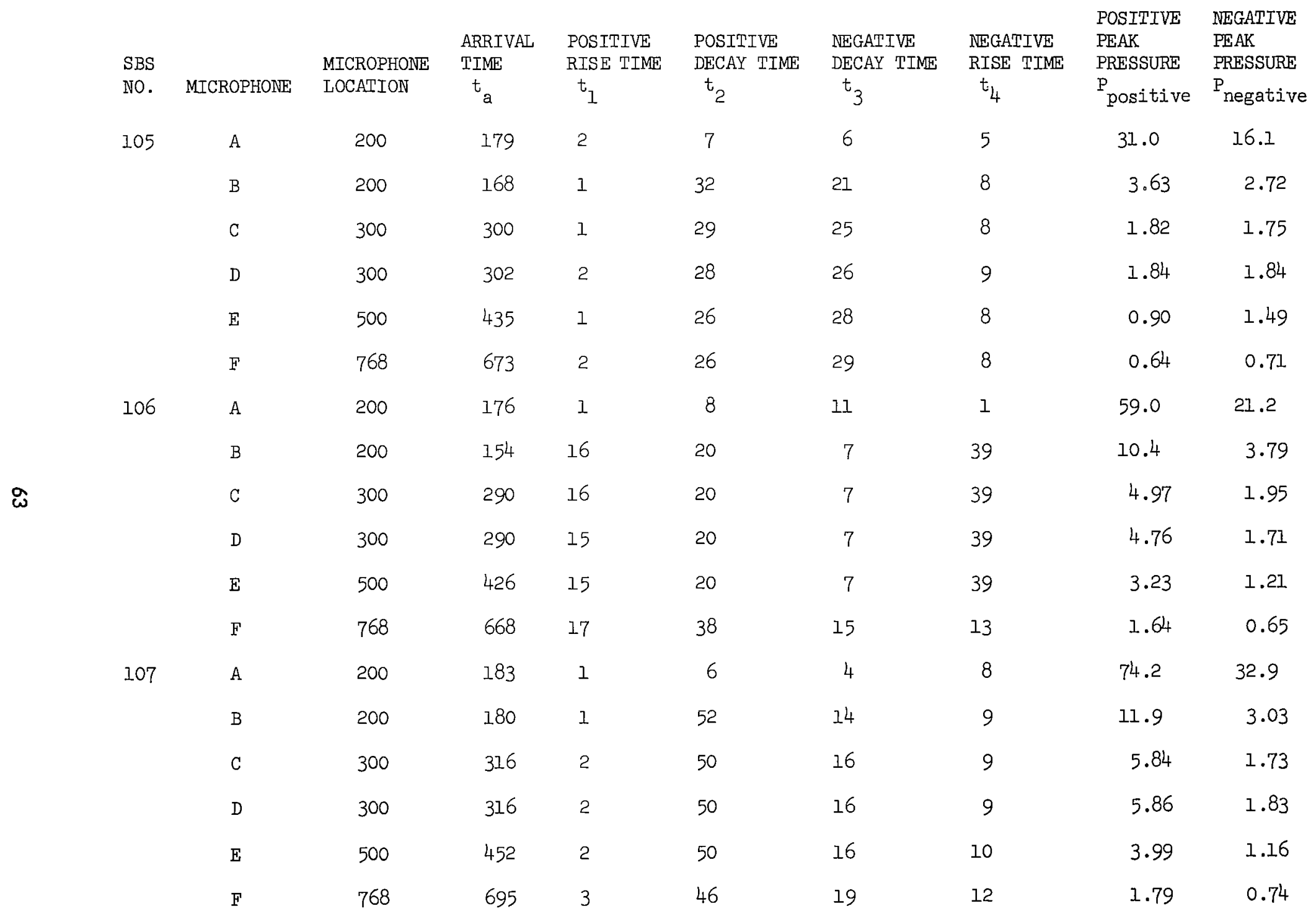




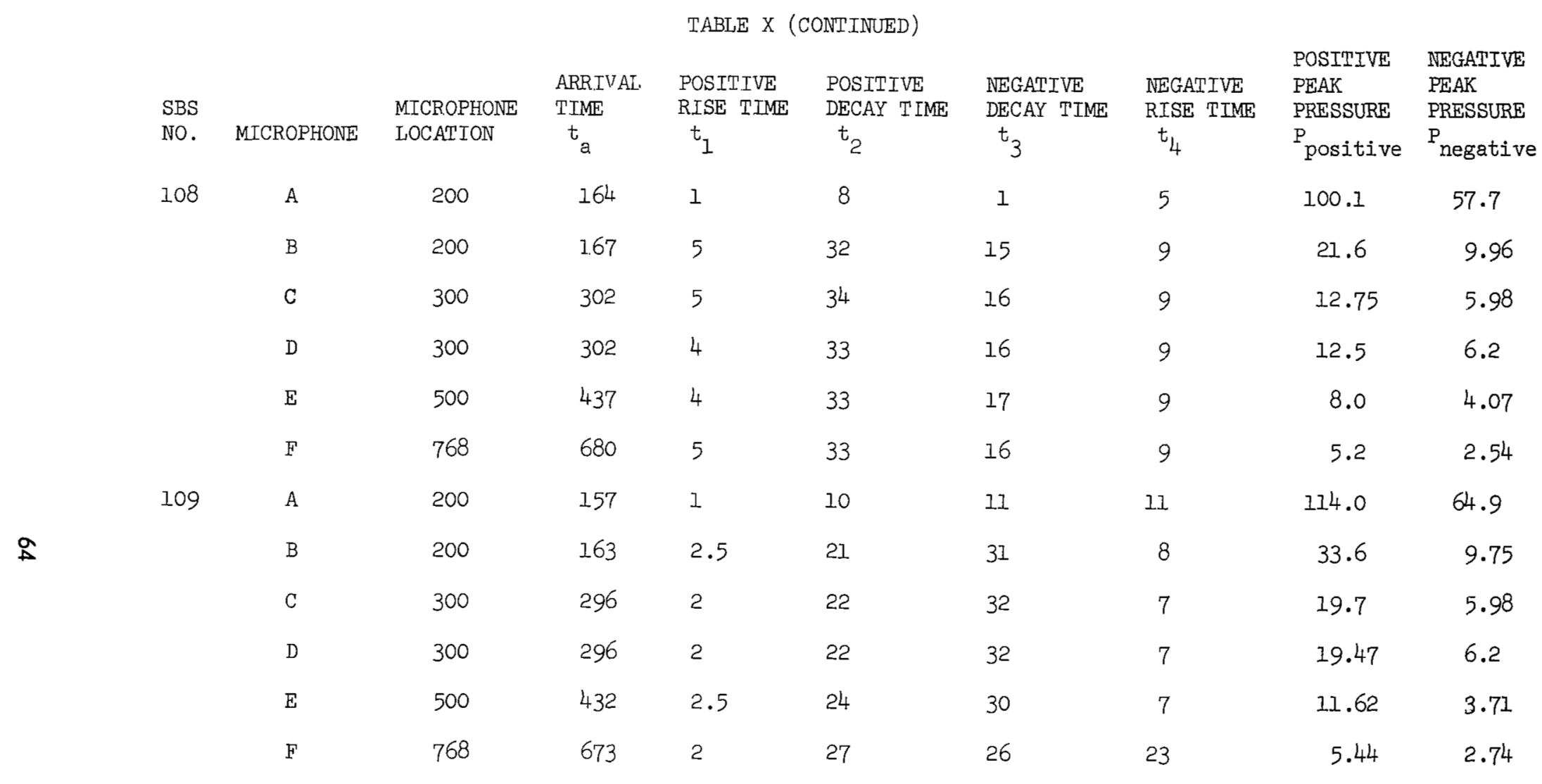


TABLE X (CONTINUED)

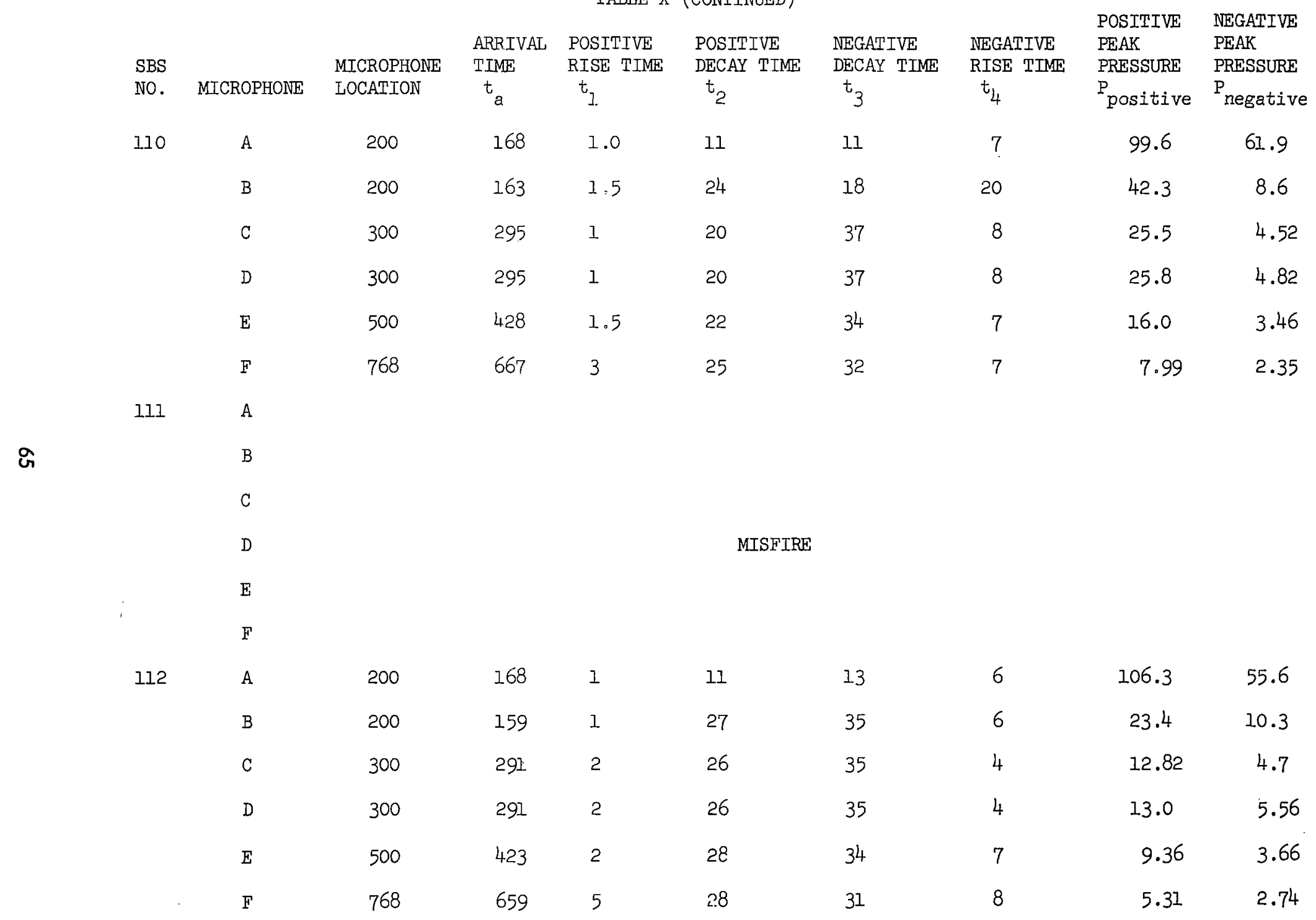




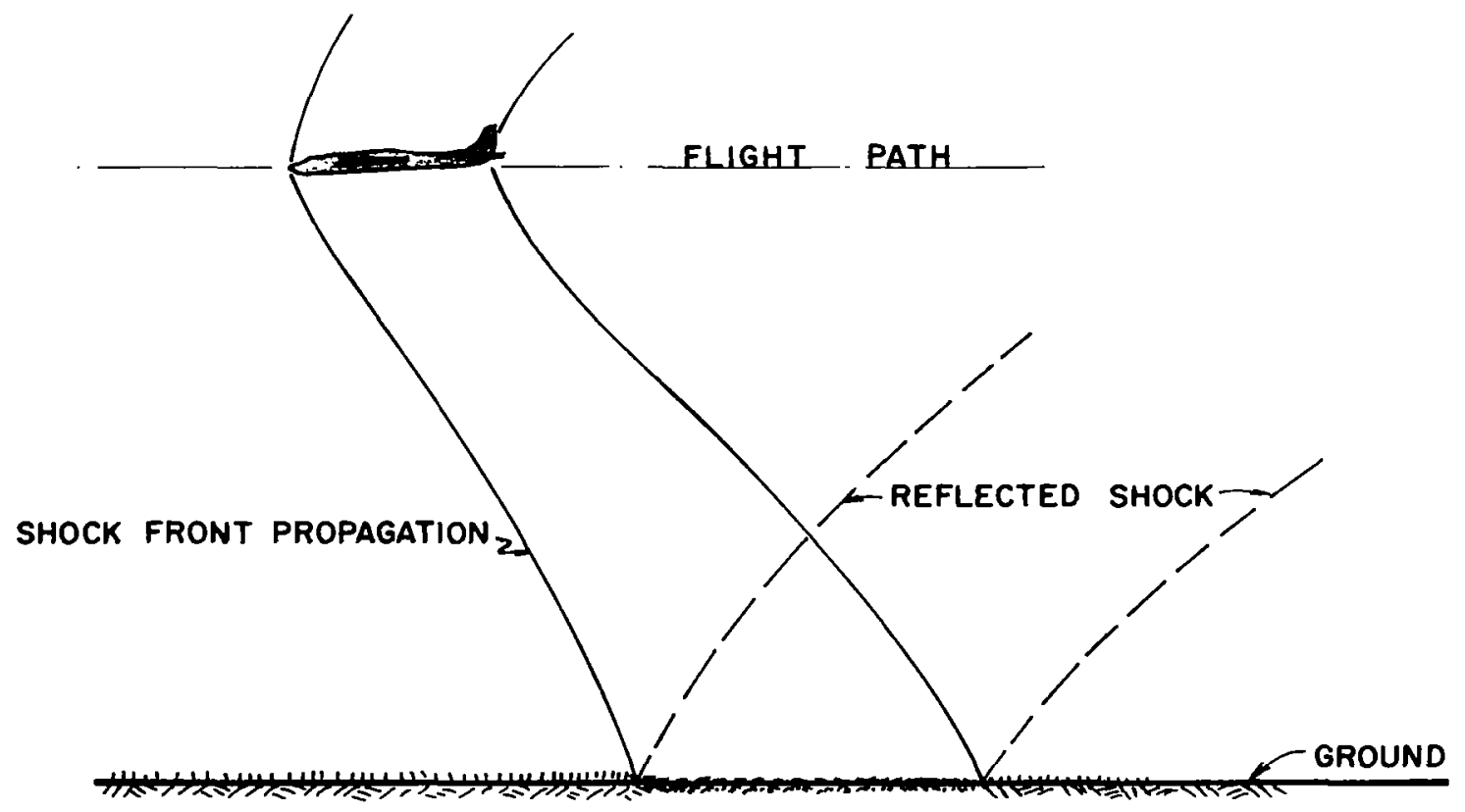

Figure I, TYPICAL SONIC BOOM GENERATION. 


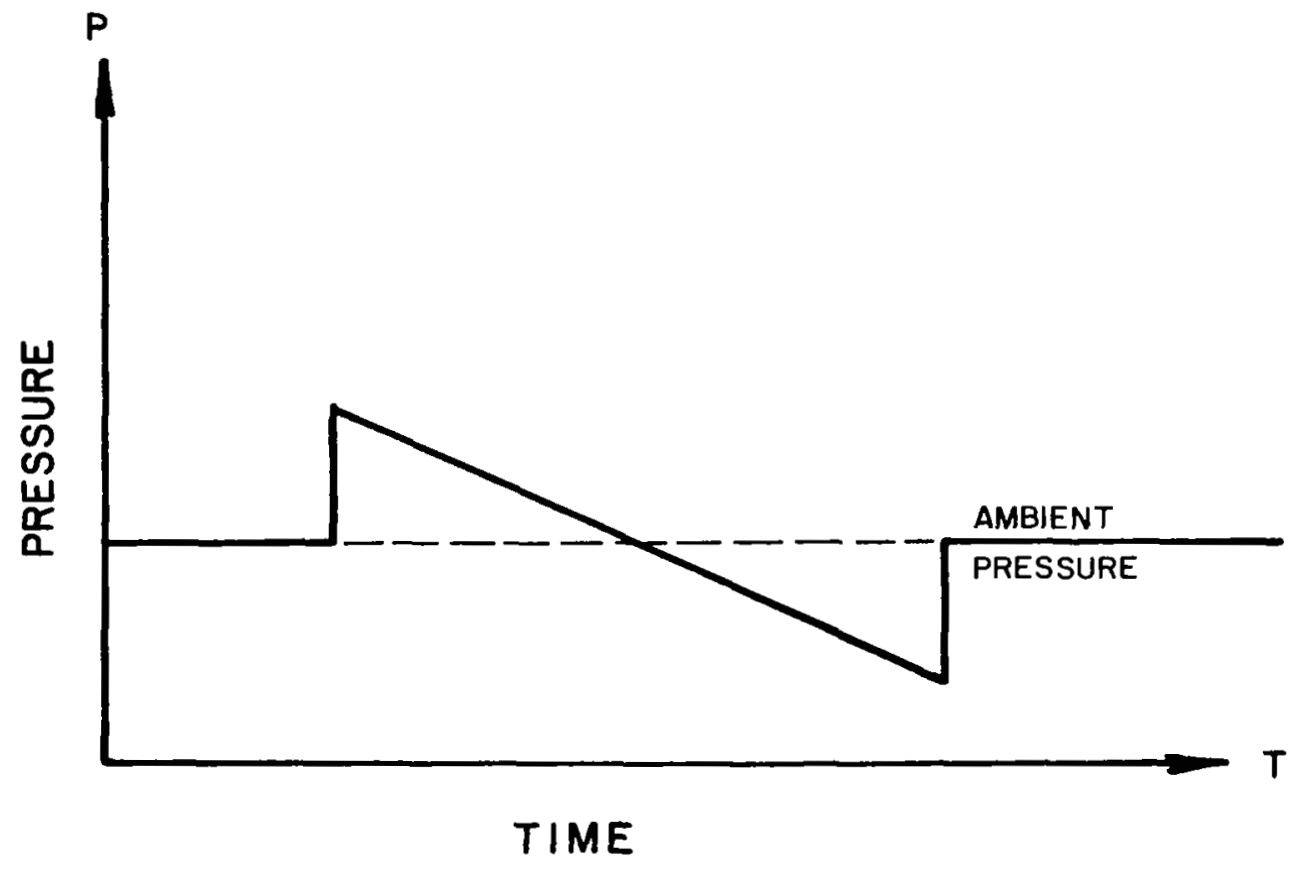

Figure 2, IDEALIZED FAR-FIELD SONIC-BOOM PRESSURE SIGNATURE. 


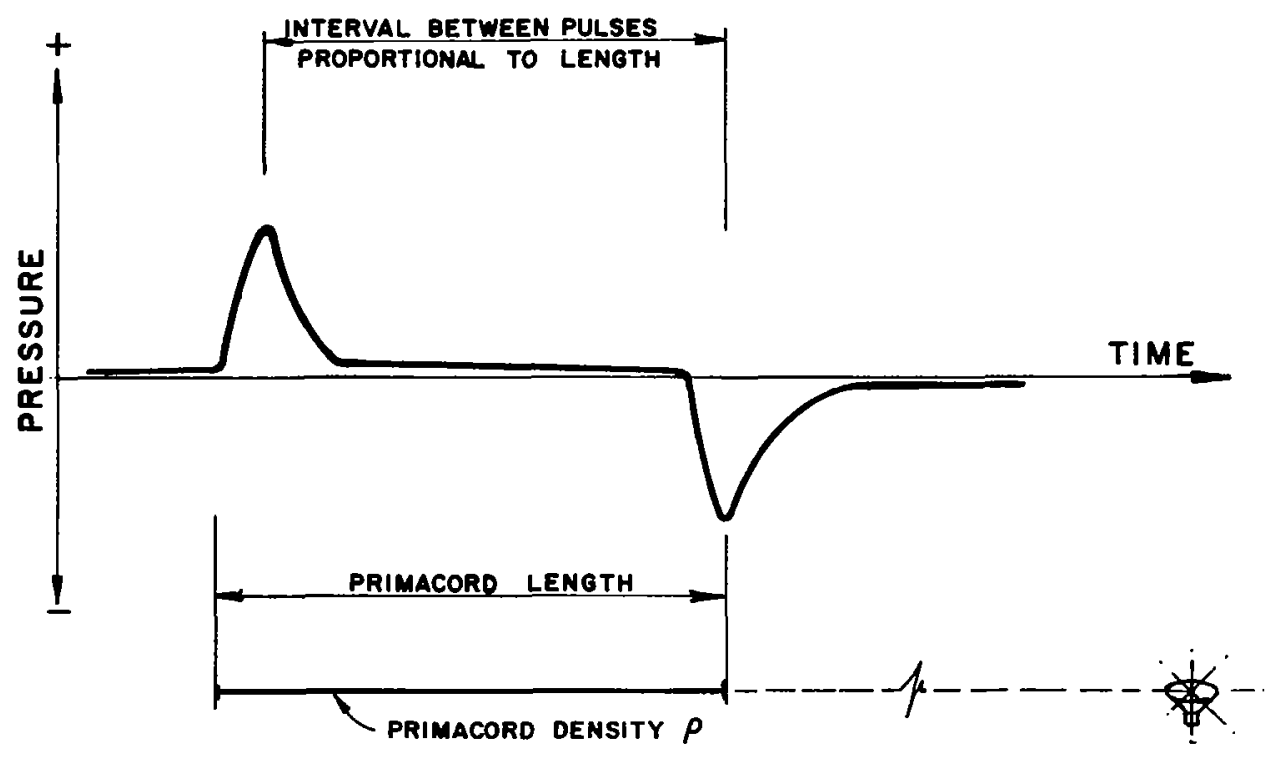

Figure 3, SCHEMATIC DIAGRAM OF THE PRESSURE PROFILE DUE TO A SINGLE UNIFORM STRAND OF PRIMACORD. (Ref. after HAWKINS AND HICKS 1966) 


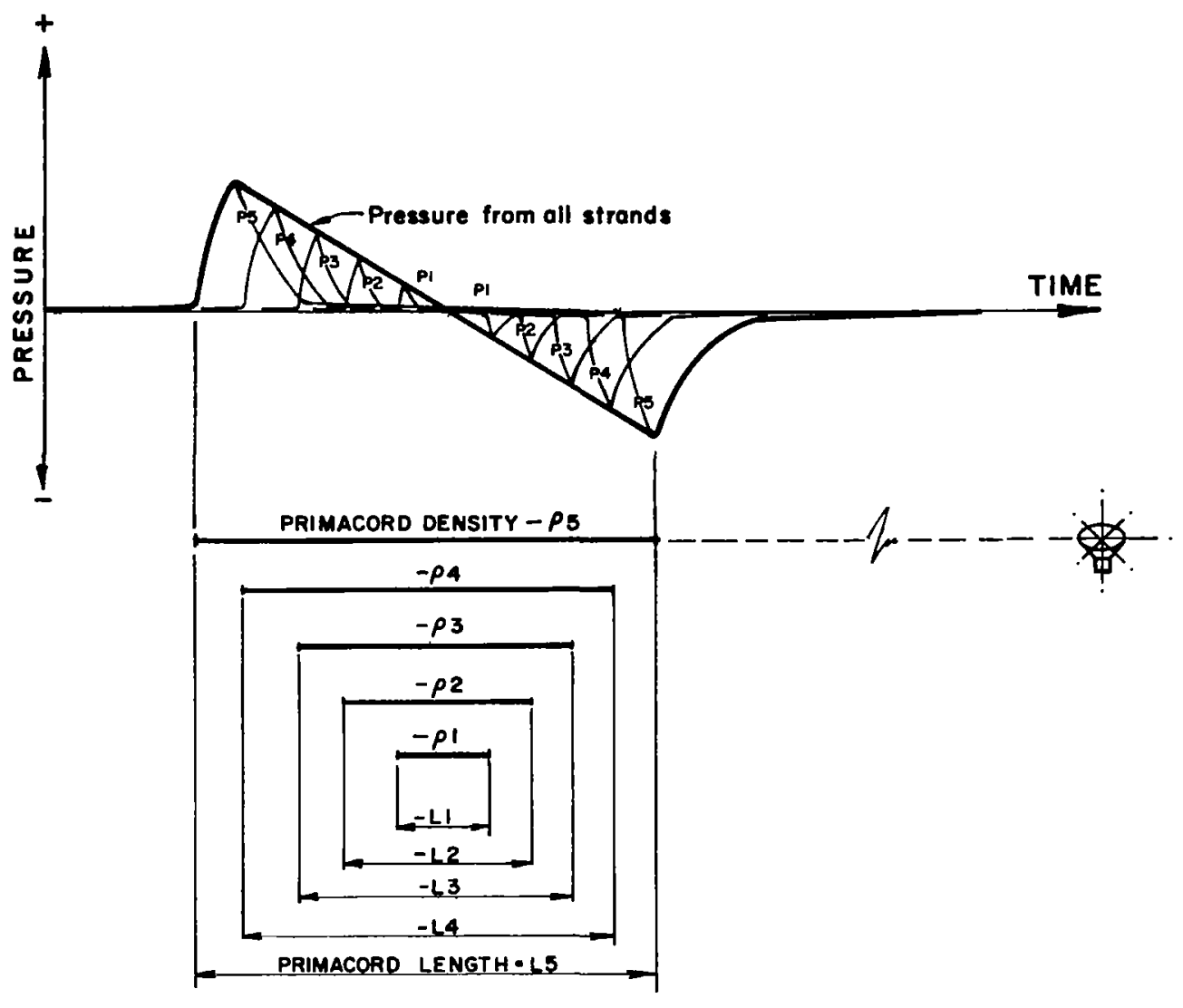

SPATIAL DISTRIBUTION OF PRIMACORD STRANDS SHOWING LENGTHS A DENSITIES.

Figure 4, SCHEMATIC DIAGRAM SHOWING EXPERIMENTAL CONSTRUCTION OF A N-WAVE USING MULTIPLE STRANDS OF PRIMACORD. (Ref. after HAWKINS AND HICKS 1966) 


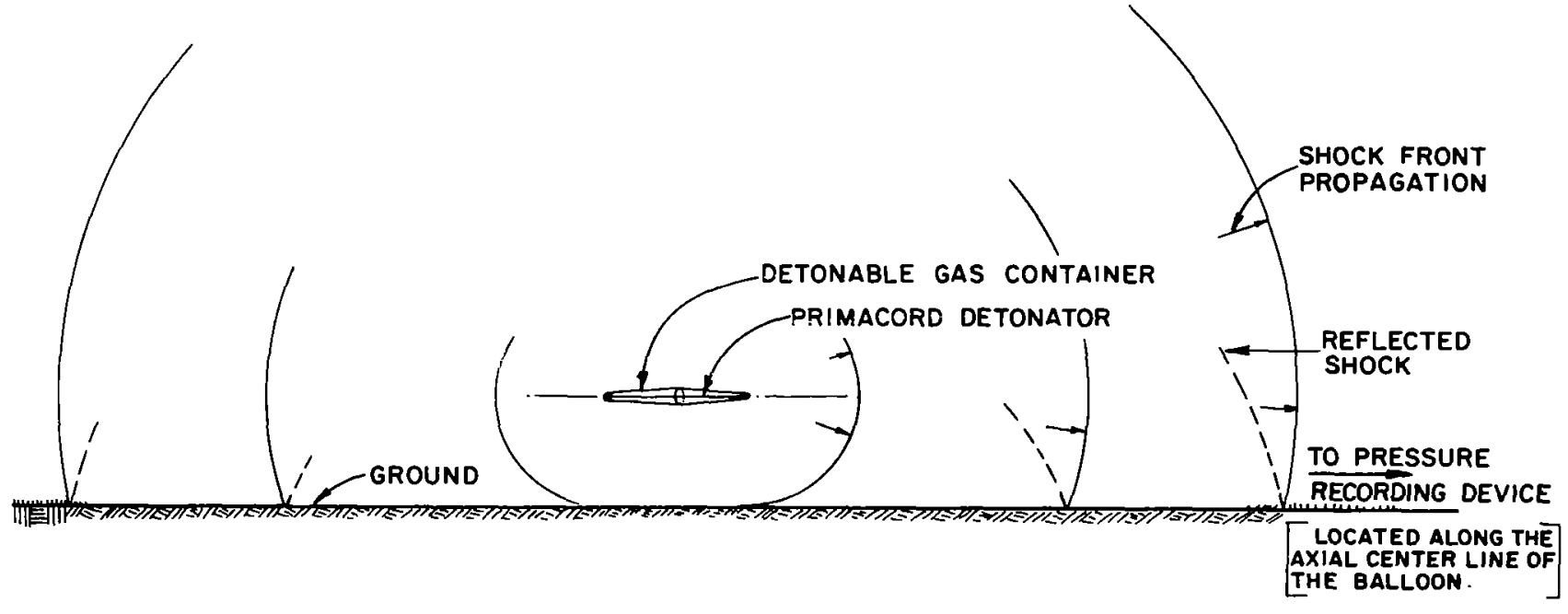

Figure 5, SONIC-BOOM SIMULATOR USING DETONABLE GASES. 


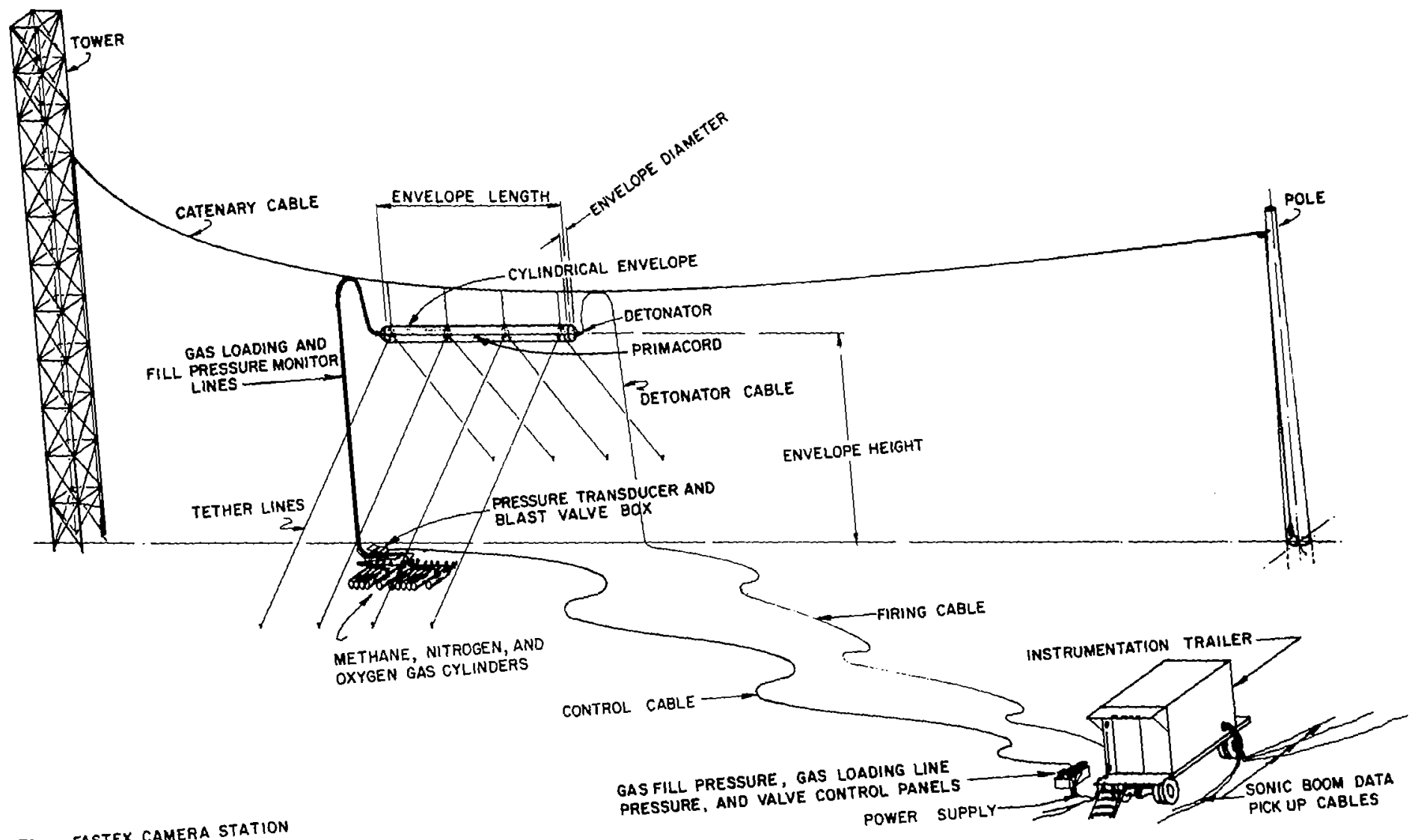

政

Figure 6

GAS, SONIC BOOM SIMULATOR, TEST SETUP. 

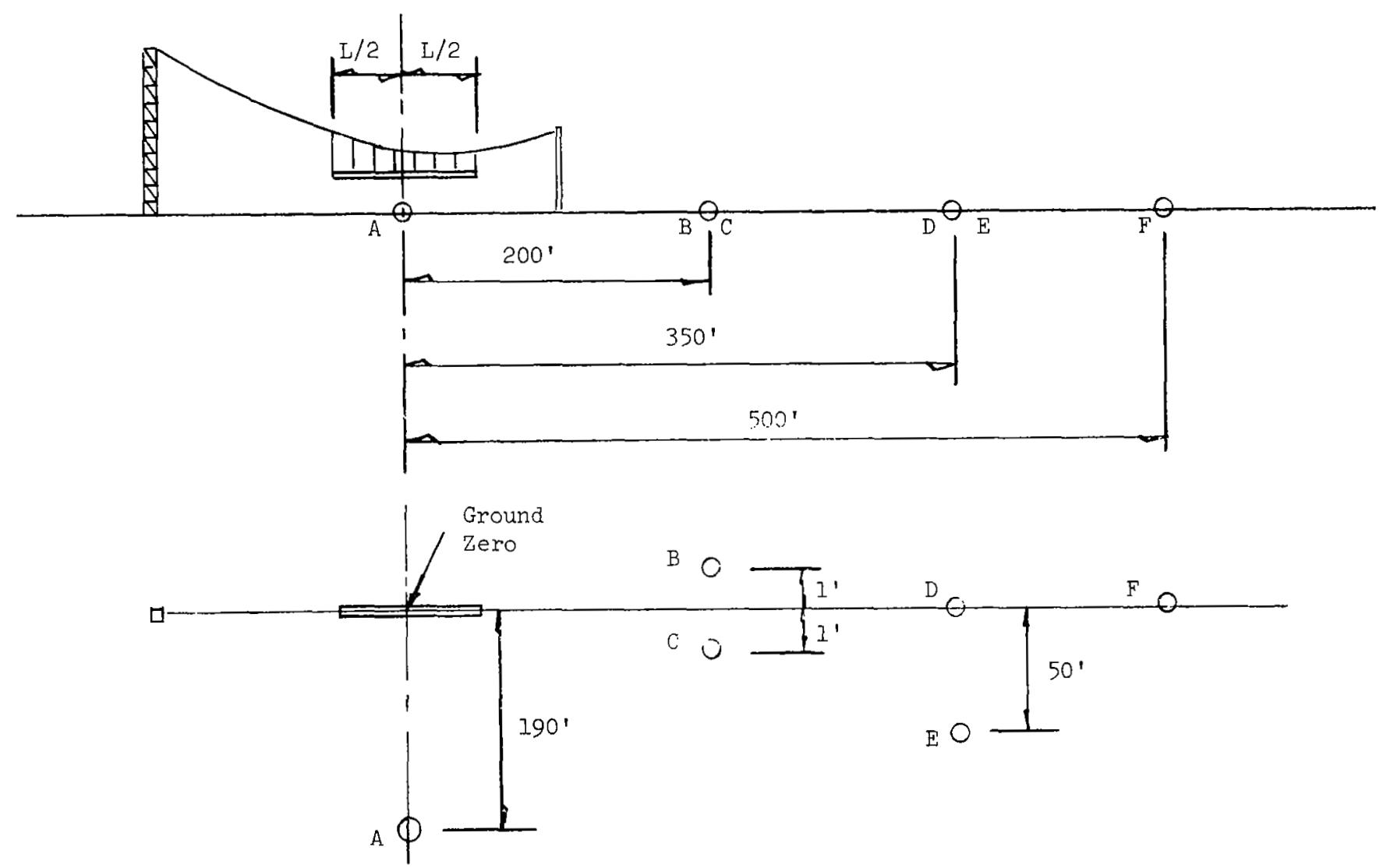

Figure 7 - MICROPHONE ARRAY FOR TEST SERIES I 


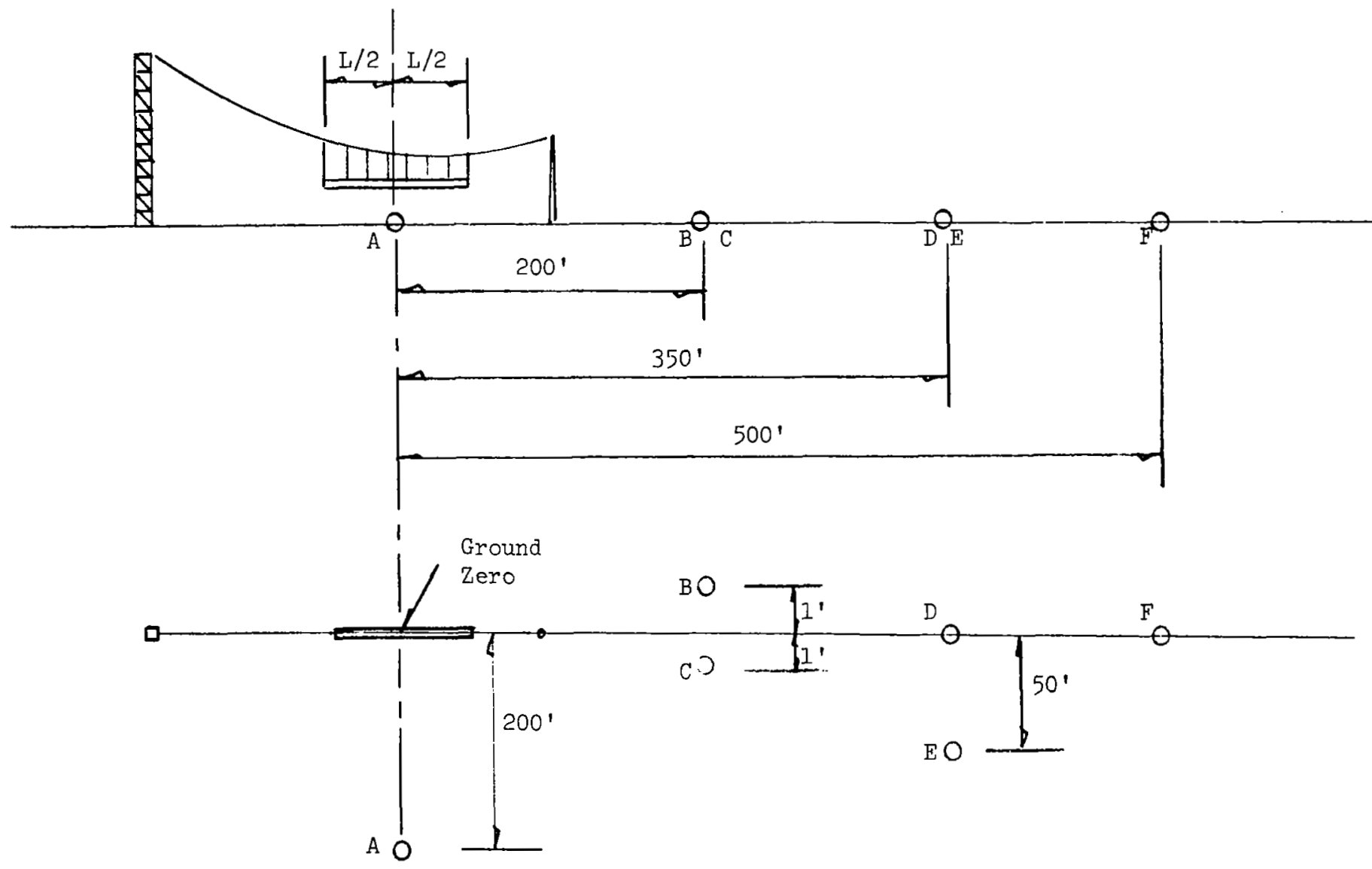

Figure 8 - MICROPHONE ARRAY FOR TEST SERIES II 

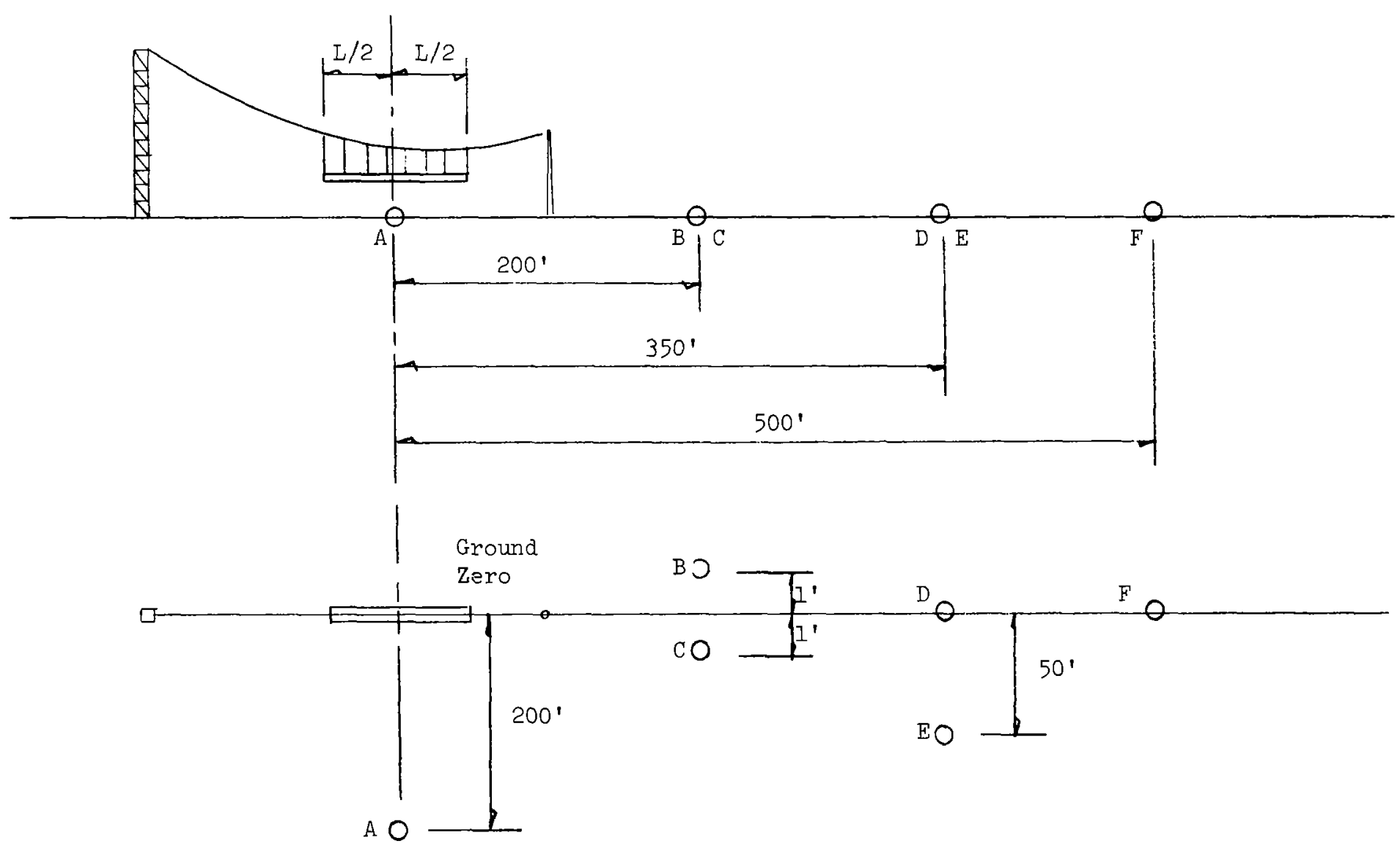

Figure 9 - MICROPHONE ARRAY FOR TEST SERIES III 
जे
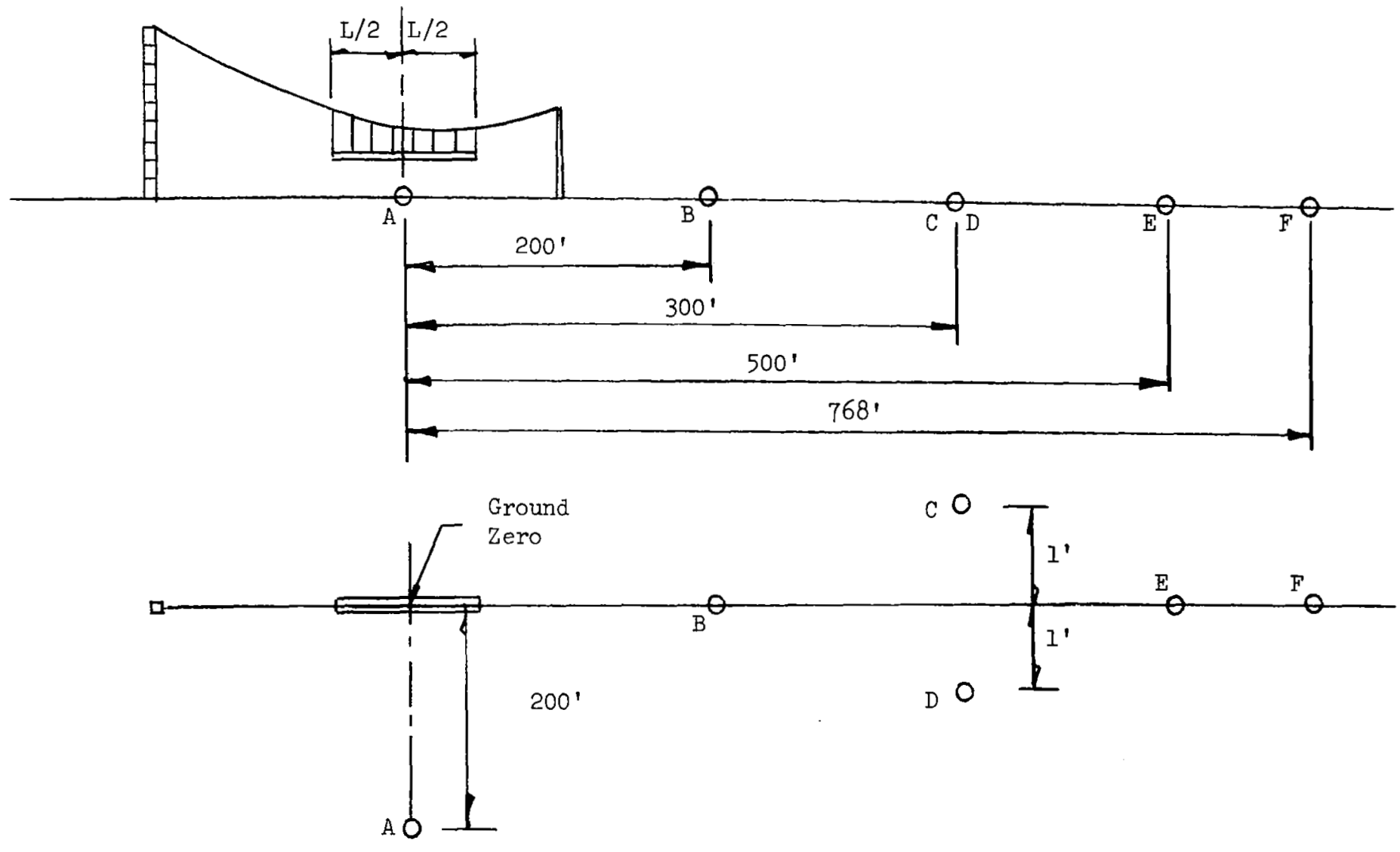

Figure IO - MICROPHONE ARRAY FOR TEST SERIES IV 


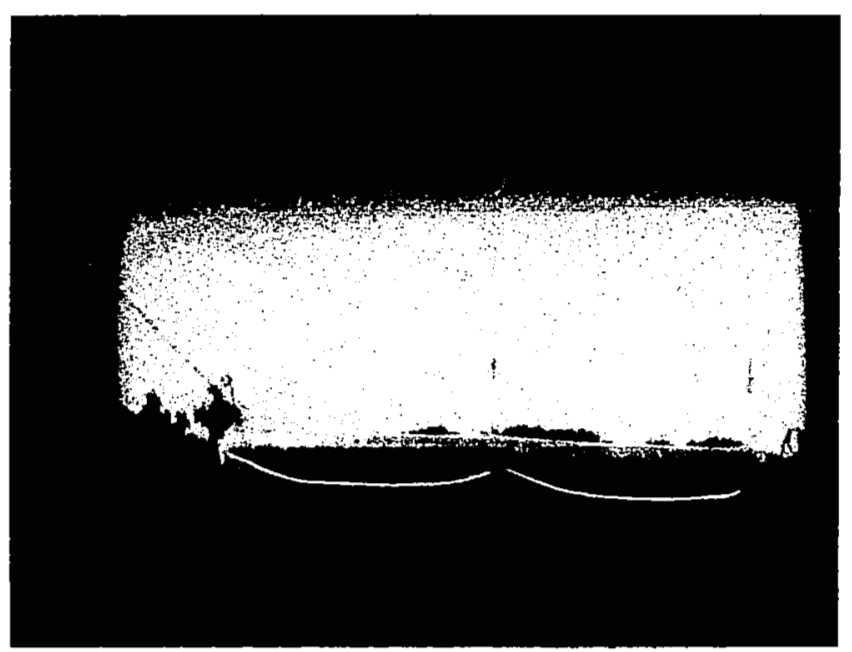

Note, Poor Primacord Installation.

Figure II, PRIMACORD INSTALLATION, SBS 77. 

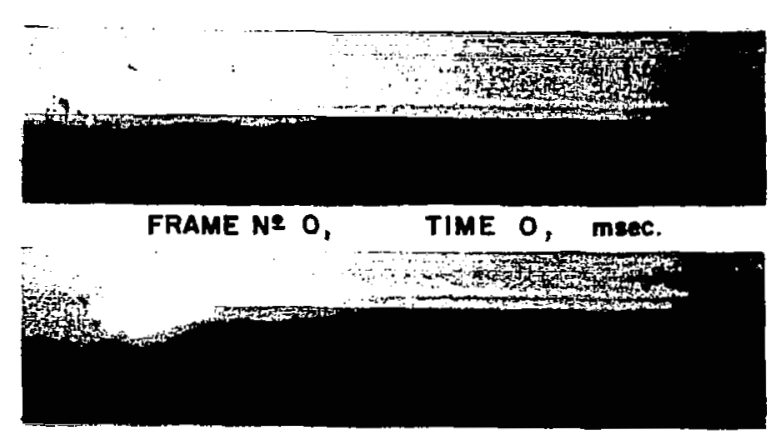

FRAME NE 1 , TIME 0.125 msec.

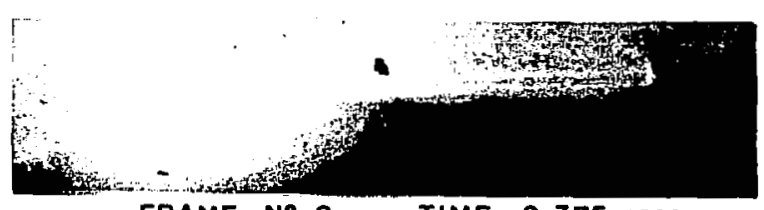

FRAME NE 2, TIME 0.375 msec.

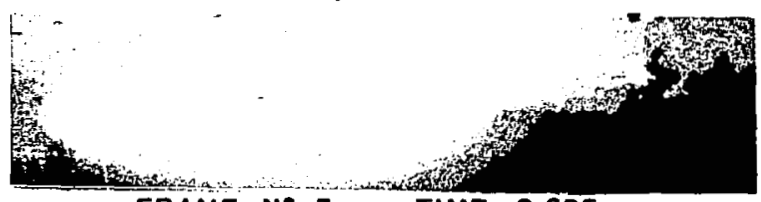

FRAME $N=3, \quad$ TIME $0.625 \mathrm{msec}$.

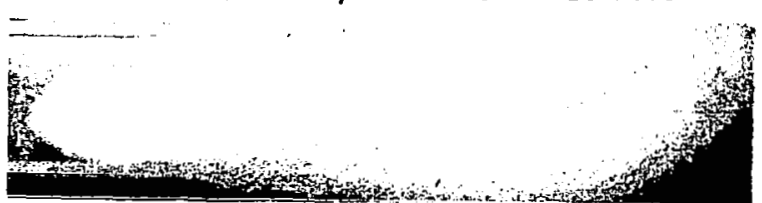

FRAME NO 4, TIME 0.875 msec.

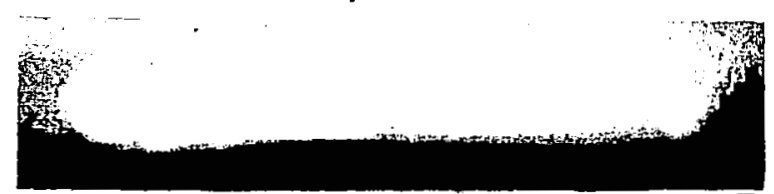

FRAME N2 5, TIME $1.125 \mathrm{msec}$.

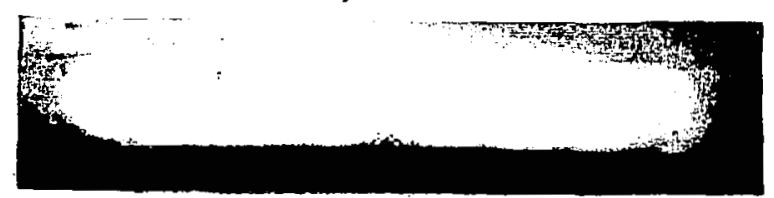

FRAME NE 6, TIME 1.375 msec.

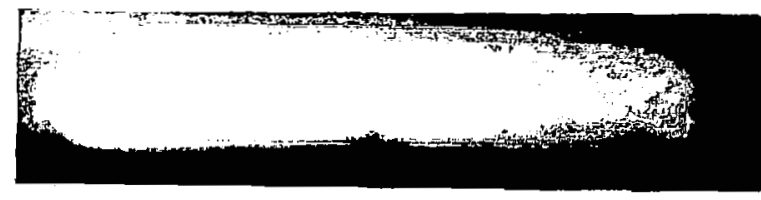

FRAME NE 7, TIME $1.625 \mathrm{msec}$.

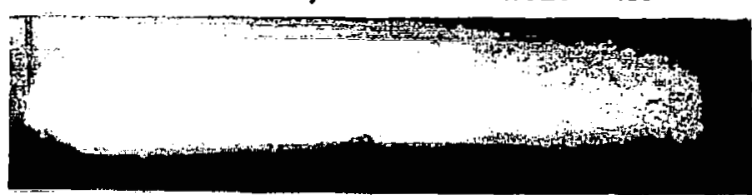

FRAME $N=12$, TIME 2,875 msec.

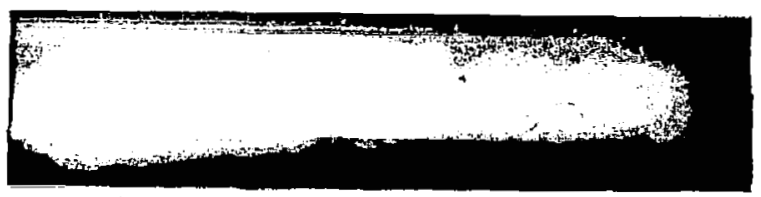

FRAME N2 17, TIME 4.125 msec.

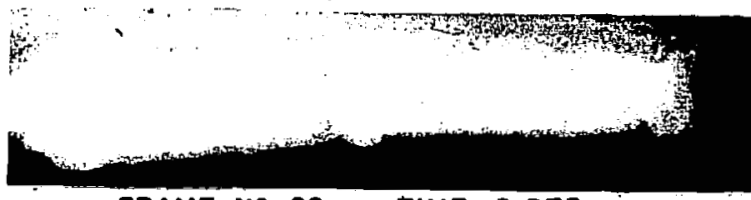

FRAME No 22, TIME 5.375 msec.

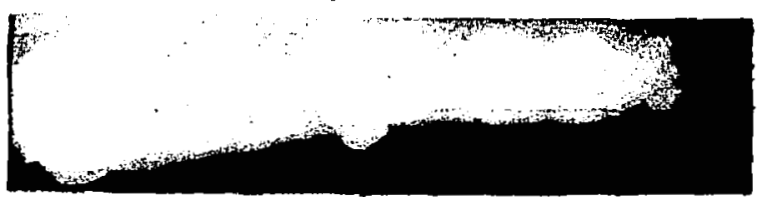

FRAME N2 32, TIME 7.875 msec.

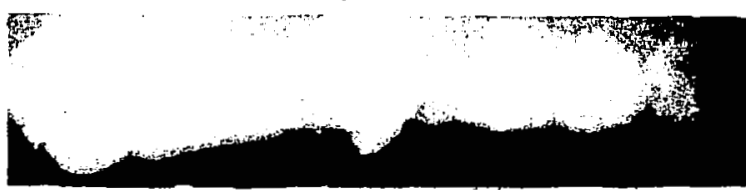

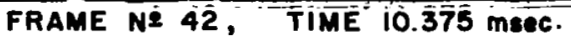

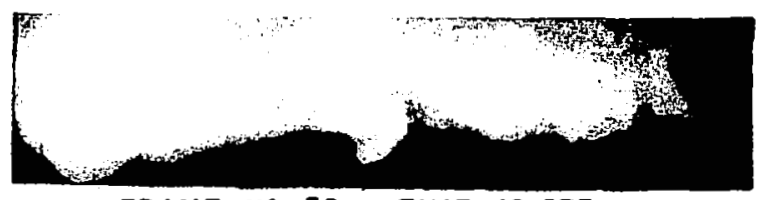

FRAME NE 52 , TIME 12.875 msec.

Figure 12, SONIC BOOM GENERATION - FRAME AND TIME SEQUENCE PHOTOGRAPHS. 


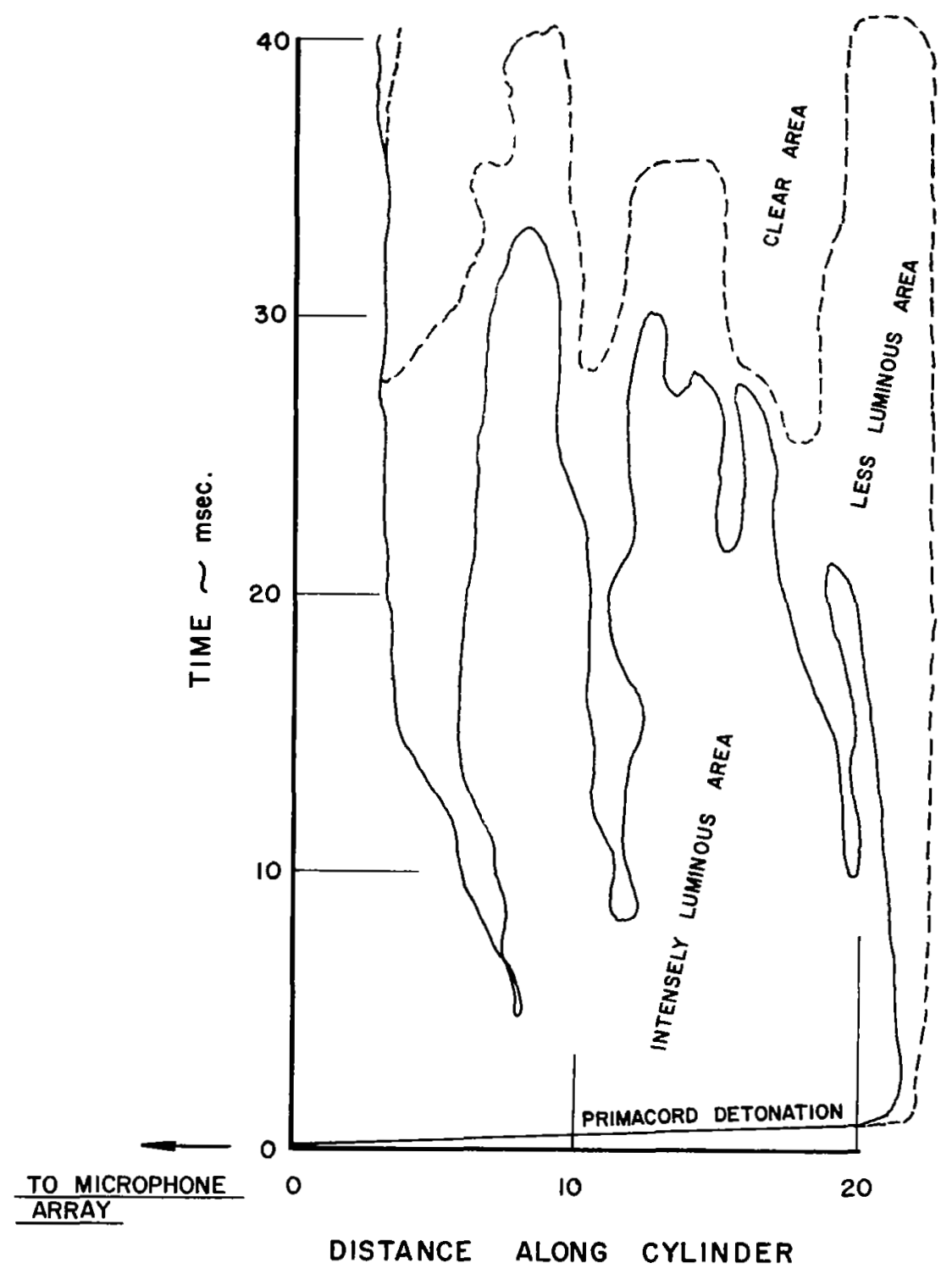

Figure 13, FIREBALL HISTORY 


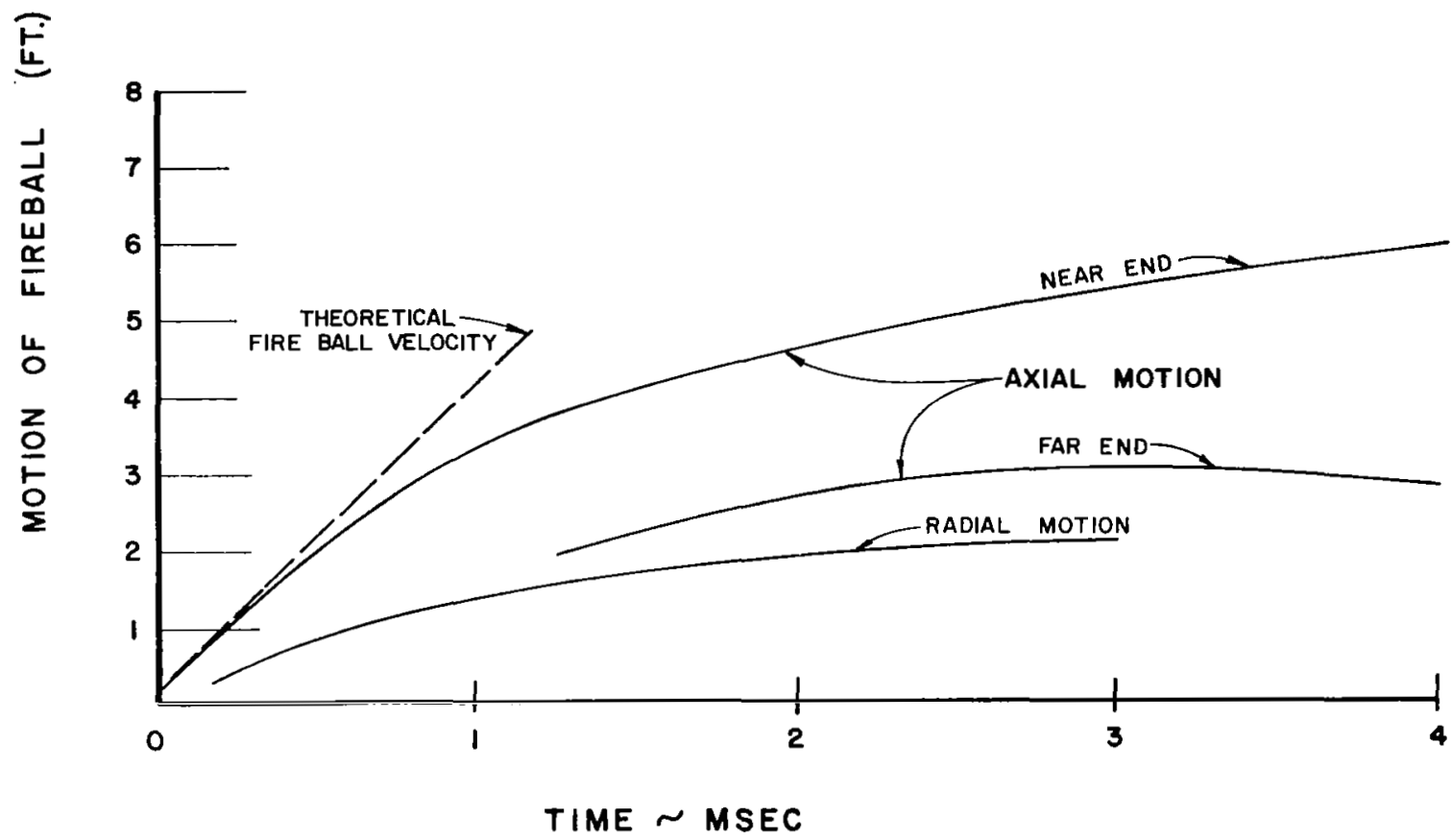

Figure 14, AXIAL AND RADIAL MOTION OF FIREBALL SONIC BOOM SIMULATOR.

$\left(I^{\prime} \times 20^{\prime}\right)$ Cylindrical Source 


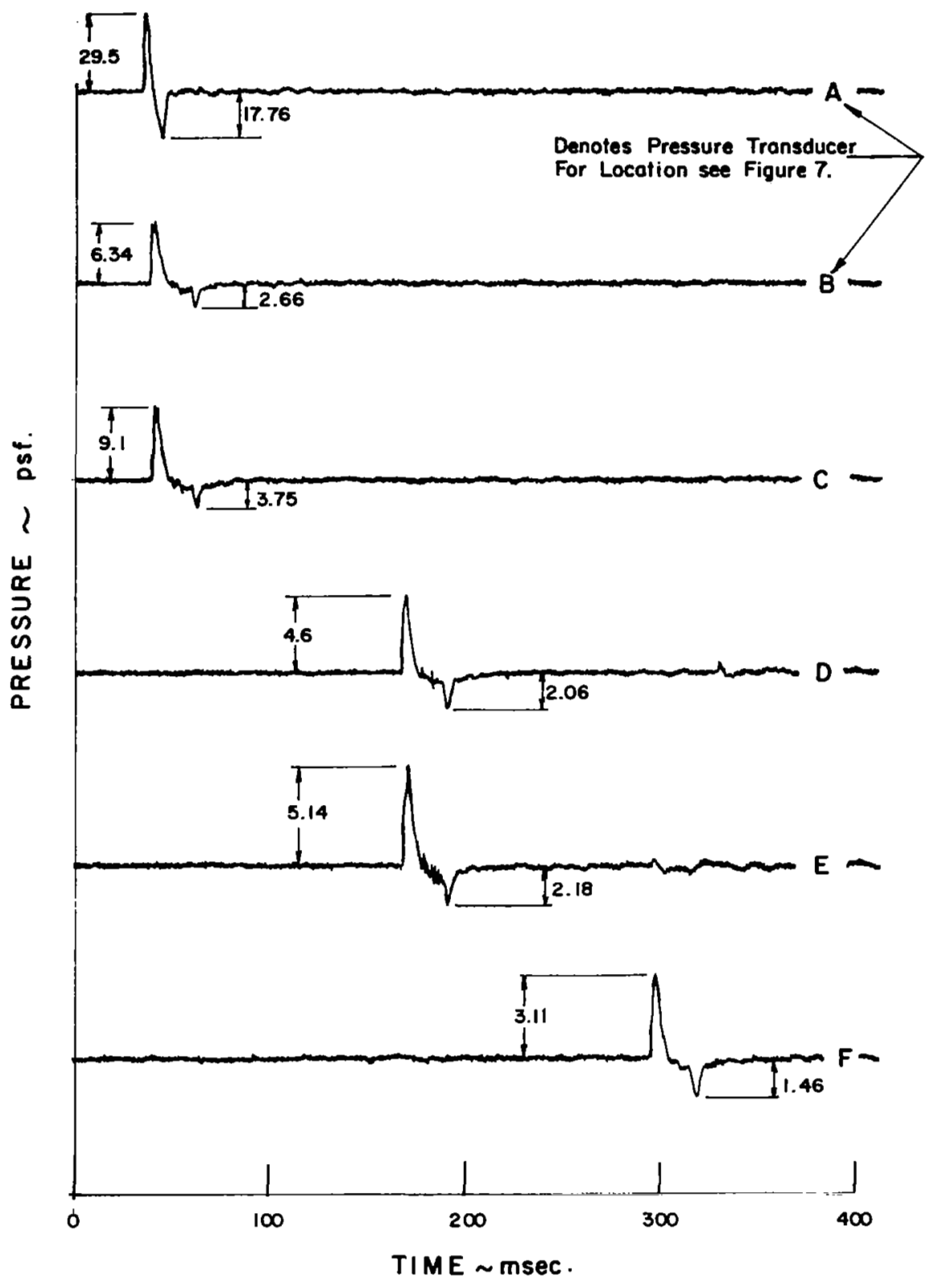

Figure 15, PRESSURE TIME HISTORY FOR SONIC BOOM SIMULATOR-76 


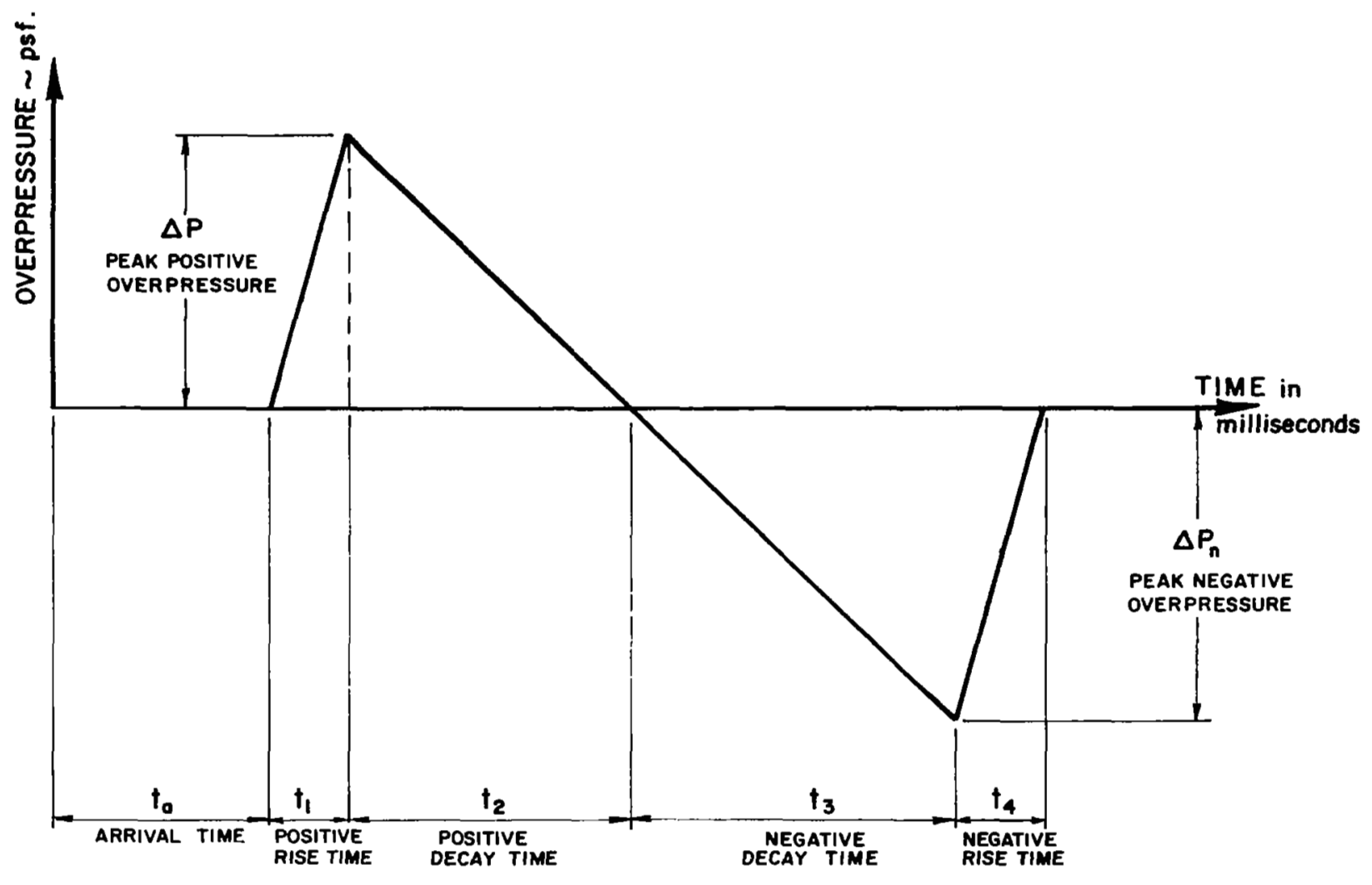

Figure 16, QUANTIfATIVE N-WAVE DEFINITION 


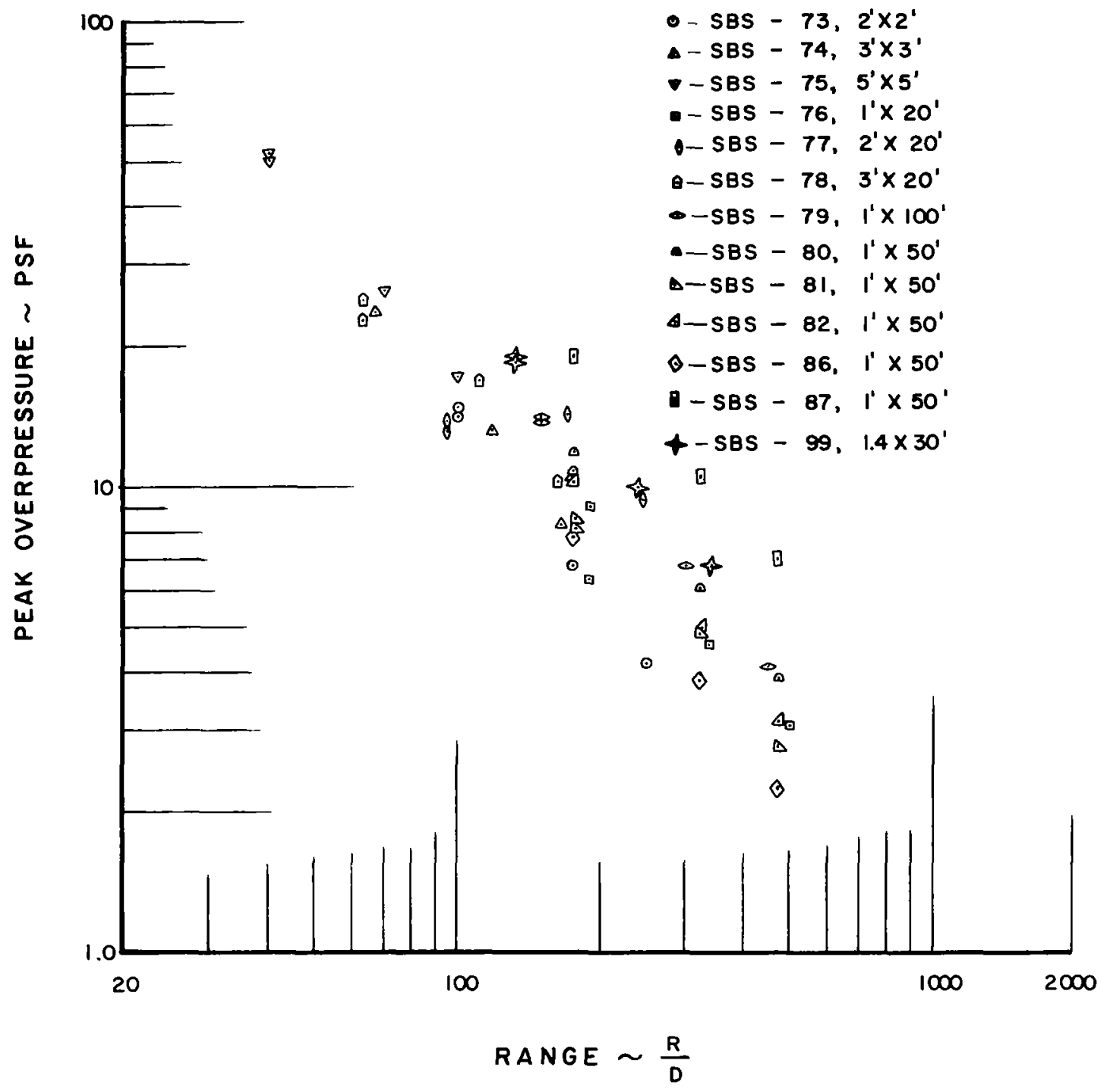

Figure 17, PEAK OVERPRESSURE VS REDUCED RANGE ALL CYLINDRICAL DATA. 


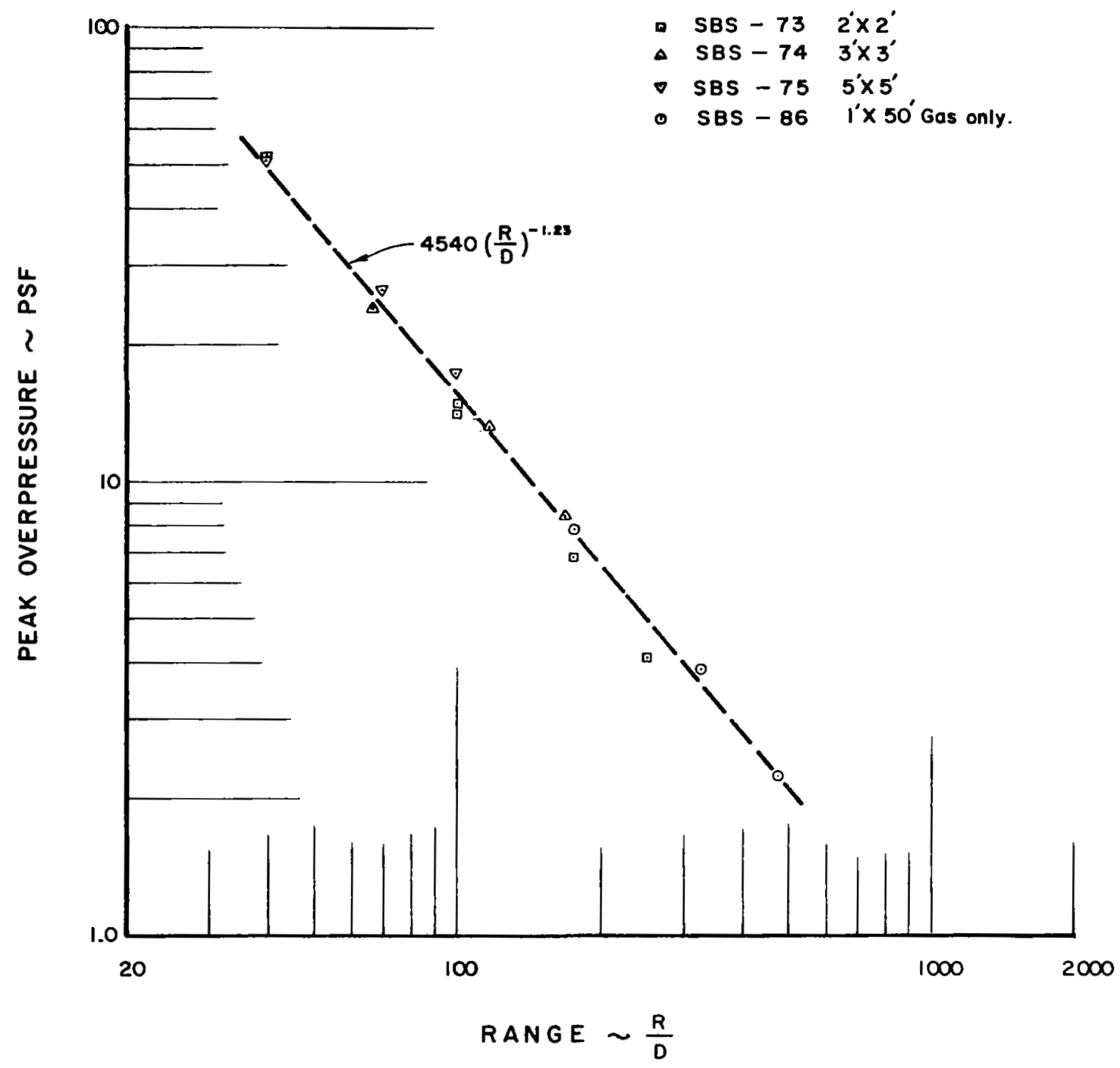

Figure 18, PEAK OVERPRESSURE VS REDUCED RANGE CYLINDRICAL ENVELOPES DETONATOR IGNITION ONLY. 


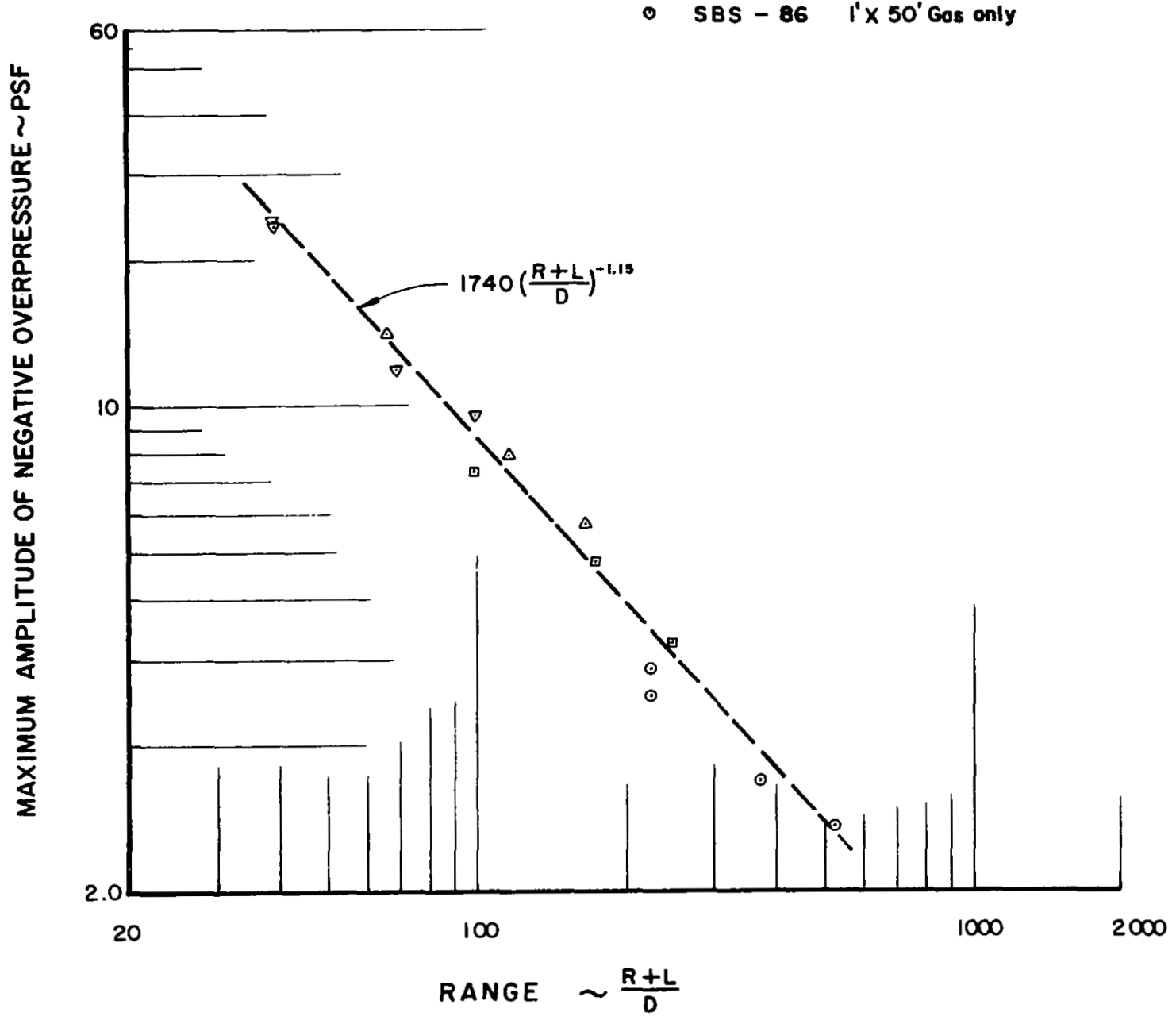

Figure 19, MAXIMUM AMPLITUDE OF NEGATIVE OVERPRESSURE VS REDUCED RANGE FOR CYLINDRICAL ENVELOPES DETONATOR IGNITION ONLY. 


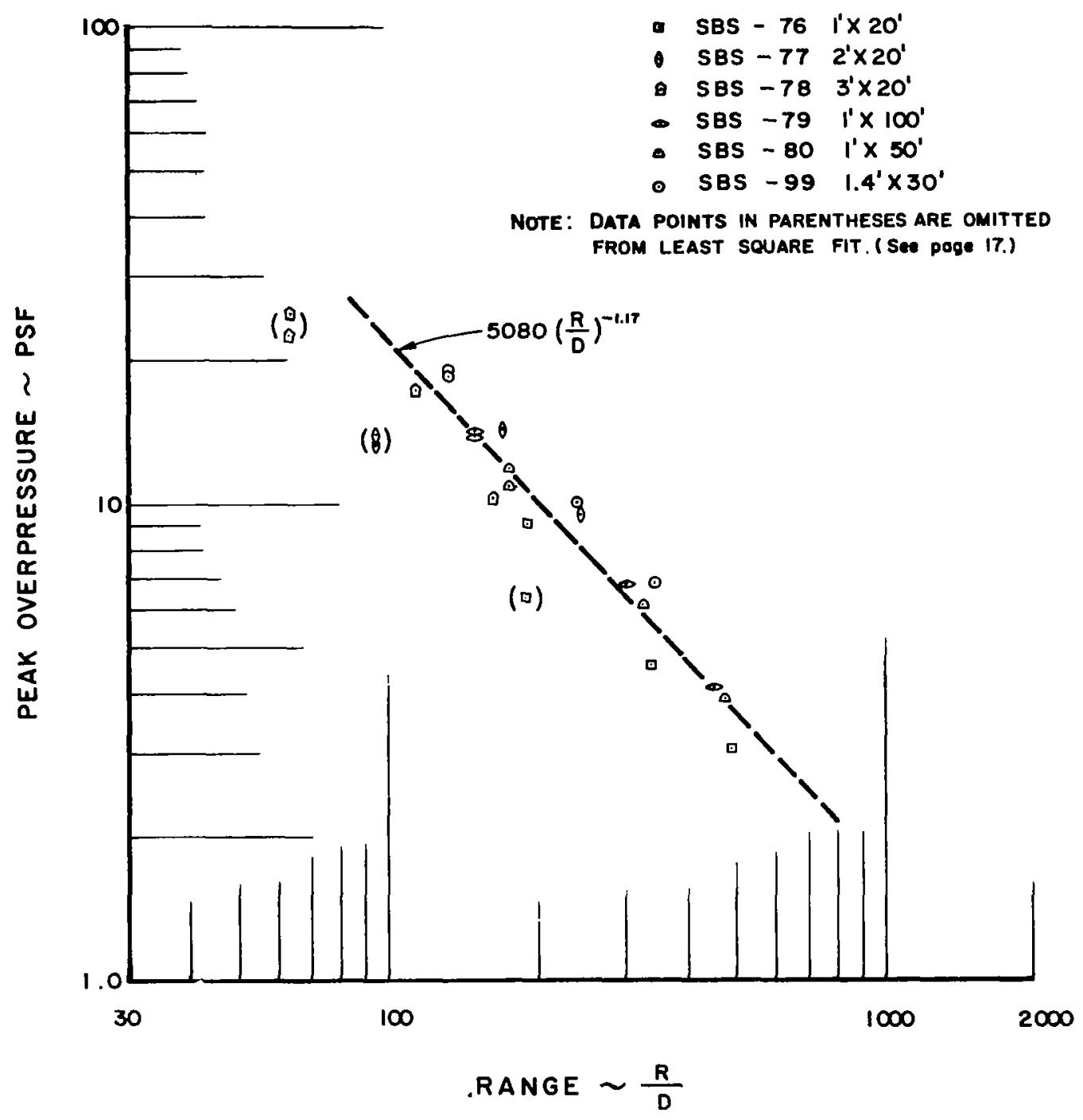

Figure 20, PEAK OVERPRESSURE VS REDUCED RANGE CYLINDRICAL ENVELOPES, PRIMACORD DRIVEN DETONATED FROM MICROPHONE END. 


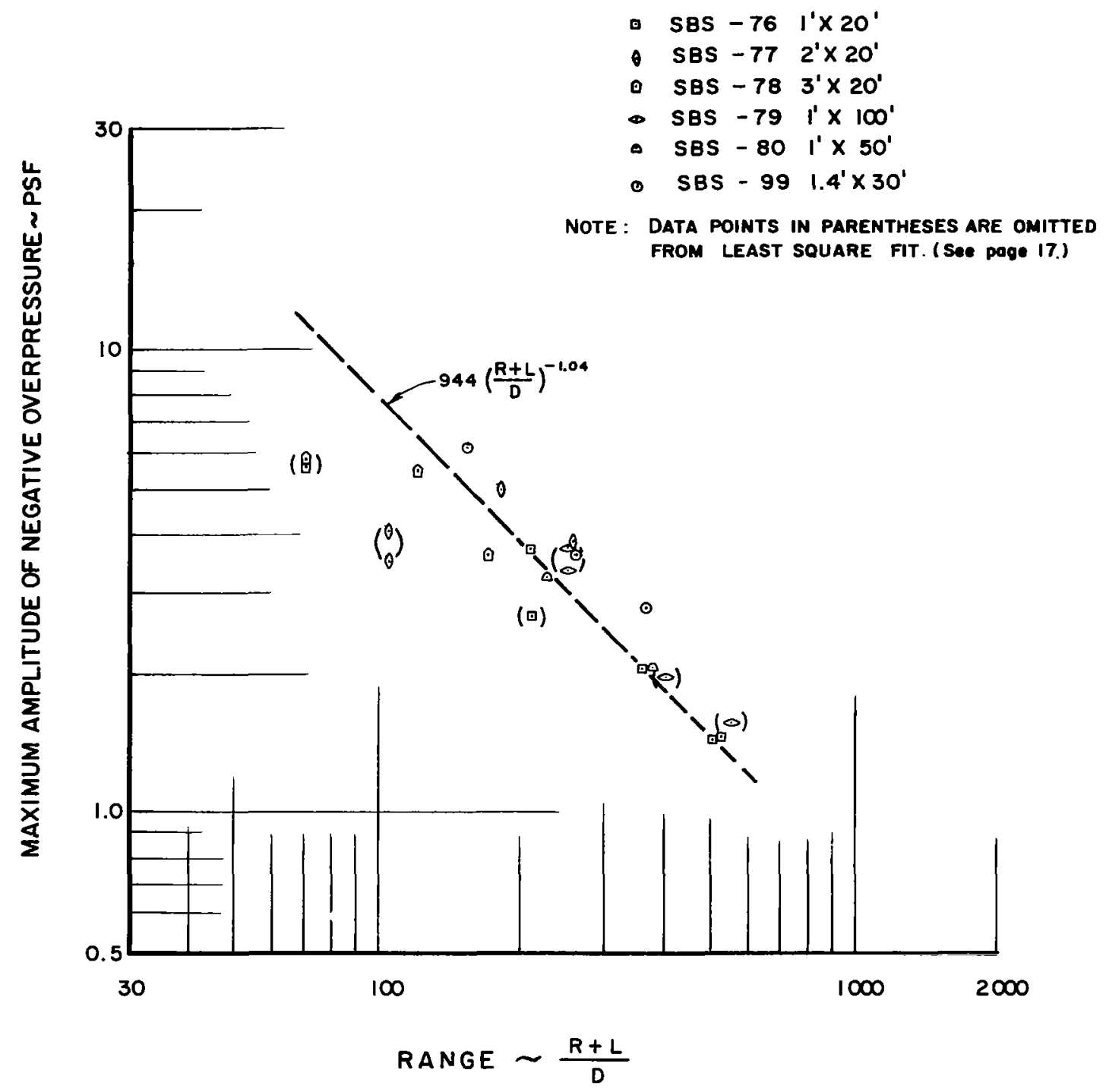

Figure 21, MAXIMUM AMPLITUDE OF NEGATIVE OVERPRESSURE VS REDUCED RANGE FROM TOWER END, PRIMACORD DRIVEN DETONATED FROM MICROPHONE END. 


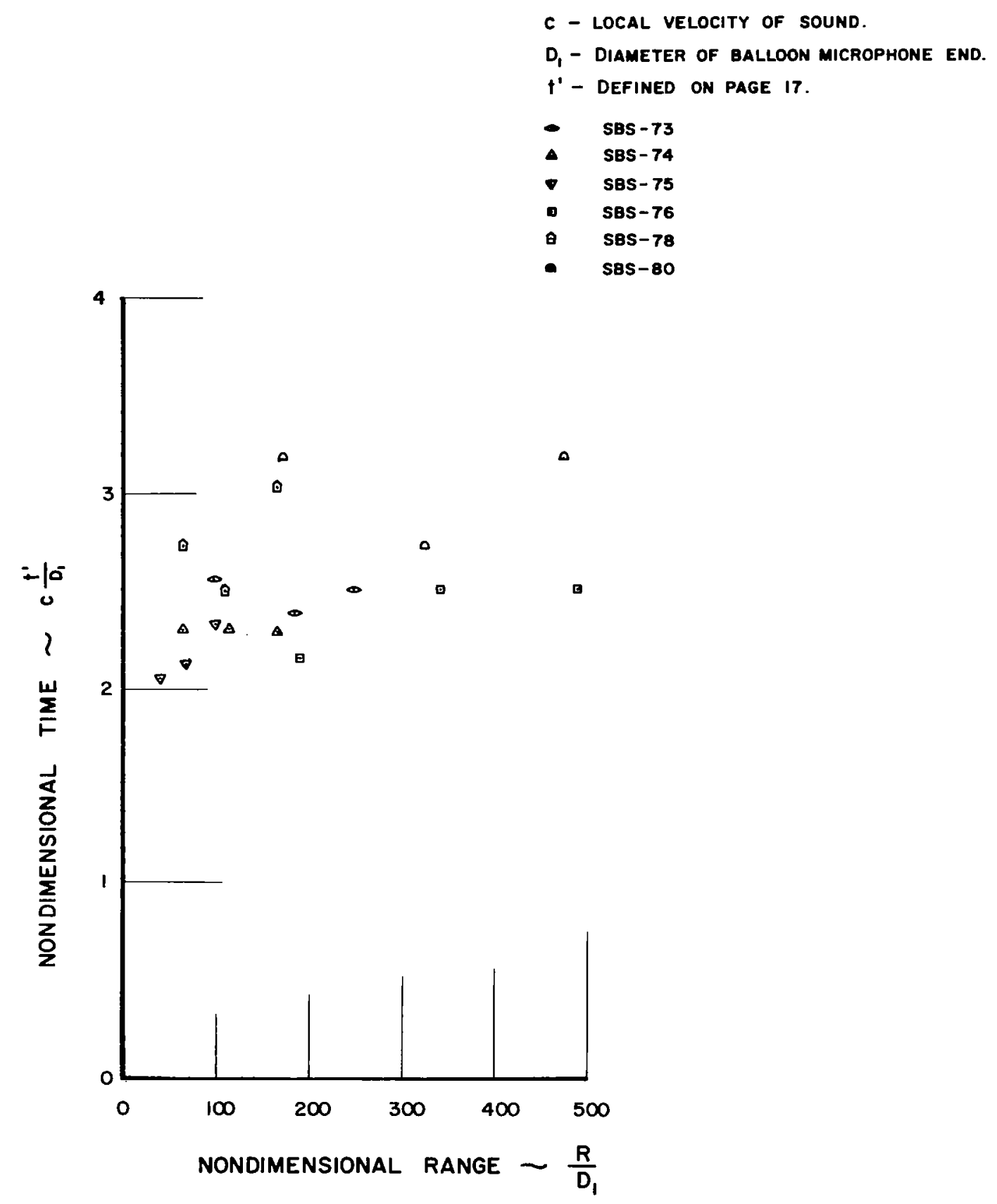

Figure 22, ANOMALOUS DURATION VS REDUCED DISTANCE, CYLINDER DETONATIONS 
- SBS - 80 note $1 A$

- SBS - 8I note IB

- SBS - 82 note IC

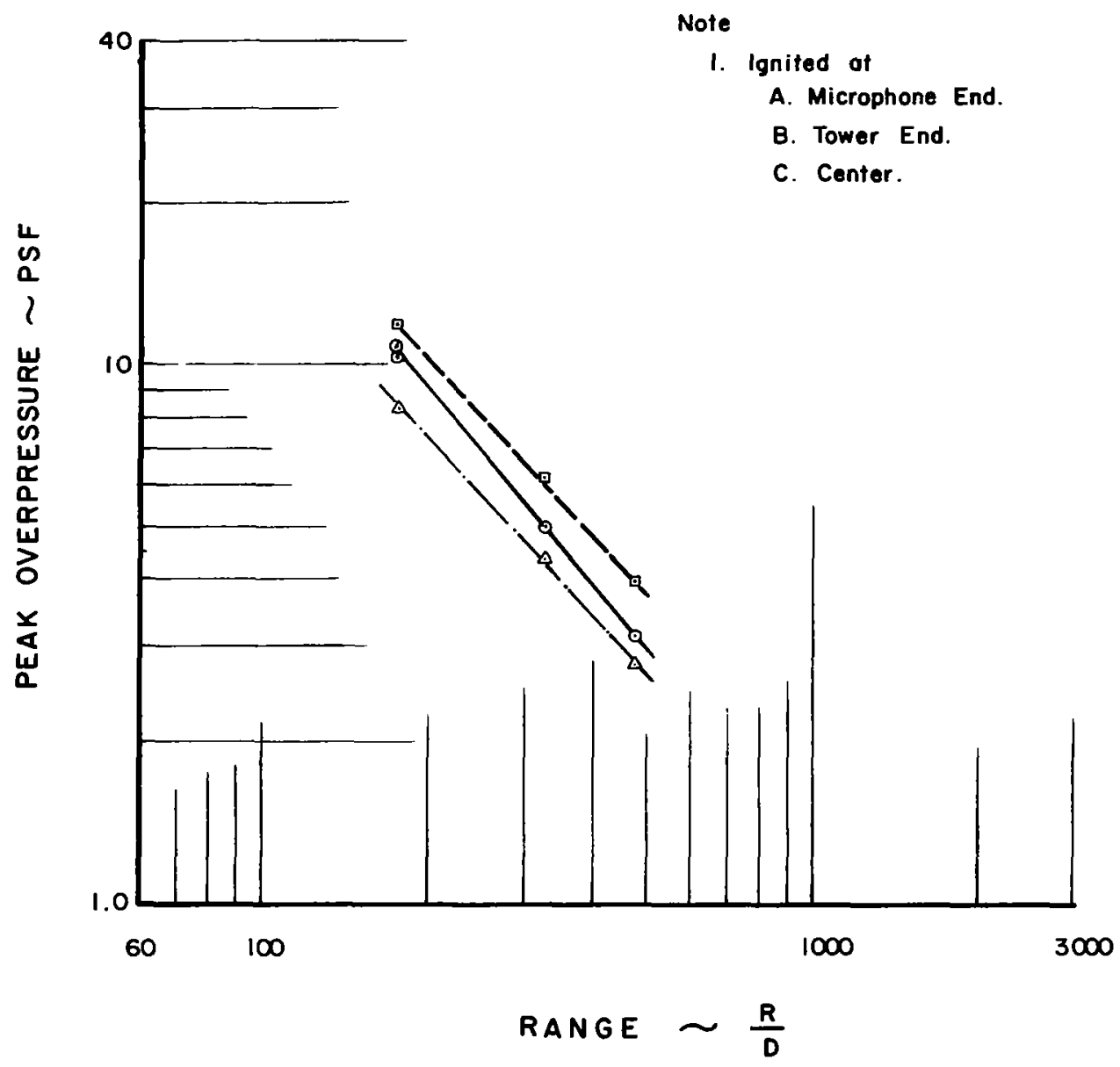

Figure 23, PEAK OVERPRESSURE VS REDUCED RANGE I'X 50' CYLINDRICAL ENVELOPES, PRIMACORD DRIVEN DETONATION, EFFECT OF POSITION OF IGNITOR. 


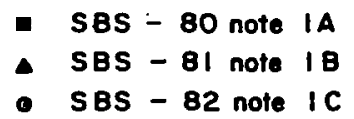

Note

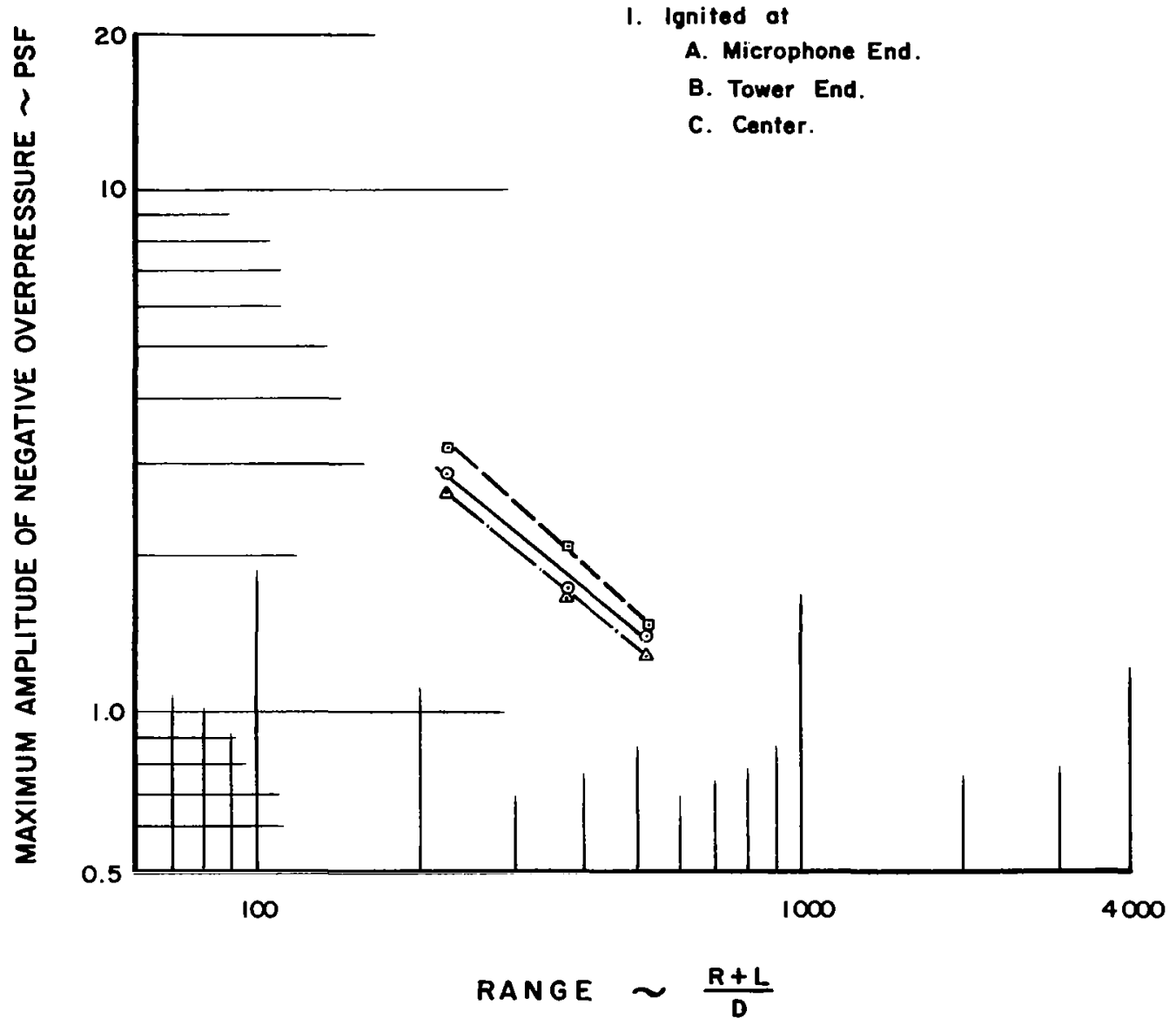

Figure 24, MAXIMUM AMPLITUDE OF NEGATIVE OVERPRESSURE VS REDUCED RANGE, I'X 50' CYLINDRICAL ENVELOPES, PRIMACORD DRIVEN DETONATION, EFFECT OF POSITION OF IGNITOR. 


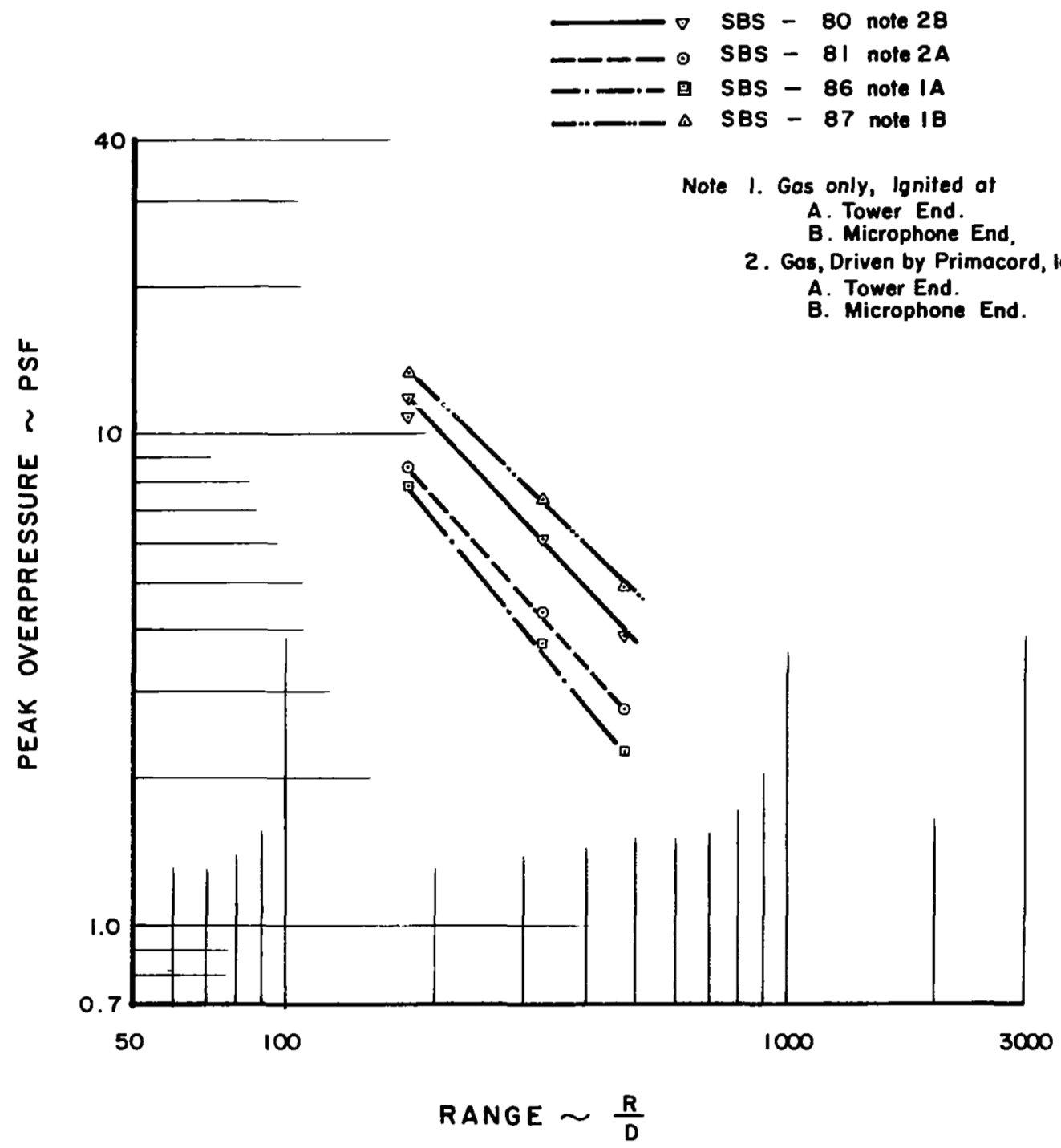

Figure 25, COMPARISON OF PEAK OVERPRESSURES VS RANGE, DETONATION OF I'X 50 ' CYLINDRICAL ENVELOPES WITH GAS ONLY AND GAS DRIVEN BY PRIMACORD 


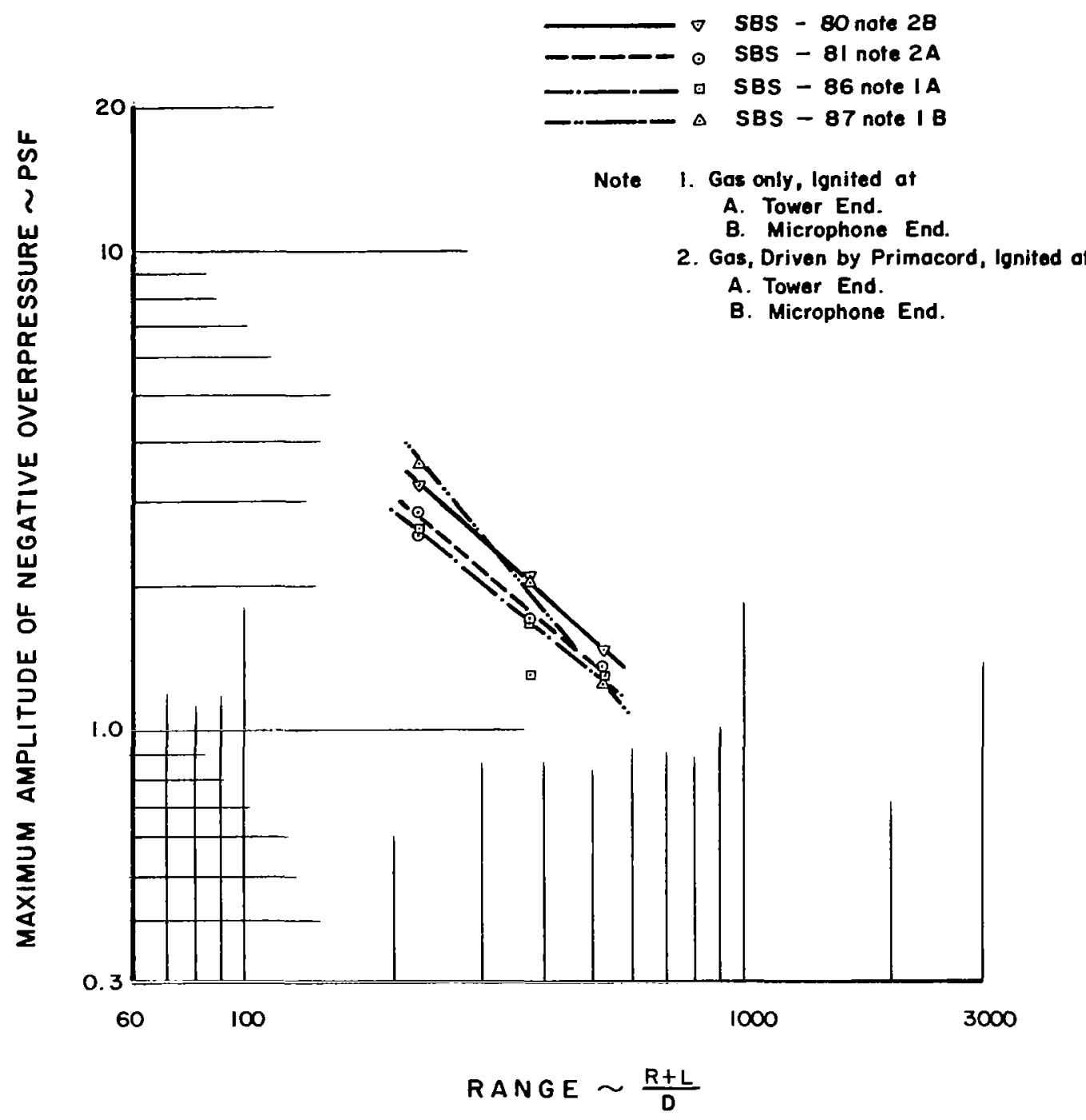

Figure 26, COMPARISON OF MAXIMUM AMPLITUDE OF NEGATIVE OVERPRESSURE FOR DETONATION OF I'X 50' CYLINDRICAL ENVELOPES WITH GAS ONLY AND GAS DRIVEN BY PRIMACORD 


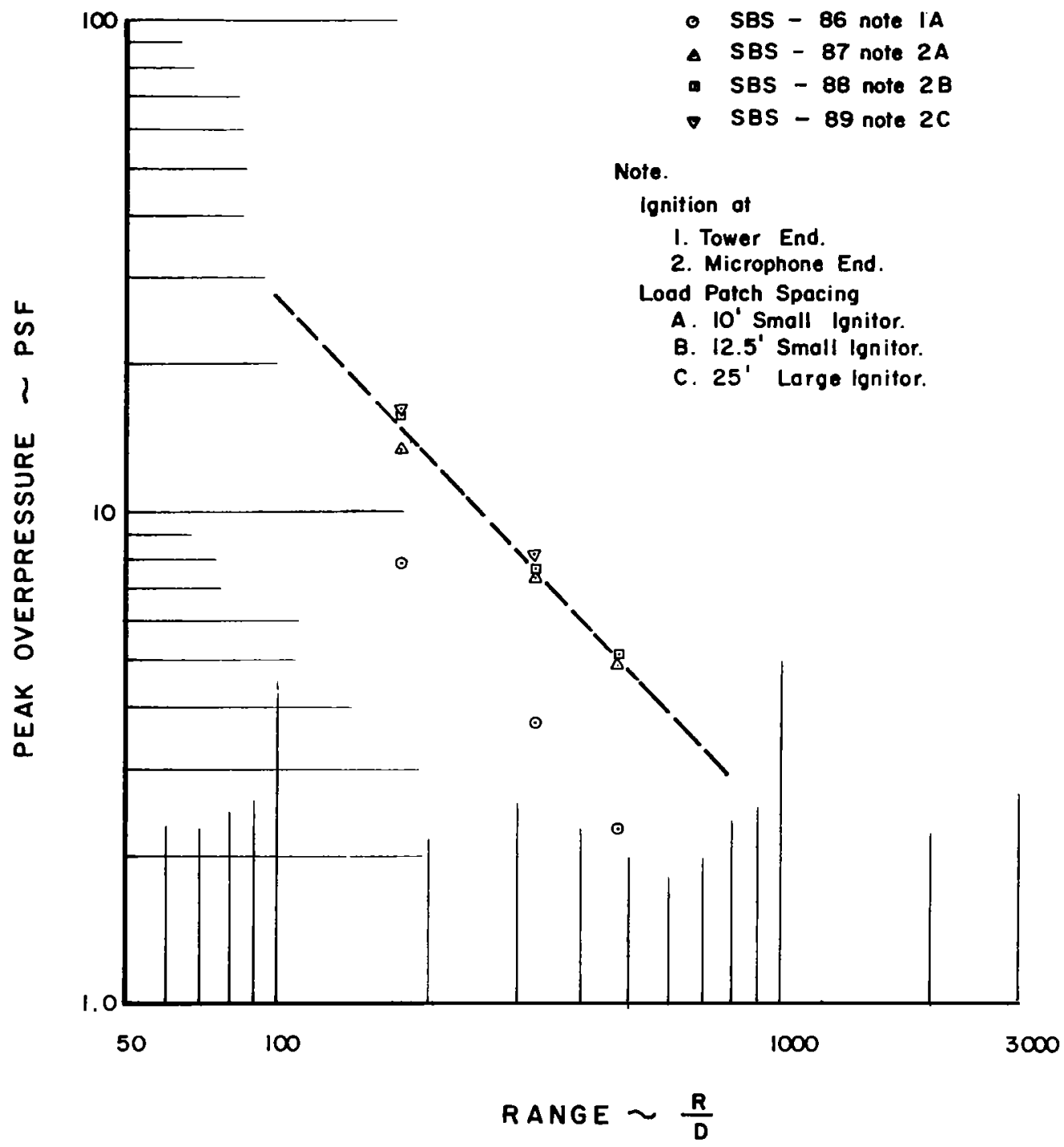

Figure 27, PEAK OVERPRESSURE VS REDUCED RANGE, I'X 50' CYLINDRICAL ENVELOPE, GAS ONLY EFFECT OF POSITION OF IGNITOR EFFECT OF LOAD PATCH SPACING. 


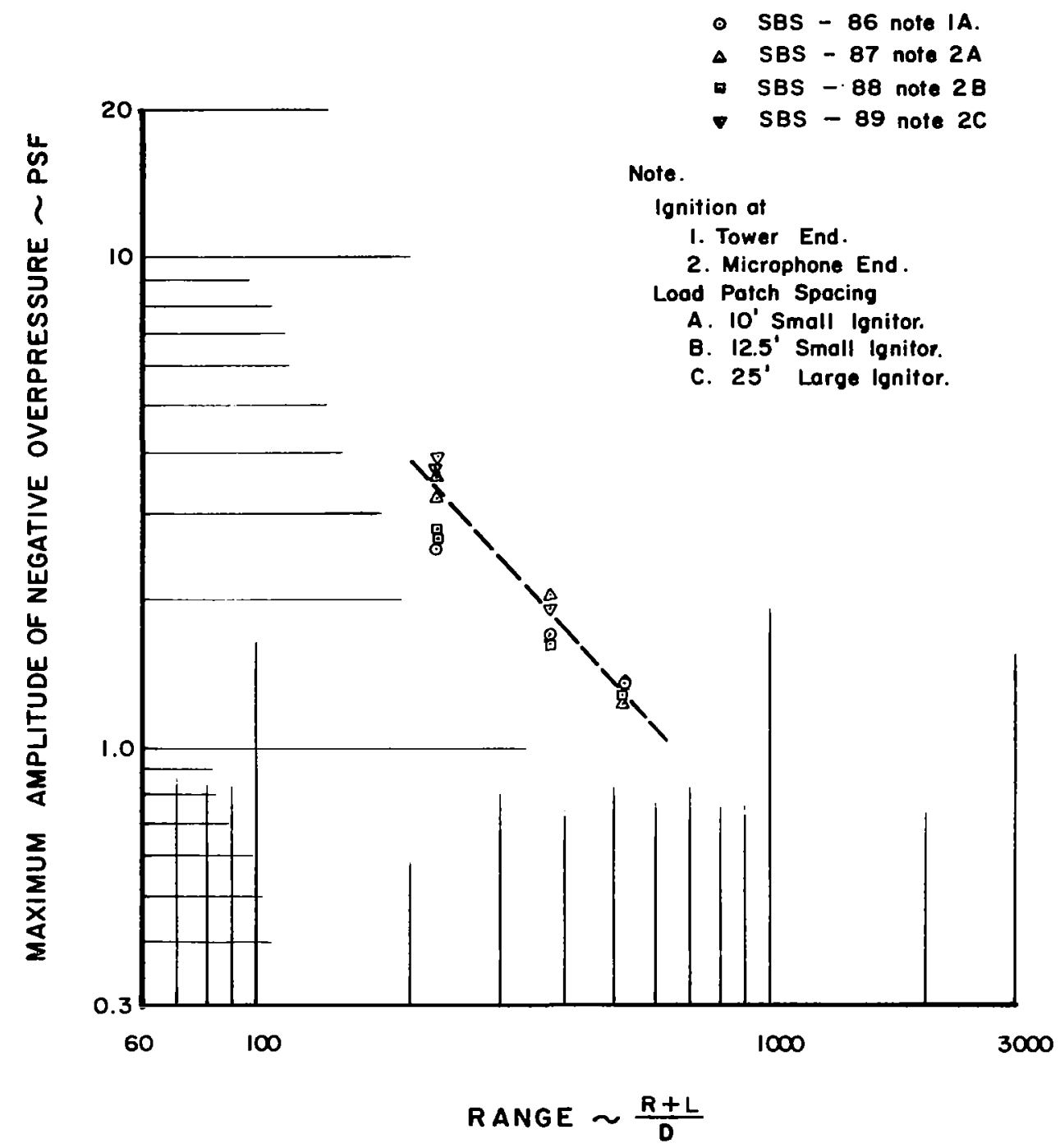

Figure 28, MAXIMUM AMPLITUDE OF NEGATIVE OVERPRESSURE VS REDUCED RANGE, I'X 50'CYLINDRICAL ENVELOPE, GAS ONLY EFFECT OF POSITION OF IGNITOR EFFECT OF LOAD PATCH SPACING EFFECT OF SIZE OF IGNITOR. 


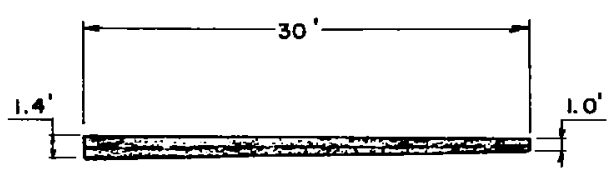

SBS -90

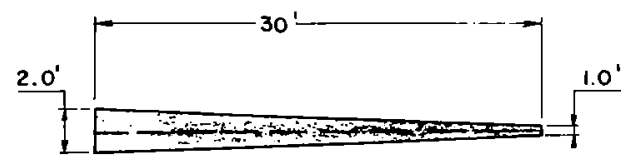

SBS -95

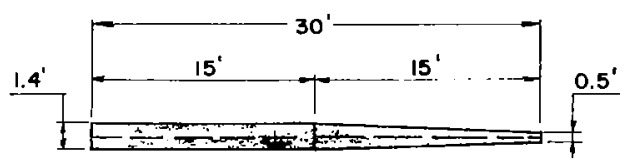

SBS -93

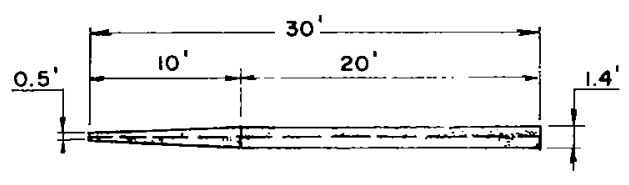

SBS -97

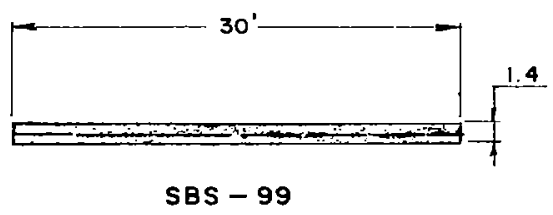

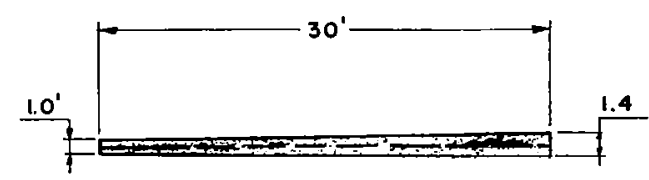

SBS - 91
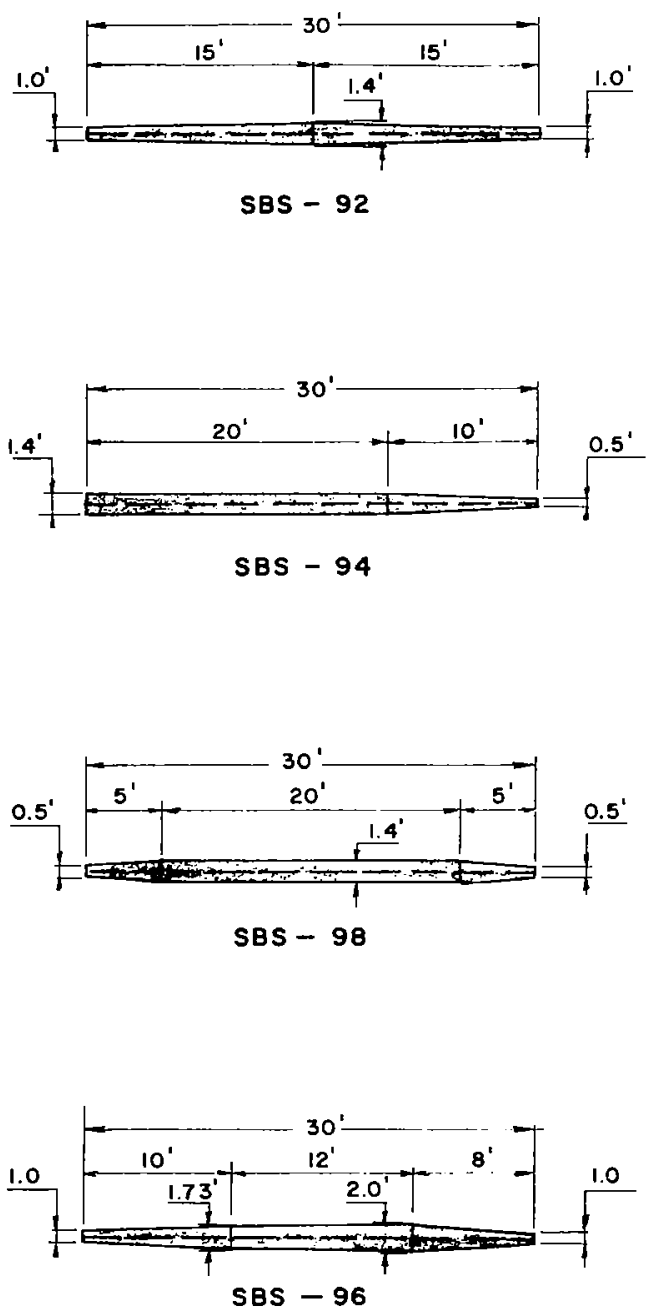

Note. Pressure Transducer arroy located to the right for all shopes.

Figure 29, EXPERIMENTAL ENVELOPE SHAPES FOR PHASE III. 


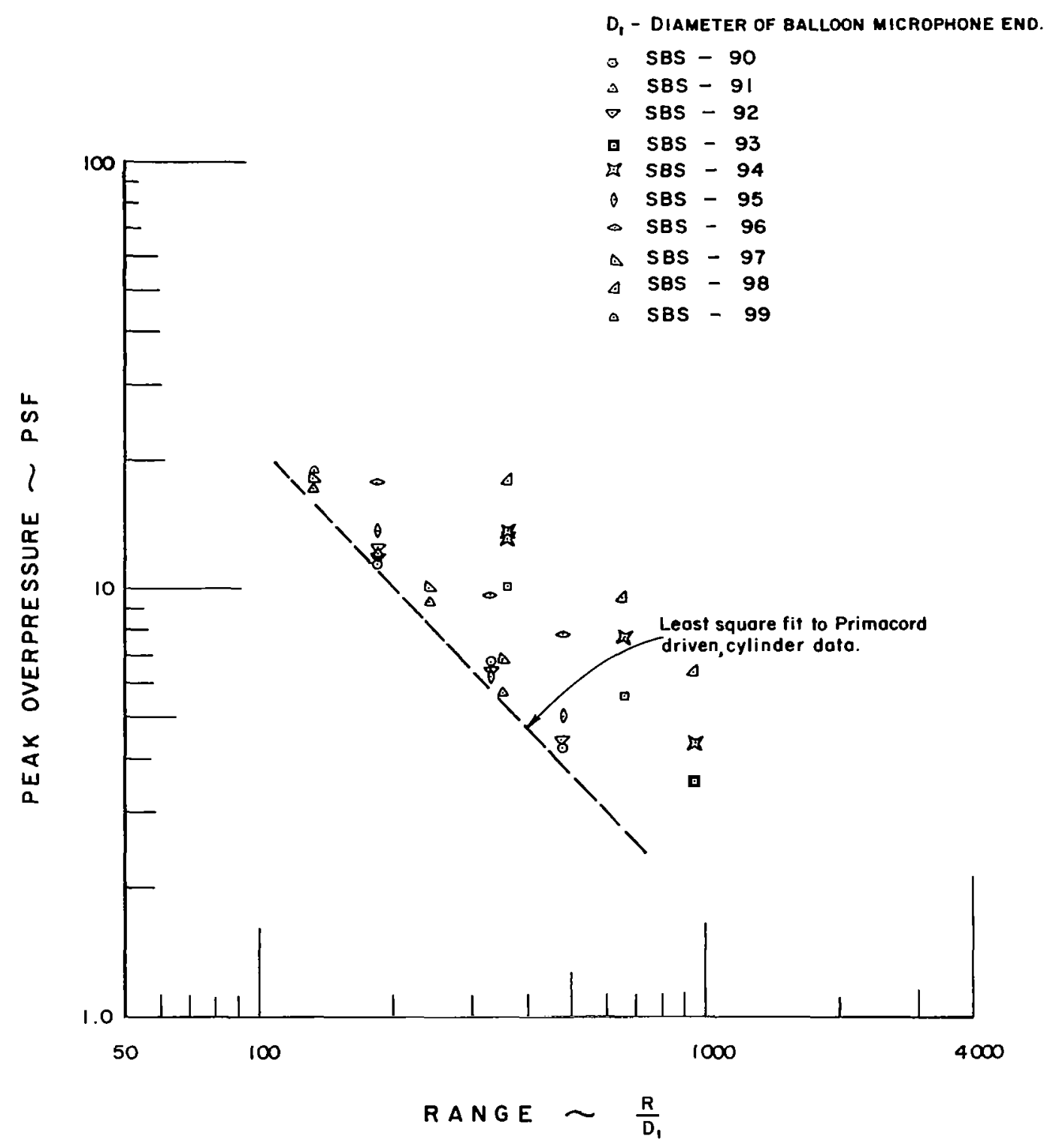

Figure 30, PEAK OVERPRESSURE VS REDUCED RANGE, COMPOSITE SERIES III. 


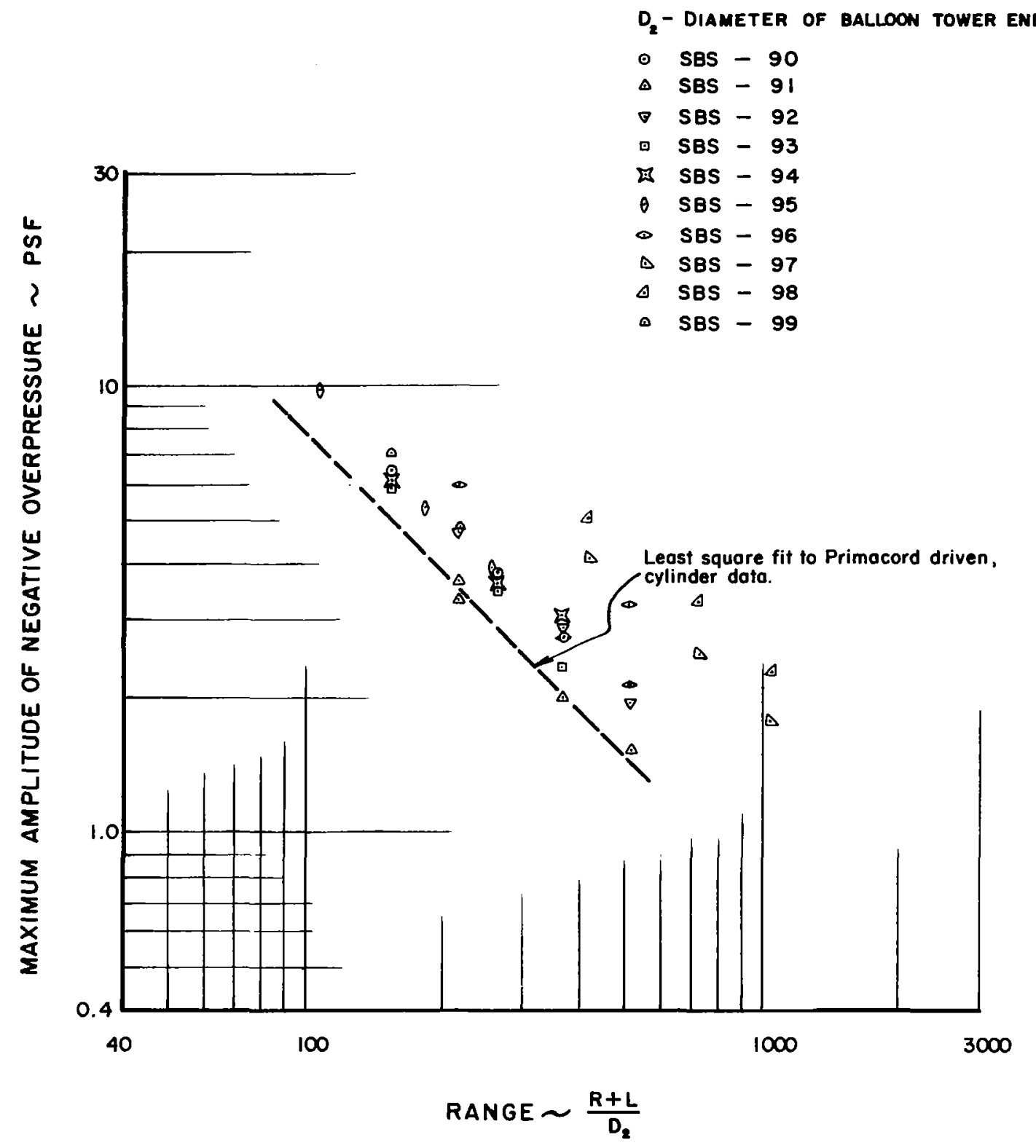

Figure 31, MAXIMUM AMPLITUDE OF NEGATIVE OVERPRESSURE VS REDUCED RANGE, COMPOSITE SERIES III. 


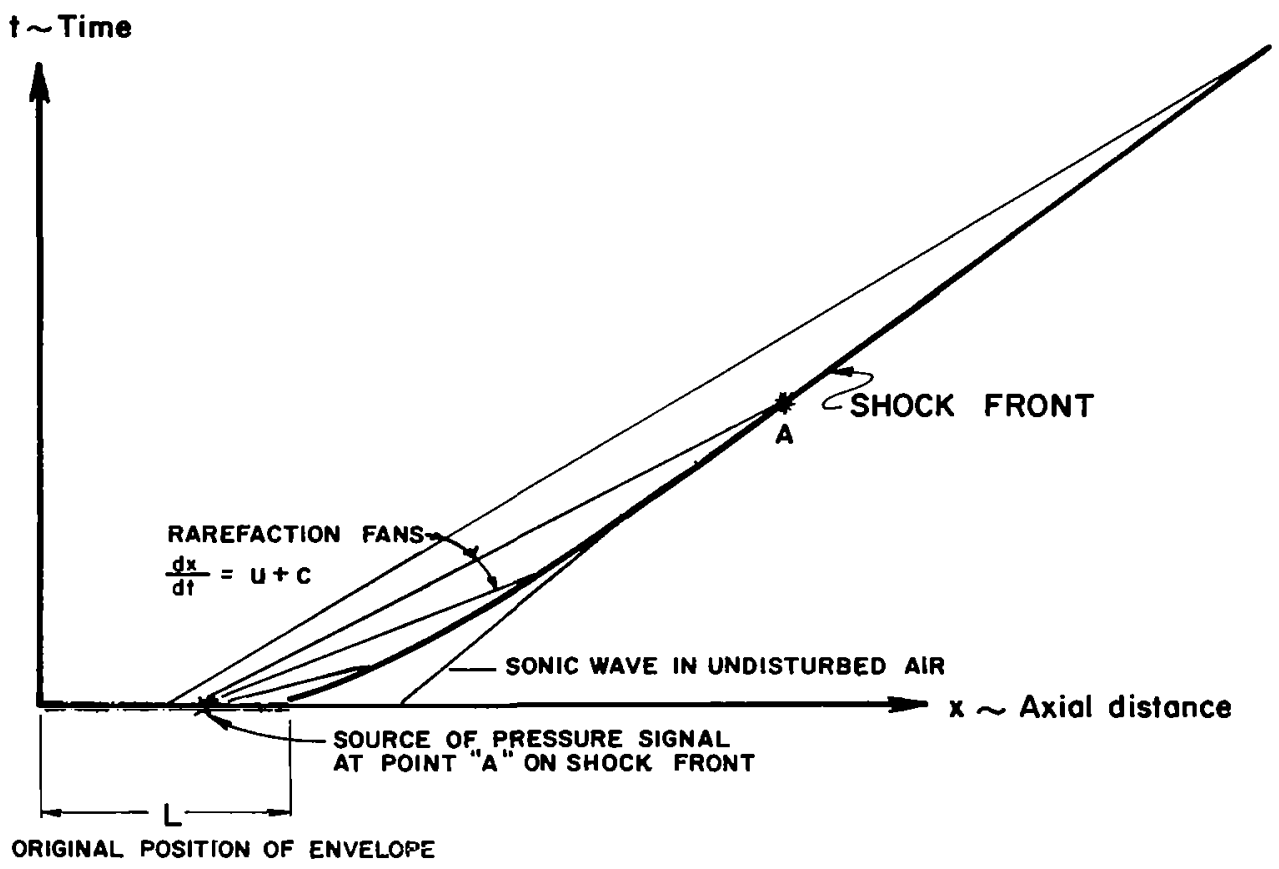

Figure 32, CHARACTERISTIC DIAGRAM SCHEMATIC SHOWING ATTENUATION OF SHOCK FRONT AND LOCATION OF FAR-FIELD PRESSURE MAXIMUM. 


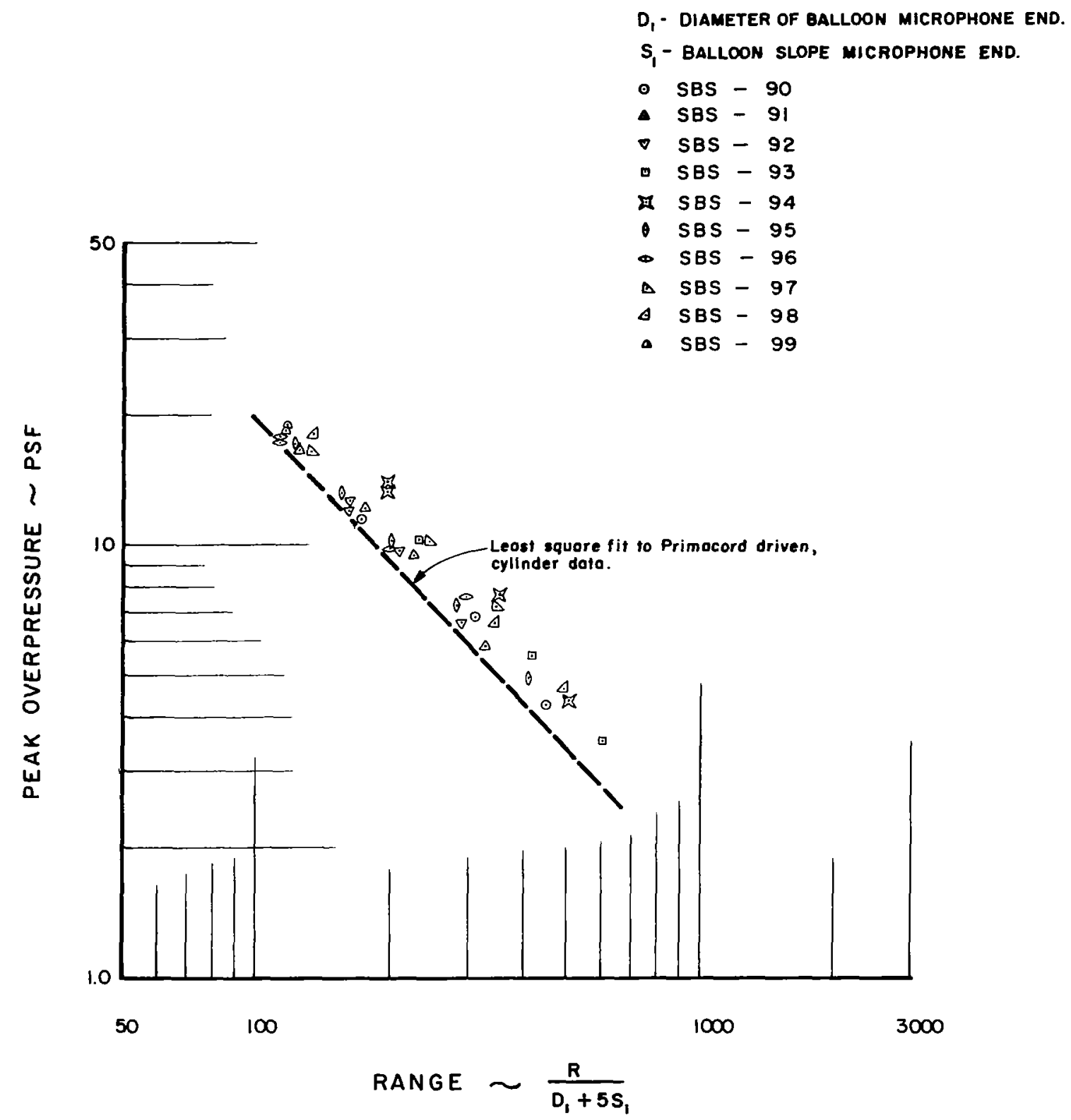

Figure 33, PEAK OVERPRESSURE VS REDUCED RANGE, CORRECTED FOR SLOPE OF NEAR CONICAL SECTION, COMPOSITE, SERIES III 


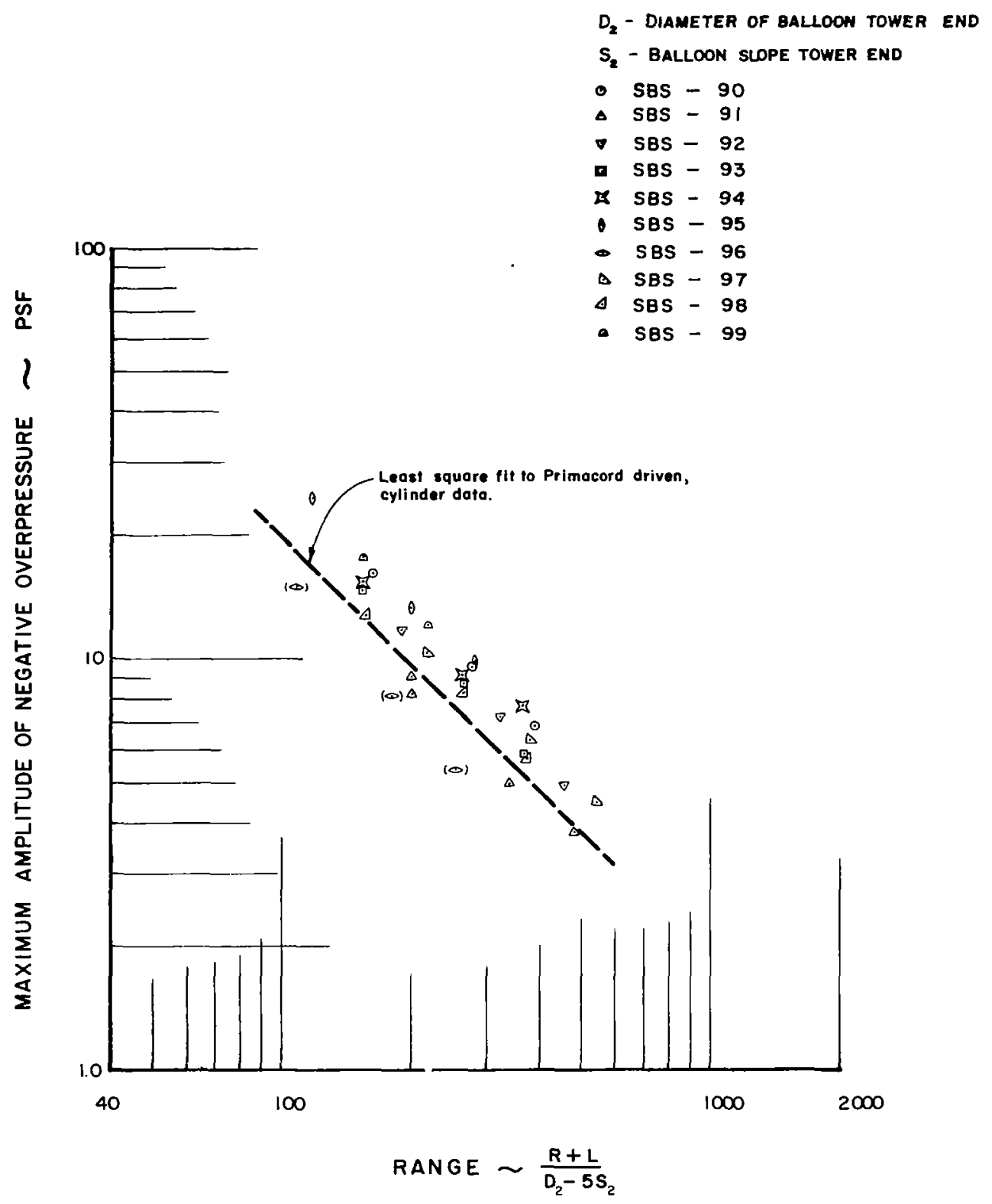

Figure 34, MAXIMUM AMPLITUDE OF NEGATIVE OVERPRESSURE VS REDUCED RANGE, CORRECTED FOR SLOPE OF REAR CONICAL SECTION, COMPOSITE SERIES III. 

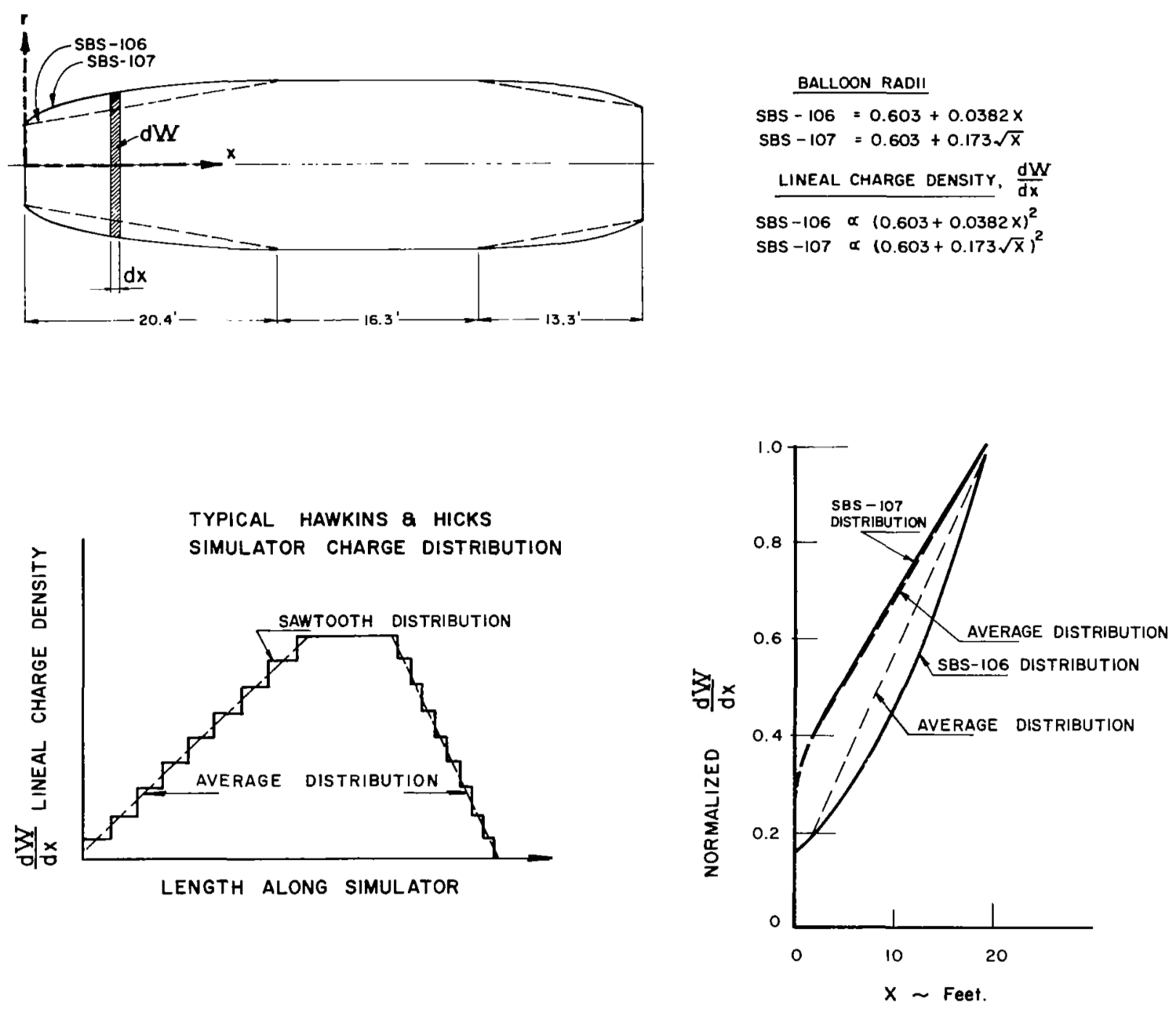

Figure 35, COMPARISON OF CHARGE DENSITIES OF BALLOONS SIMULATING HAWKINS \& HICKS SIMULANTS. 


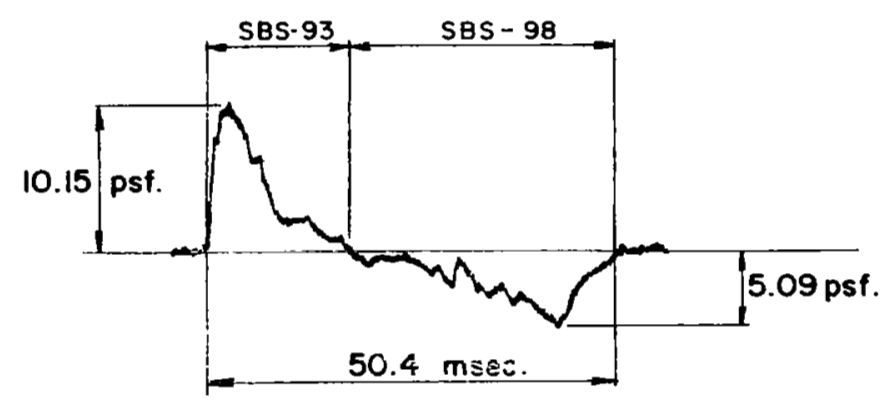

Figure 36, PREDICTED PRESSURE PROFILE FOR SBS-102 AS DEDUCED FROM MEASURED PROFILES OF SBS- 93 AND SBS-98 AT THE $200 \mathrm{FT}$. GAUGE STATION. 


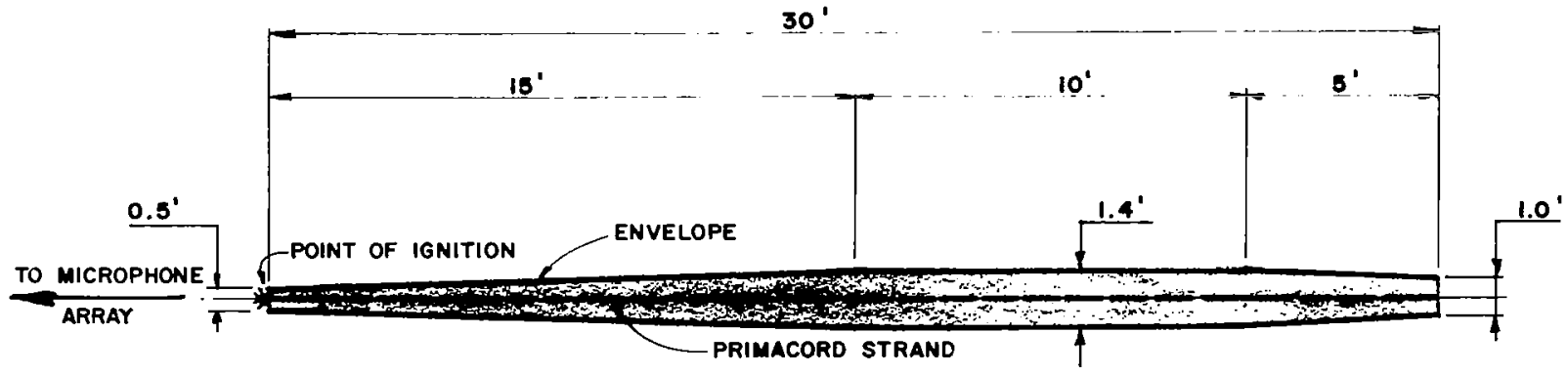

Figure 37 BALLOON CONFIGURATION TO OBTAIN N WAVE. SBS - 102 


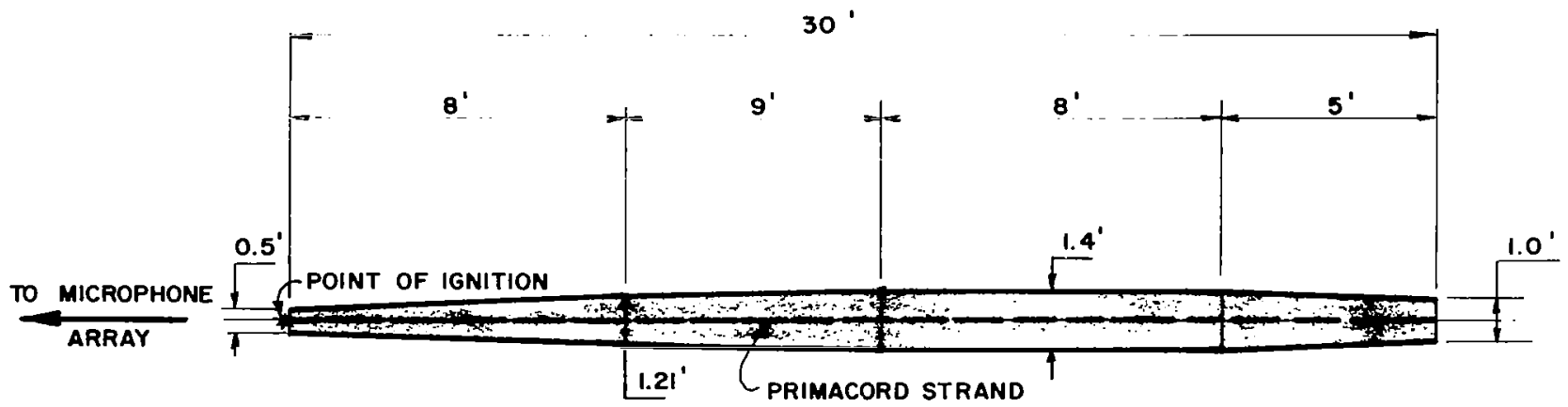

Figure 38, ALTERNATE BALLOON CONFIGURATION TO OBTAIN N WAVE. $S B S-103$ 

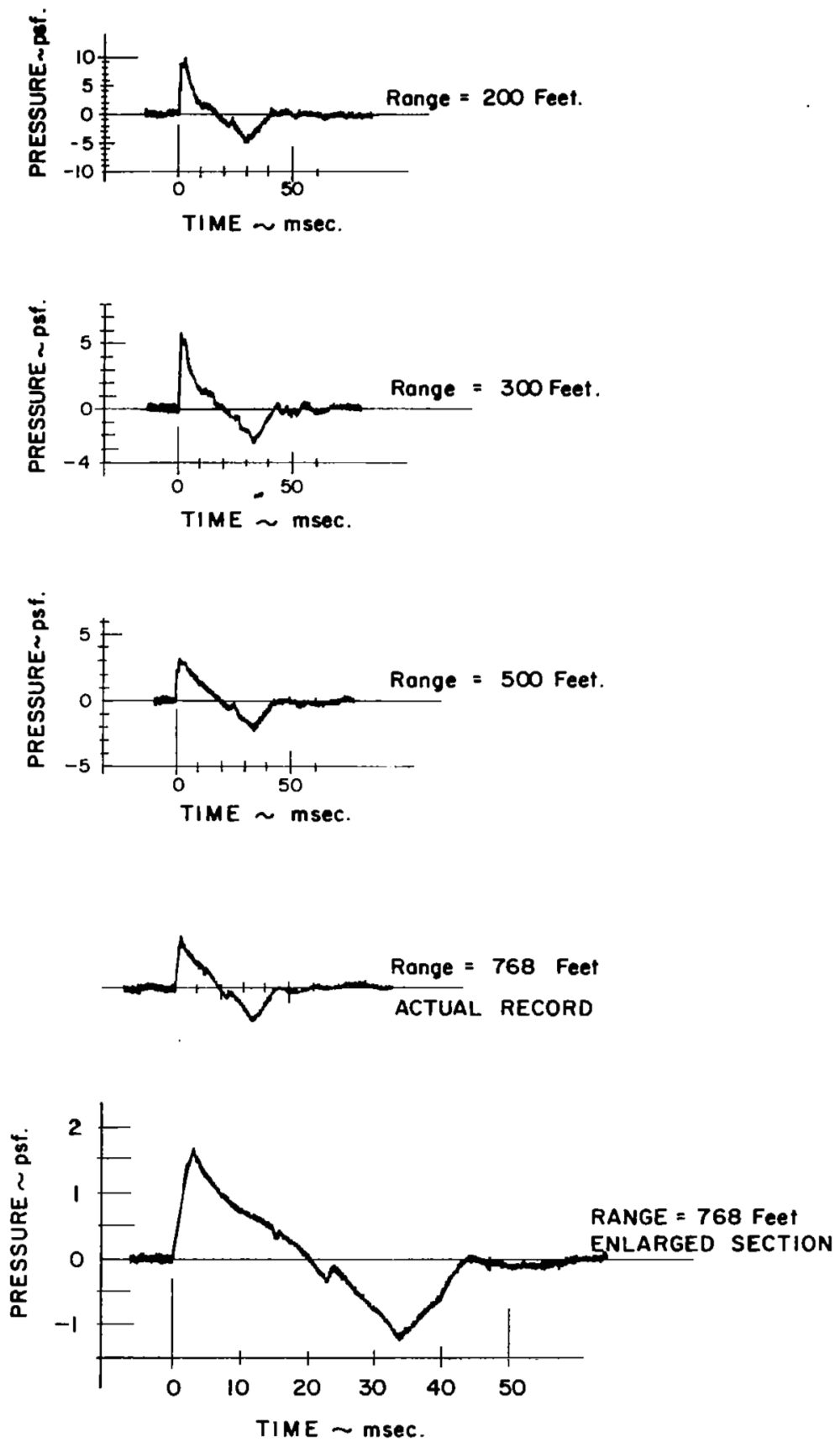

Figure 39, PRESSURE TIME HISTORIES AT VARIOUS RANGES, FOR SBS 102. (Illustrating development of $N$ wave) 
RANGE $=200$ Feet.

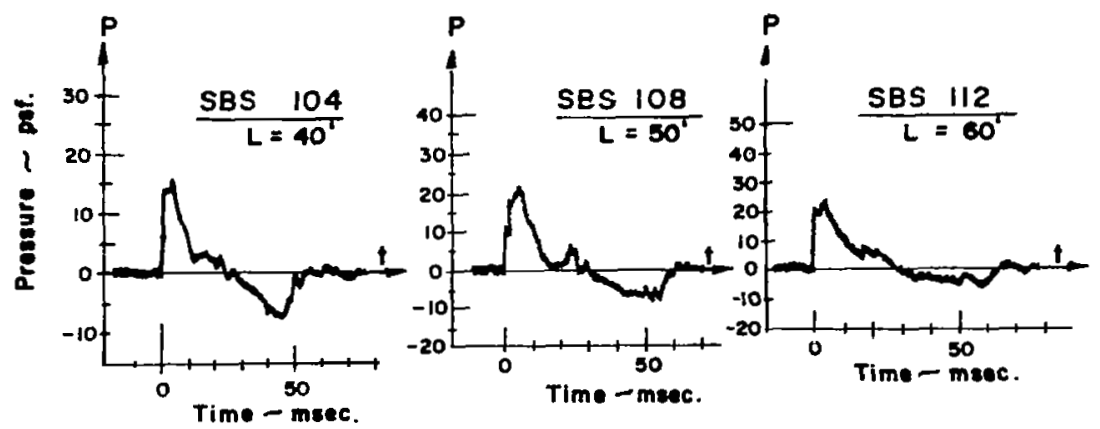

RANGE $=300$ Feet.
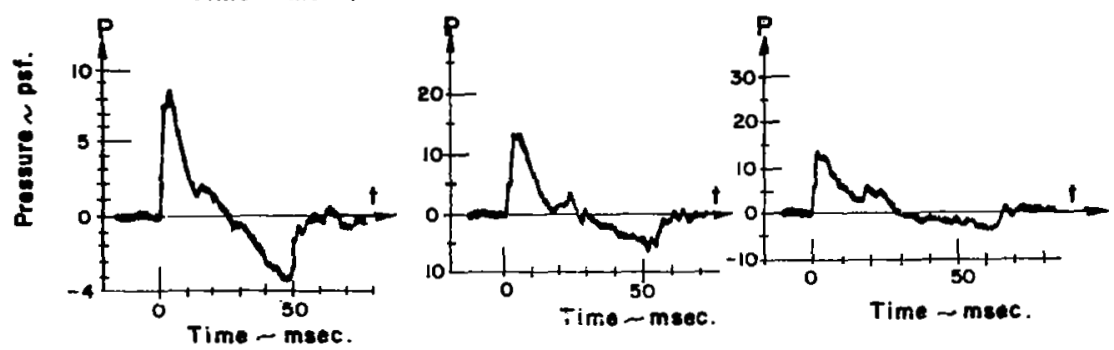

RANGE $=500$ Feet.
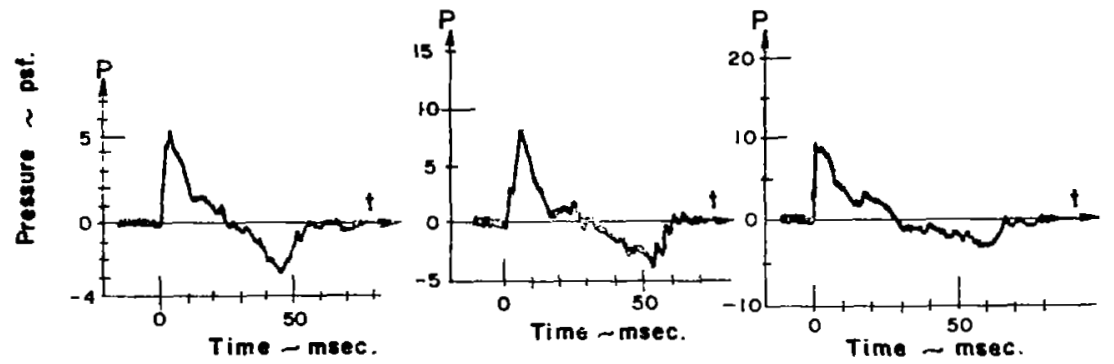

RANGE $=768$ Feet.
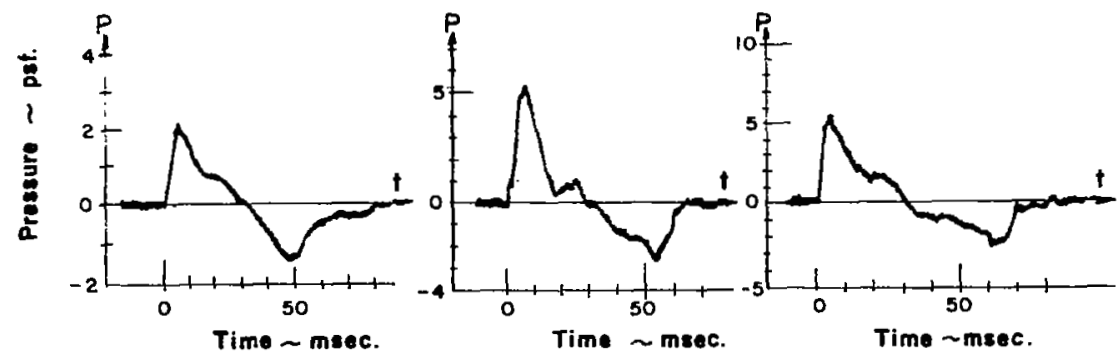

Figure 40, PRESSUFE VS TIME AT VARIOUS RANGES AND SBS NUMBERS. (Showing approsch to $\mathbf{N}$ wove.) 
EXPERIMENTAL PRESSURE PROFILE.

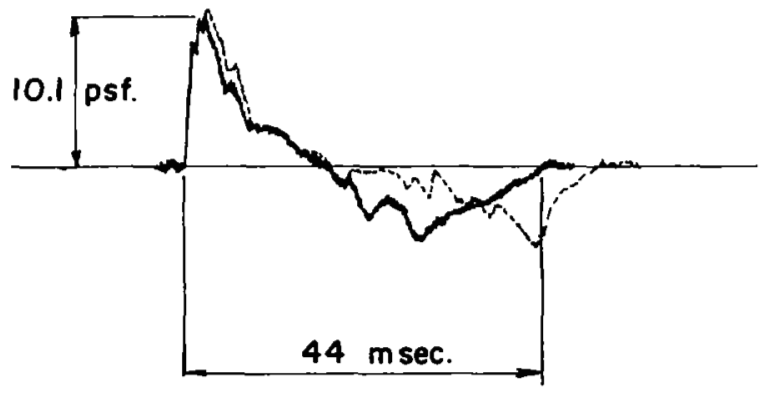

Figure 41, EXPERIMENTAL AND PREDICTED PRESSURE PROFILES FOR SBS - 102 AT THE $200 \mathrm{FT}$. GAUGE STATION. 


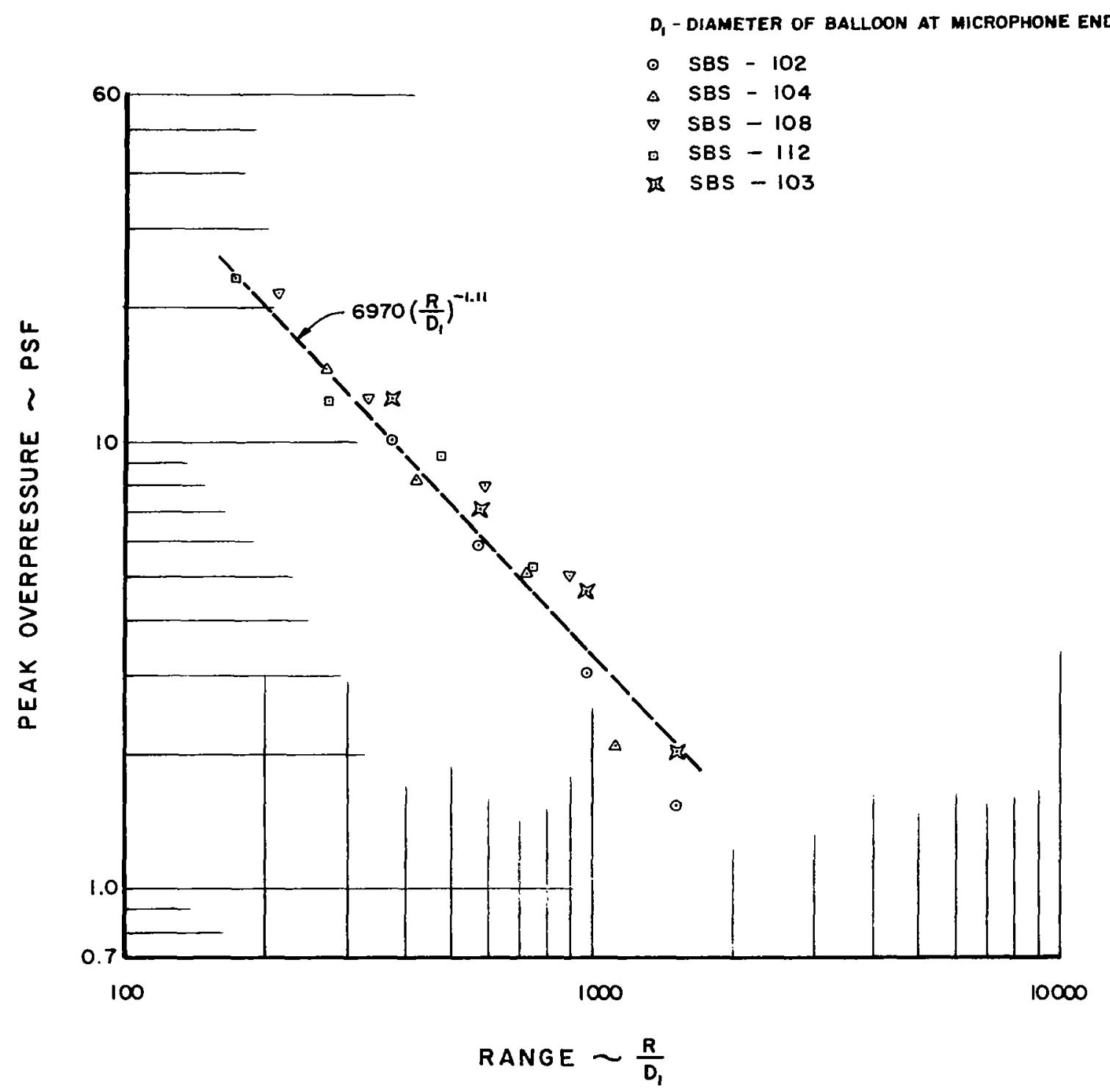

Figure 42, PEAK OVERPRESSURE VS REDUCED RANGE N-WAVE ENVELOPES - SERIES IV. 


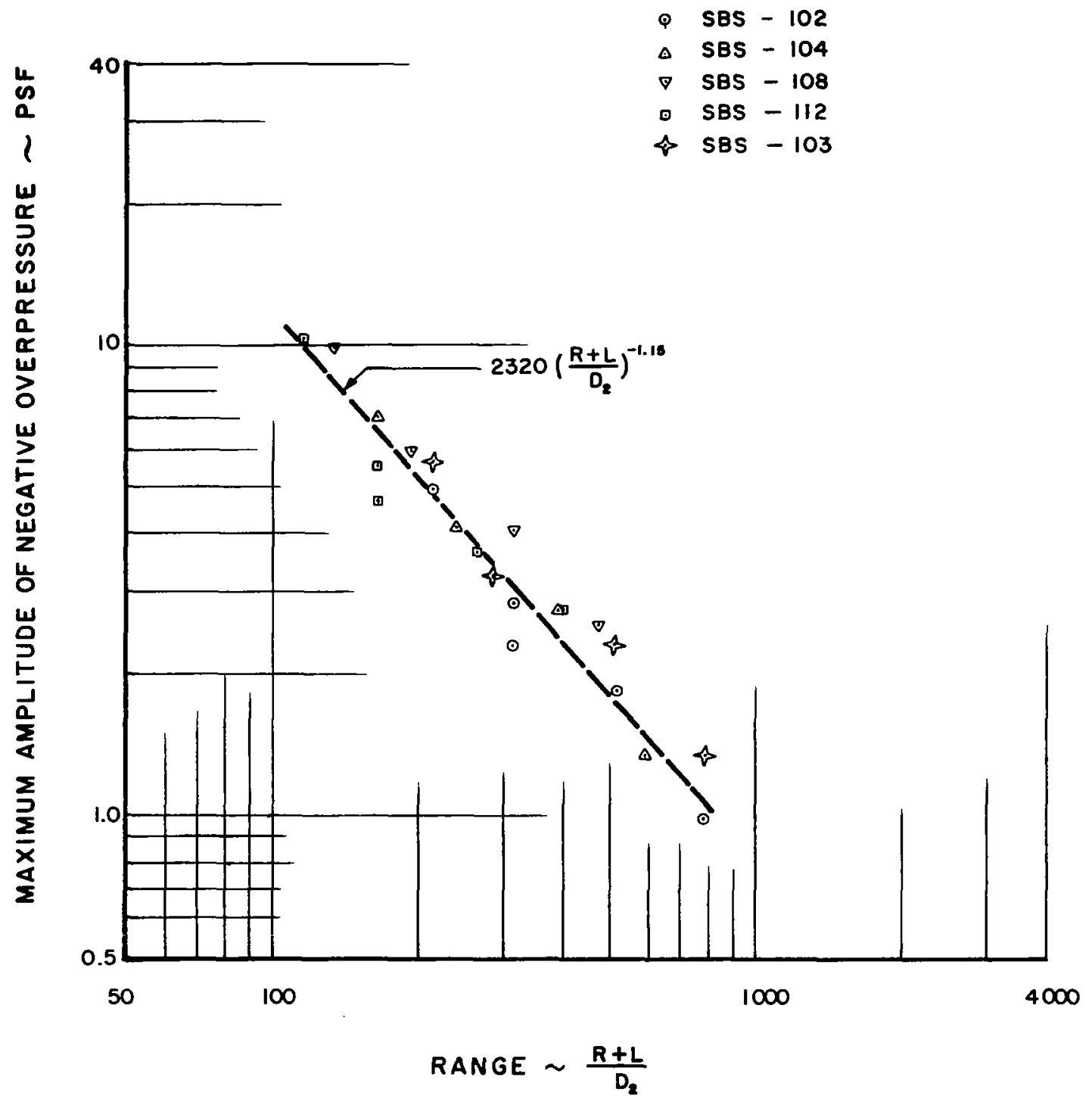

Figure 43, MAXIMUM AMPLITUDE OF NEGATIVE OVERPRESSURE VS REDUCED RANGE N-WAVE ENVELOPES - SERIES IV. 


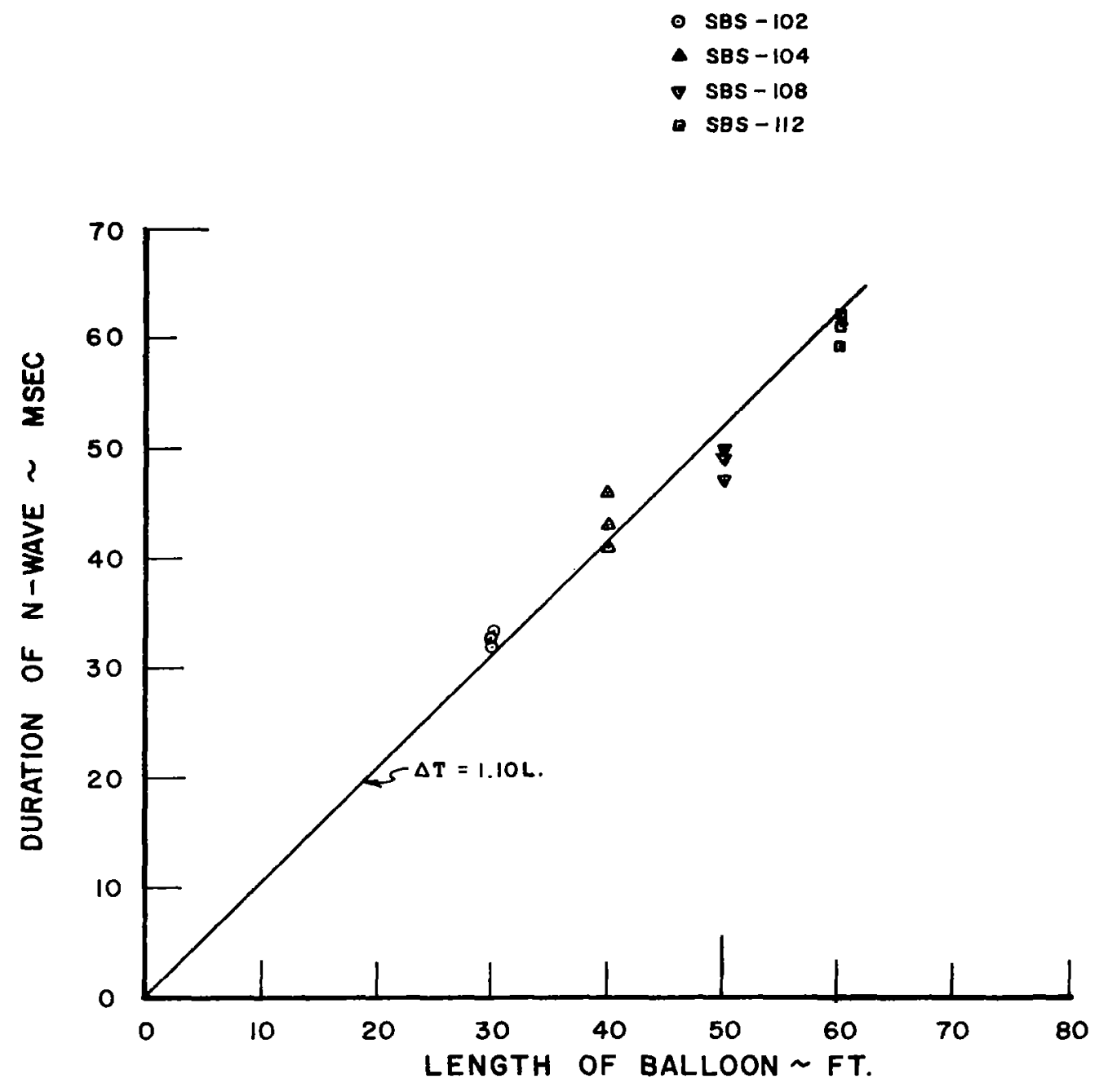

Figure 44, DURATION OF N-WAVE PULSE VERSUS LENGTH OF BALLOON 


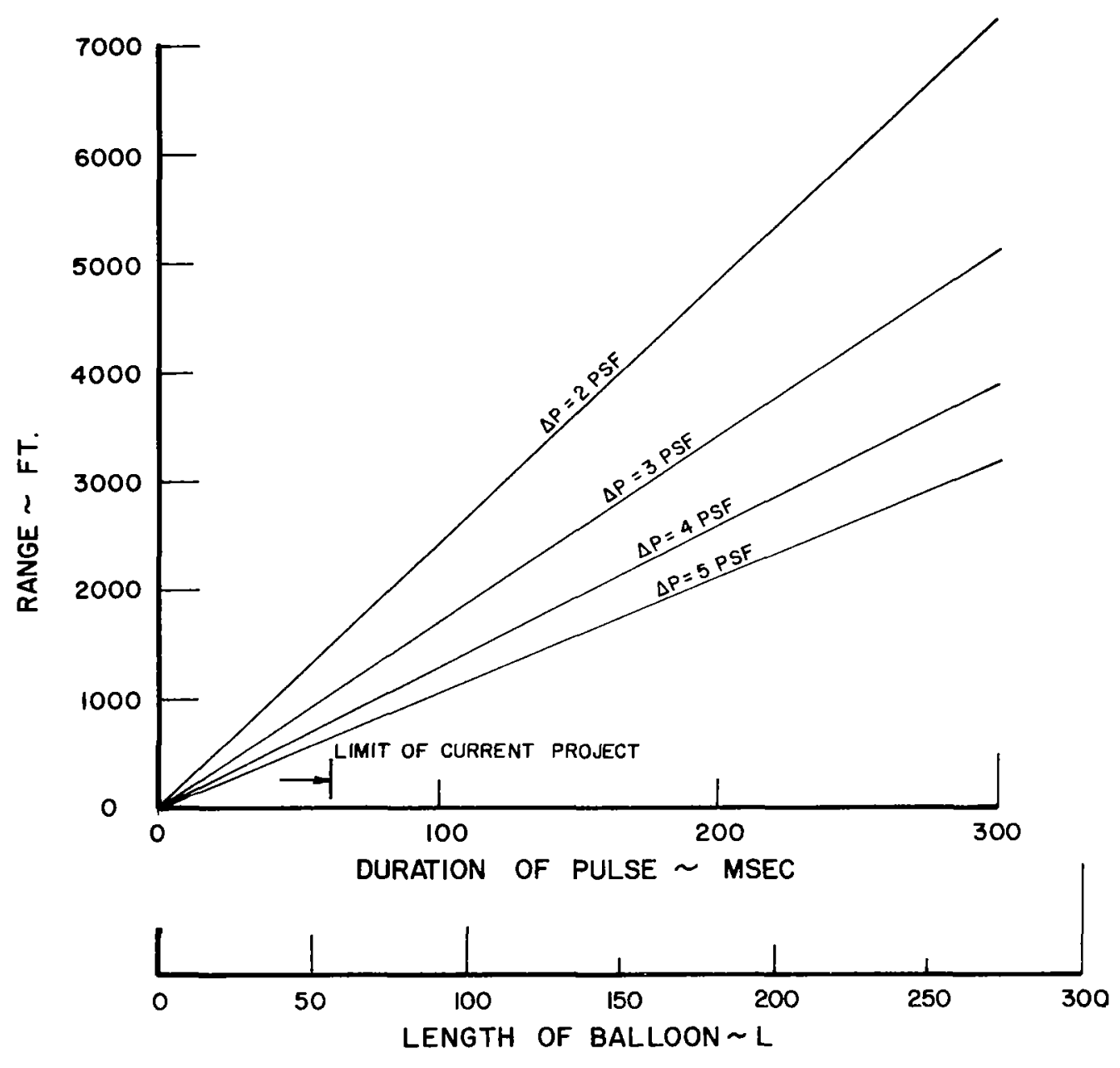

Figure 45, REQUIRED RANGE FOR SONIC BOOM SIMULATIONS, GIVEN REQUIRED PEAK-PRESSURE AND DURATION (EXTRAPOLATED) 


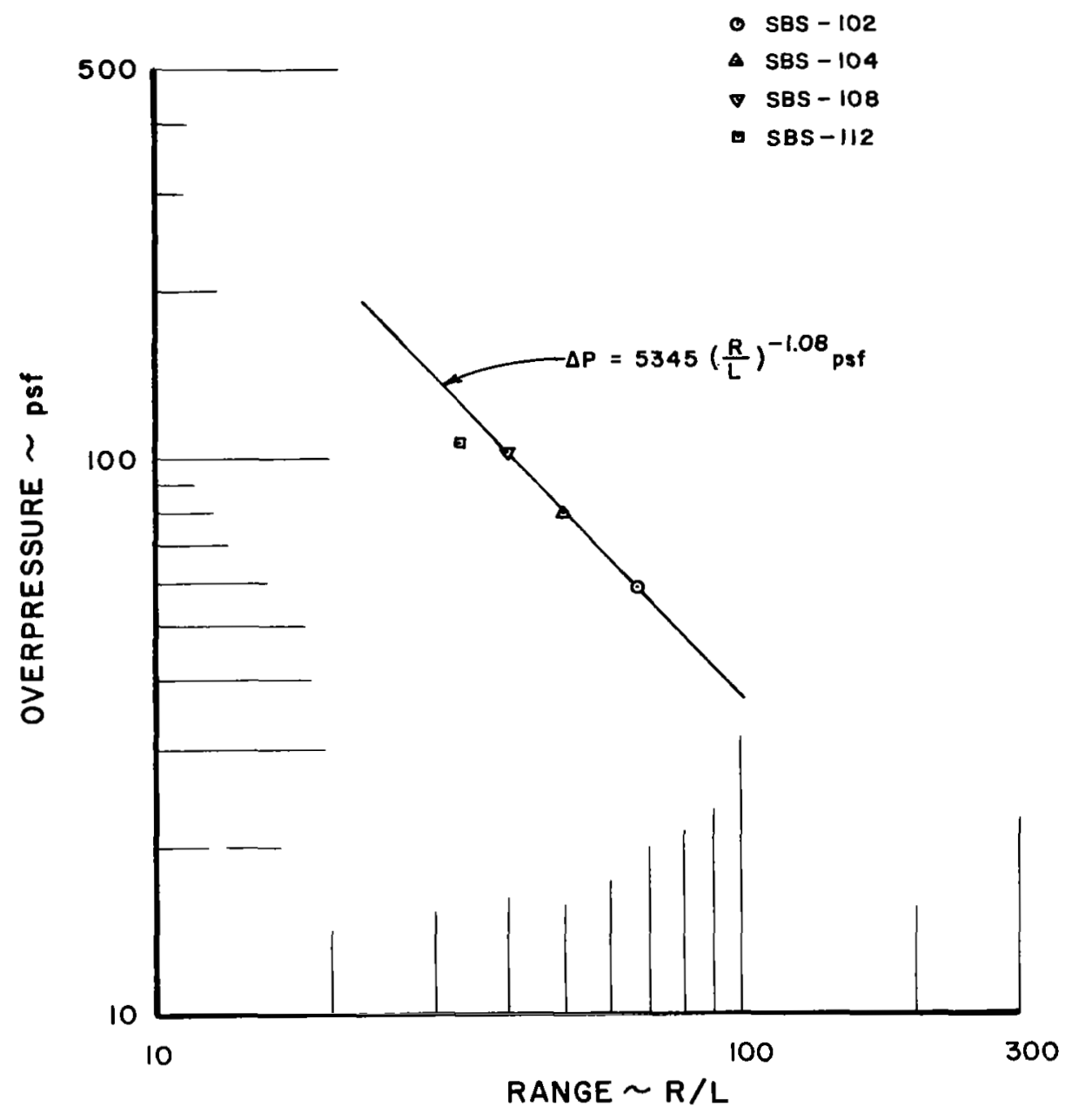

Figure 46, PEAK OVERPRESSURE VS RANGE NORMAL TO AXIS OF $\mathbf{N}$ - WAVE BALLOONS 

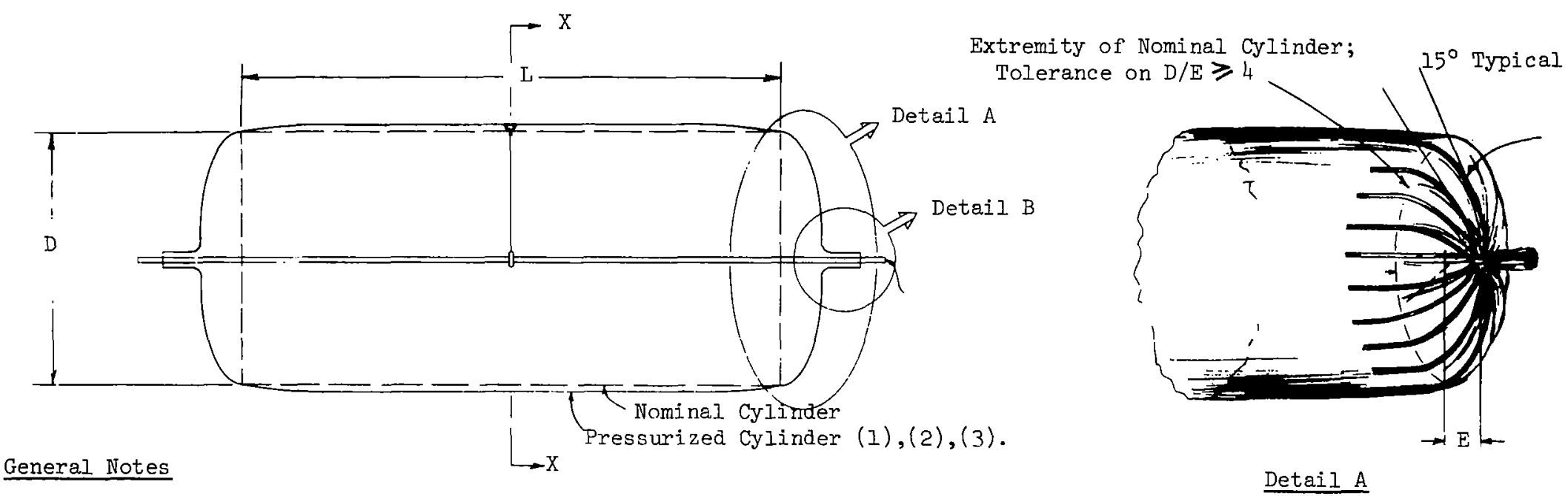

1. All envelopes will be

fabricated of 1 mil mylar with 20-25 lb/in breaking strength.

2. Envelope seaming per fabricator's option such that after inflation, nominal cross-sectional circulerity and longitudinal straightness are visually attained.

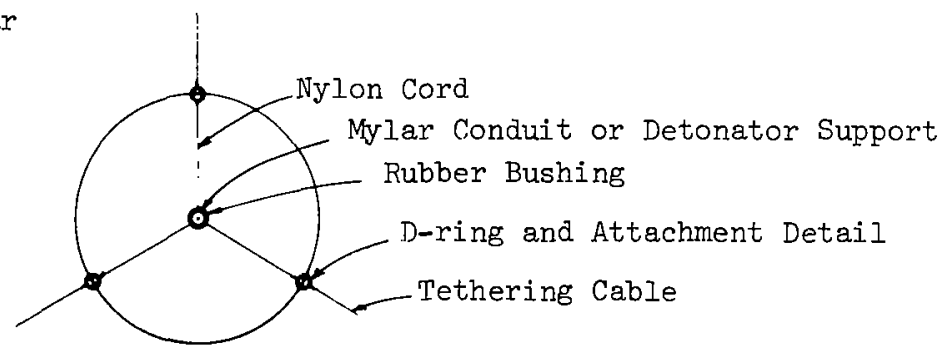

3. Packing Instructions:

Extend to full length, evacuate to max. extent possible and accordian fold

to optimum compactness.

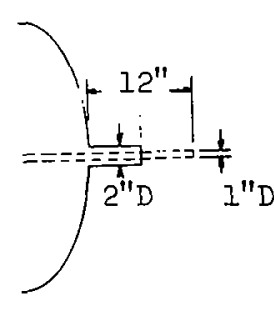

Detail B

NOZZLE SPECIFICATION AND CONDUIT CLOSURE 


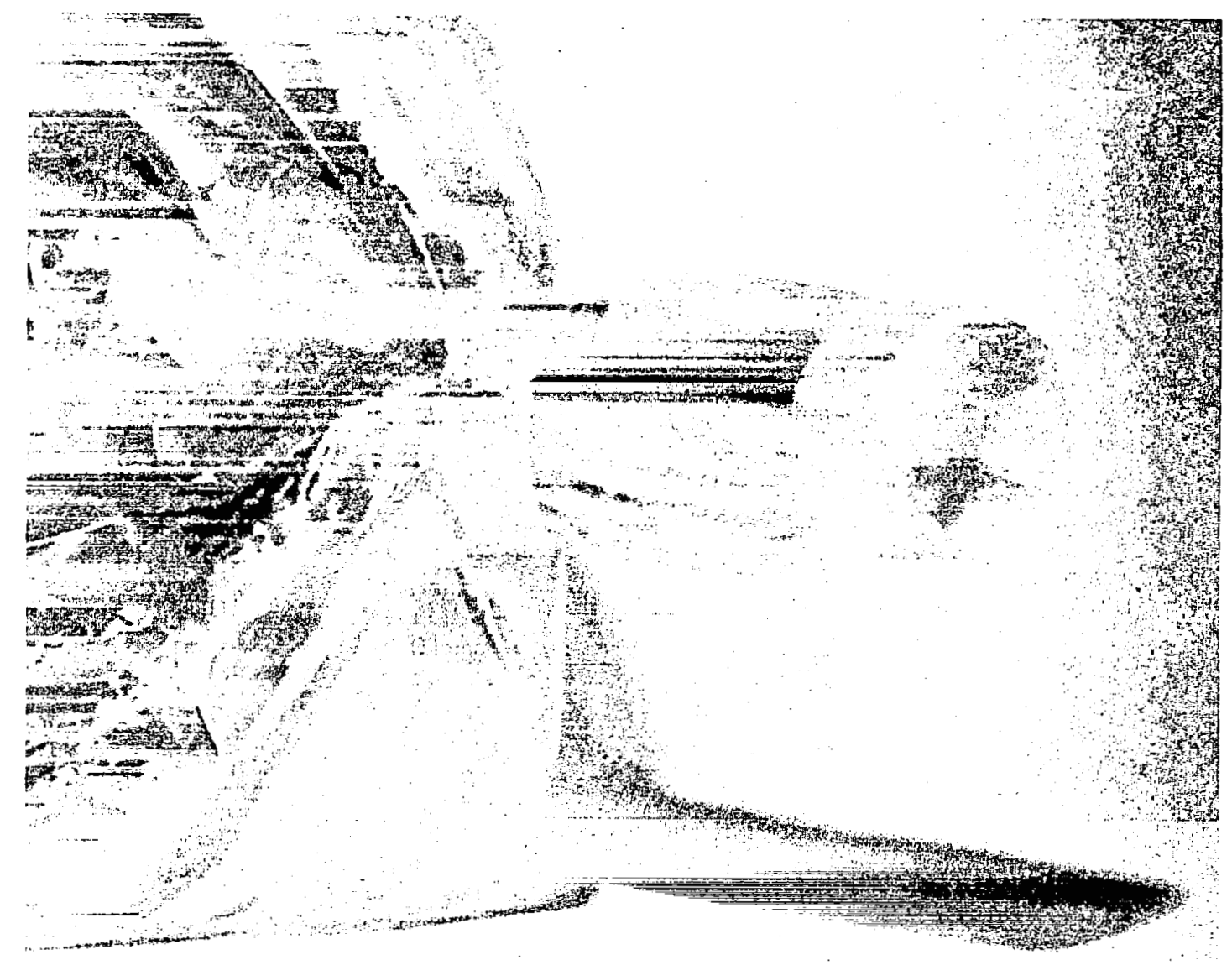

Figure 48, TYPICAL END GATHERING 


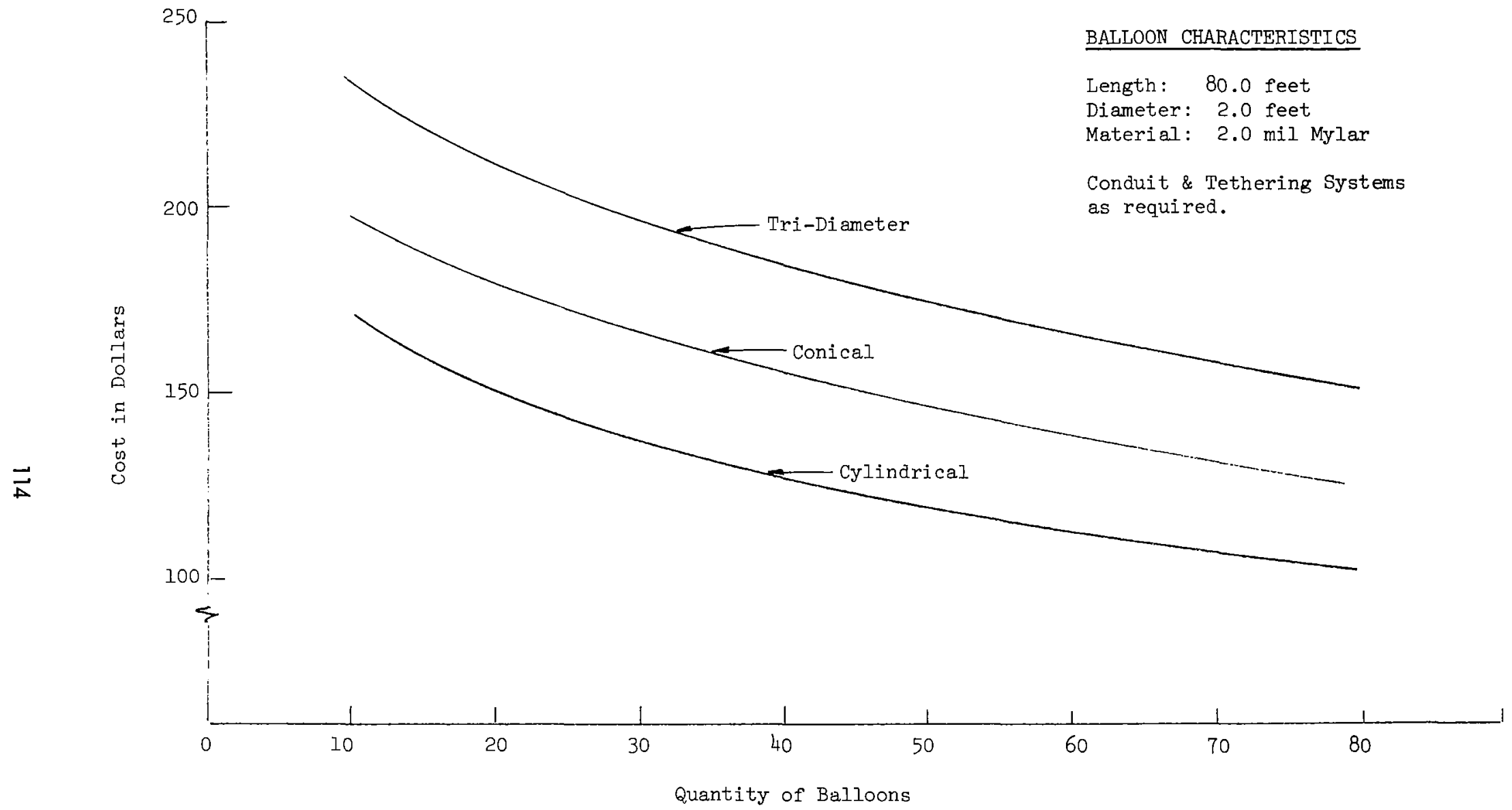

Figure 49 - PRICE FACTOR VS. QUANTITY OF SONIC BOOM ENVELOPES 


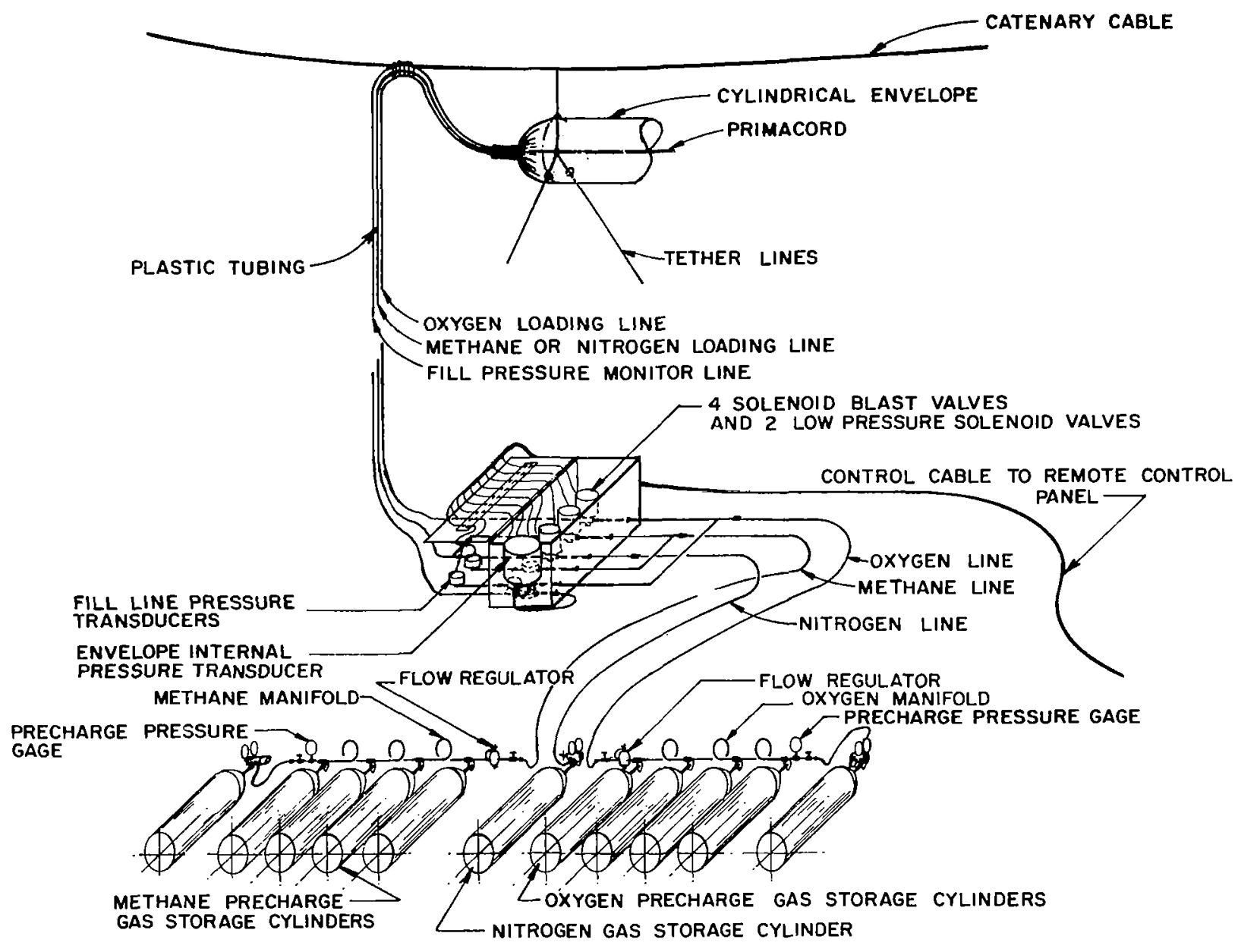

Figure 50, SONIC BOOM SIMULATOR, DETONABLE GAS LOADING SYSTEM SETUP 




REMOTE CONTROLLED SOLENOID VALVES AND REMOTE PRESSURE MONITORING SYSTEM, WIRING SCHEMATIC FOR TEST SERIES N2 3 AND N2 4

Figure 51 GAS LOADING VALVES AND REMOTE CONTROL ELECTRONIC SYSTEMS FOR TEST SERIES $1 ; 2$ AND $3 ; 4$ 

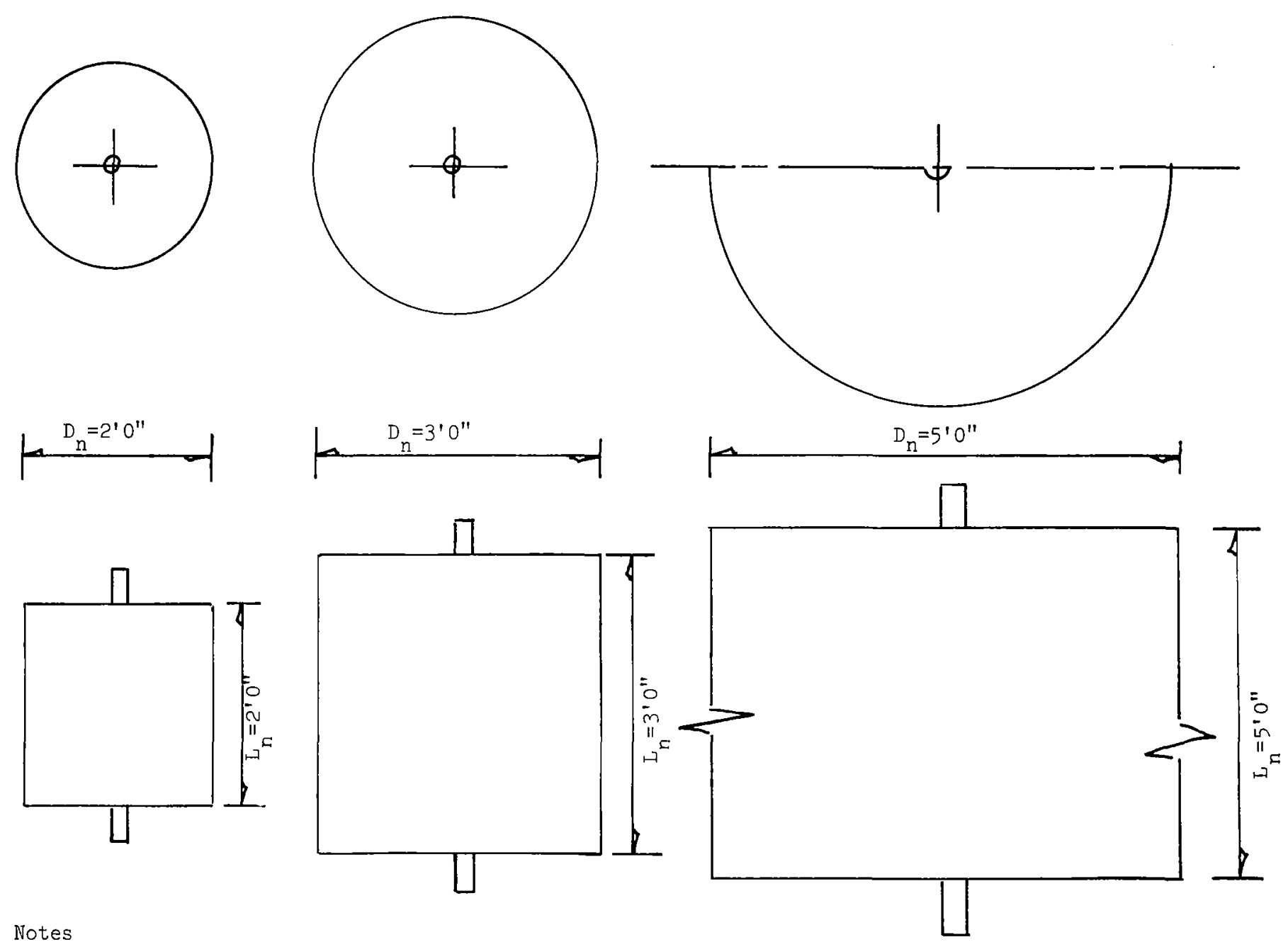

Notes

1. All cylinder ends per Detail A, Figure 47.

2. Nozzles per Detail B, Figure 47 .

Figure 52 Specimens for SBS 73,74 and 76 

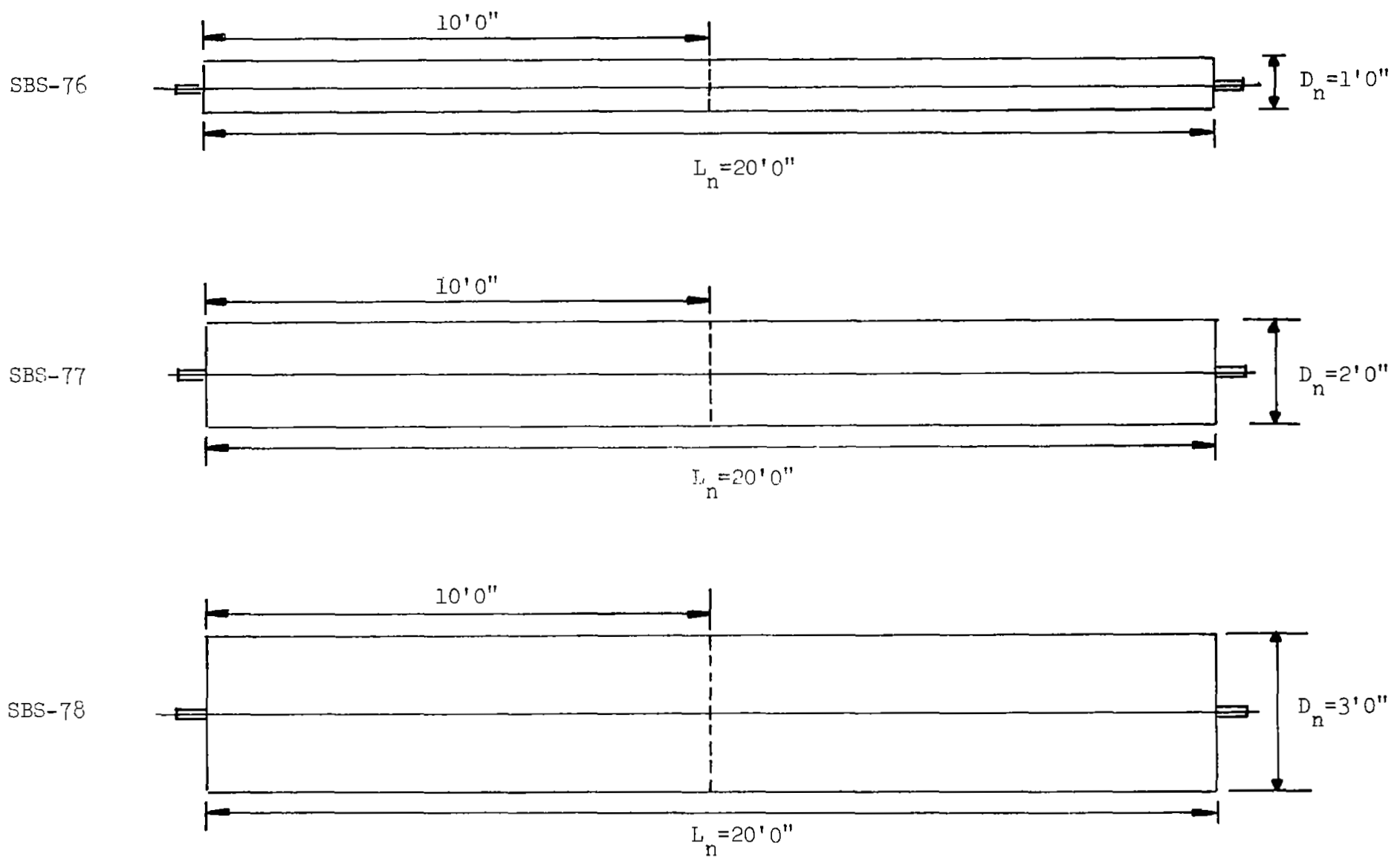

Notes

1. All cylinder ends per Detail A, Figure 47.

2. Mozzles rer Detail B, Figure 47.

3. Tether attachment and/or conduit support per Section $x x$, Figure 47. 
See Figure 47 for nozzle and

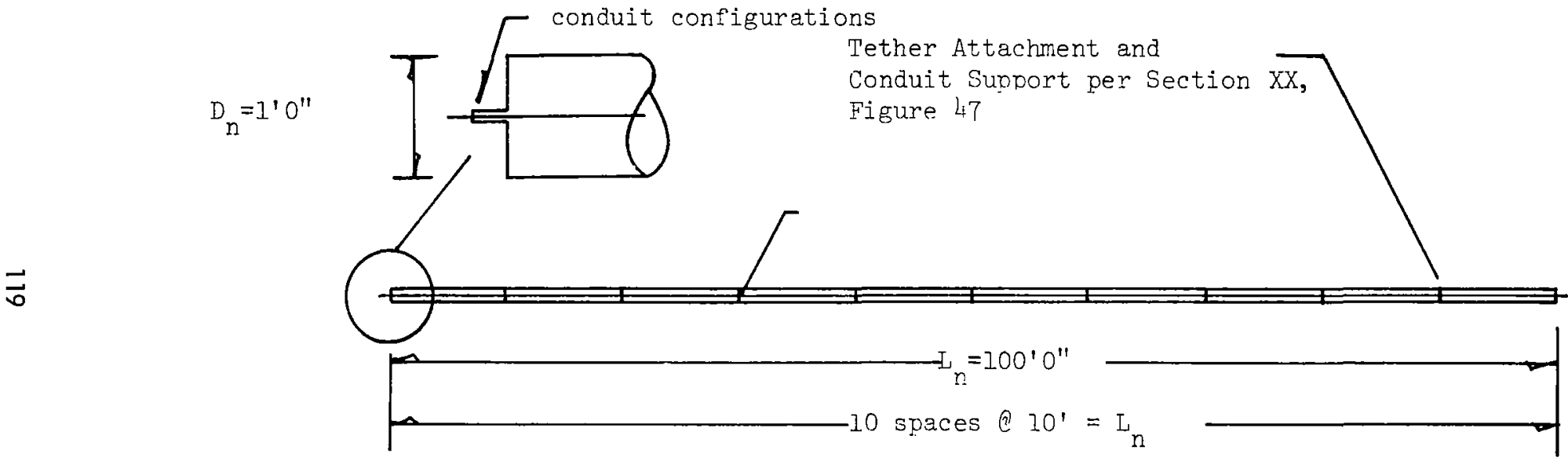

Figure 54 Specimen for SBS 79 
SBS- 80

SBS- 81

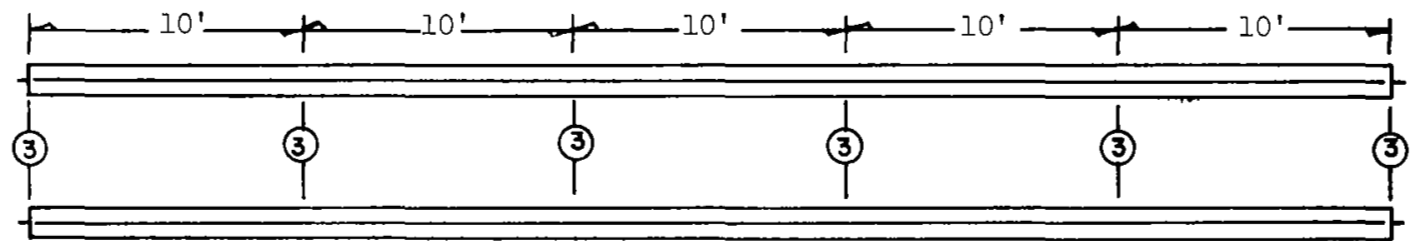

Mylar Conduit (Typical Five Places)

SBS- 82

SBS -86

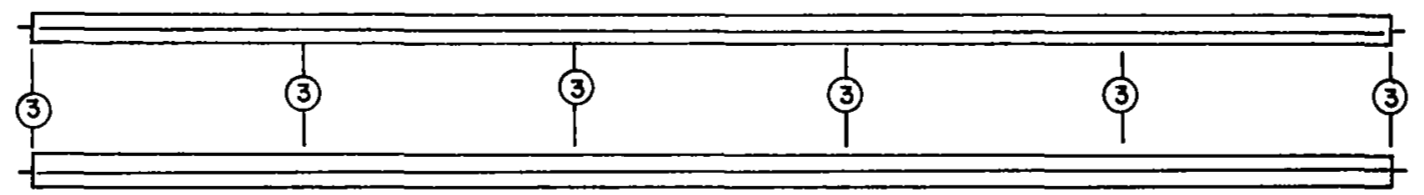

$253-87$

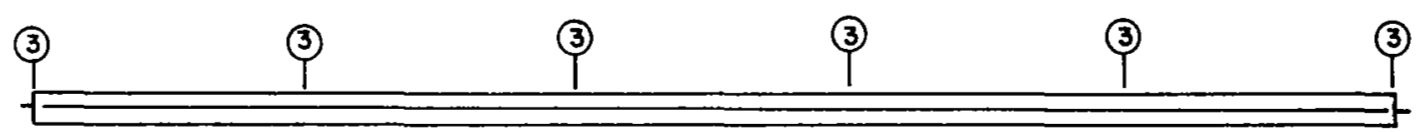

$\overrightarrow{\widetilde{O}}$

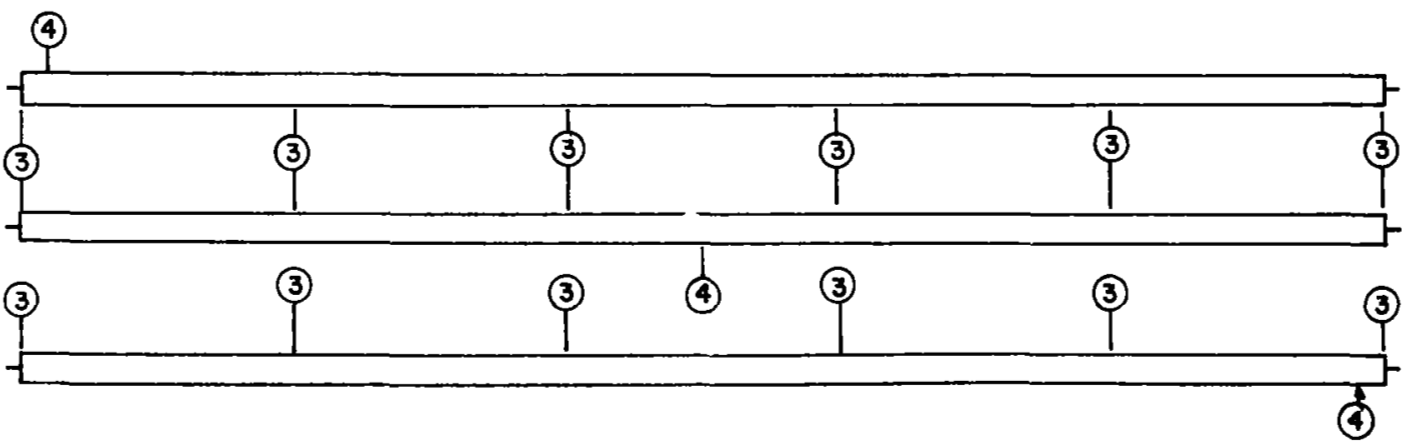

Notes

All specimens, $D_{n}=I^{\prime} O^{\prime \prime} ; L_{1}=50^{\prime} O^{\prime \prime}$

1. All cylinder ends per Detail A, Figure 47.

2. Nozzles per Detail B, Figure 47.

3. Tether attachment and/or conduit support per section XX, Figure 47.

4. Detonator Support per Section XX, Figure 47 .

Figure 55 Specimens for SBS 80 through 87 


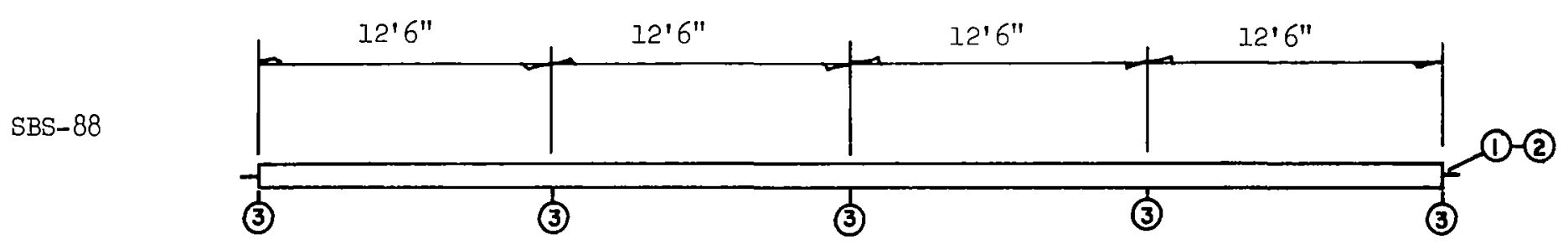

$\widetilde{N}$

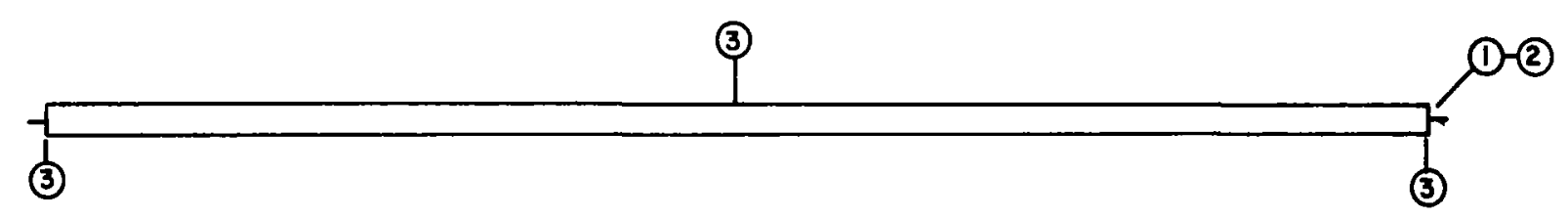

Notes

Both specimens $=D_{n}=I^{\prime} O^{\prime \prime} ; L_{n}=50^{\prime} 0^{\prime \prime}$

1. All cylinder ends per Detain A, Figure 47.

2. Nozzles per Detail $B$, Figure 47.

3. Tether attachment per Section $X X$, Figure 47.

Figure 56 Specimens for SBS 88 and 89 


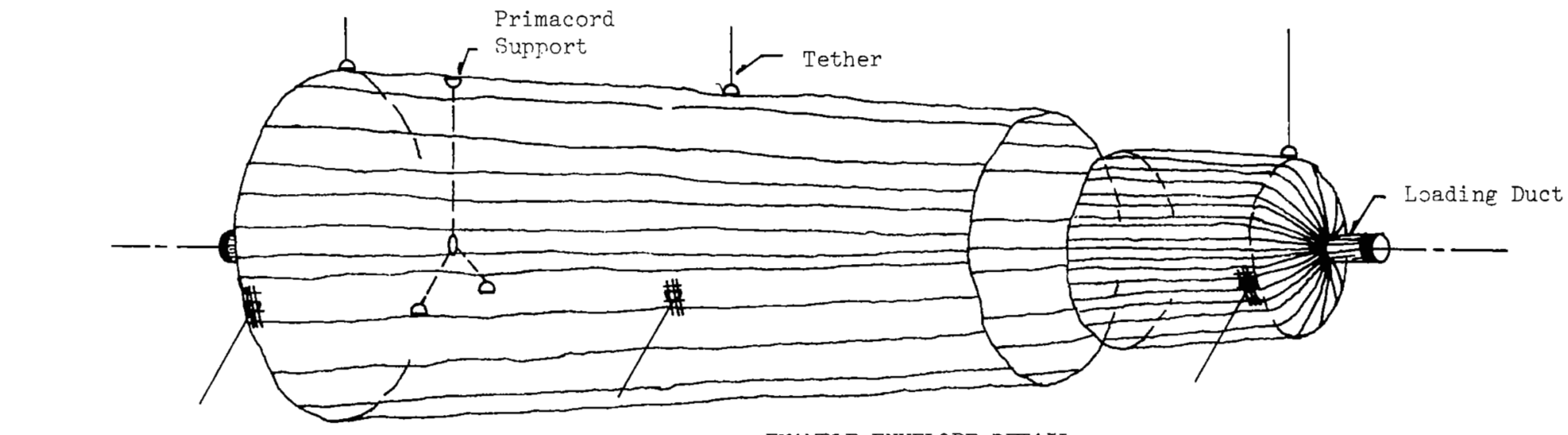

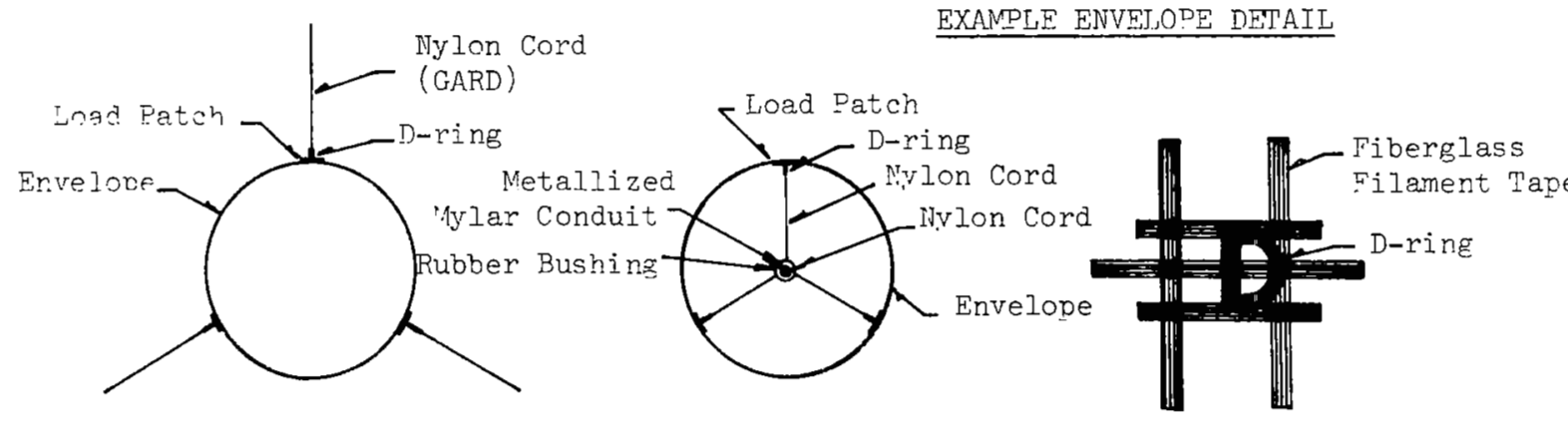

TETHERINS: DETAIL
PRIMACORD SUPPORT DETAIL

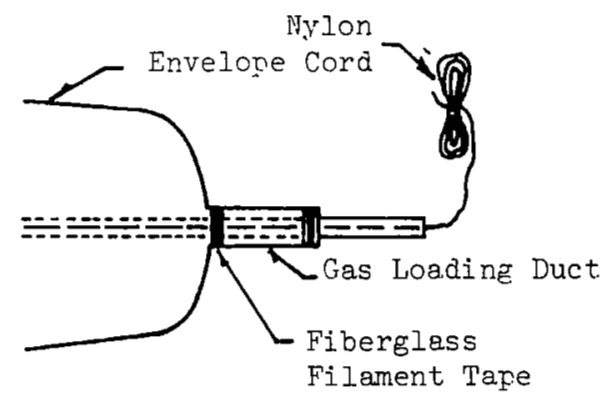

LOADING DUCT DETAII

Figure 57 Envelope Details for SB: 90 through 112 


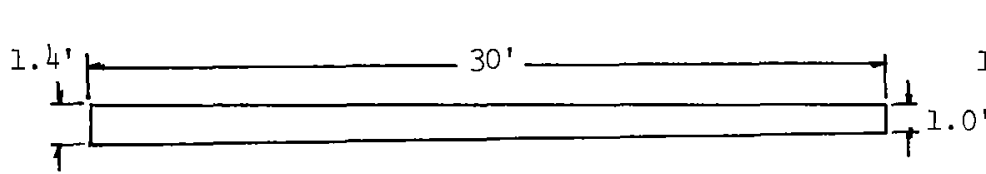

SBS-90 and 91
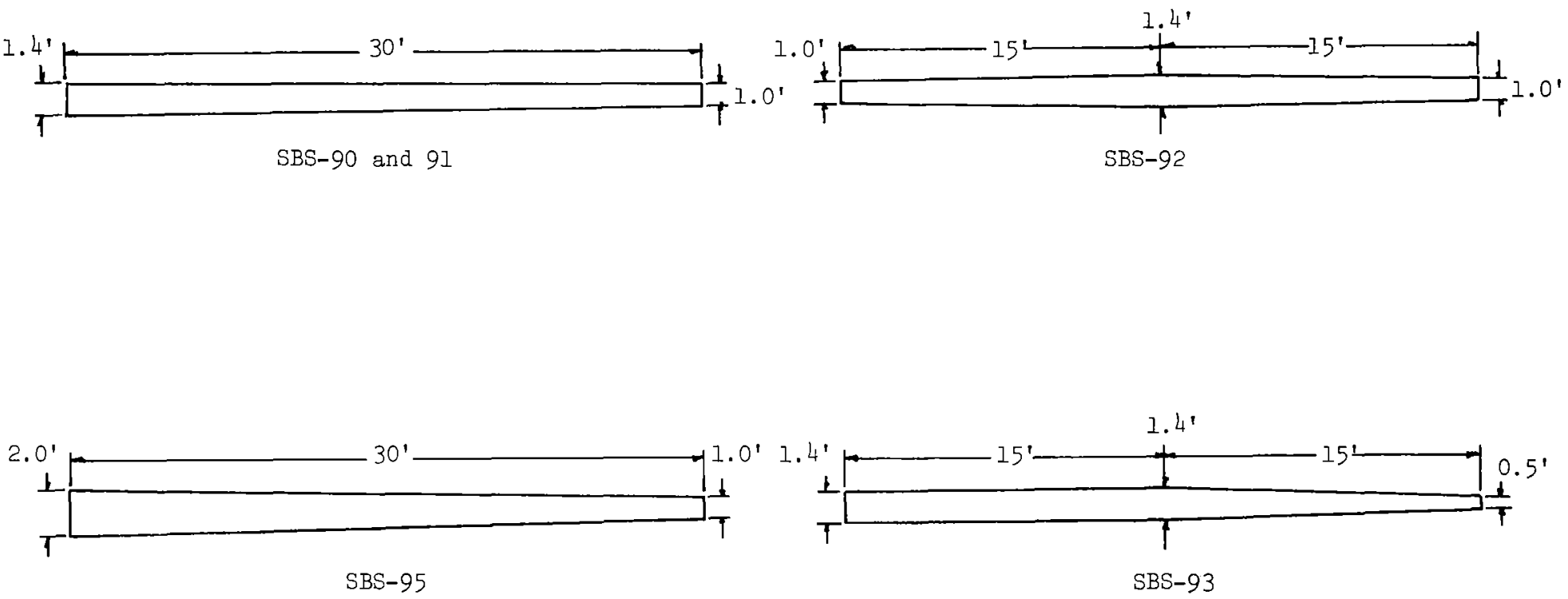

General Notes

1) Mylar conduit supports to be installed at 7.5 foot intervals per Primacord Support Detail on Figure 57.

2) Tethering supports to be installed at envelope ends and at center of 30 foot span per Tethering Detail on Figure 57.

3) Loading ducts to be installed at both ends of envelope per Loading Duct Detail on Figure 57.

4) A 40 foot length of nylon cord to be installed inside of the metallized mylar conduit and secured to each end of the conduit.

5) Envelope dimension tolerance to be \pm 0.25 inch.

Figure 58 Svecimens for SBS $90,91,92,93$ and 95 
SBS 94 and 97

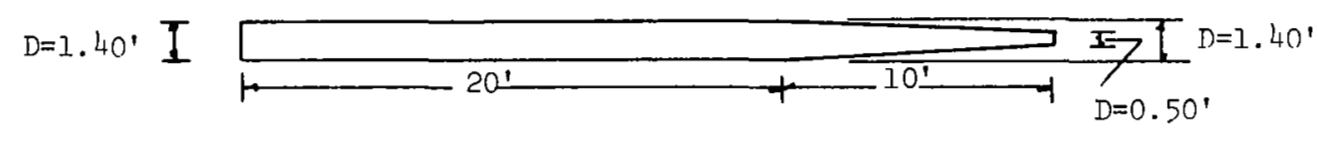

SPECIMEN NOT MANUFACTURFD

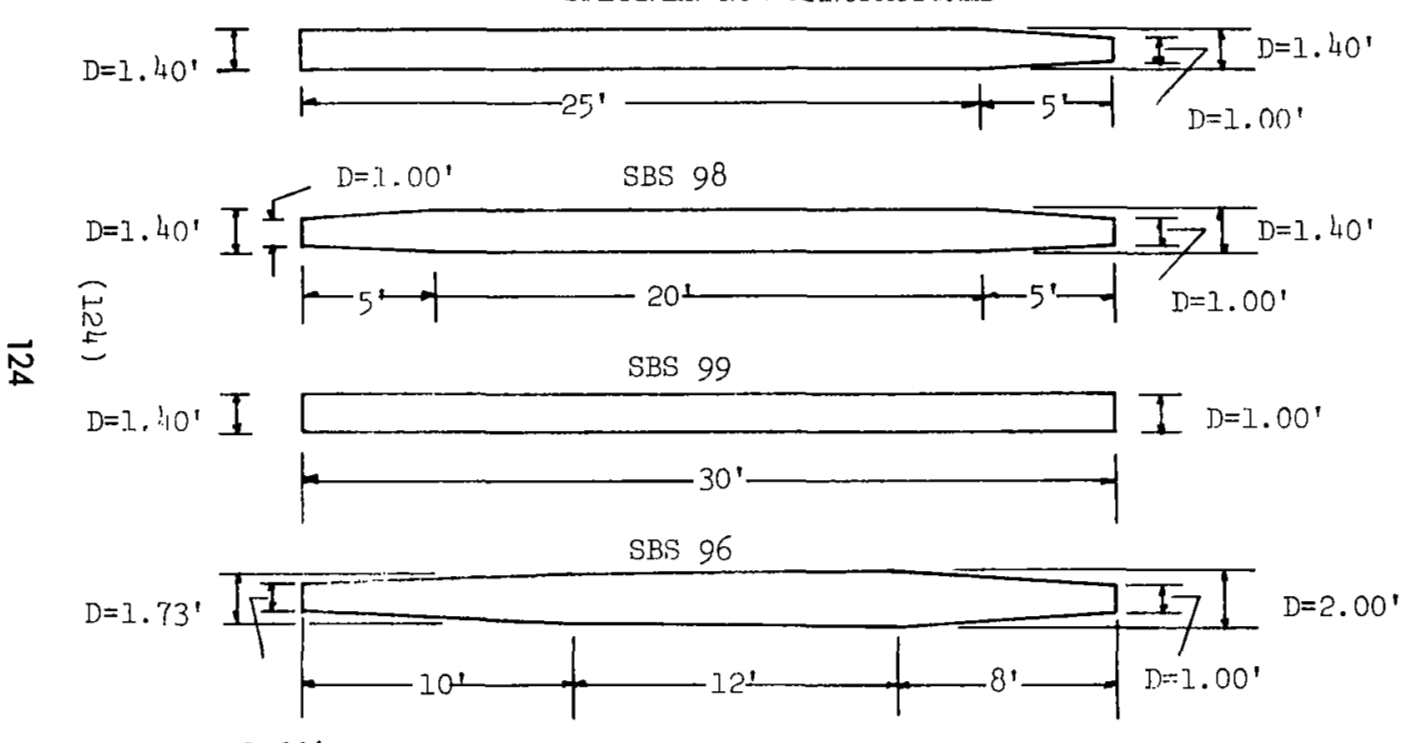

General Notes

1) Mylar conduit supports to be installed at 7.5 foot intervals per Primacord Support Detail on Figure 57.

2) Tethering supports to be installed at envelope ends and at center of 30 foot span per Tethering Detail on Figure 57.

3) Loading ducts to be installed at both ends - $f$ envelope per Loading Duct Detail on Figure 57.

4) A 40 foot length of nylon cord to be installed inside of the metallized mylar conduit and secured to each end of the conduit.

5) Envelope dimension tolerance to be \pm 0.25 inch. 


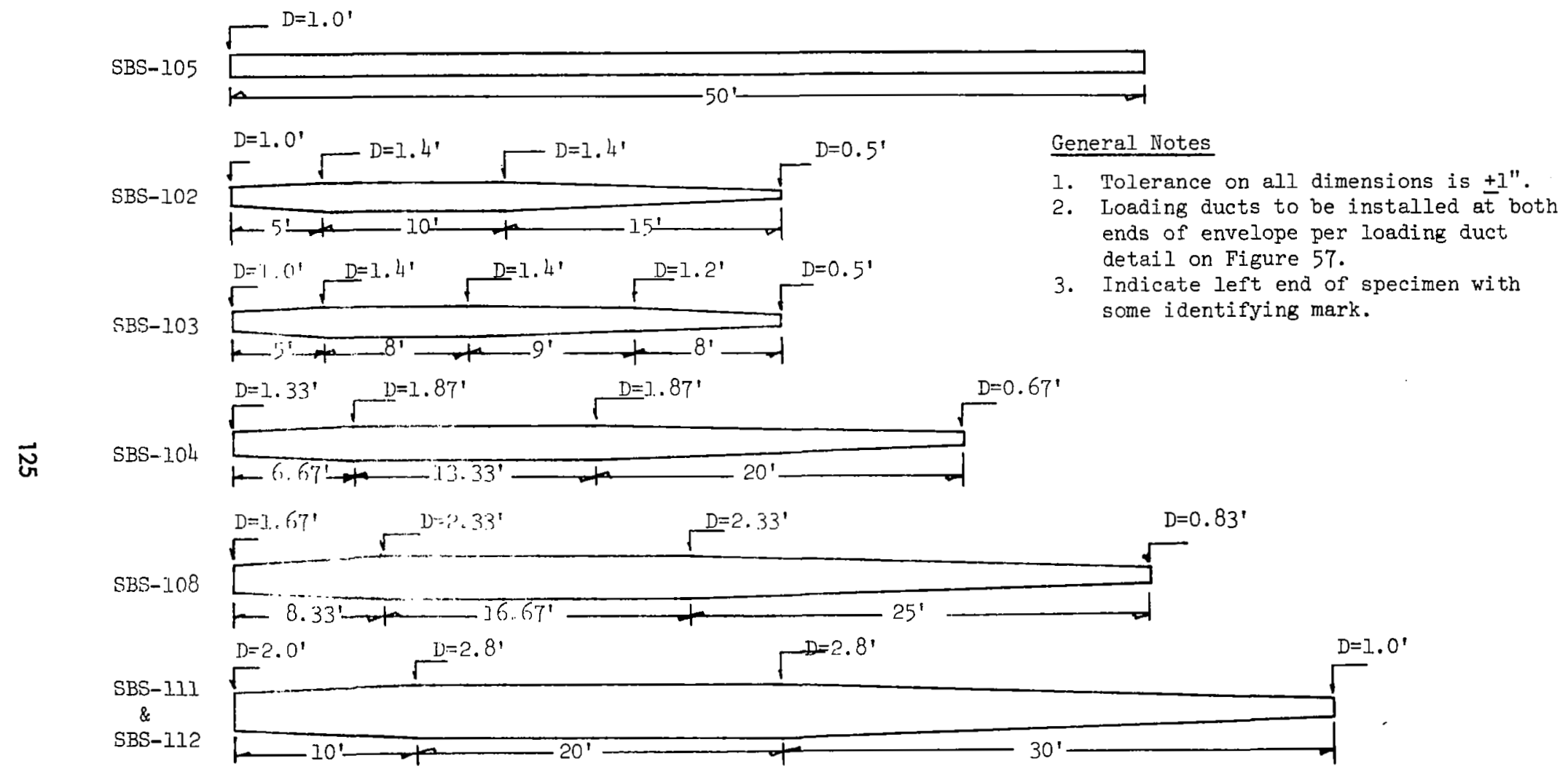

Figure 60 Dimensional Definition of Specimens for SBS 102, 103, 104, 105, 108, 111 and 112 
SBS-105

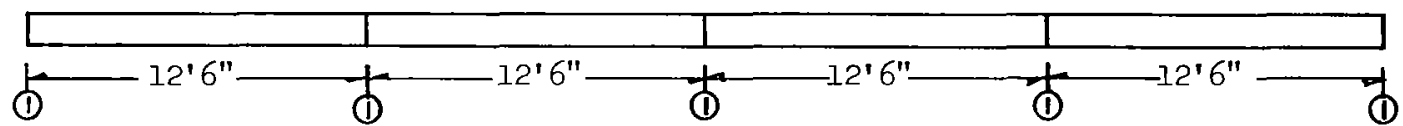

SBS-102

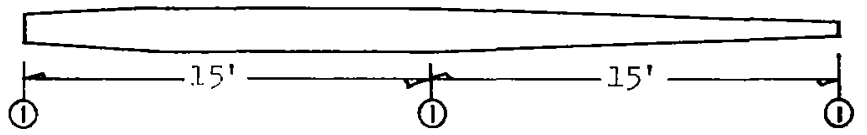

General Note

1. Install tethering supports at designated locations per tethering and D-ring details of Figure 57.

SBS-103

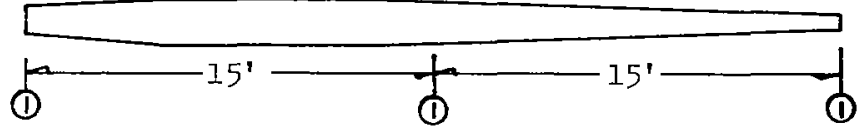

SBS-104

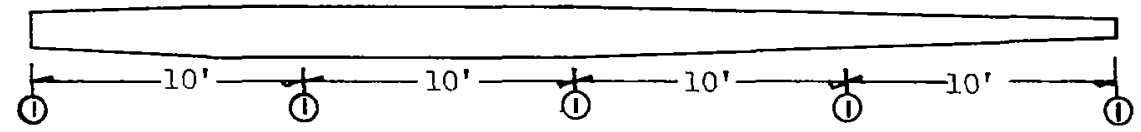

SBS-108

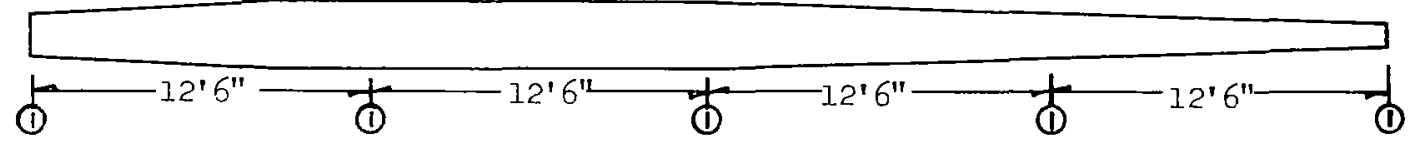

SBS-111

$\&$

$\operatorname{SBS}-112$

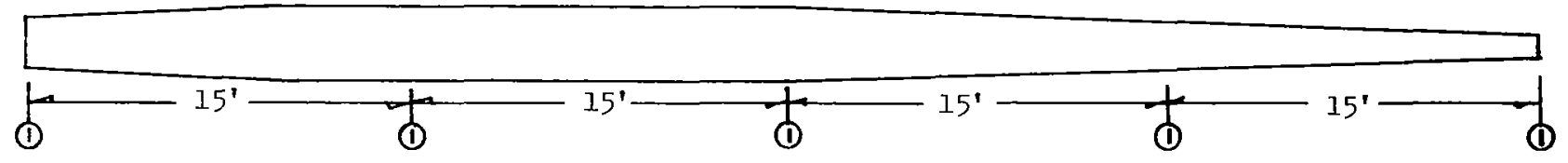

Figure 61 Tethering Details of Specimens for

SBS 102, 103, 104, 105, 108, 111 and 112 
SBS-105

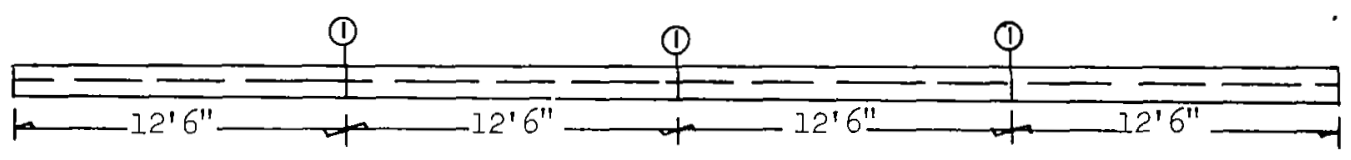

SBS-102

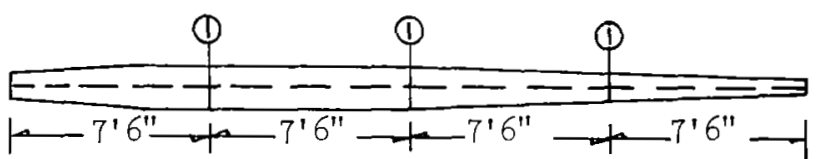

\section{General Notes}

1. Install Primacord supports as indicated per detail of Figure 5 .

2. Dotted lines denote metallized mylar conduits. Conduit ends to be as shown in loading duct detail of Figure 57.

SBS-103
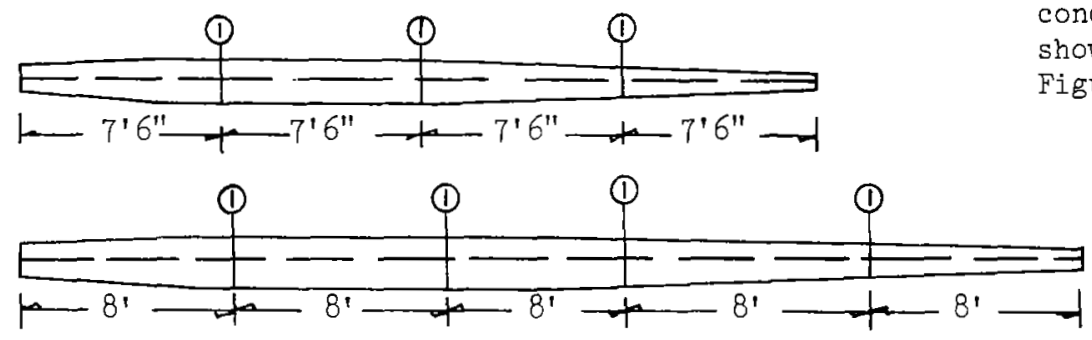

SBS-108

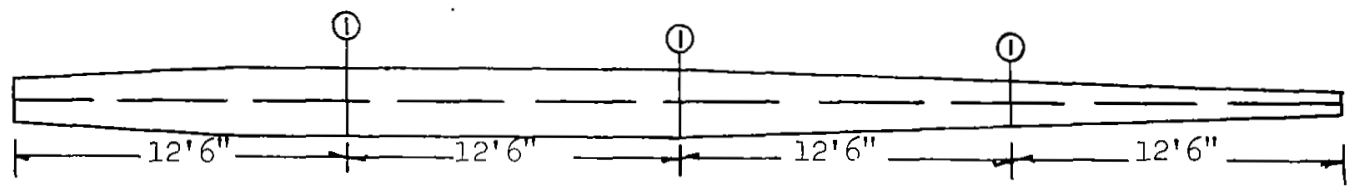

SBS-III

$$
\text { \& }
$$

SBS-112

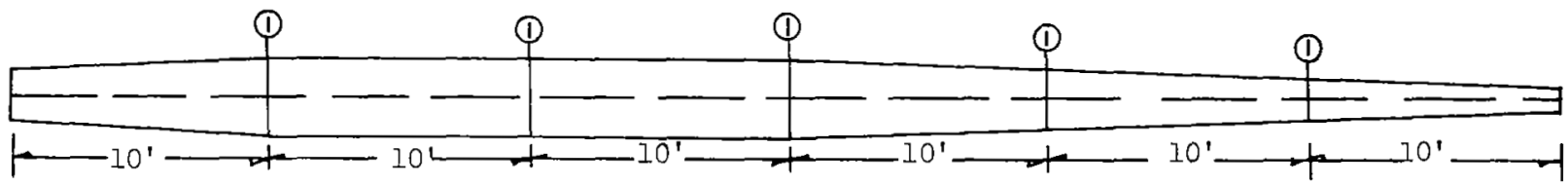

Figure 62 Conduit Support Details of Specimens for SBS 102, 103, 104, 105, 108, 111 and 112 

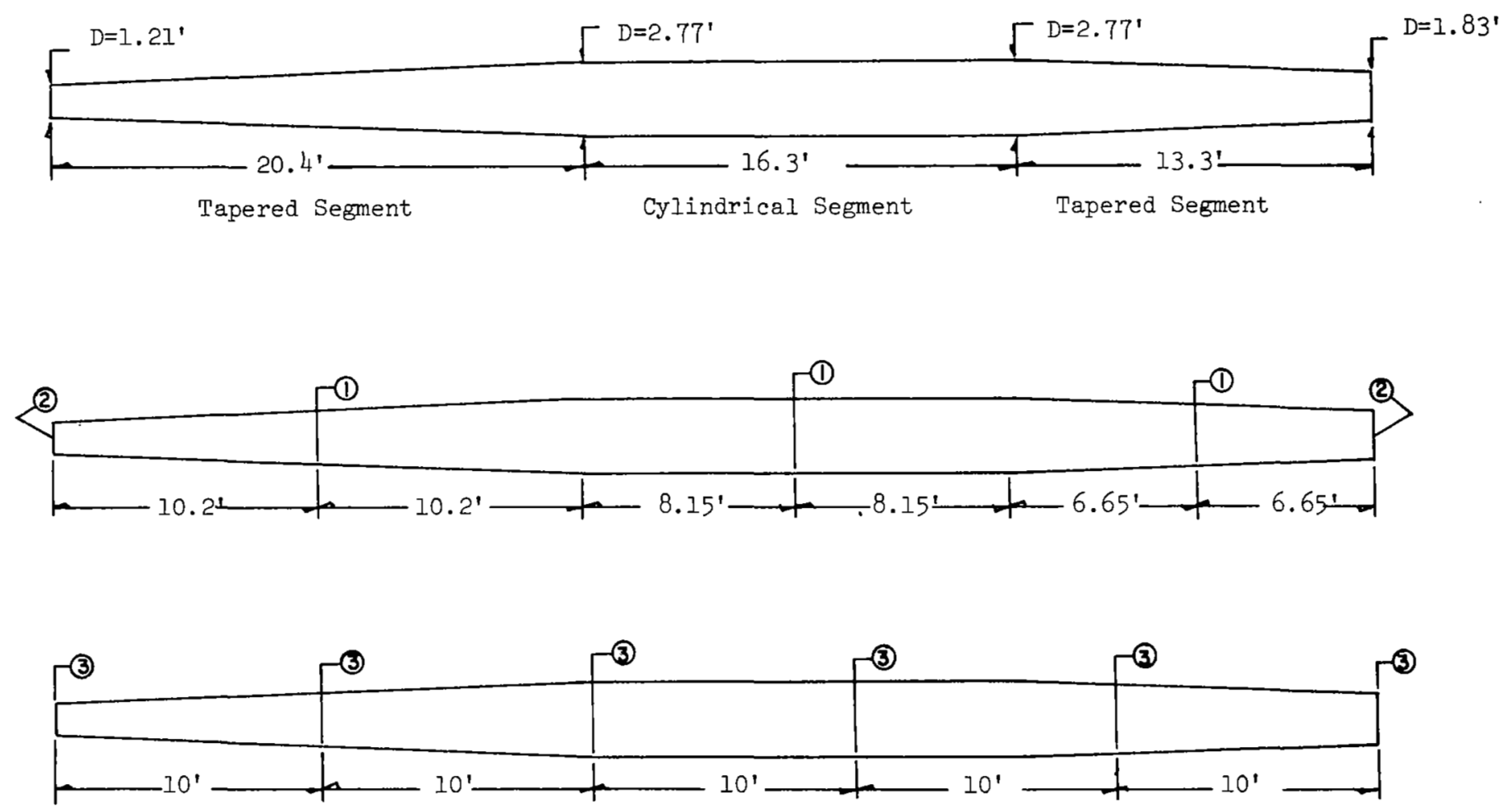

\section{General Notes}

1. Primacord support detail per Figure 57.

2. Loading duct detail per Figure 57.

3. Tethering and load patch details per Figure 57.

In addition all of the provisions specified as GENERAL NOTES on Figure 57 must be fulfilled. 


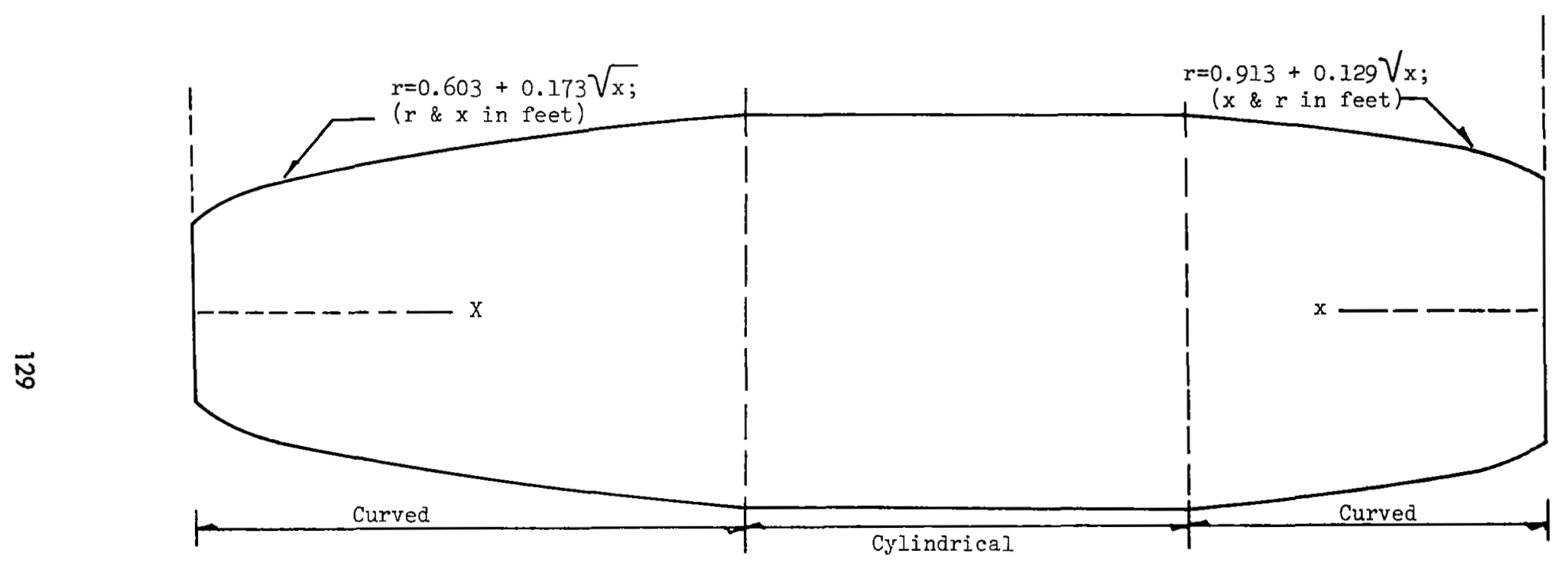

Figure 64 Specimen for SBS 107 

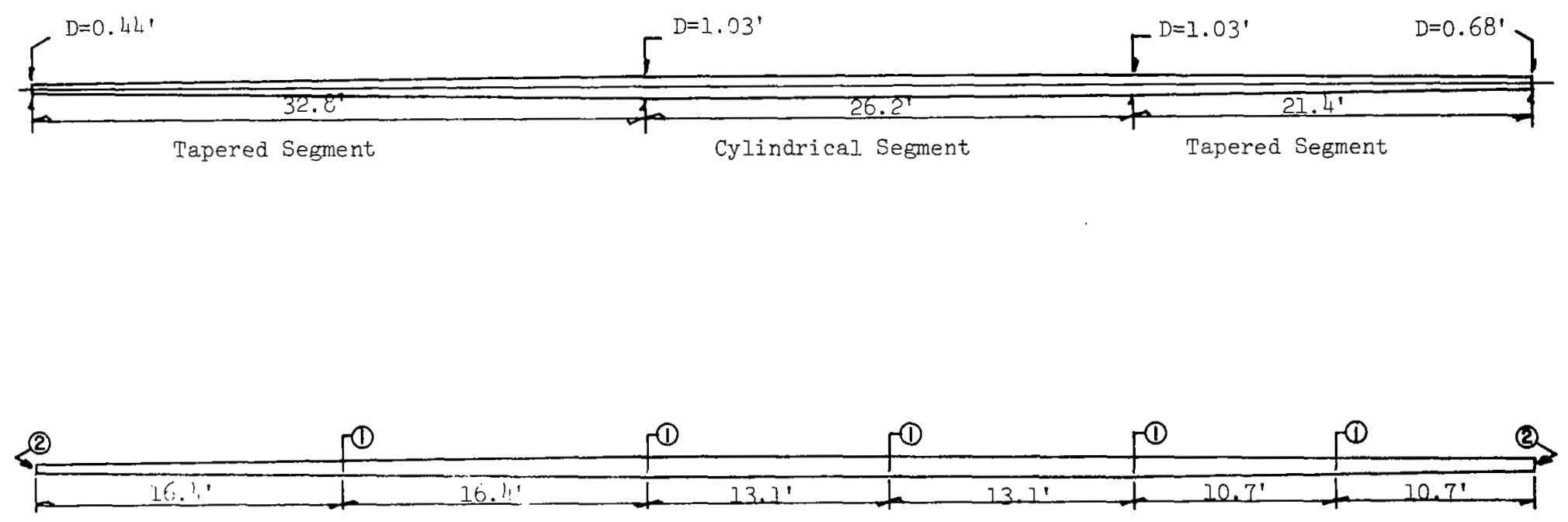

\begin{tabular}{|c|c|c|c|c|c|c|c|c|}
\hline (3) & (3) & (3) & (3) & (3) & (3) & (3) & $\Gamma^{3}$ & $\Gamma^{3}$ \\
\hline $10^{\prime}$ & $10^{\prime}$ & 101 & $10^{\prime}$ & $10^{\prime}$ & $70^{\prime}$ & & & \\
\hline
\end{tabular}

General Notes

1. Frimacord support detail per Figure 57.

2. Loading duct detail per Figure 57.

3. Tethering and load natch details per Figure 57. 


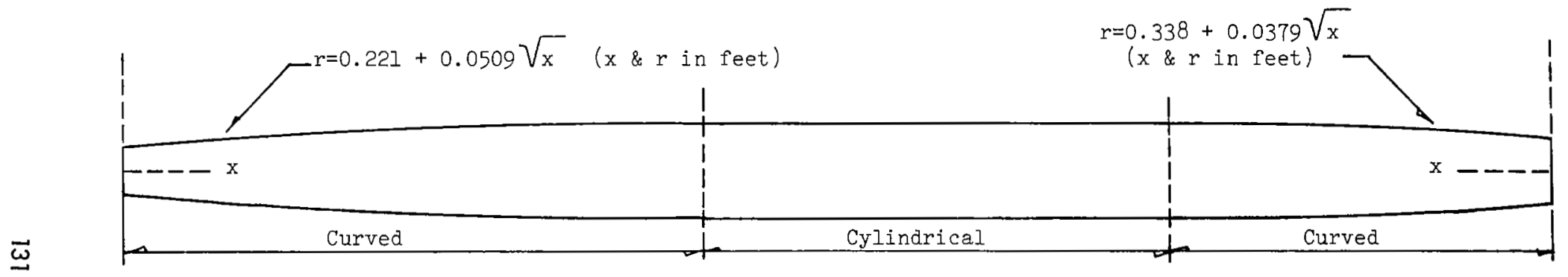

Figure 66 Specimen for SBS 110 


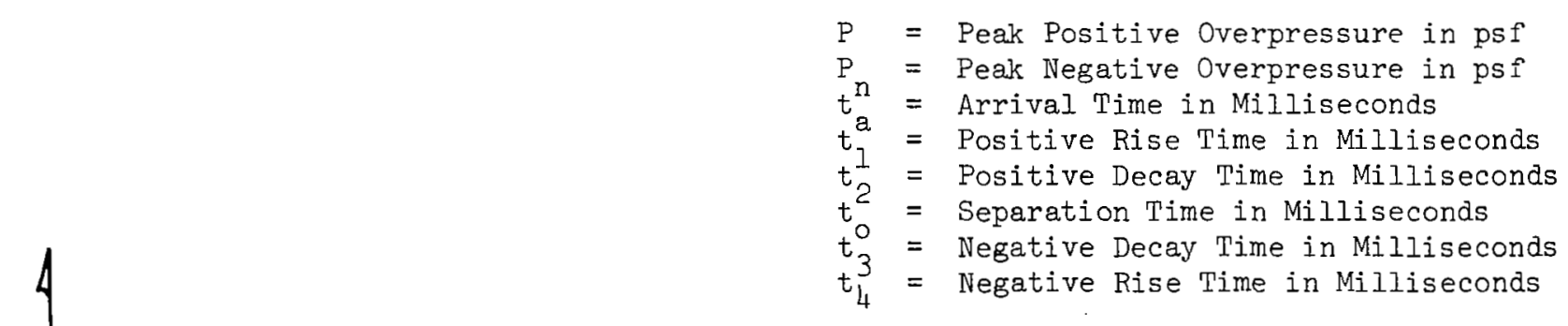

Figure 67 Separated N-Wave Definition 
milliseconds 50 IOS ASSOCIATED TIME SCALE FOR ALL SIX MICROPHONES

CAIJBRATION PRESSURE (Ibs/sq $\mathrm{ft}$ ) RESPONSE AT MICROPHONE B
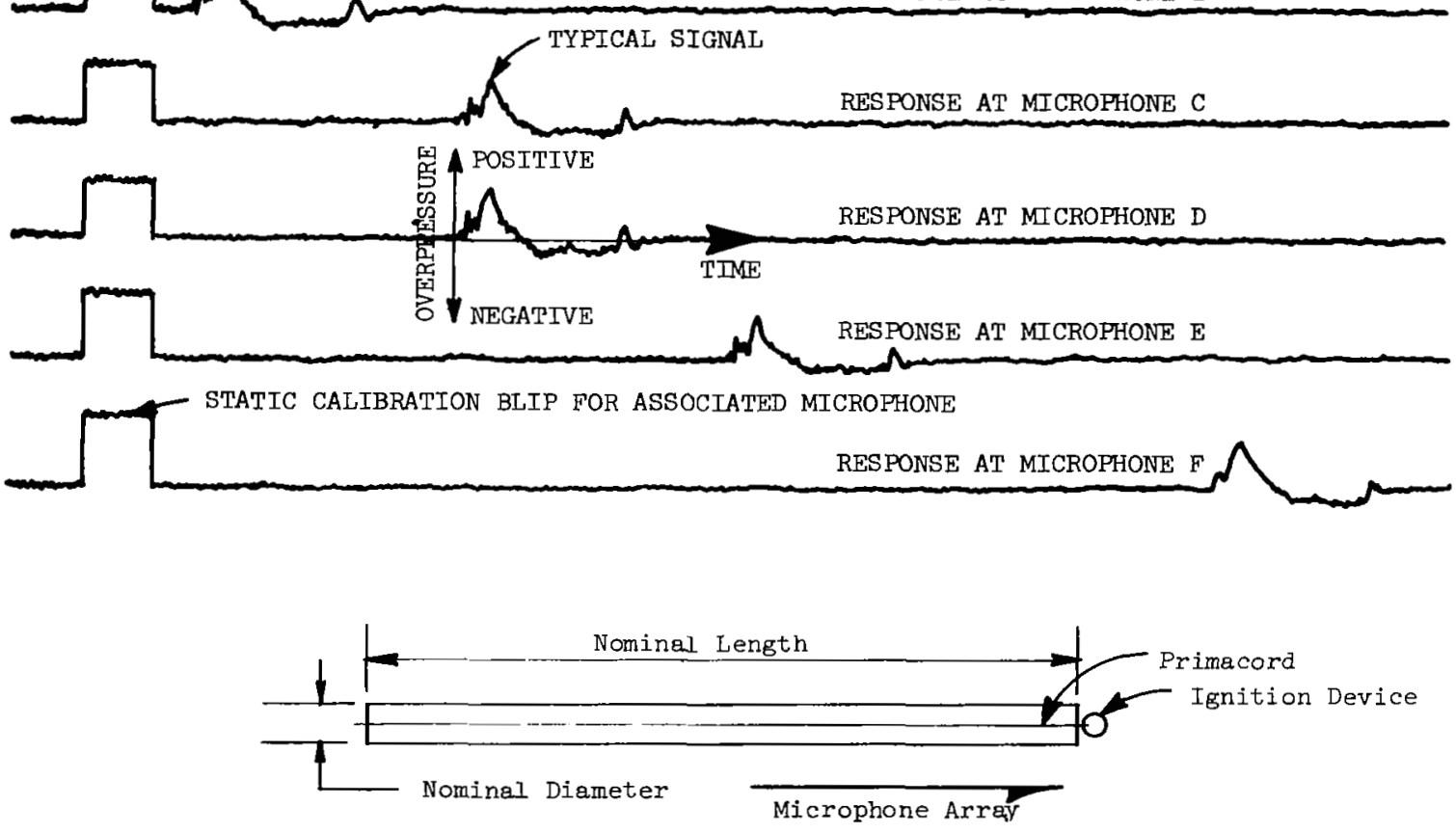

$\underline{\mathrm{KEY}}$

- EB-106 Detonator

Match Squib

$\triangle$ Augmented Detonator
FOR SPECIFIC MICROPHONE LOCATIONS SEE

Figure 7 SBS 70-79

Figure 8 SBS $80-89$

Figure 9 SBS 90-99

Figure 10 SBS 102-112

Figure 68 KEY TO PRESSURE PULSES 
$\mathrm{L}^{2}+\mathrm{L}^{50}$

100 Milliseconds

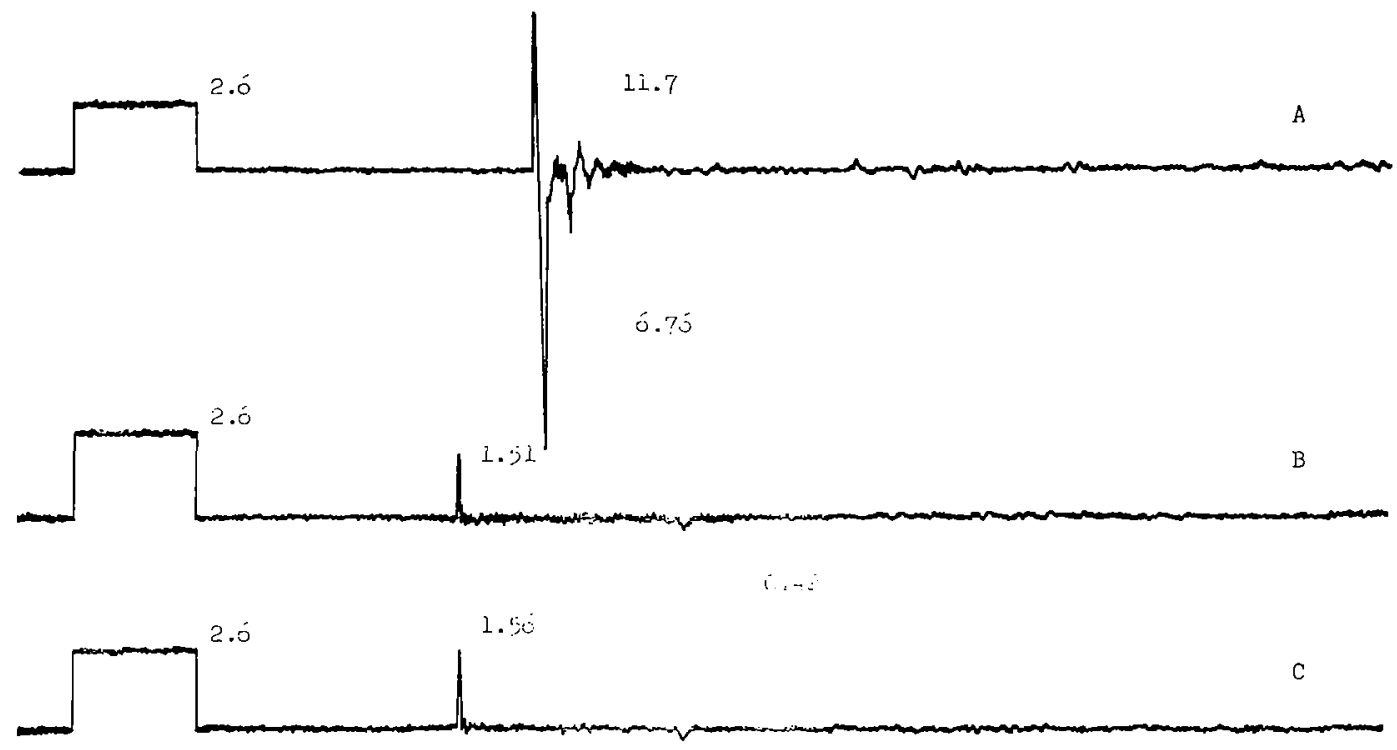

6.:
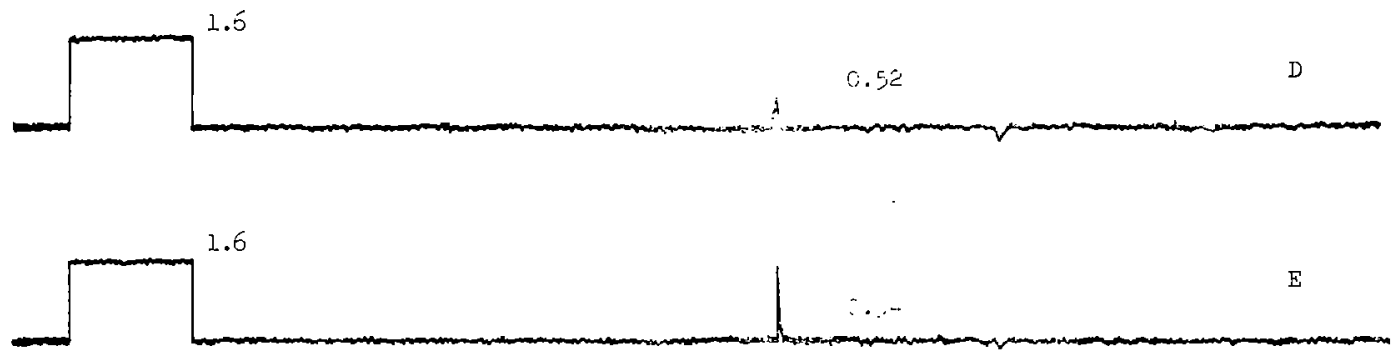

0.21
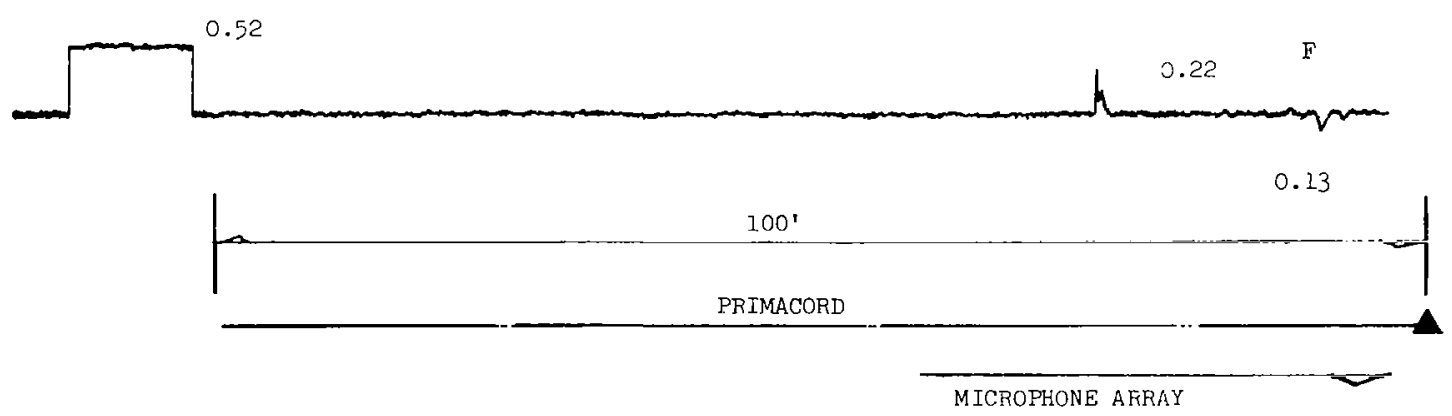

Figure 09 SBS-70 

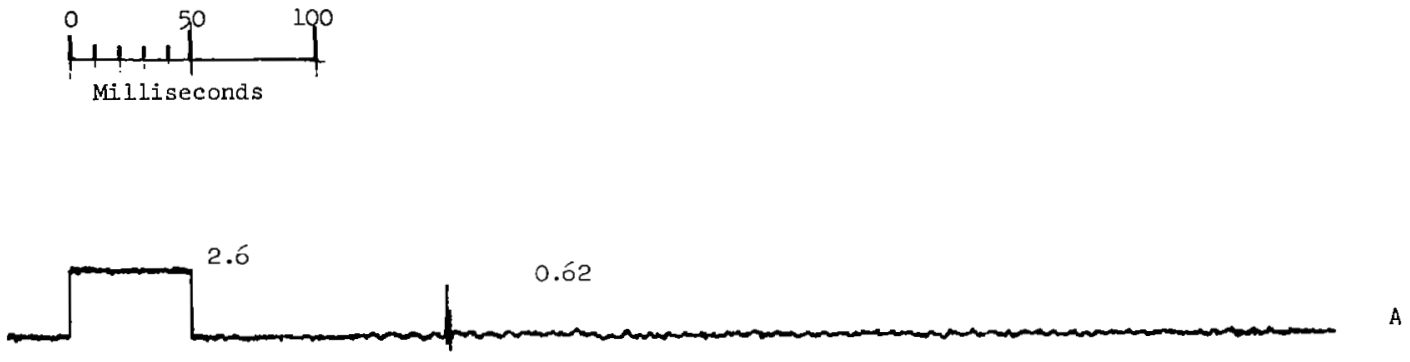

0.52

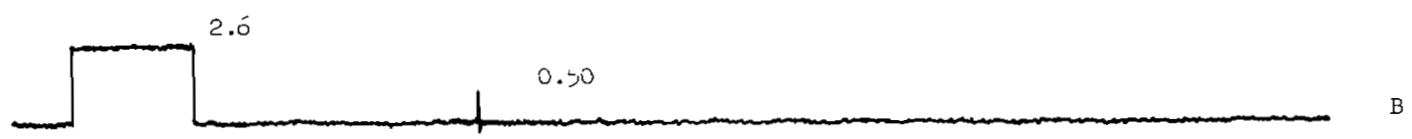

0.20

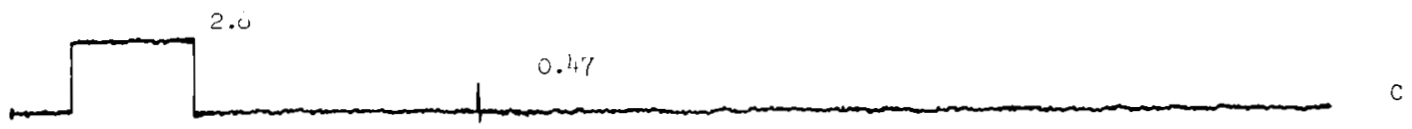

0.19

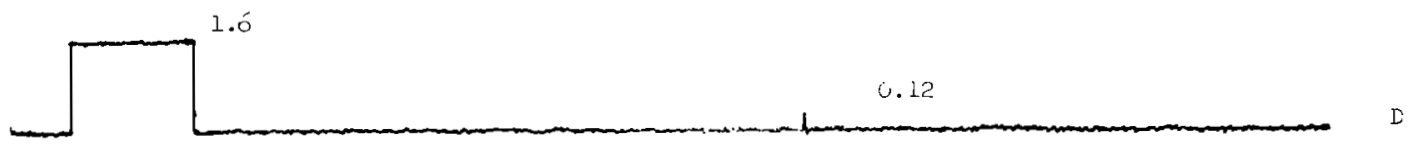

0.09

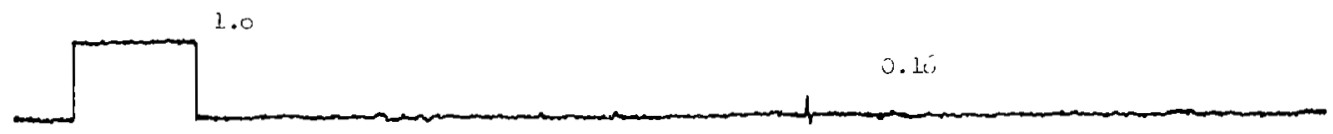

E

0.09

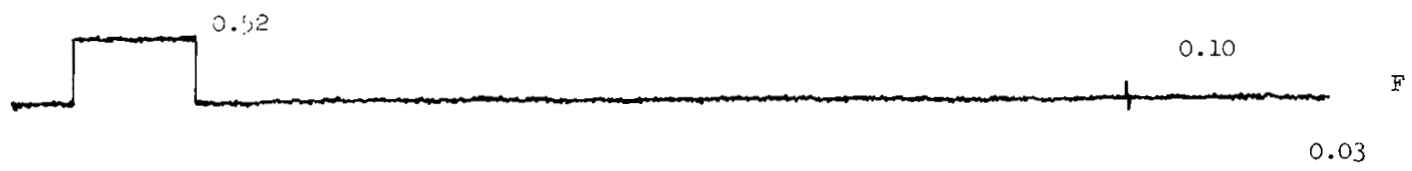

A DETONATOR - EBI06

MICROPHONE ARRAY

Figure $70 \quad$ SBS-71 

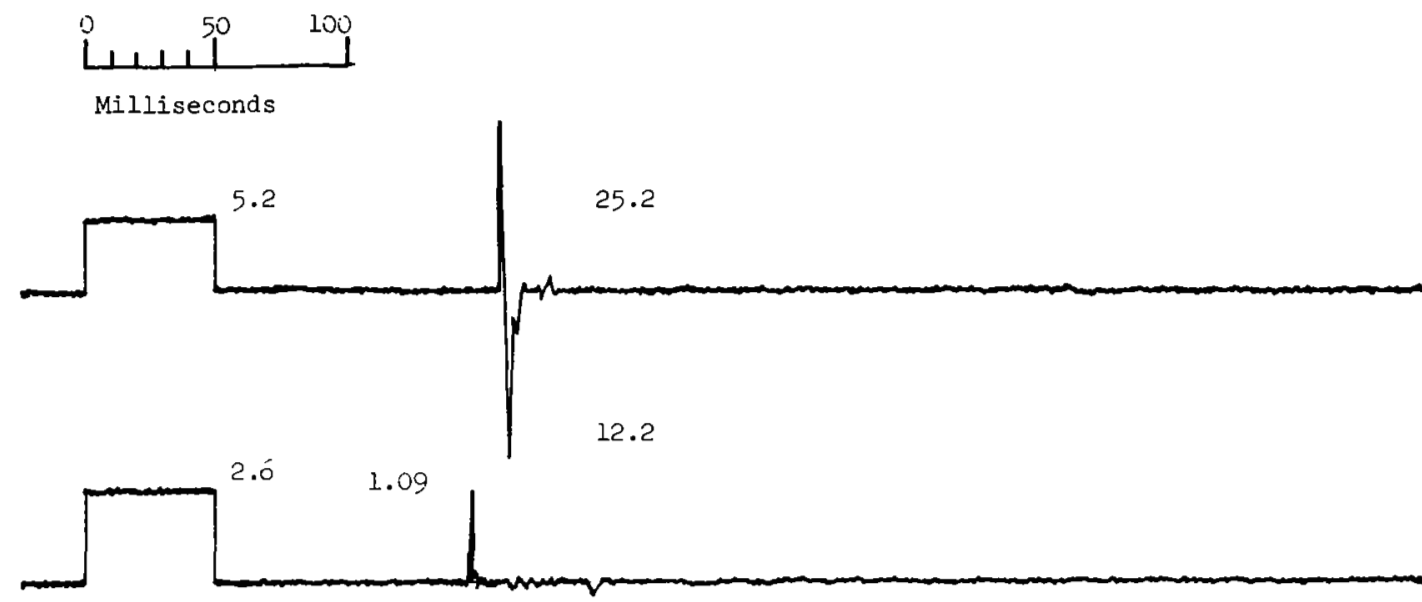

\subsection{1}

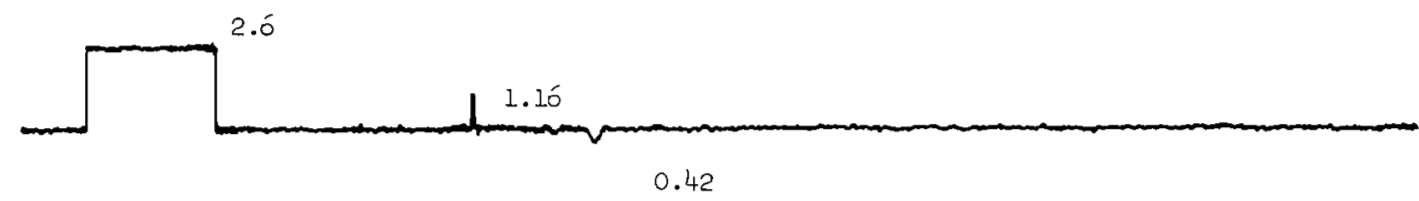

C

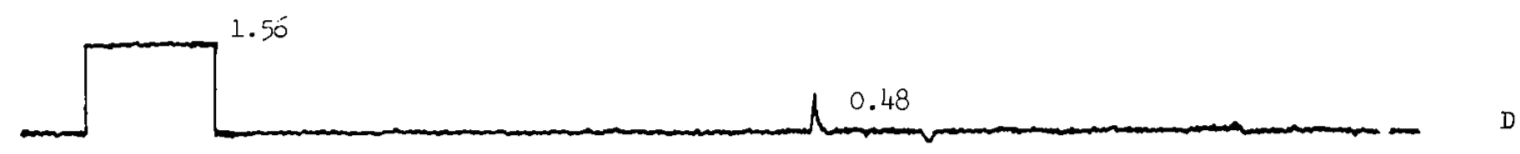

$$
0.23
$$

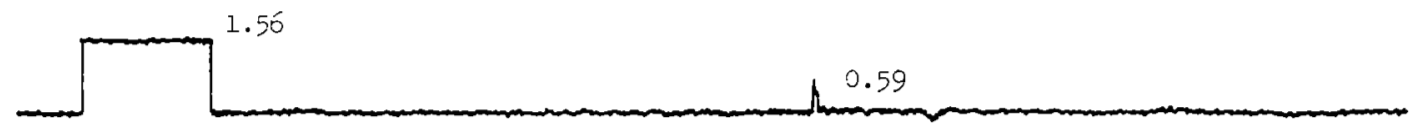

$$
0.27
$$
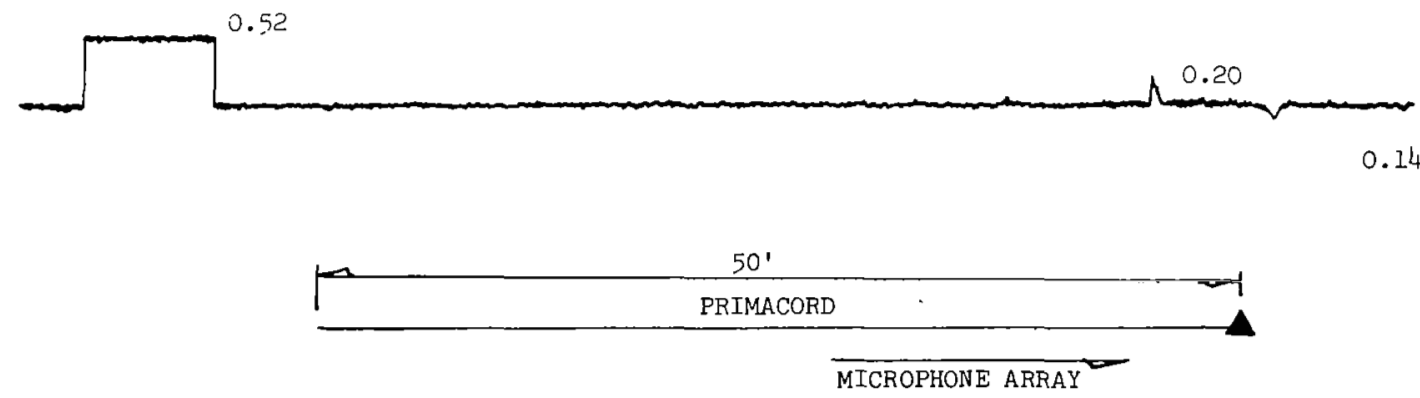

Figure $71 \quad$ SBS-72 

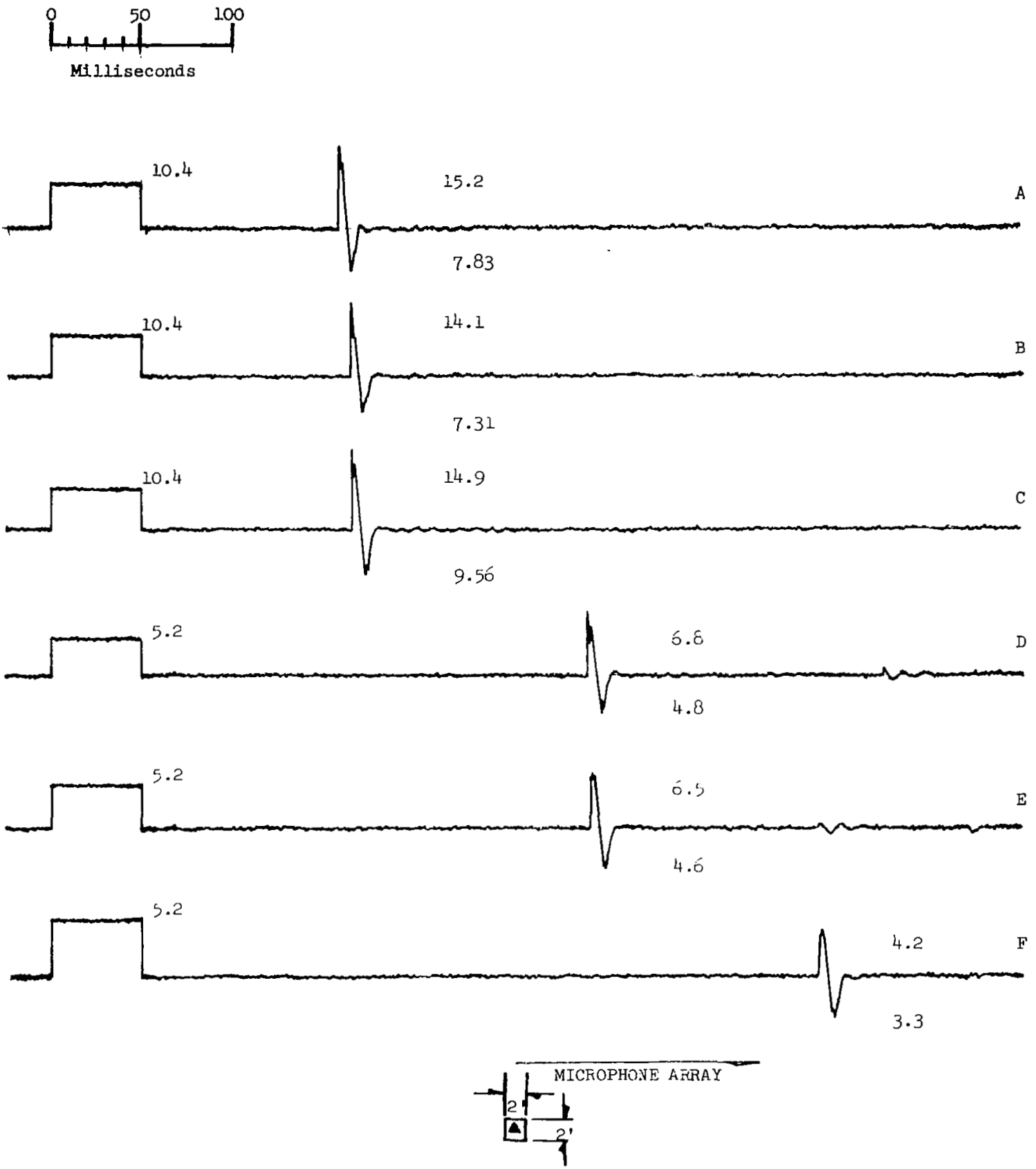

Figure 72 SBS-73 


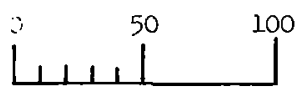

Milliseconds
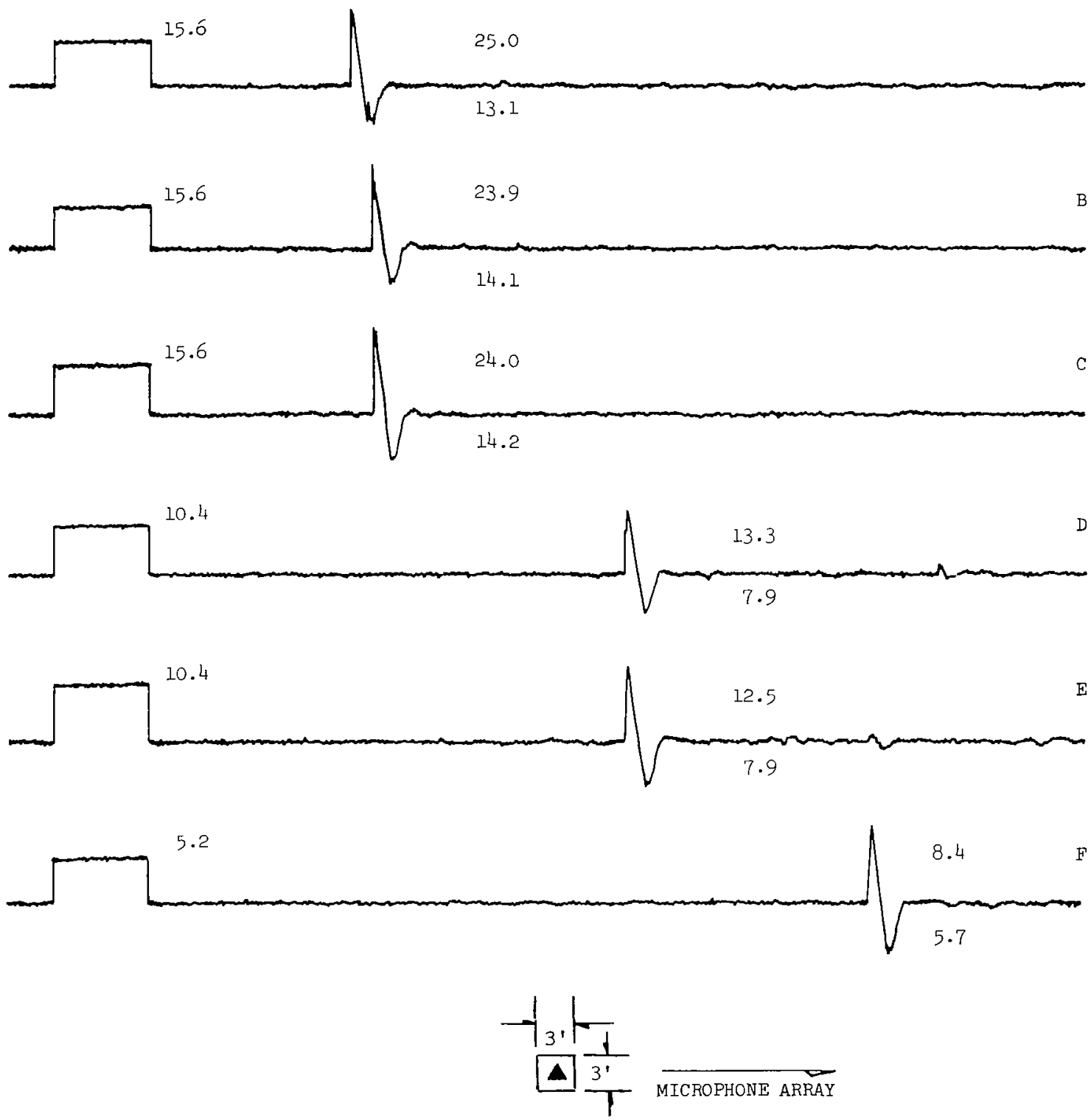

Figure $73 \quad$ SBS-74 


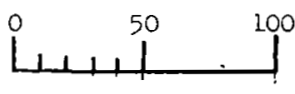

Milliseconds
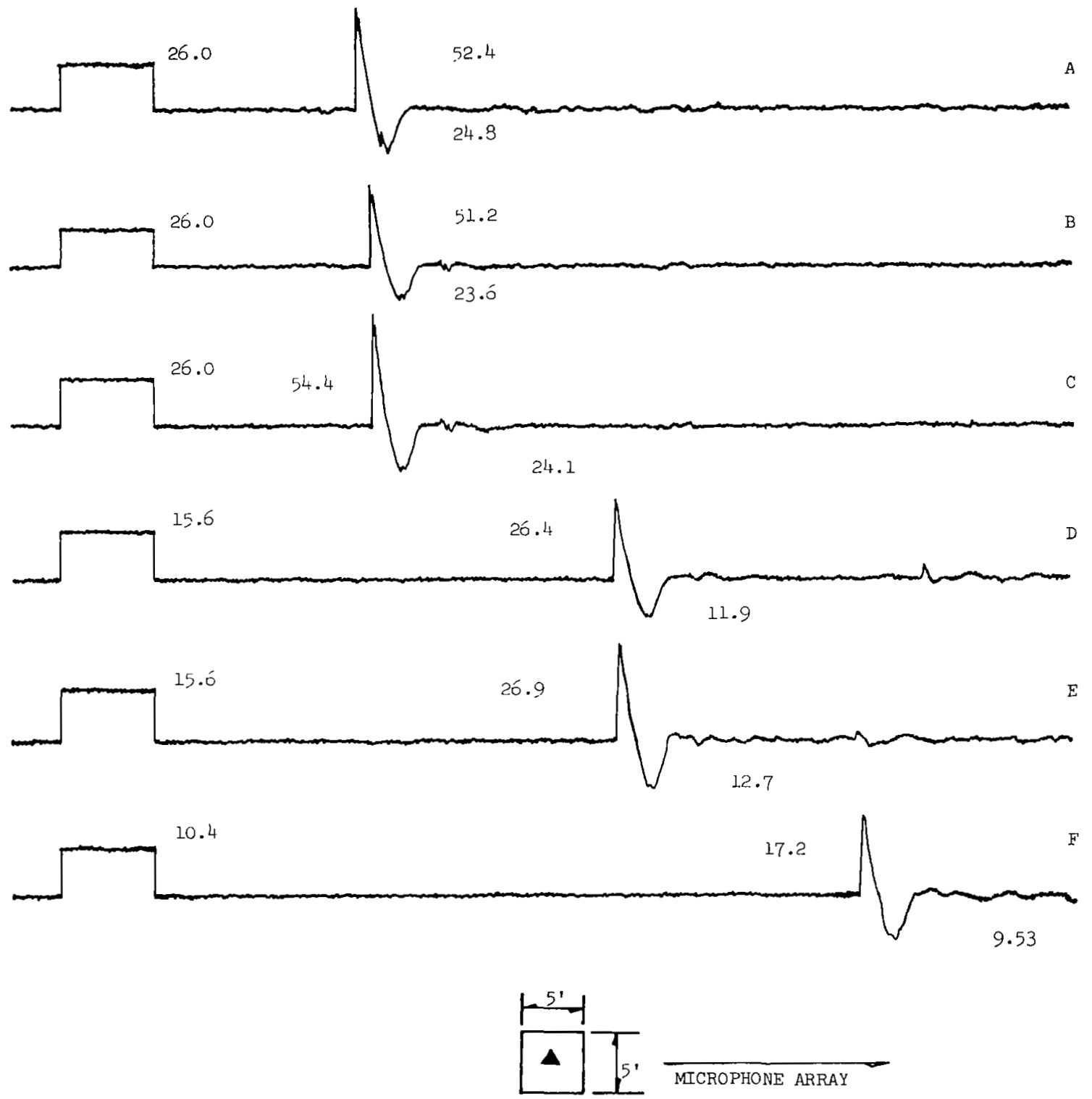
$\stackrel{O}{M i l l i s e c o n d s}_{100}^{50}$
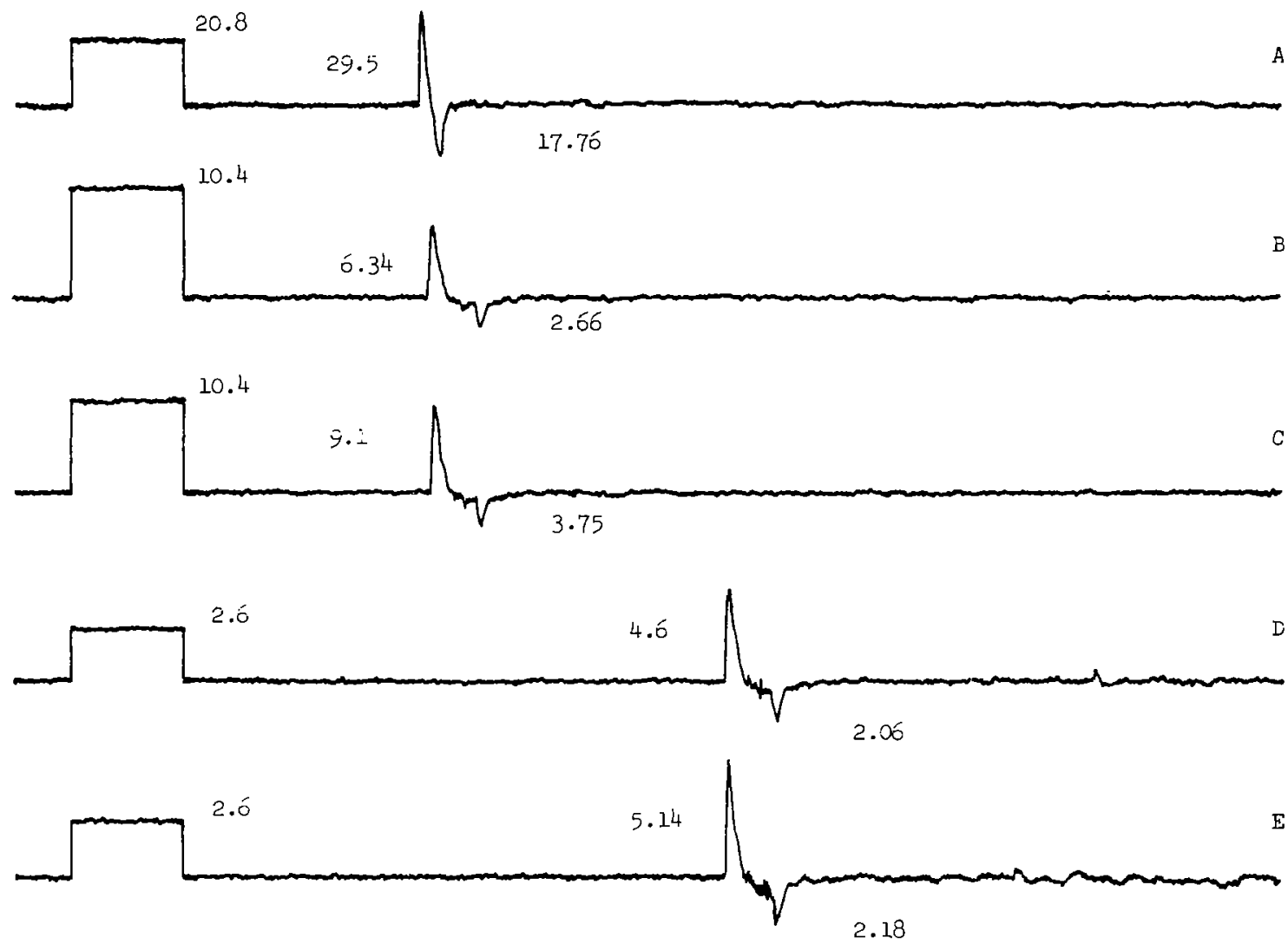

2.6
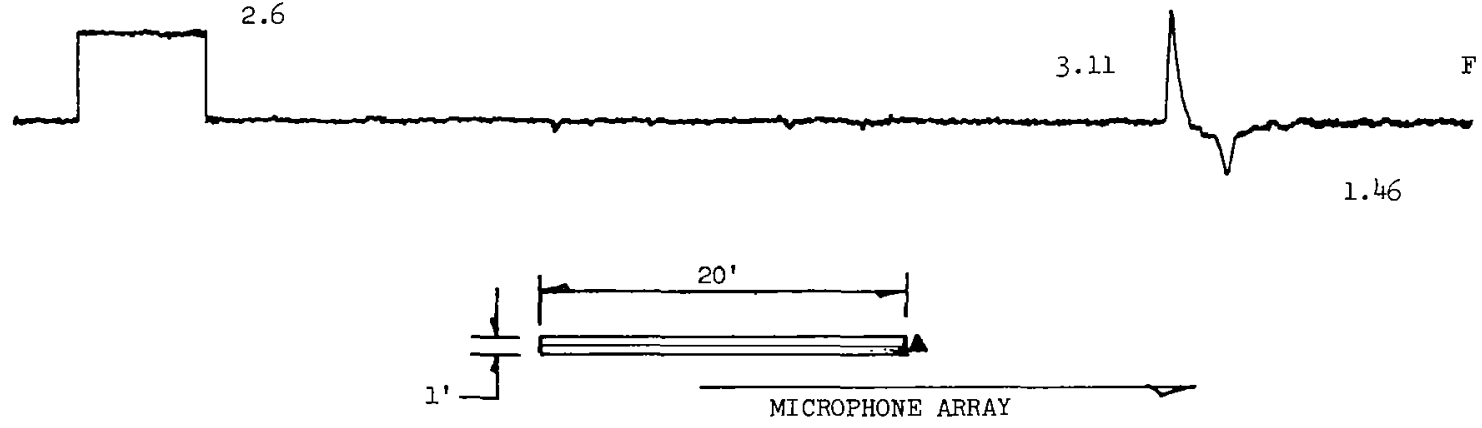

Figure $75 \quad$ SBS-76 


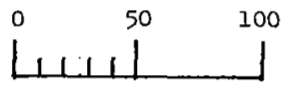

Milliseconds
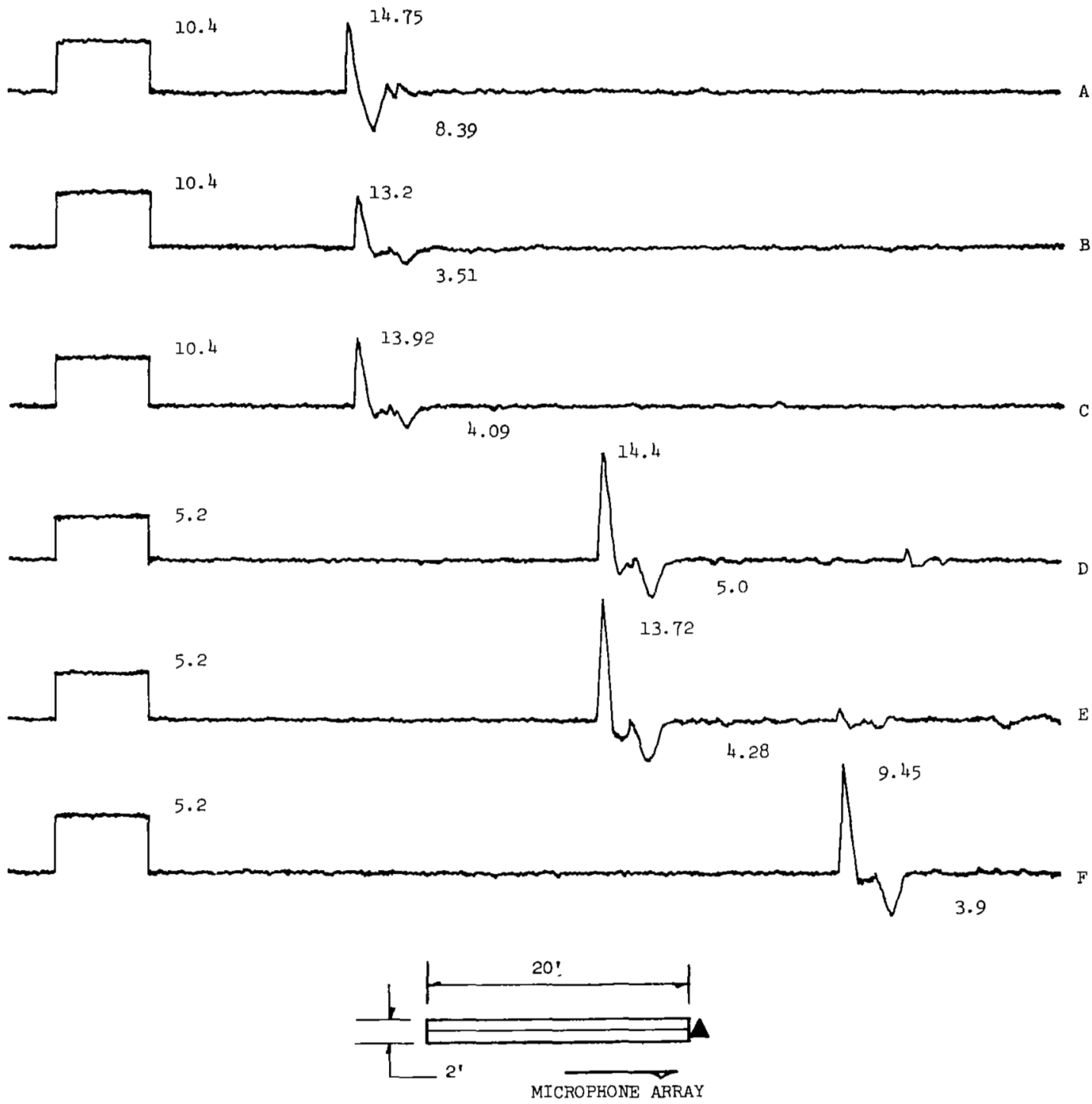

Figure $76 \quad$ SBS-77 


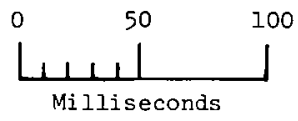
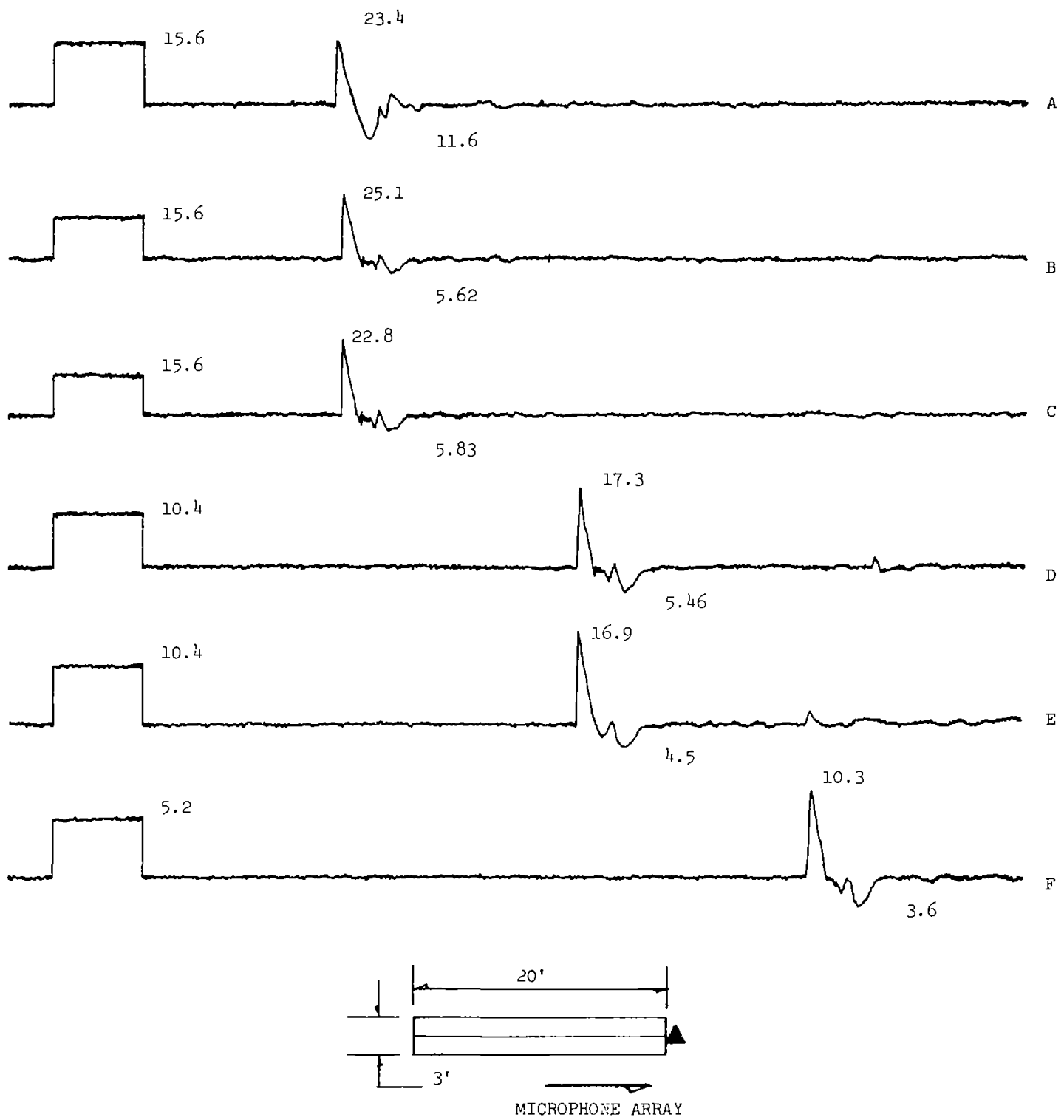

Figure 77 SBS-78 


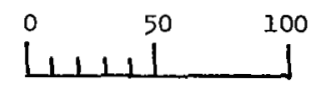

Milliseconds
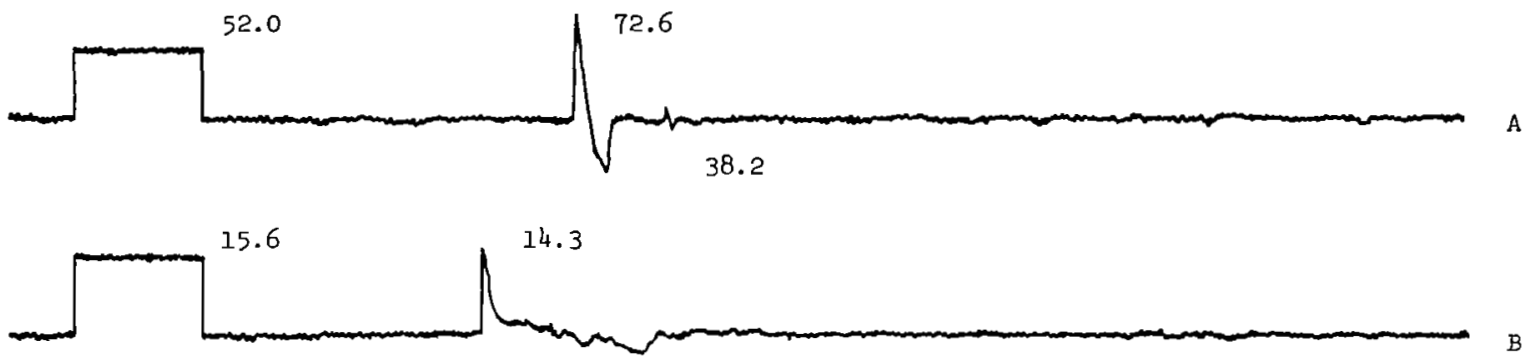

3. 79
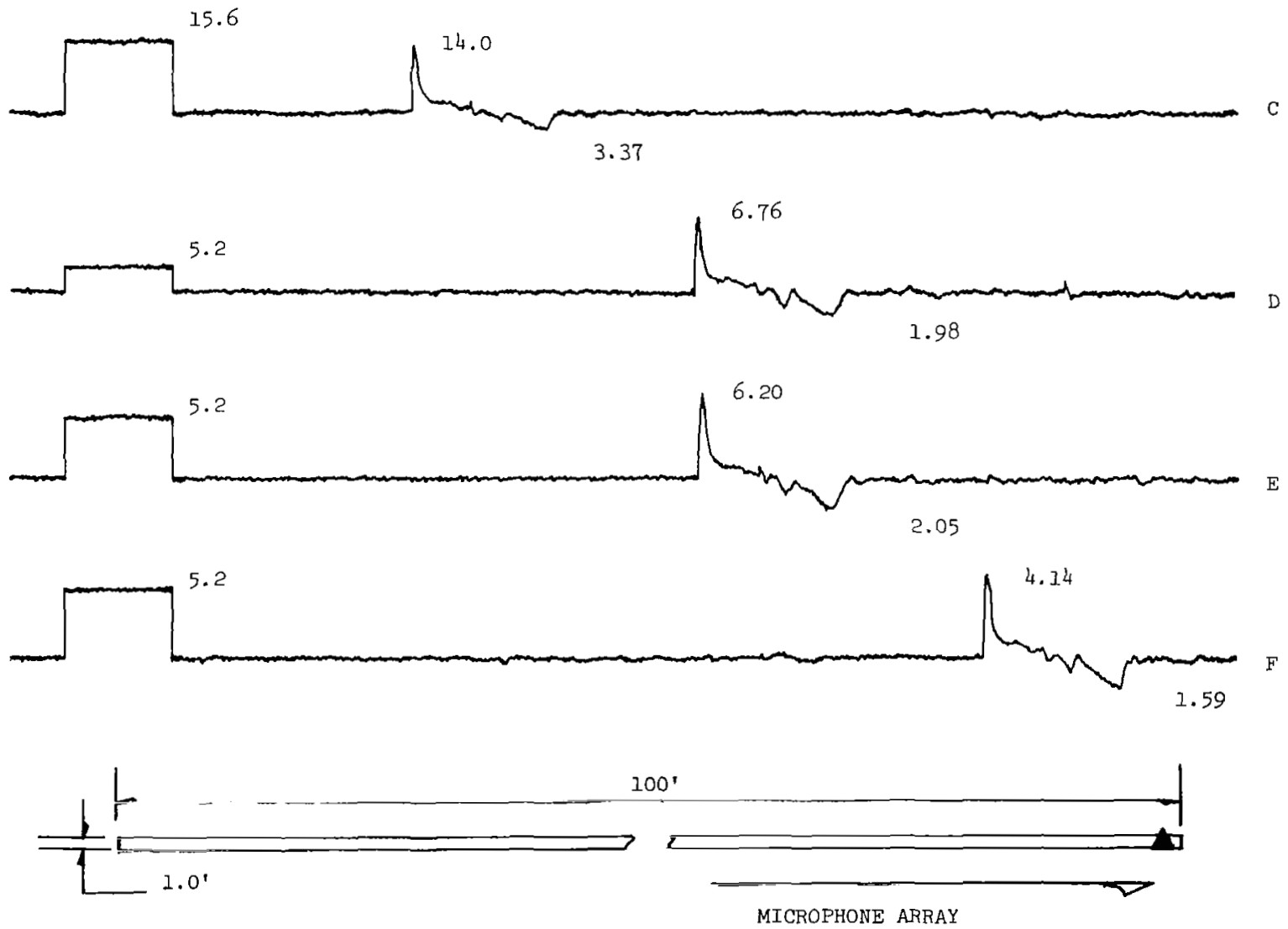

Figure 78 SBS-79 

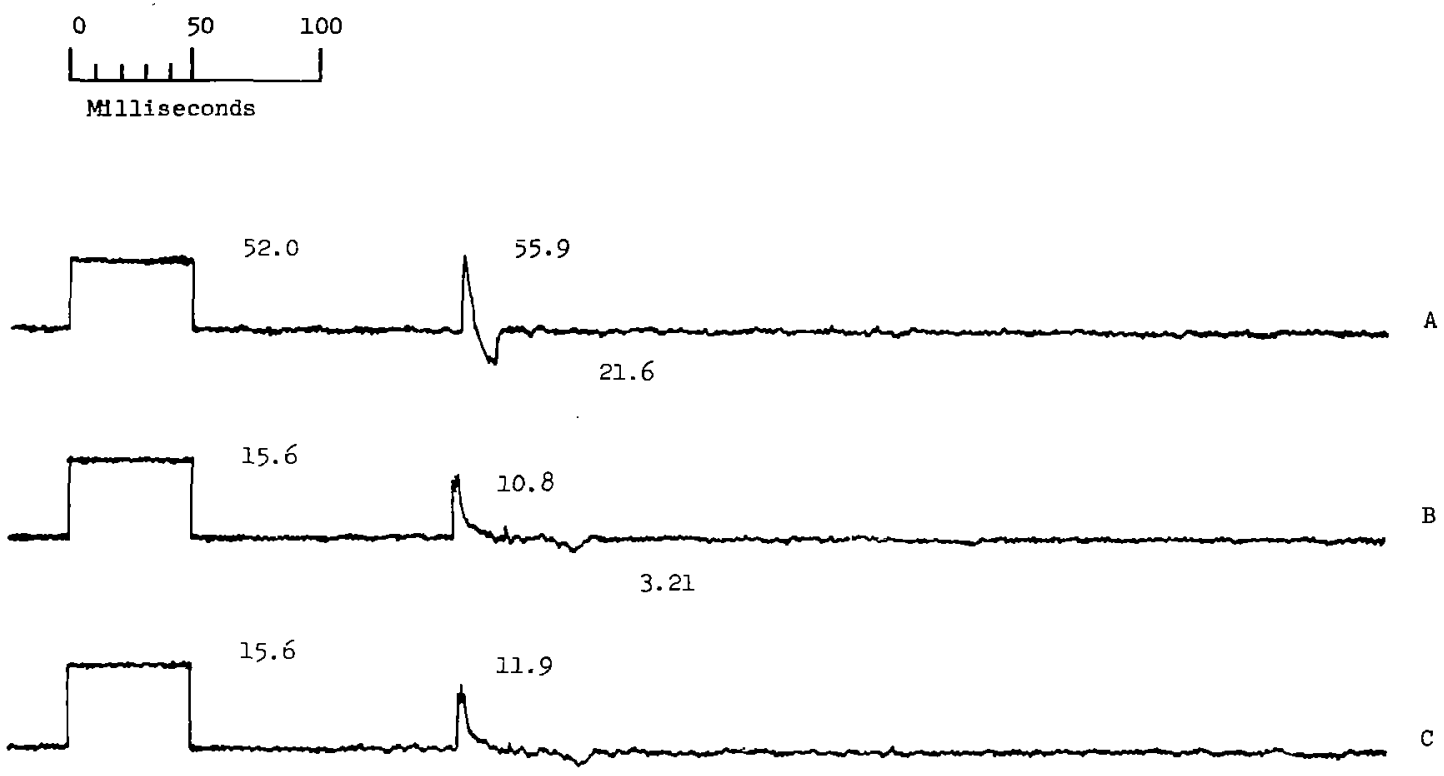

3.24
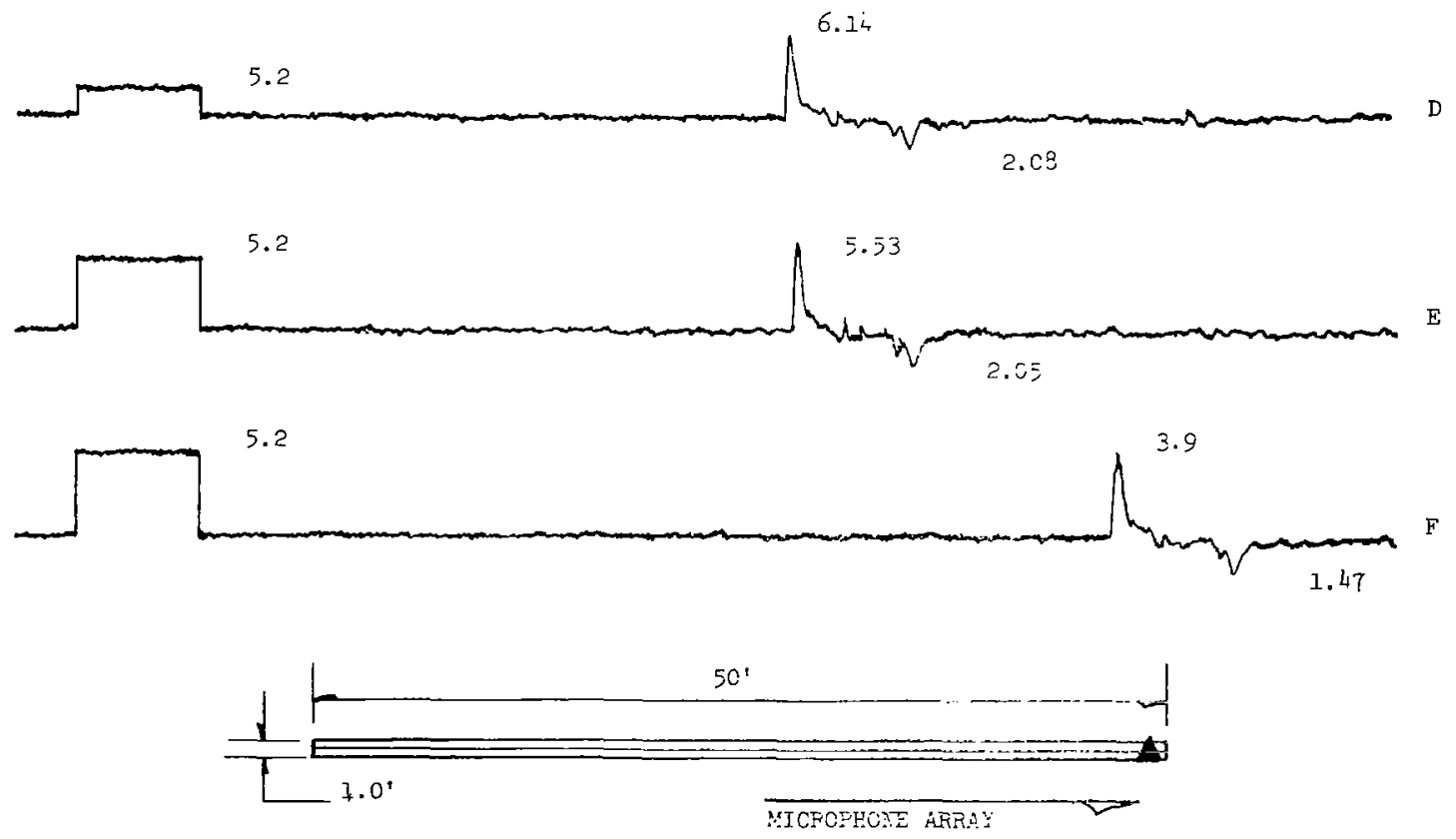

Figure 79 SBS-80 
$\underbrace{50}_{\text {Milliseconds }}$

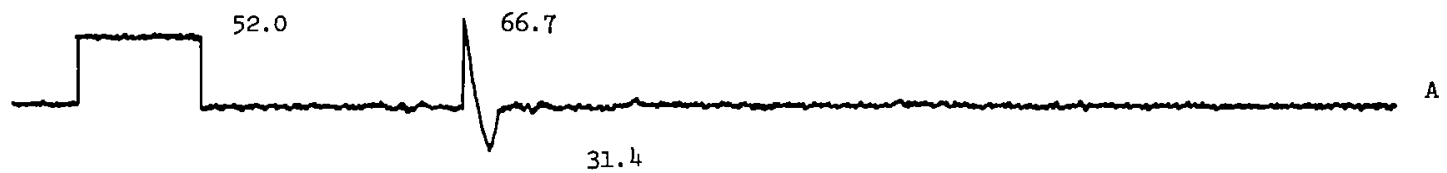

15.6

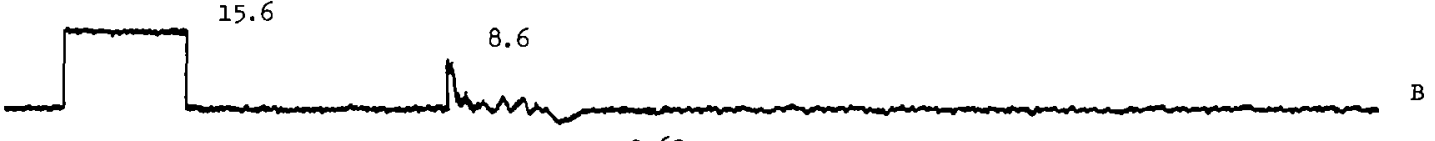

2.62
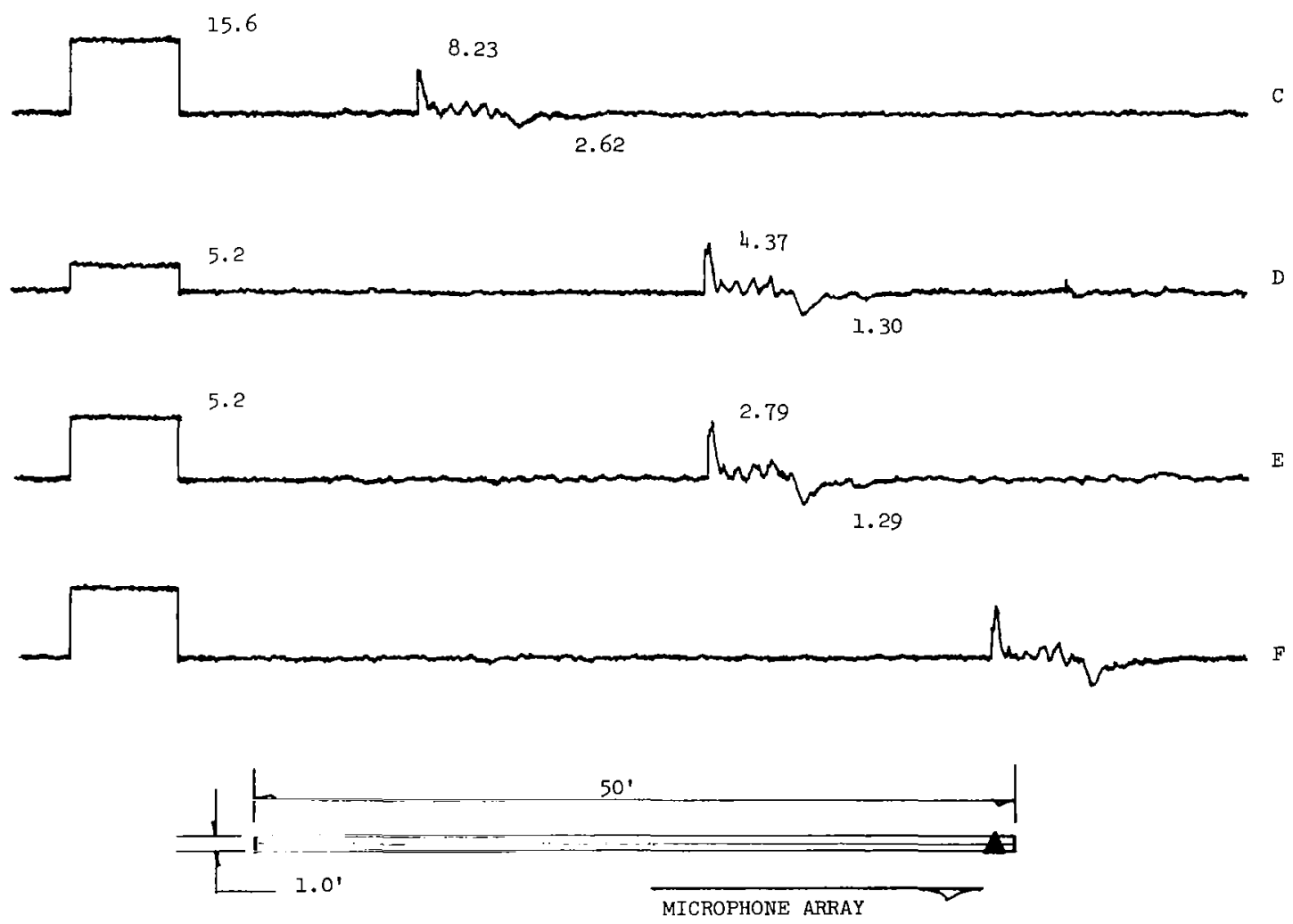

Figure $80 \quad$ SBS-81 
$\left.\right|_{\text {Milliseconds }} ^{|1 \perp 1|^{50}}$
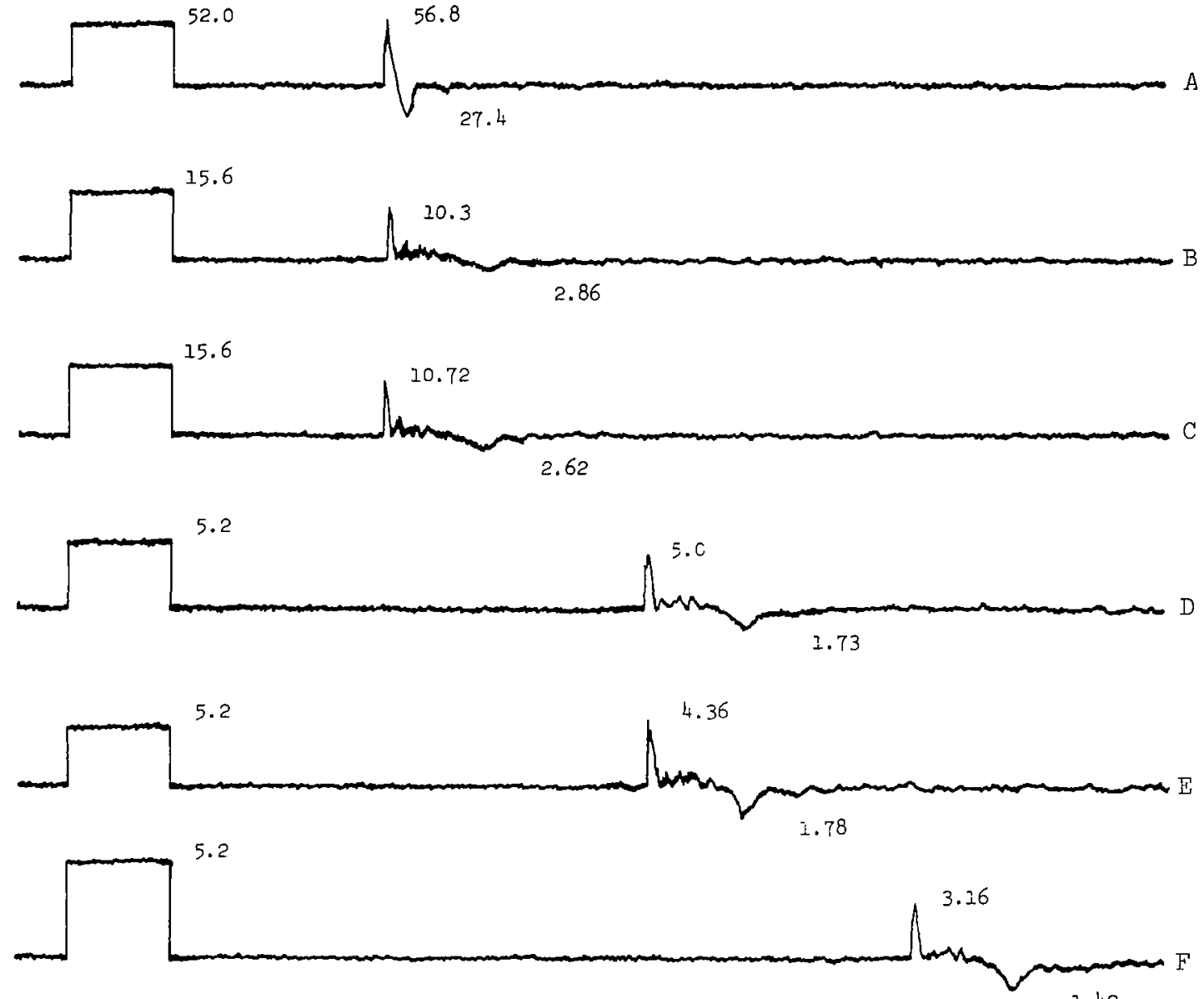

1.42

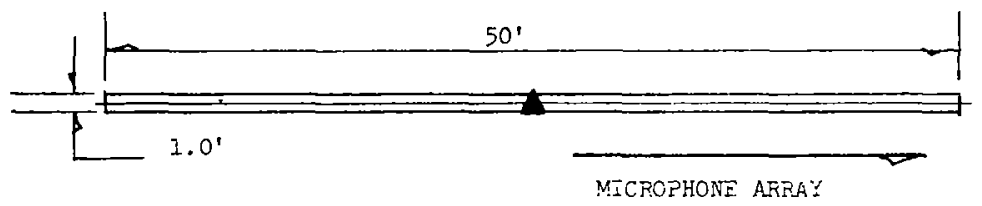

Figure $81 \quad$ SBS-82 

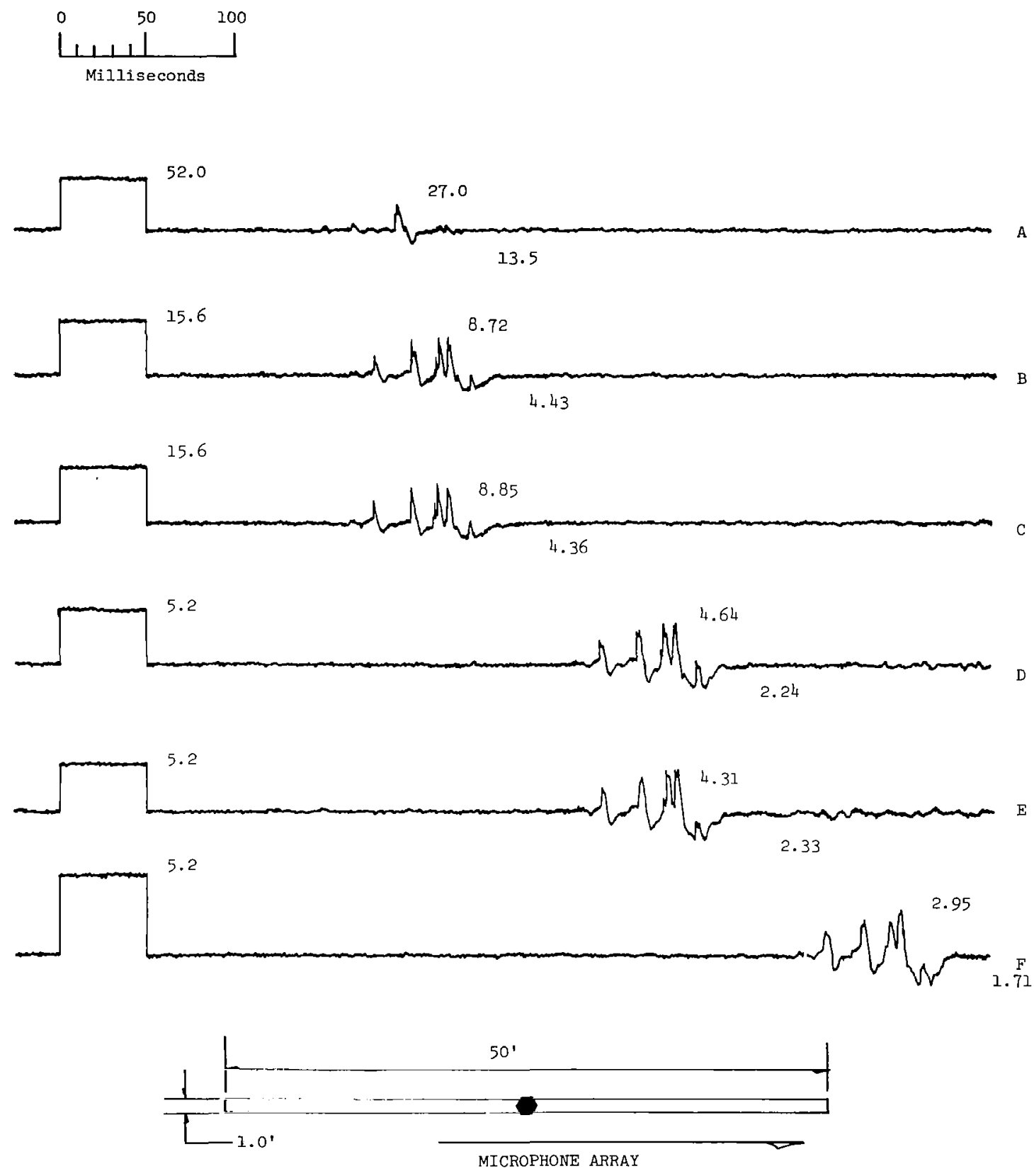

Figure 82 SBS-83 
$\left[\begin{array}{l}90 \\ 1+1,100\end{array}\right.$

Milliseconds

52.0

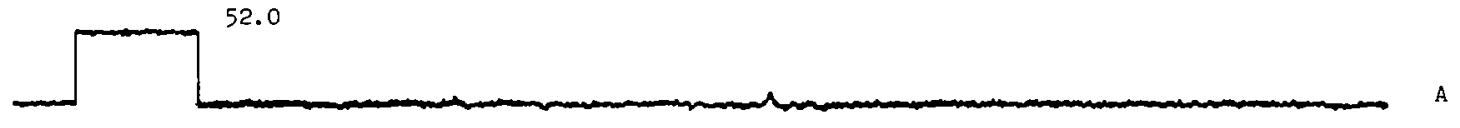

15.6

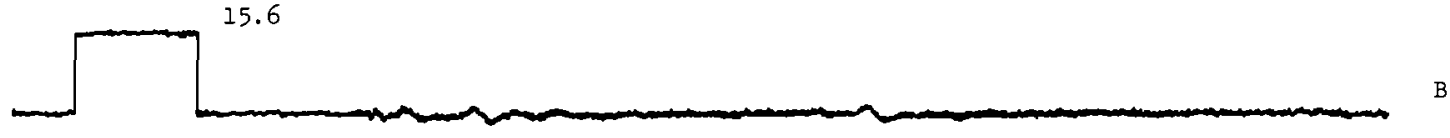

15.6
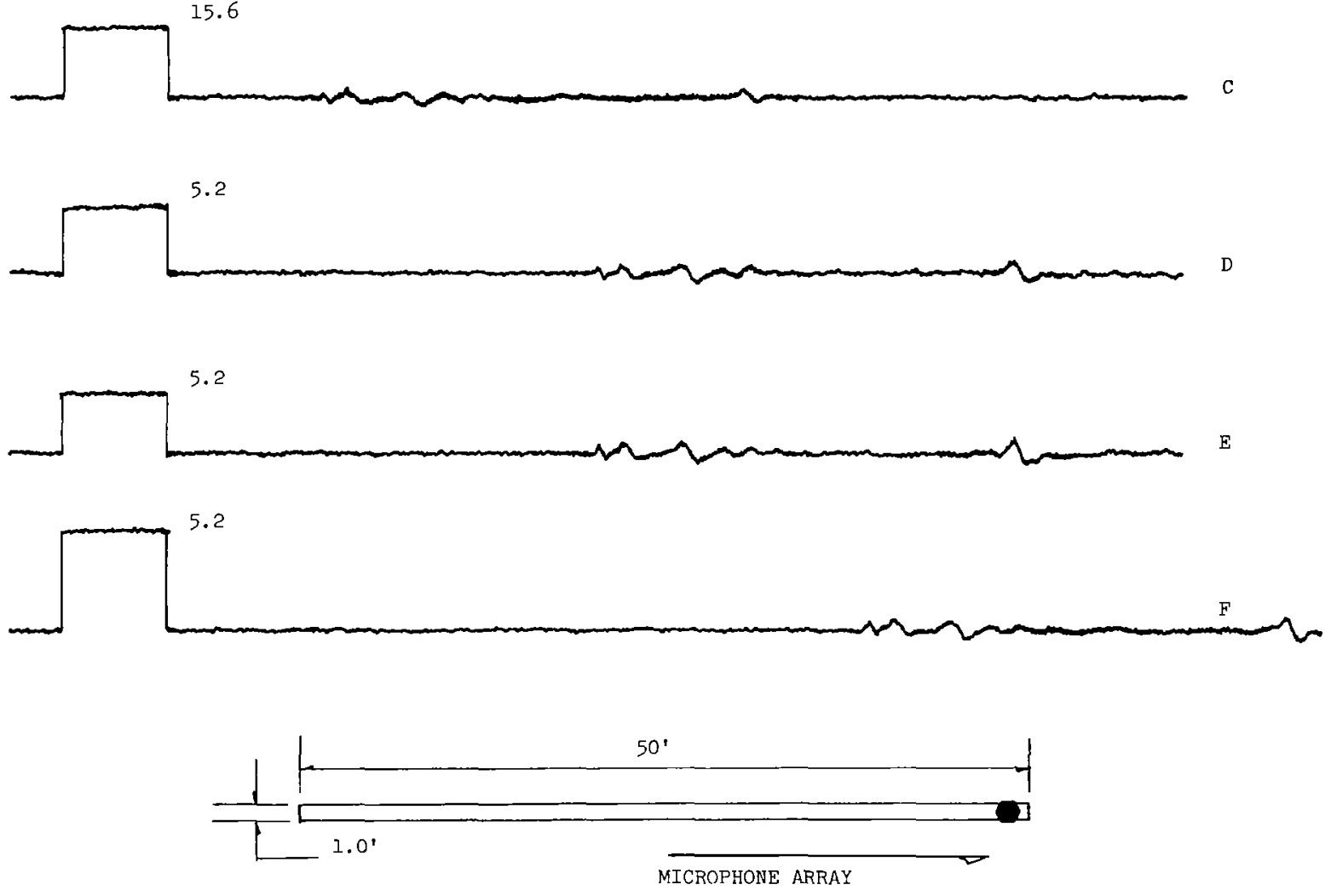

Figure 83 SBS-84 

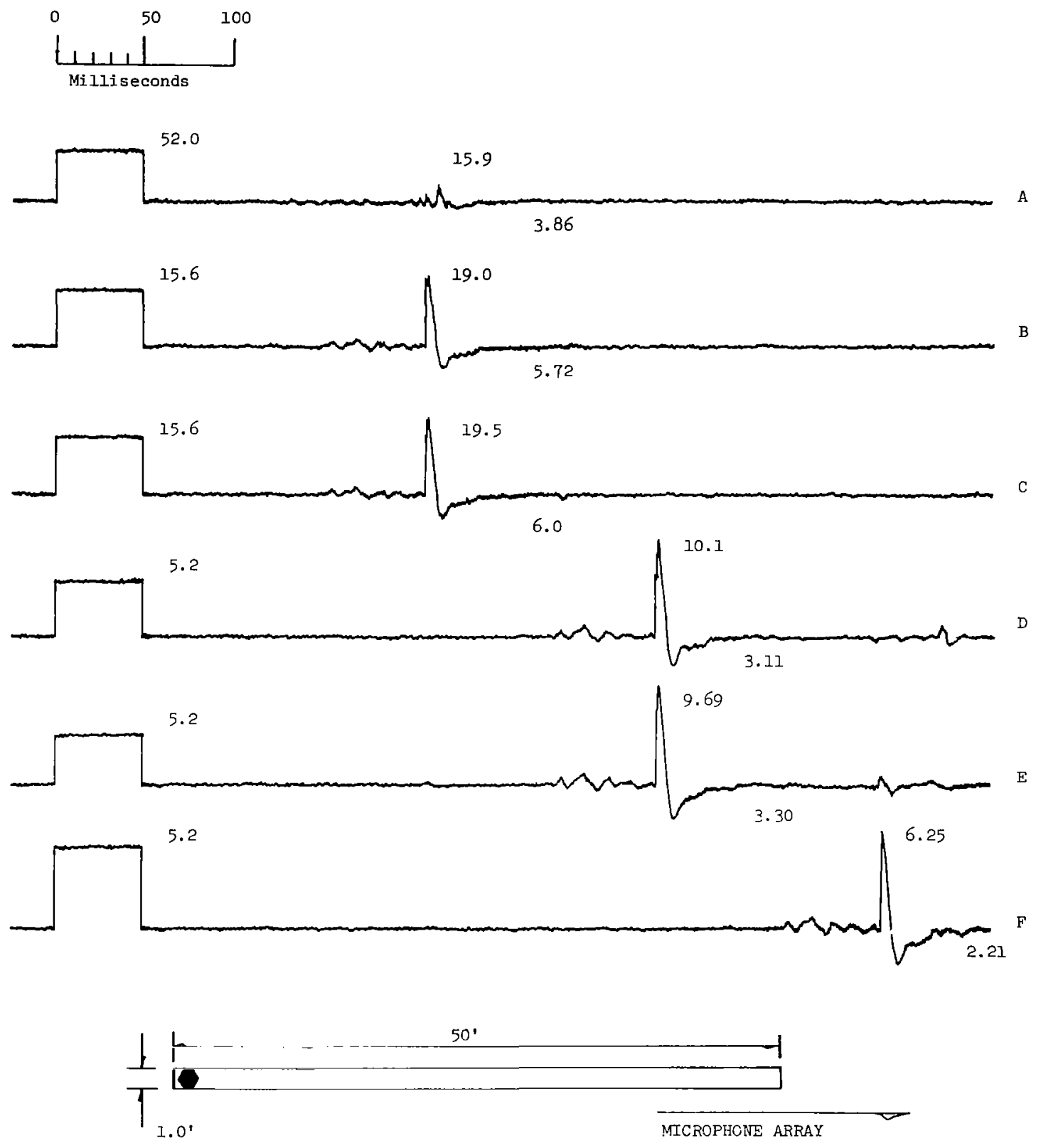

Figure $84 \quad$ SBS-85 

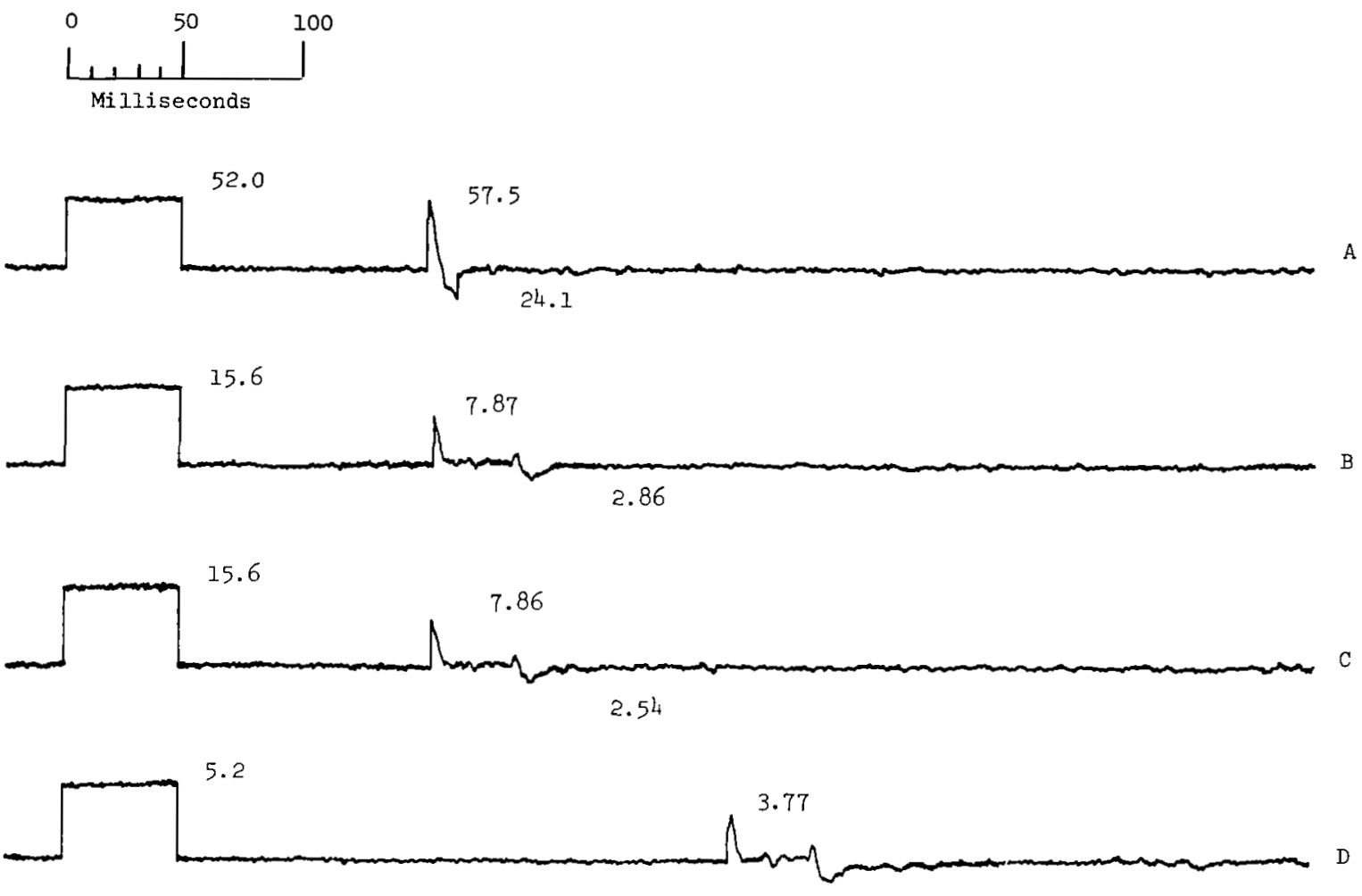

1.70
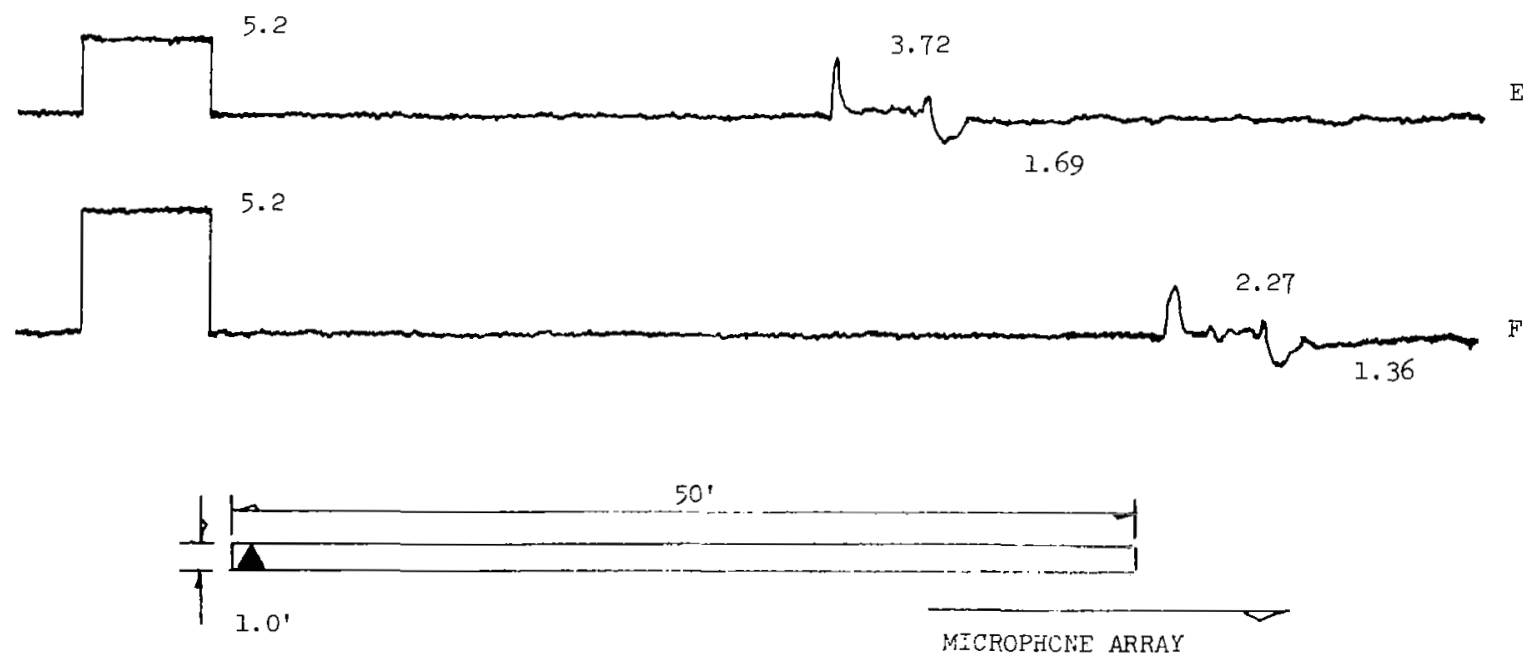

Figure 85 SBS-86 


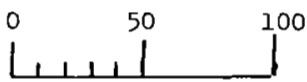

Milliseconds
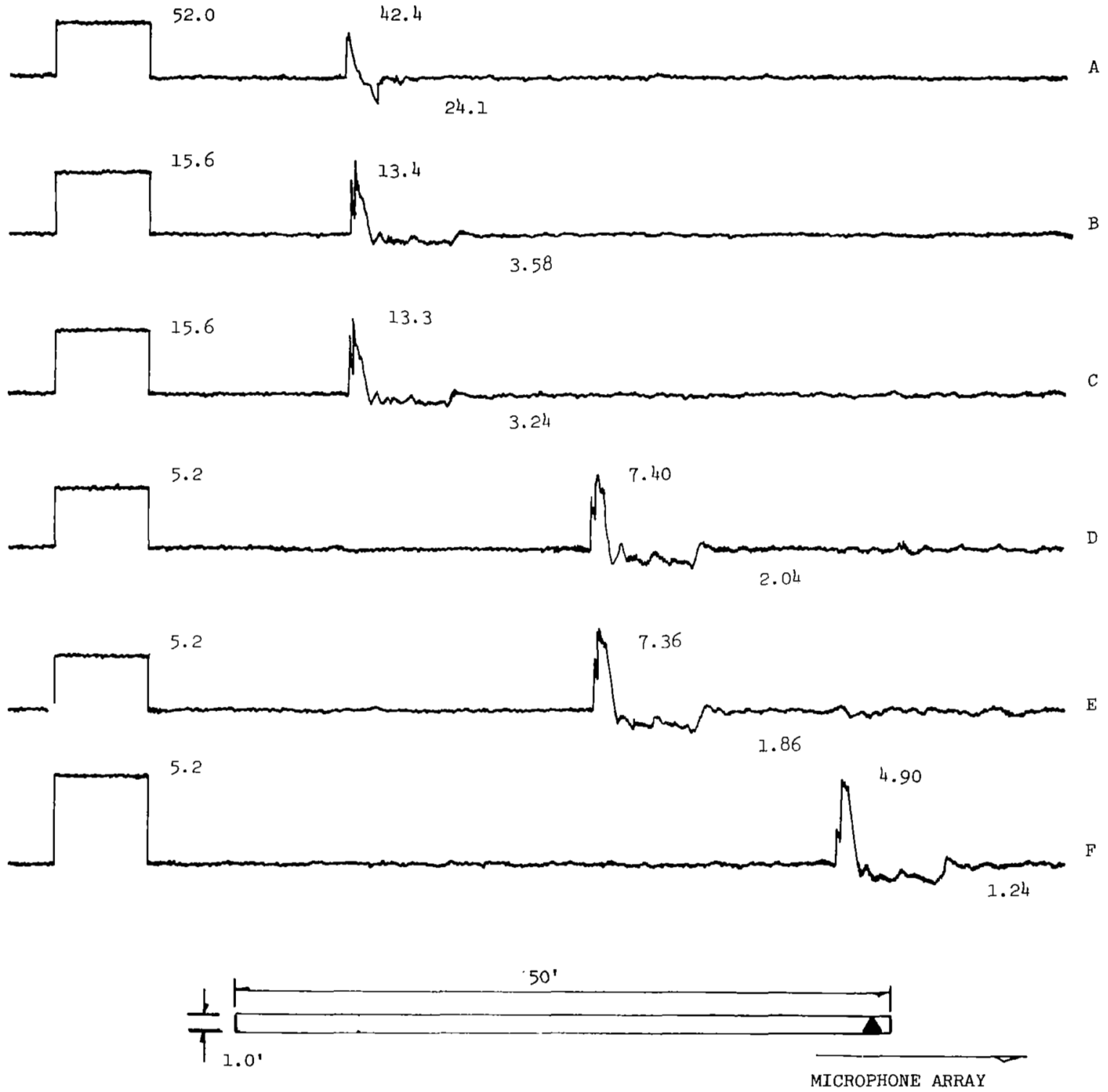

Figure $86 \quad$ SBS-87 


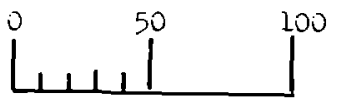

Milliseeonds
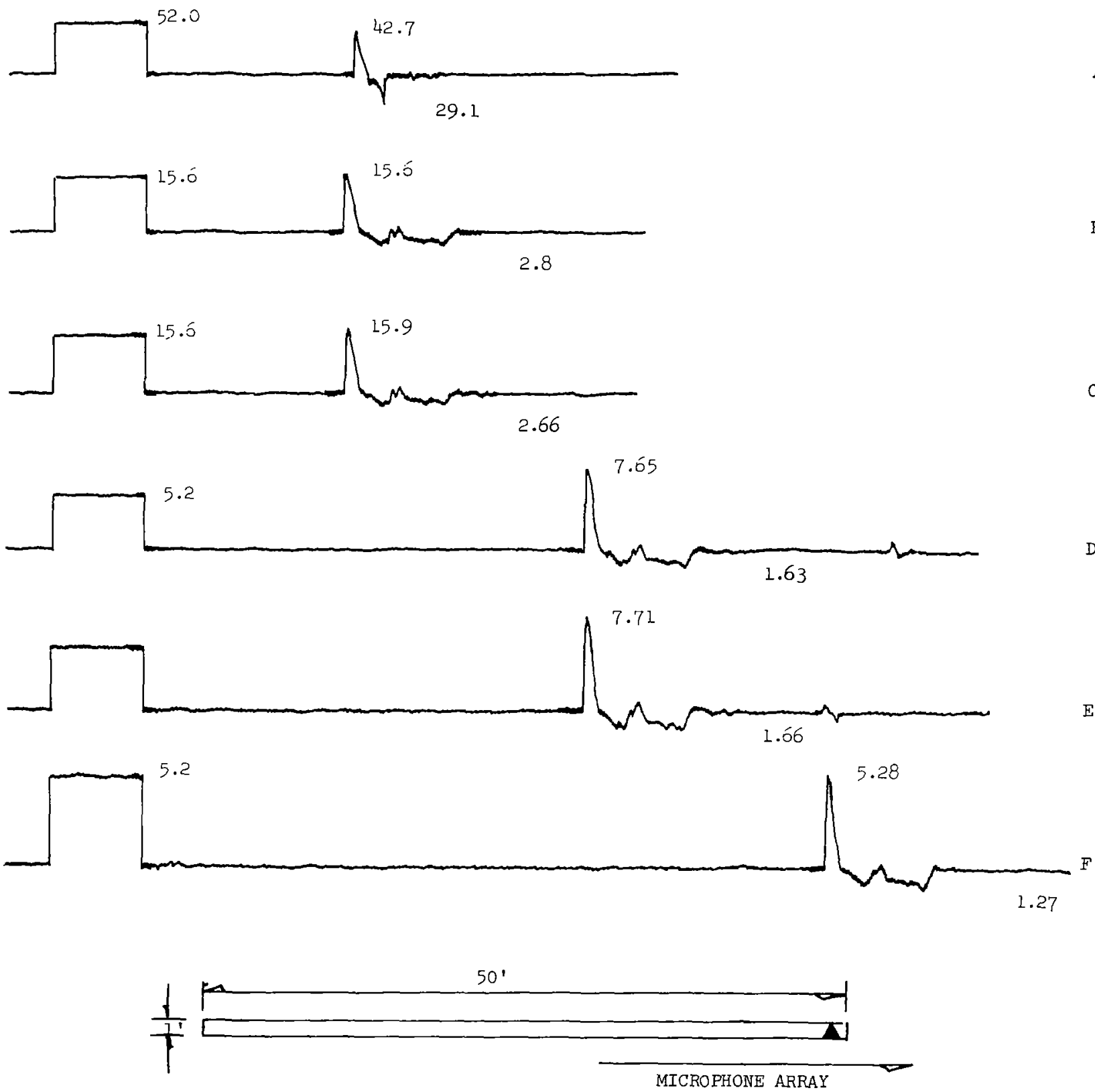

Figure $87 \quad$ SBS-88 

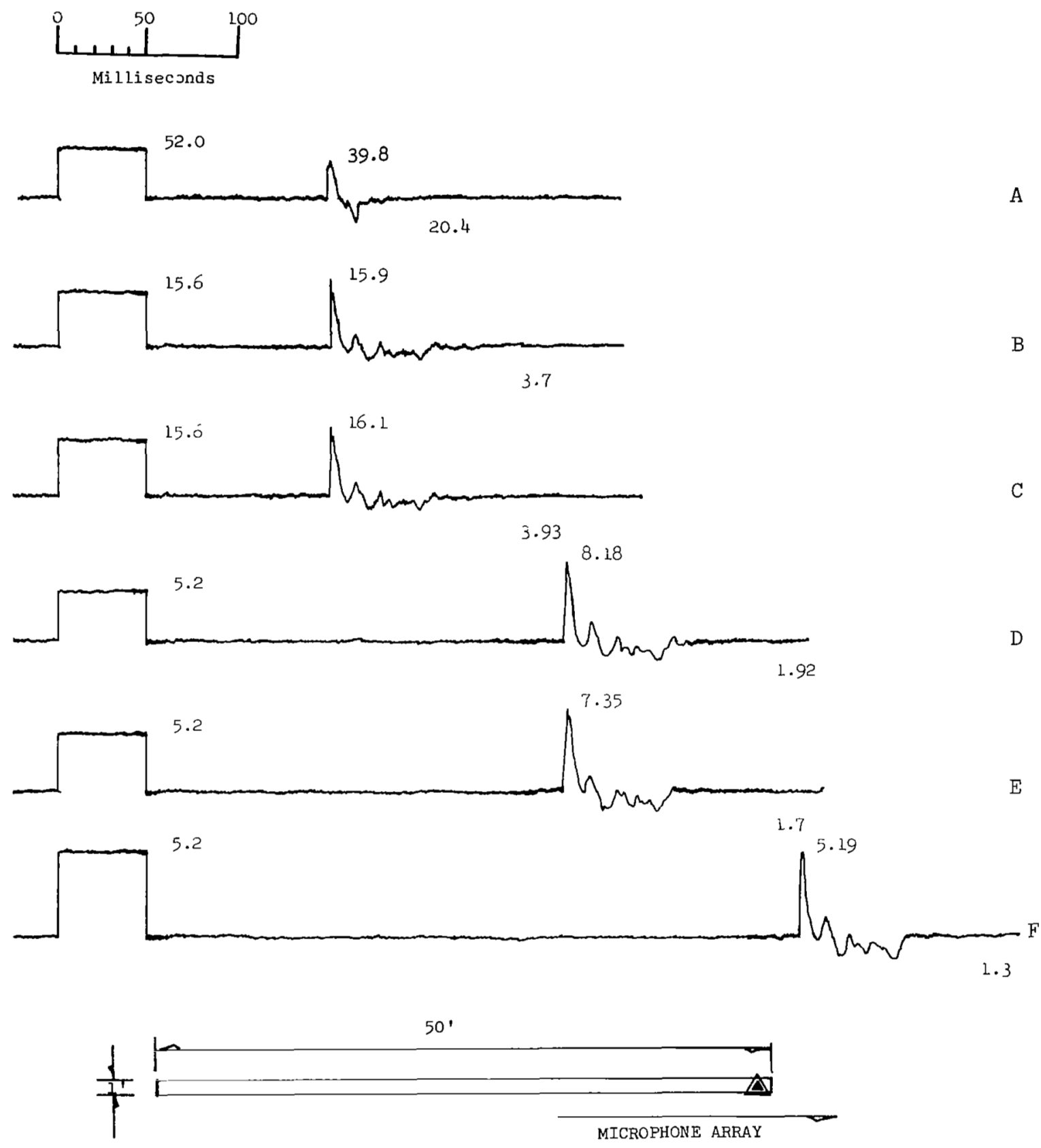

Figure $88 \quad$ SBS-89 


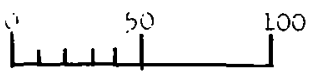

Millisec onds
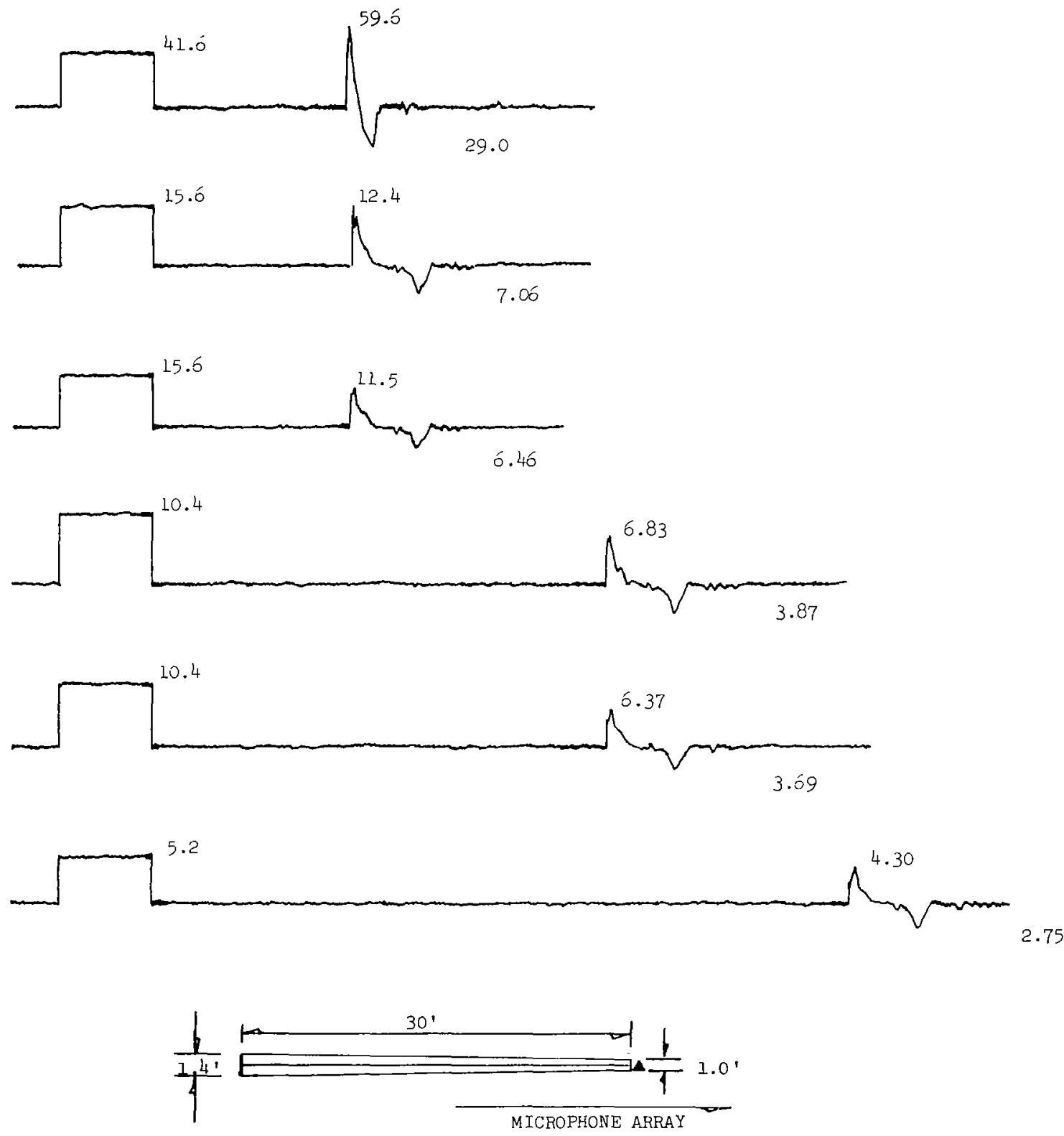

Figure 89 SBS-90 


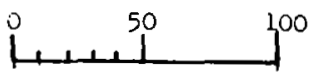

MiLliseconds
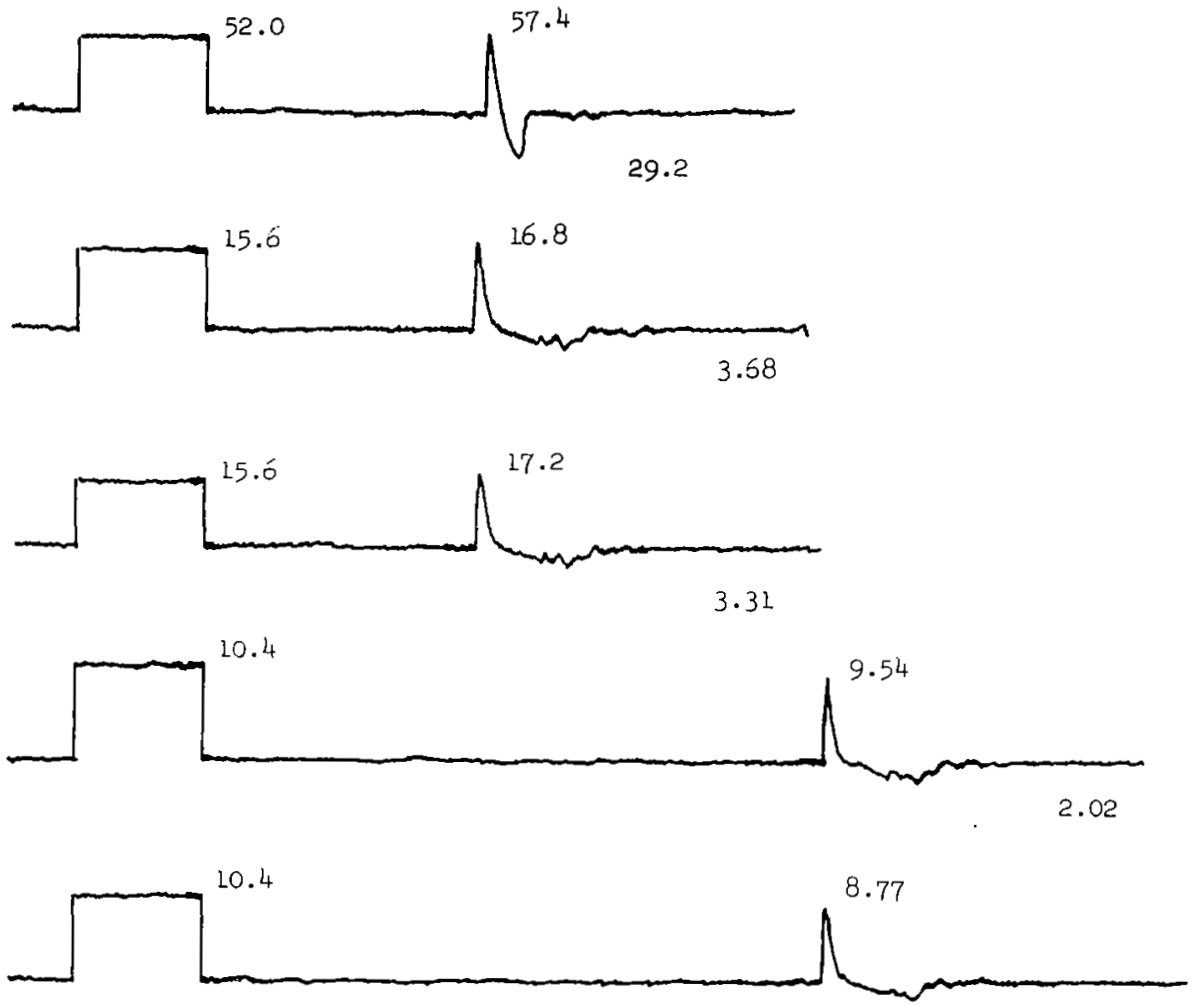

1.79
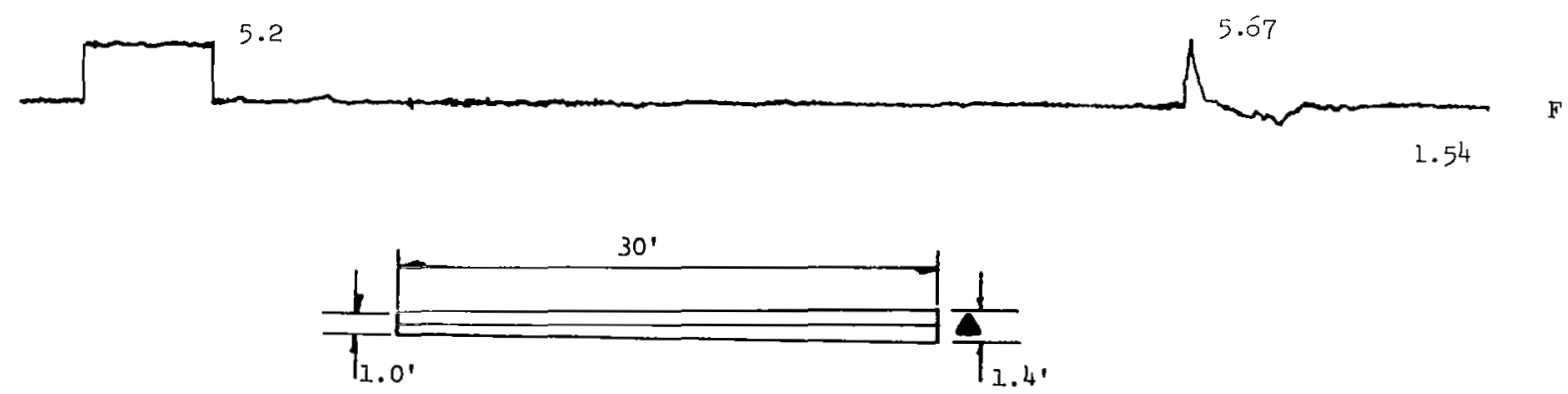

MICROPHONE ARRAY

Figure 90 SBS 91 


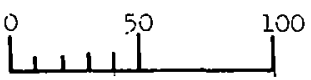

Milliseconds
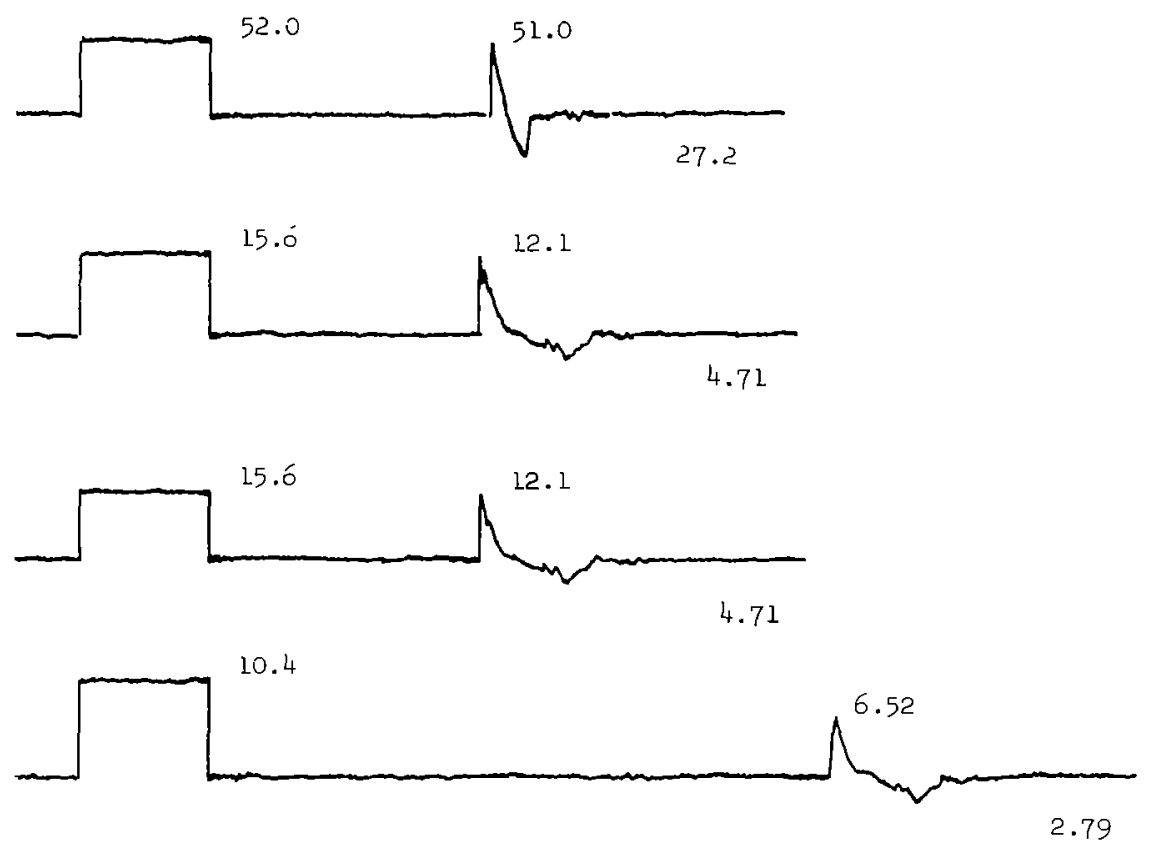

10.4
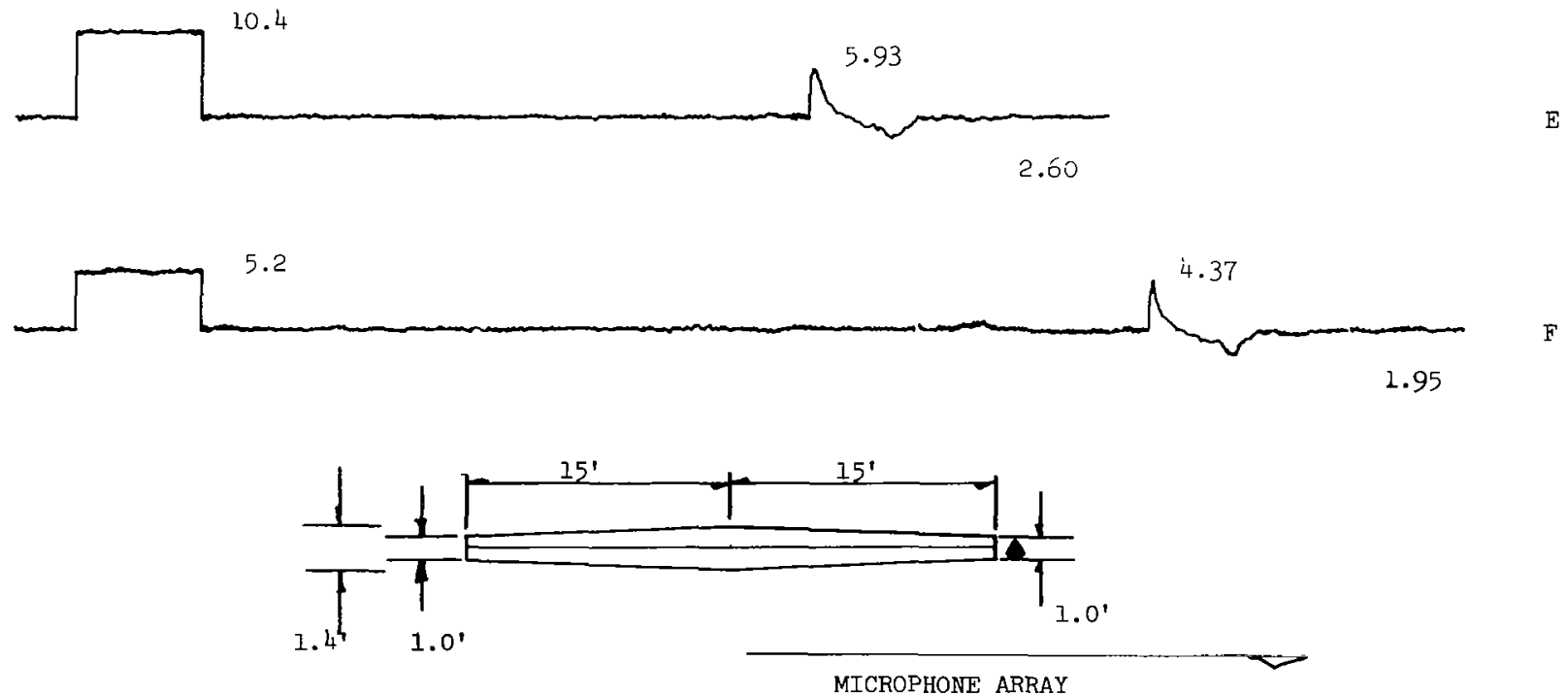

Figure 91 SBS-92 

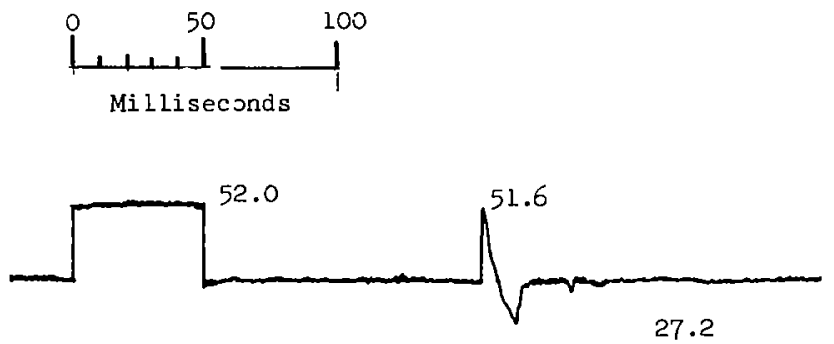

A

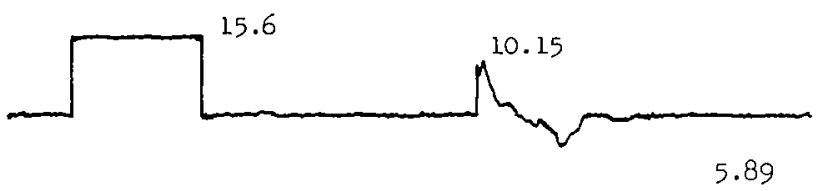

B
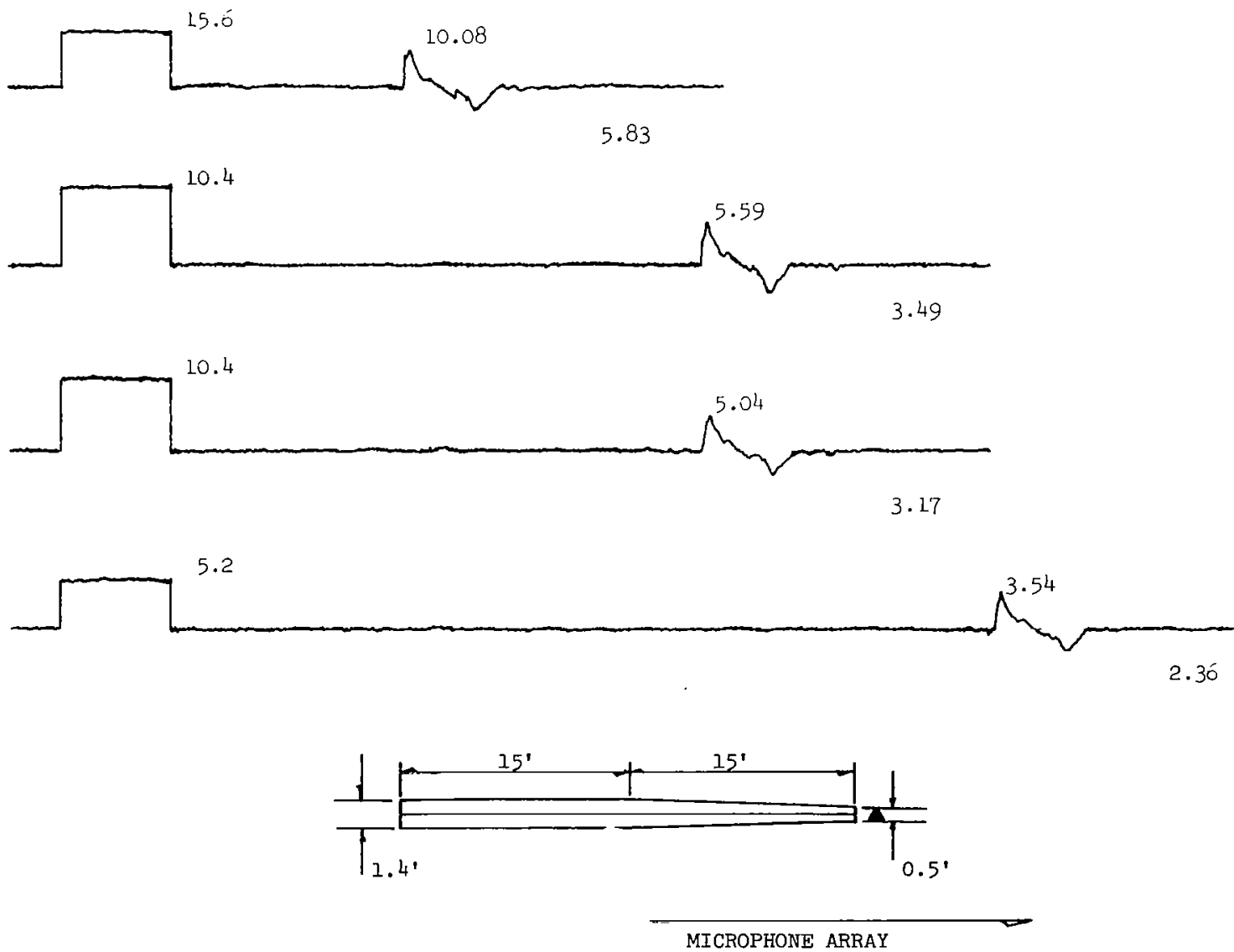

Figure 92 SBS-93 

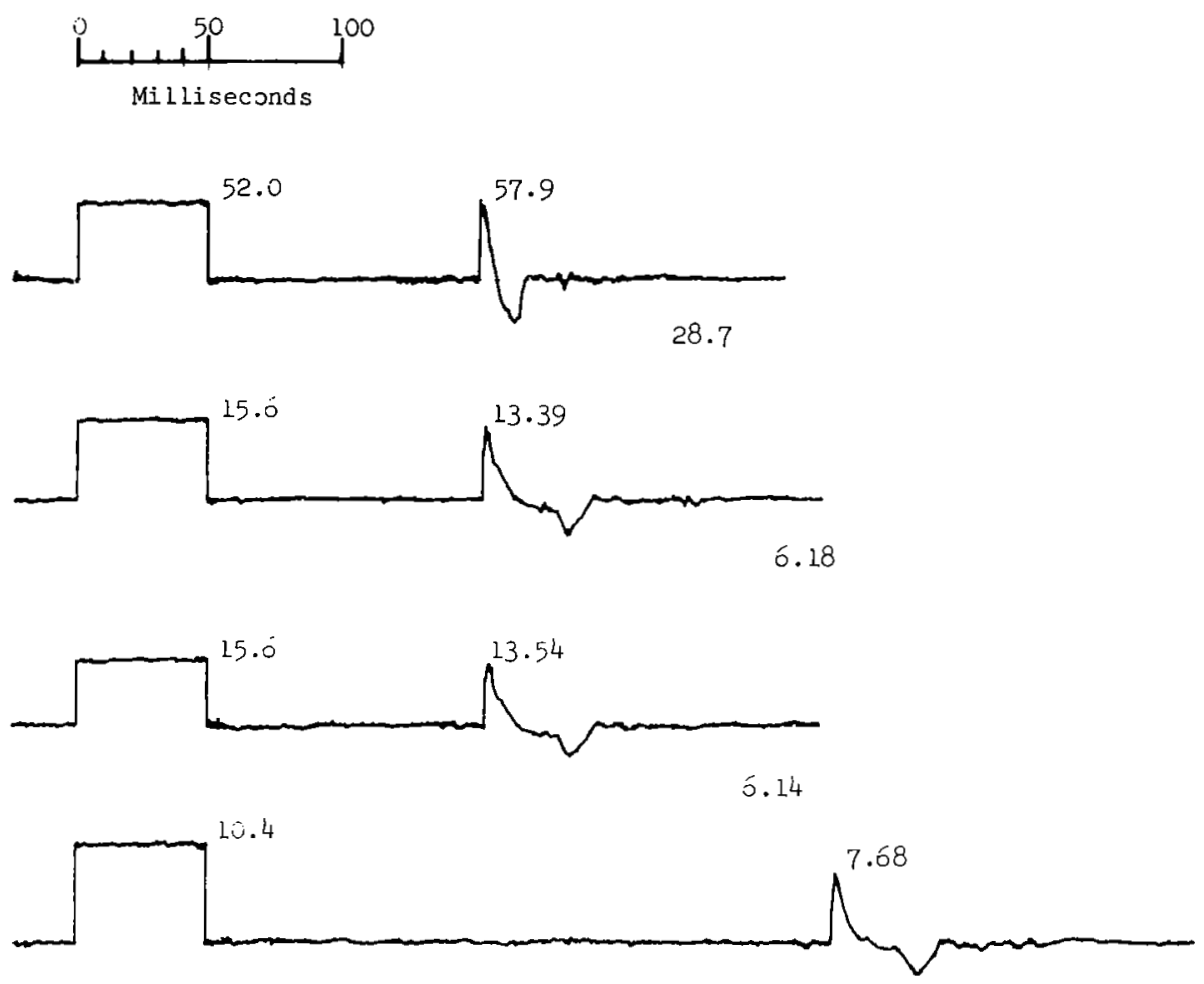

3.55
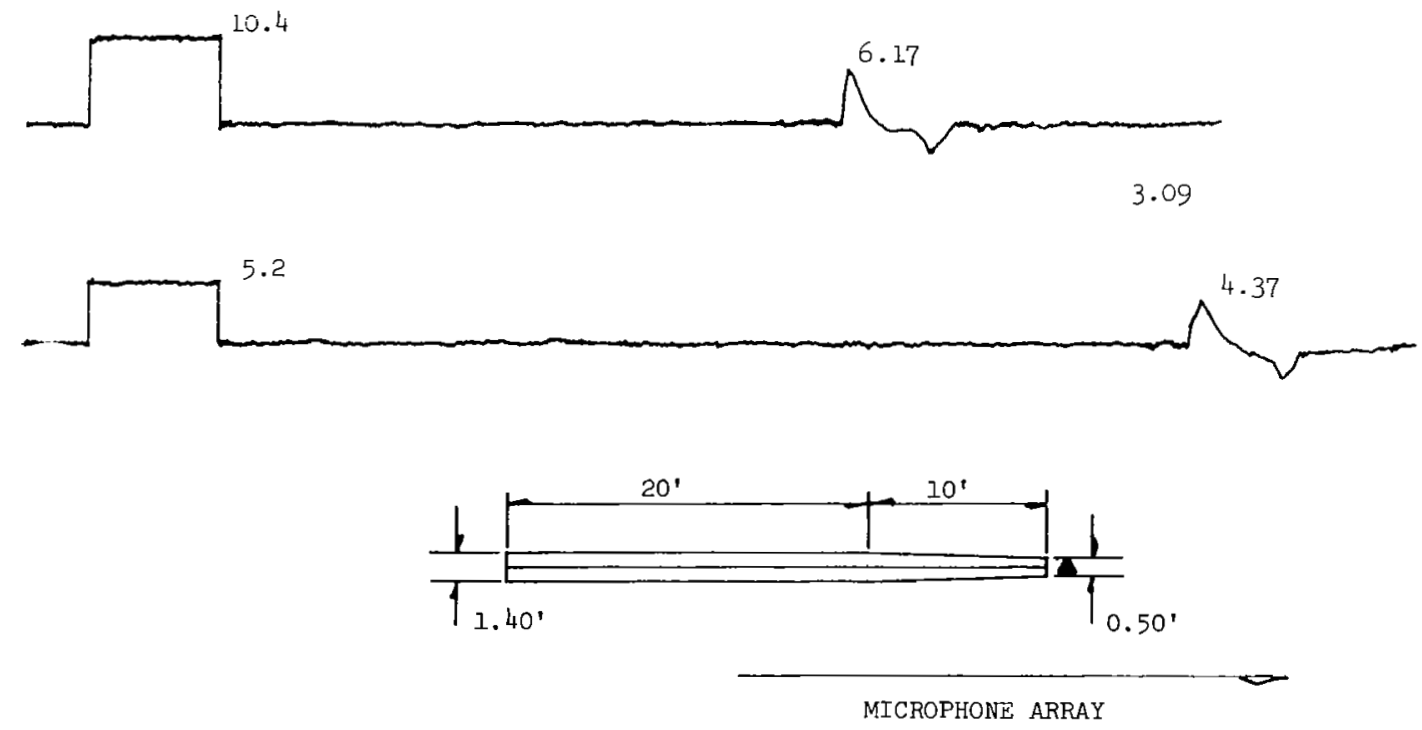

Figure 93 SBS-94 

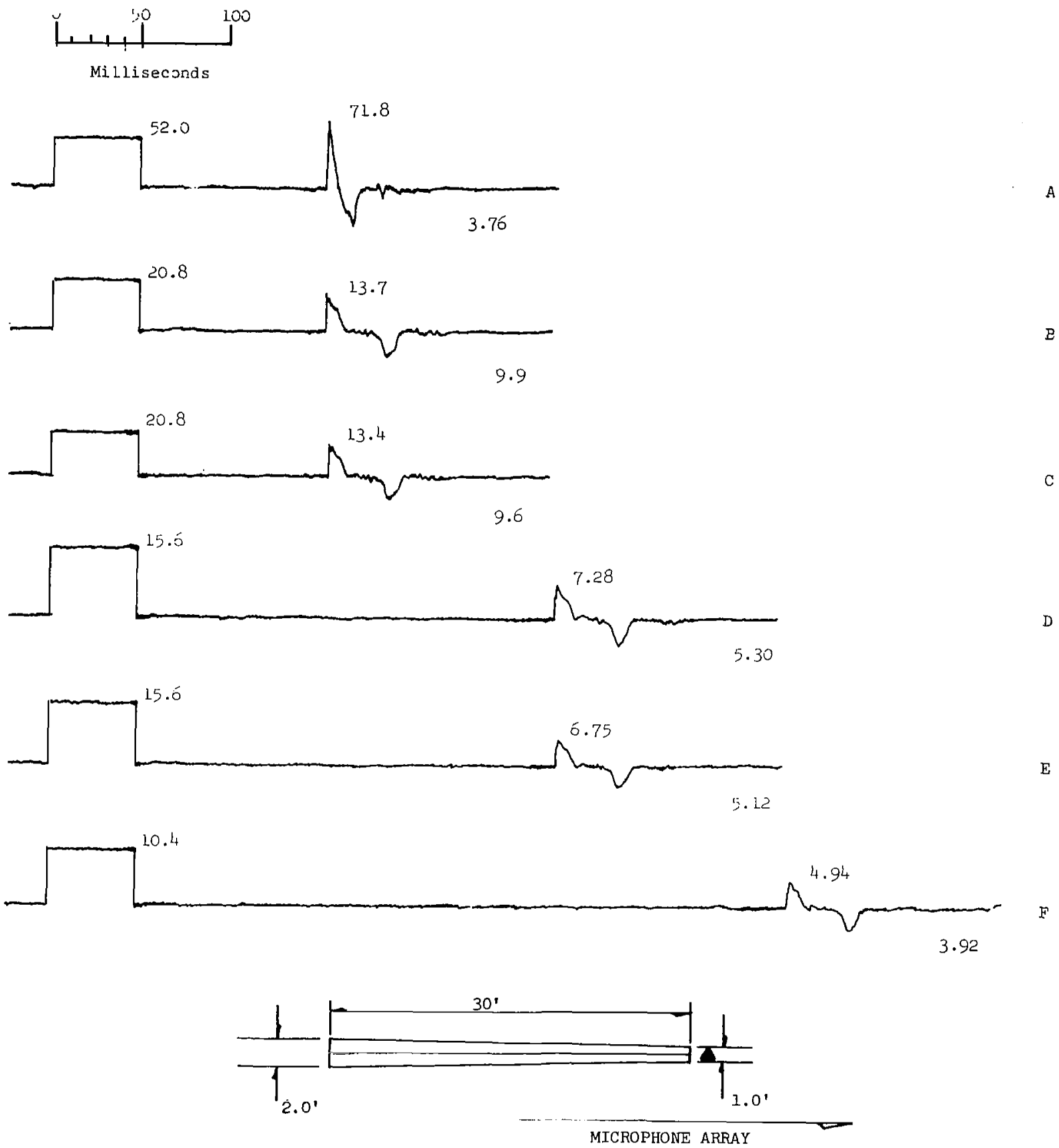

Figure 94 SBS-95 

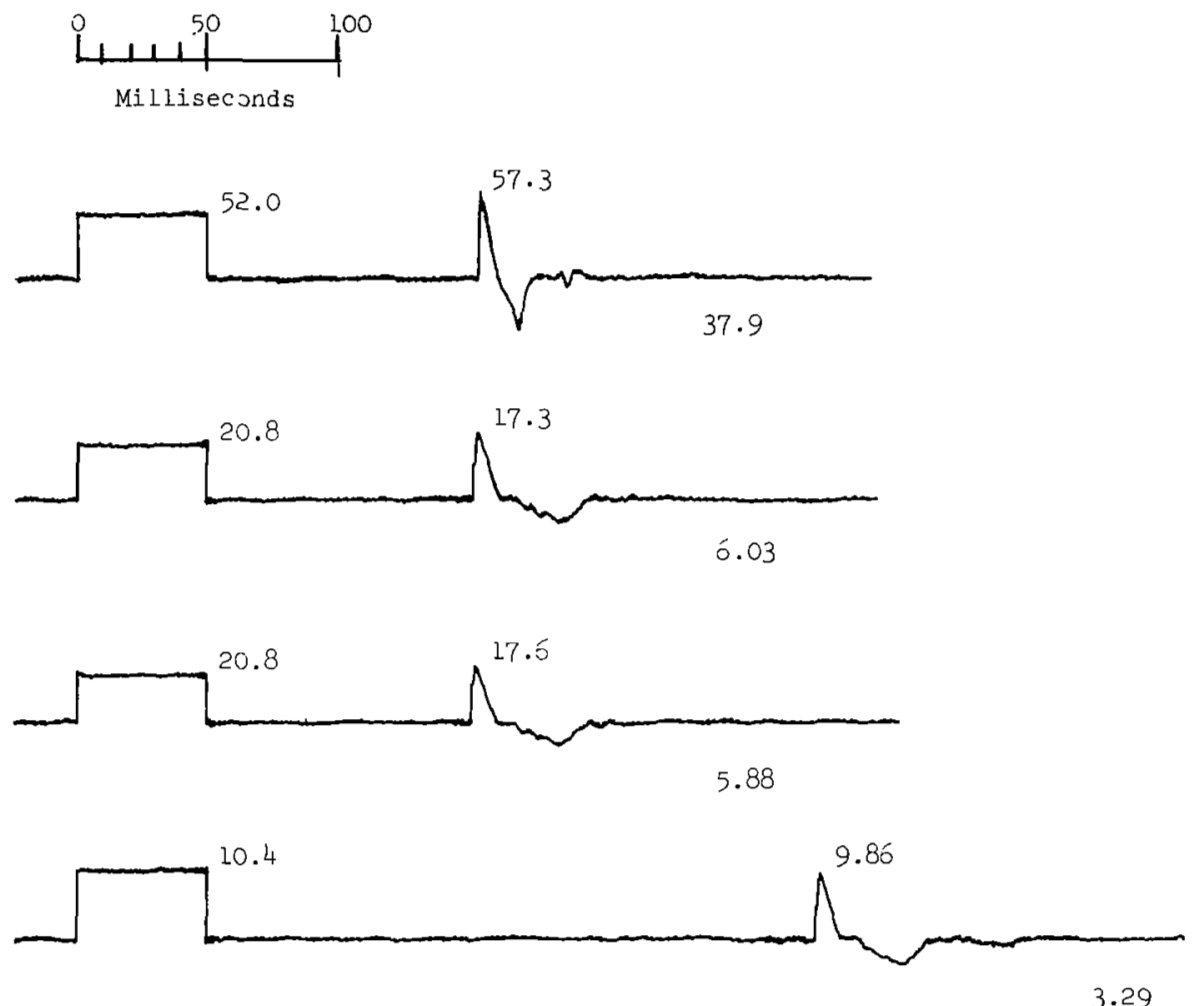

D
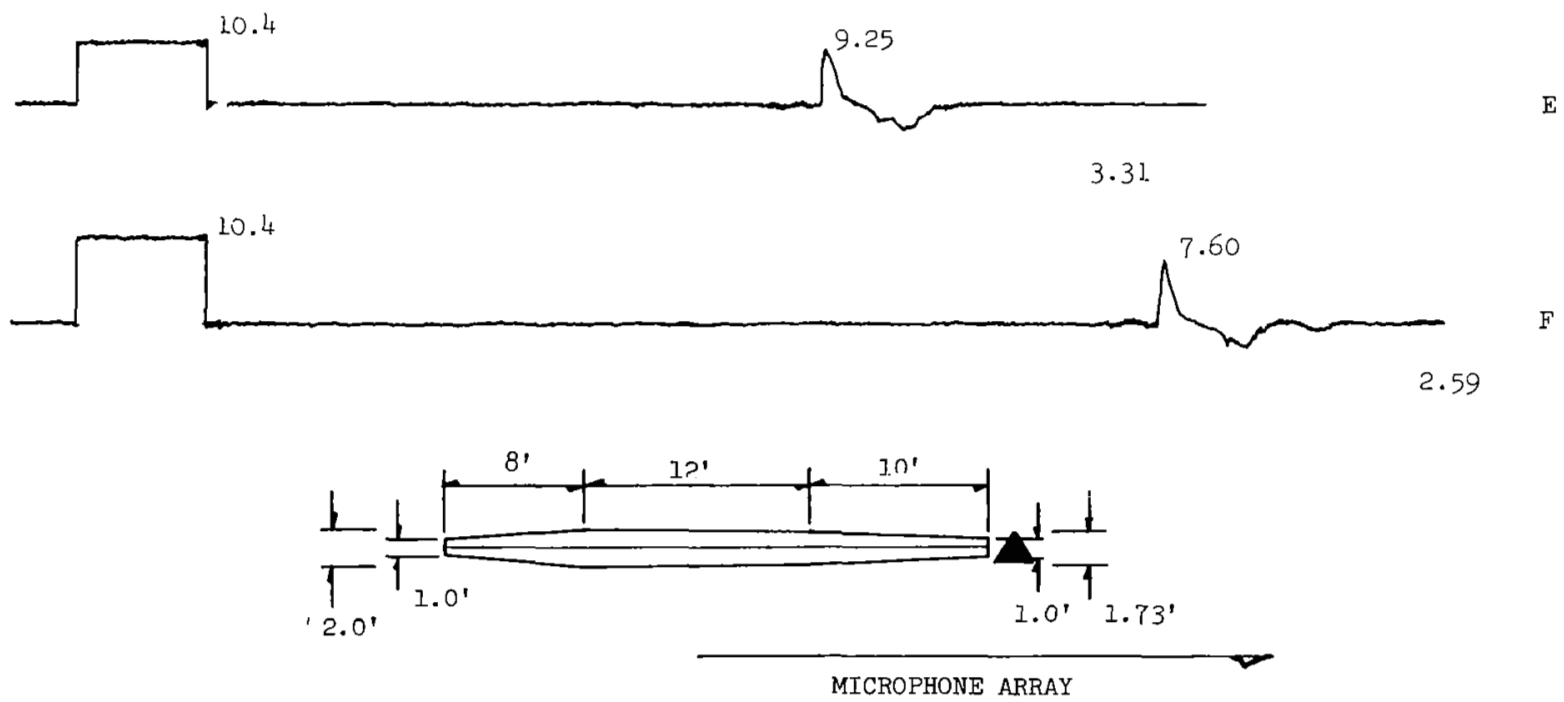

Figure 95 SBS 96 


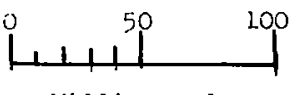

Millisec onds
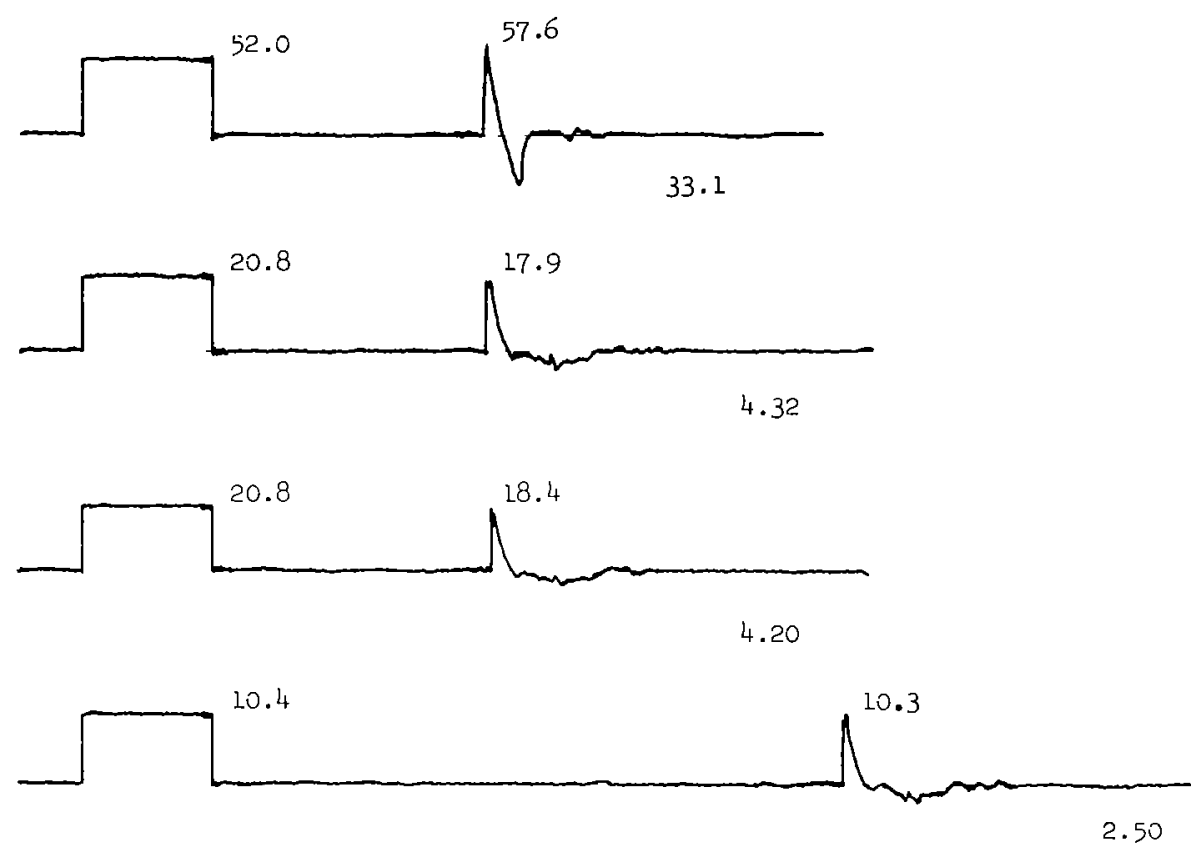

2.19
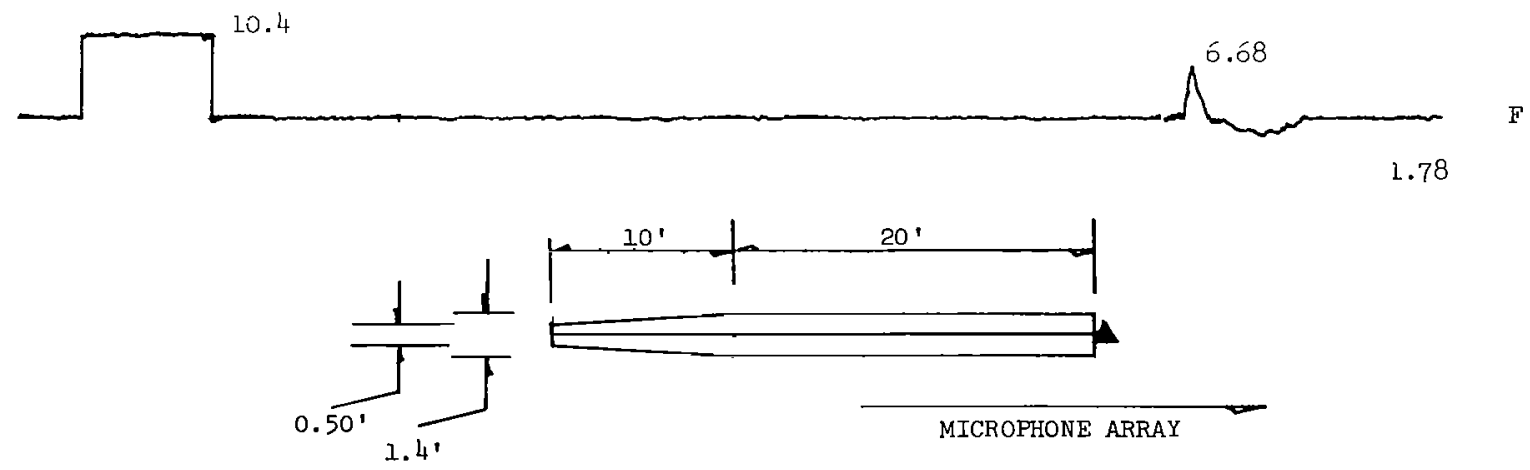

Figure 96 SBS-97 


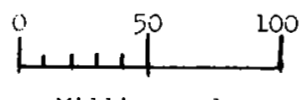

Milliseconds
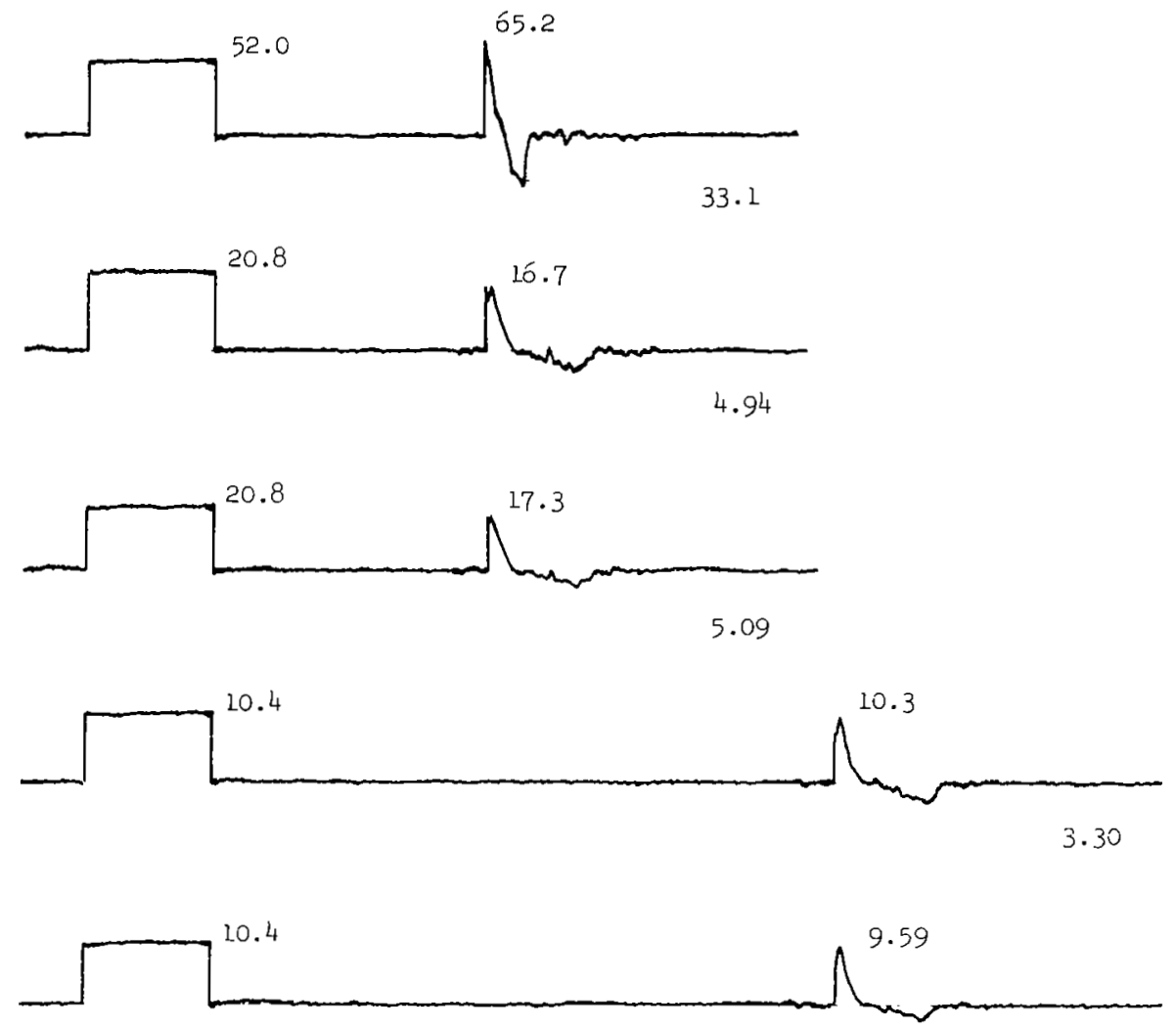

3.0
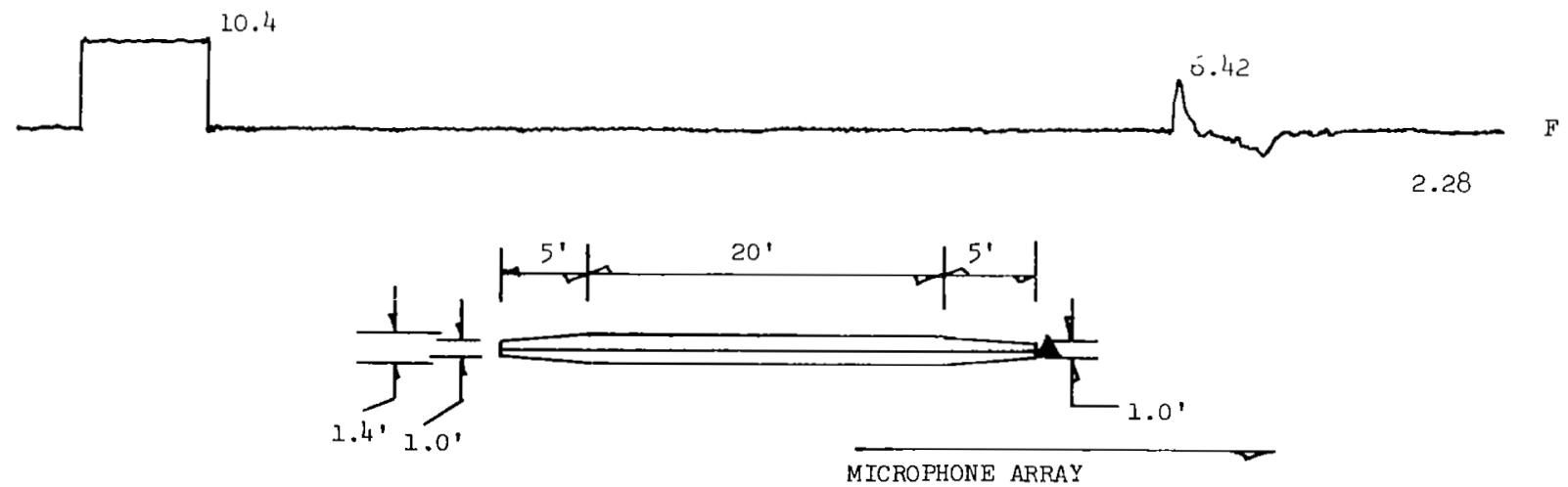

Figure 97 SBS-98 

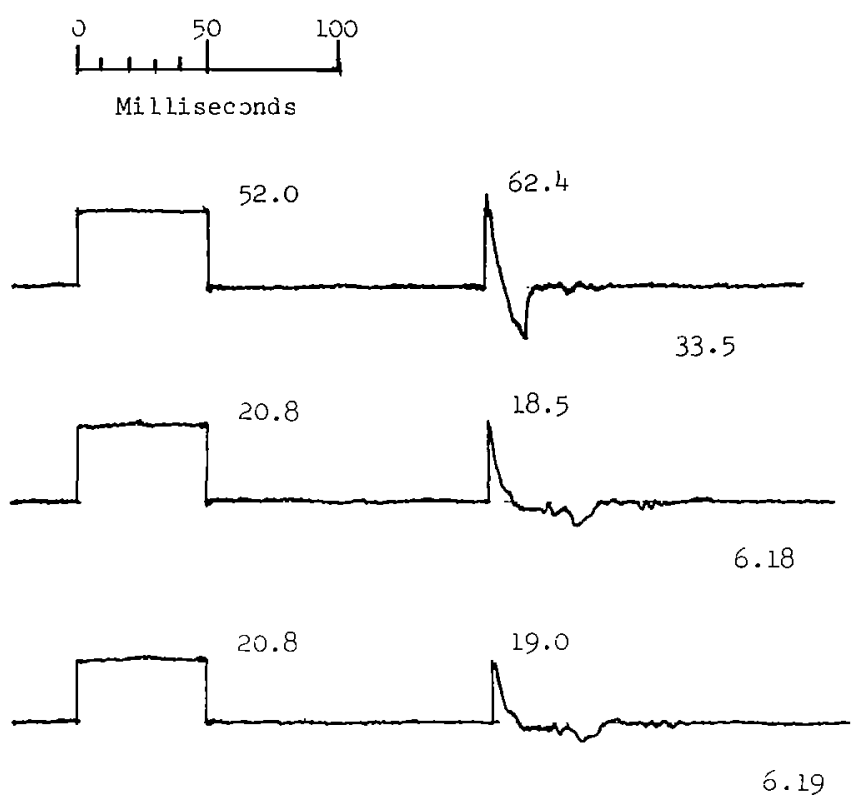

10.4
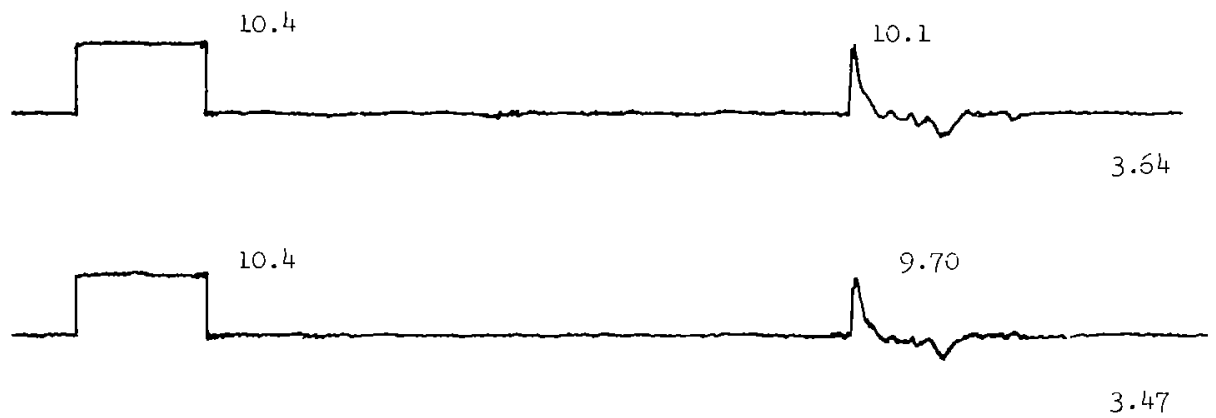

10.4
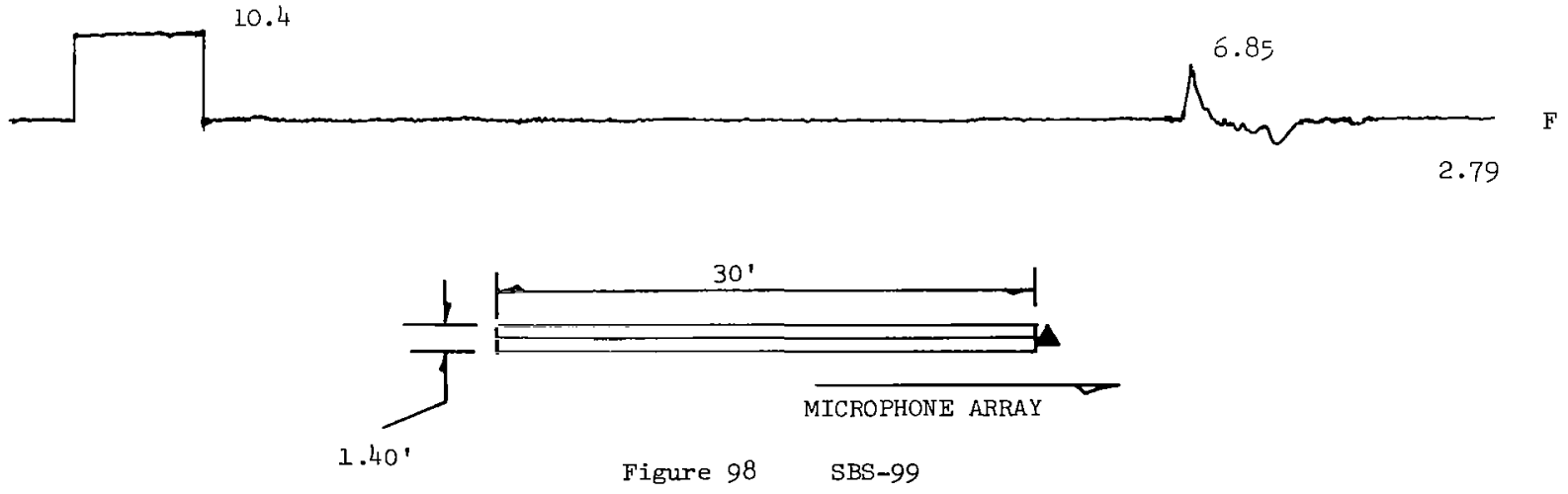
|

Milliseconòs

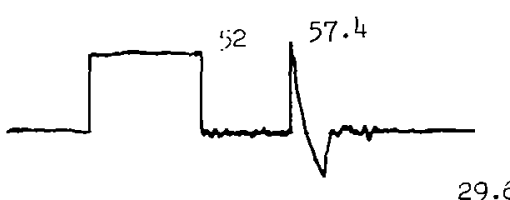

A

29.6
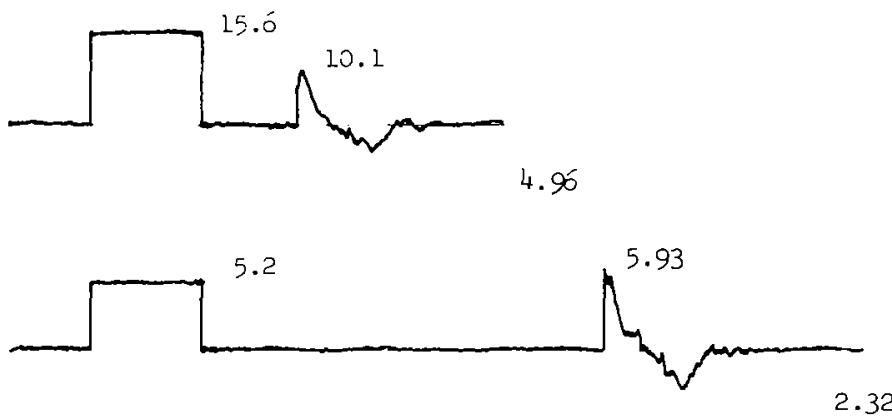

$\mathrm{C}$

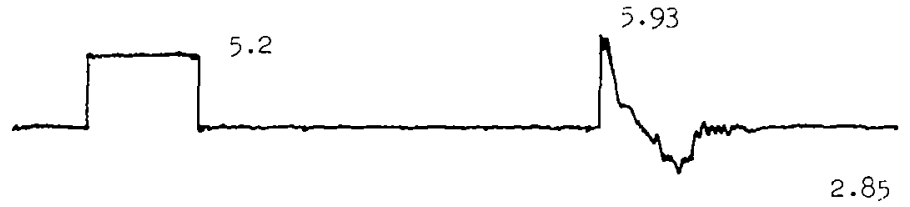

B

D

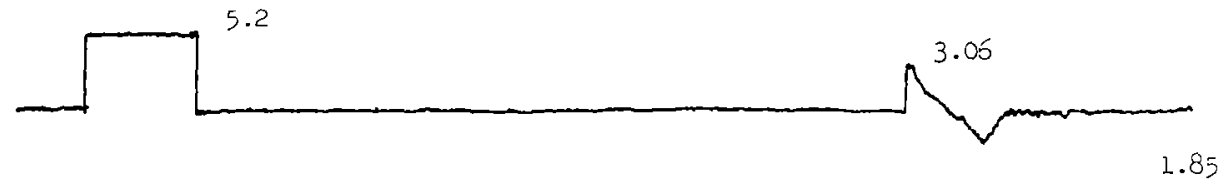

E
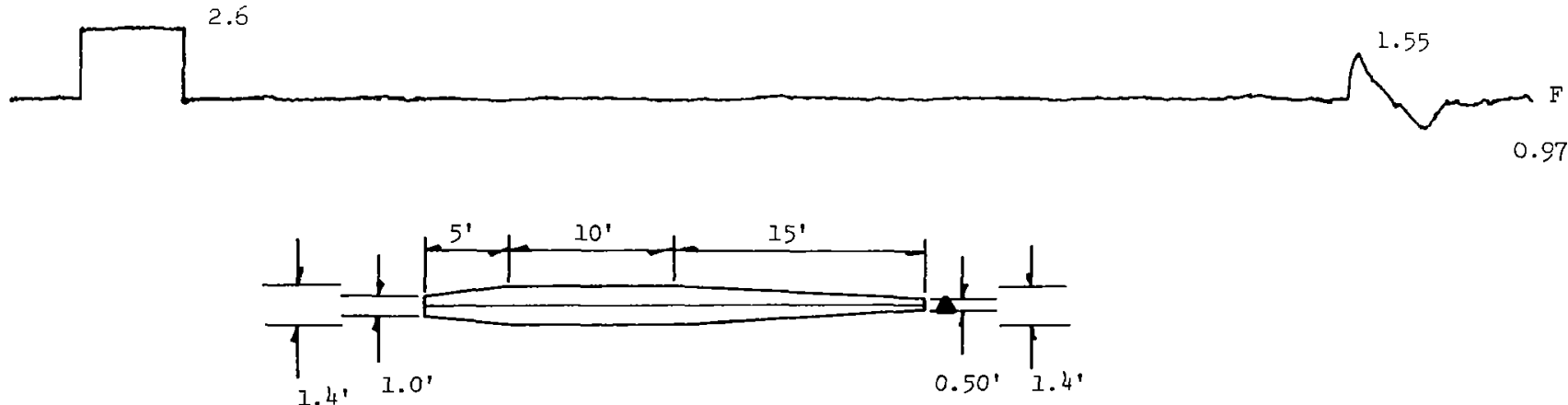

MICROPHONE ARRAY

Figure 99 SBS-102 


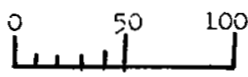

Millisec onds

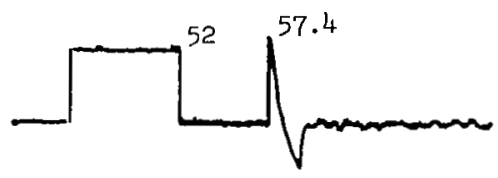

31.1

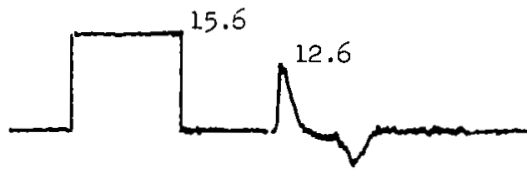

B

$$
5.66
$$
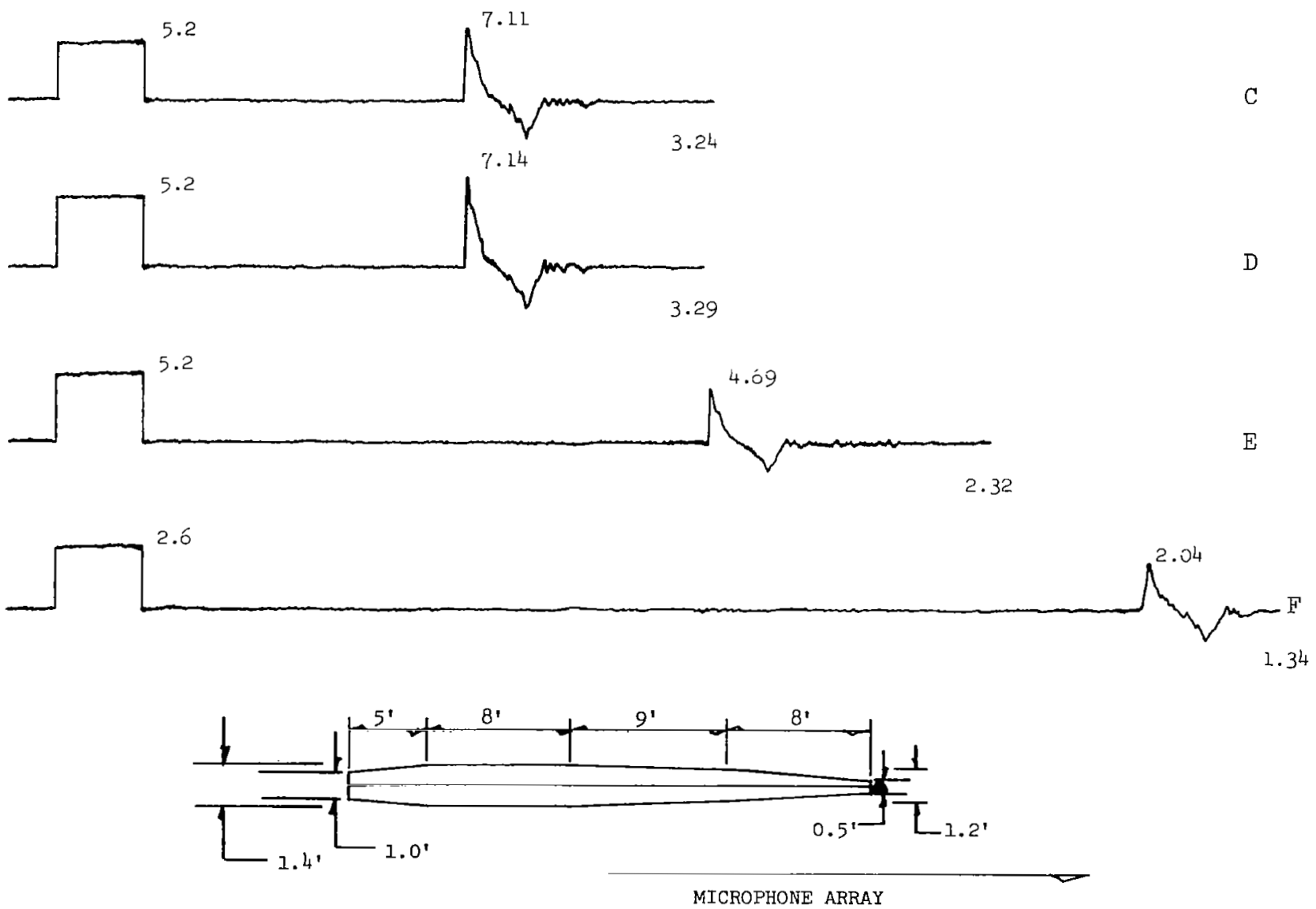

Figure 100 SBS 103 


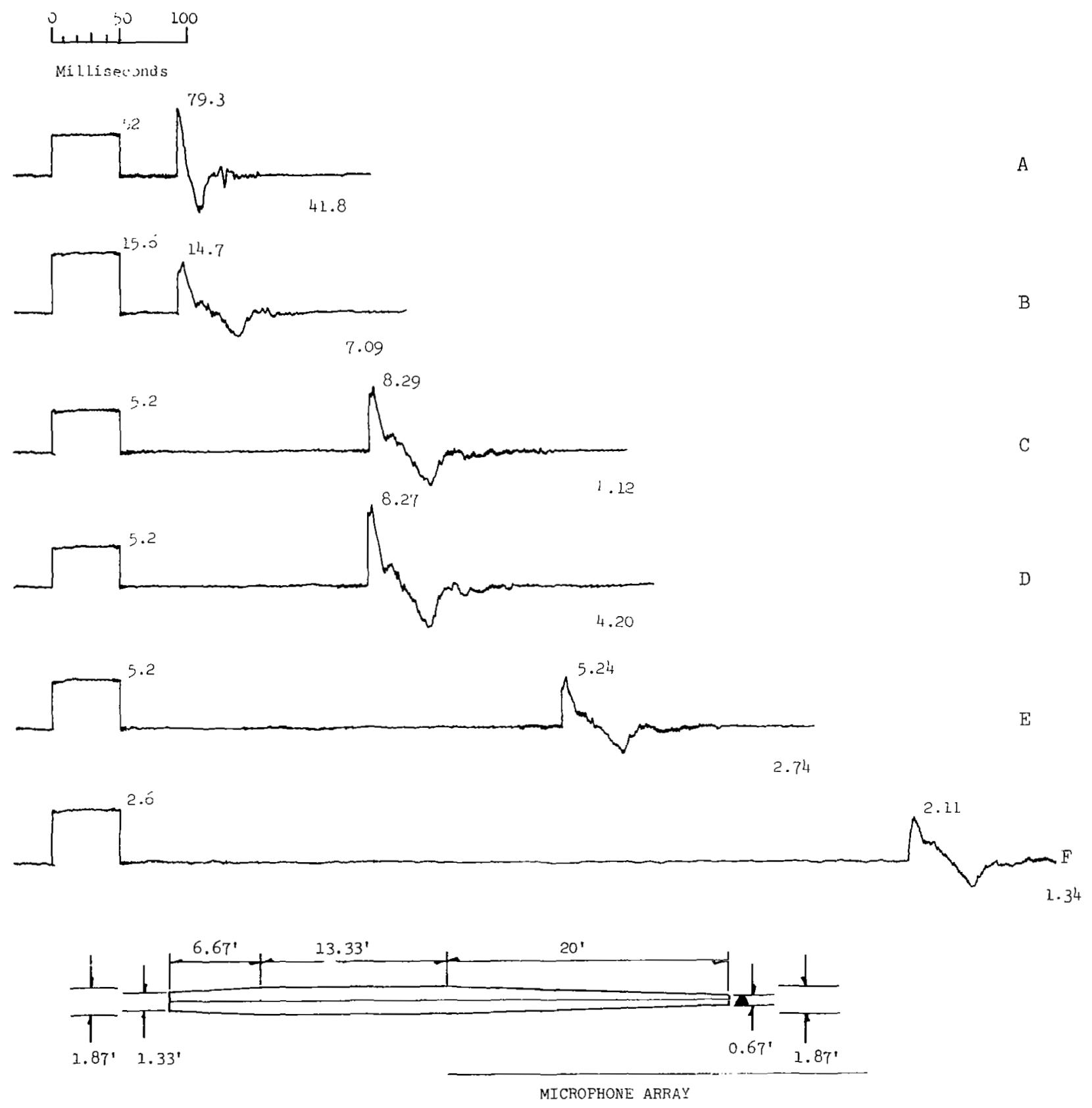

Figure 101 SBS 104 


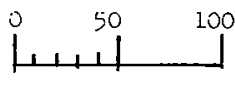

Milliseconds

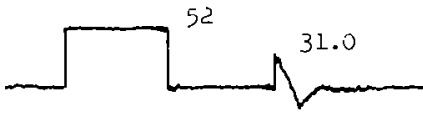

16.1

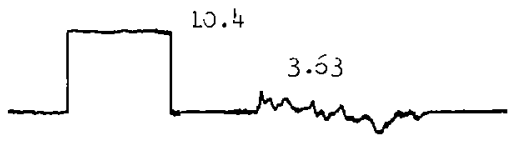

2.72

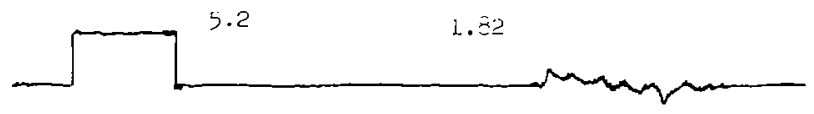

1.75

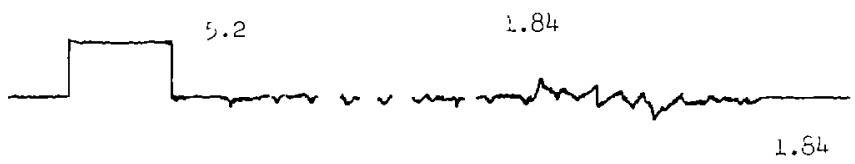

D

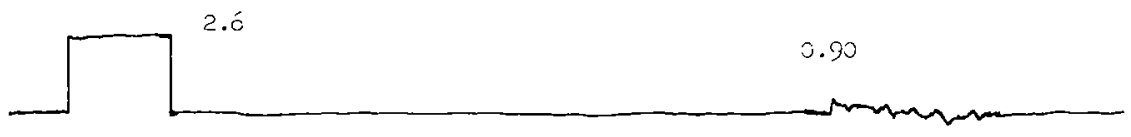

1.49
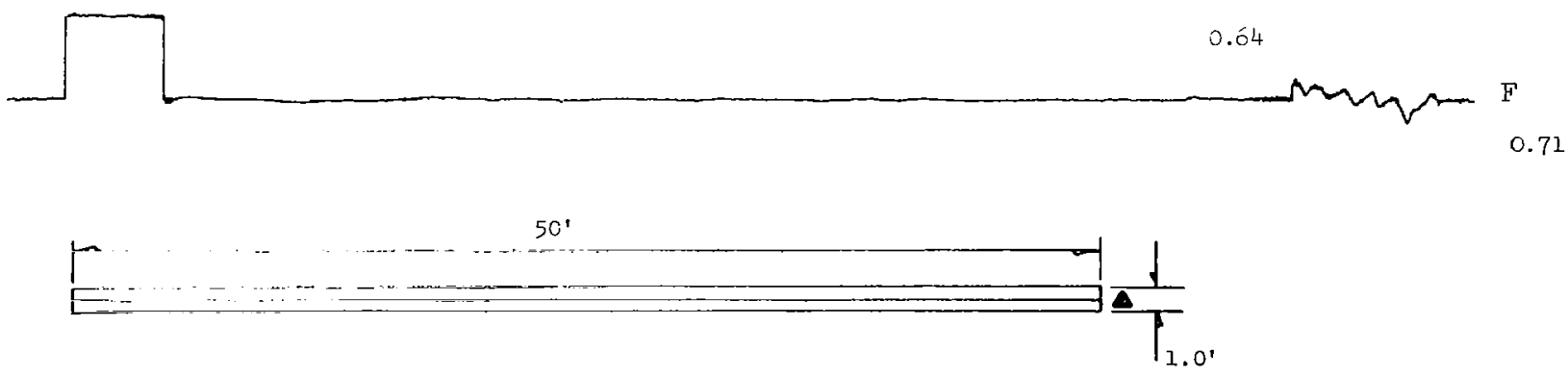

MICROPHONE ARRAY

Figlire 102 SBS-105 


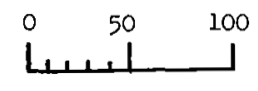

Milliseconds

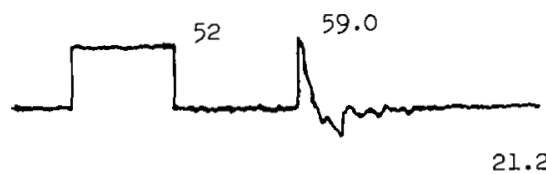

21.2
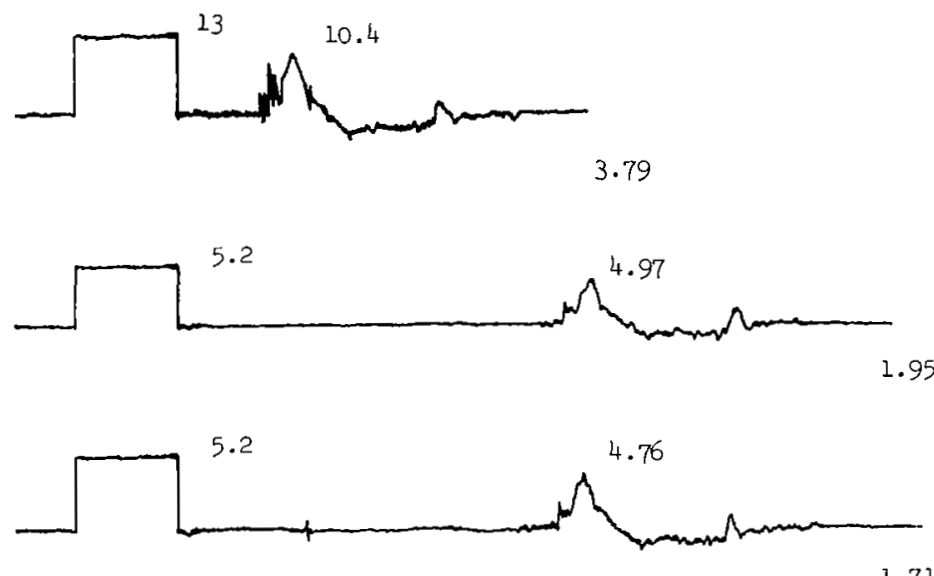

D

1.71

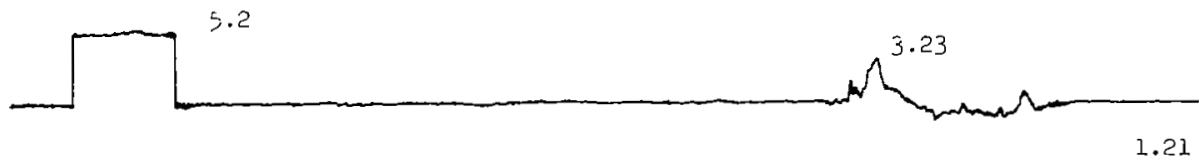

E
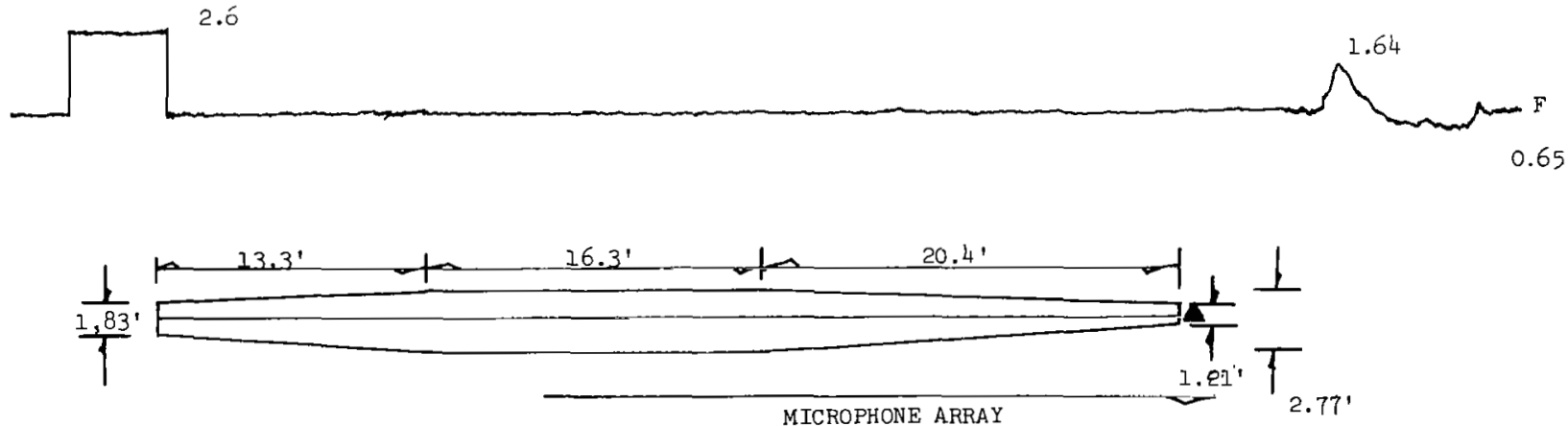

Figure $103 \quad$ SBS 106 
لـ

Milliseconds
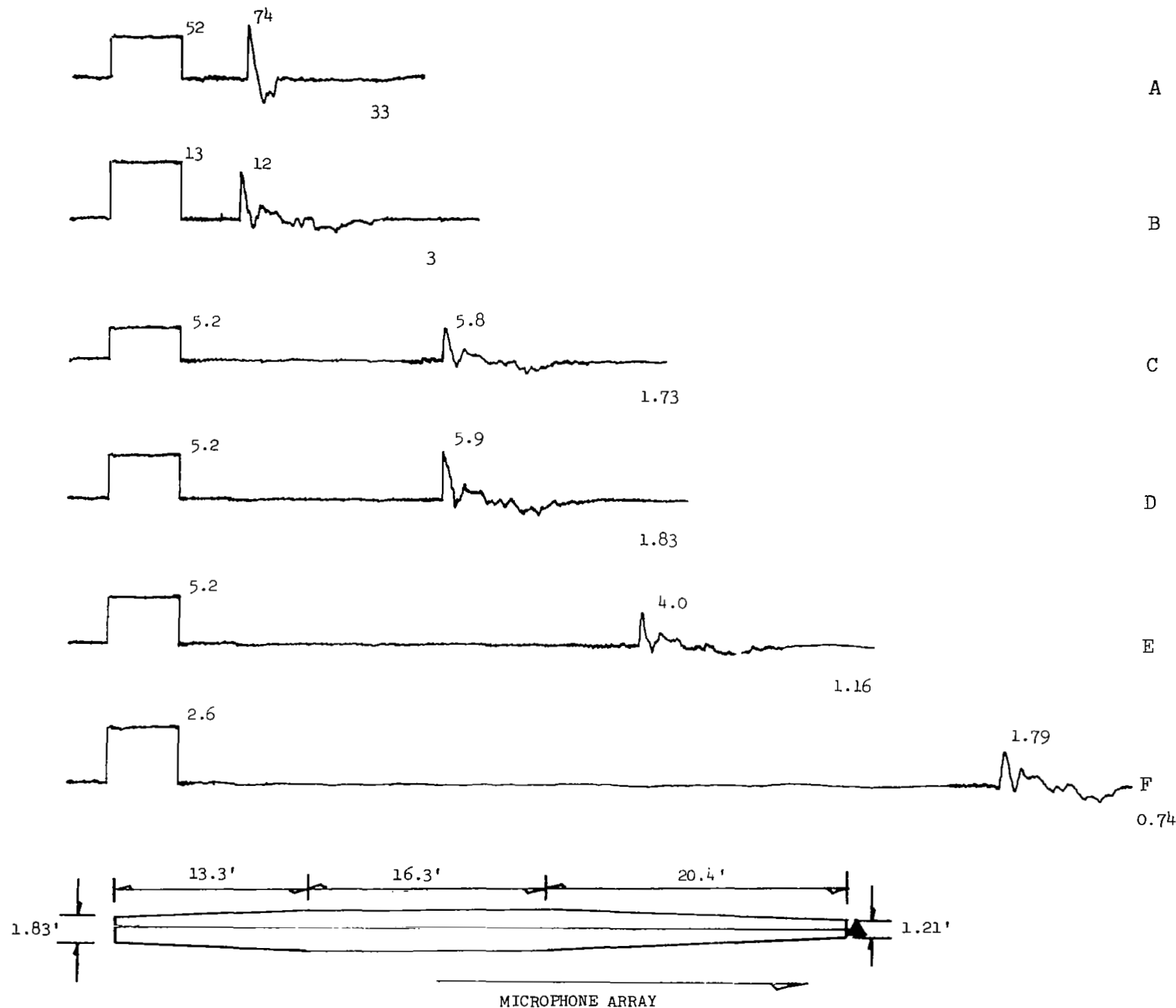

Figure 104 SBS 107 

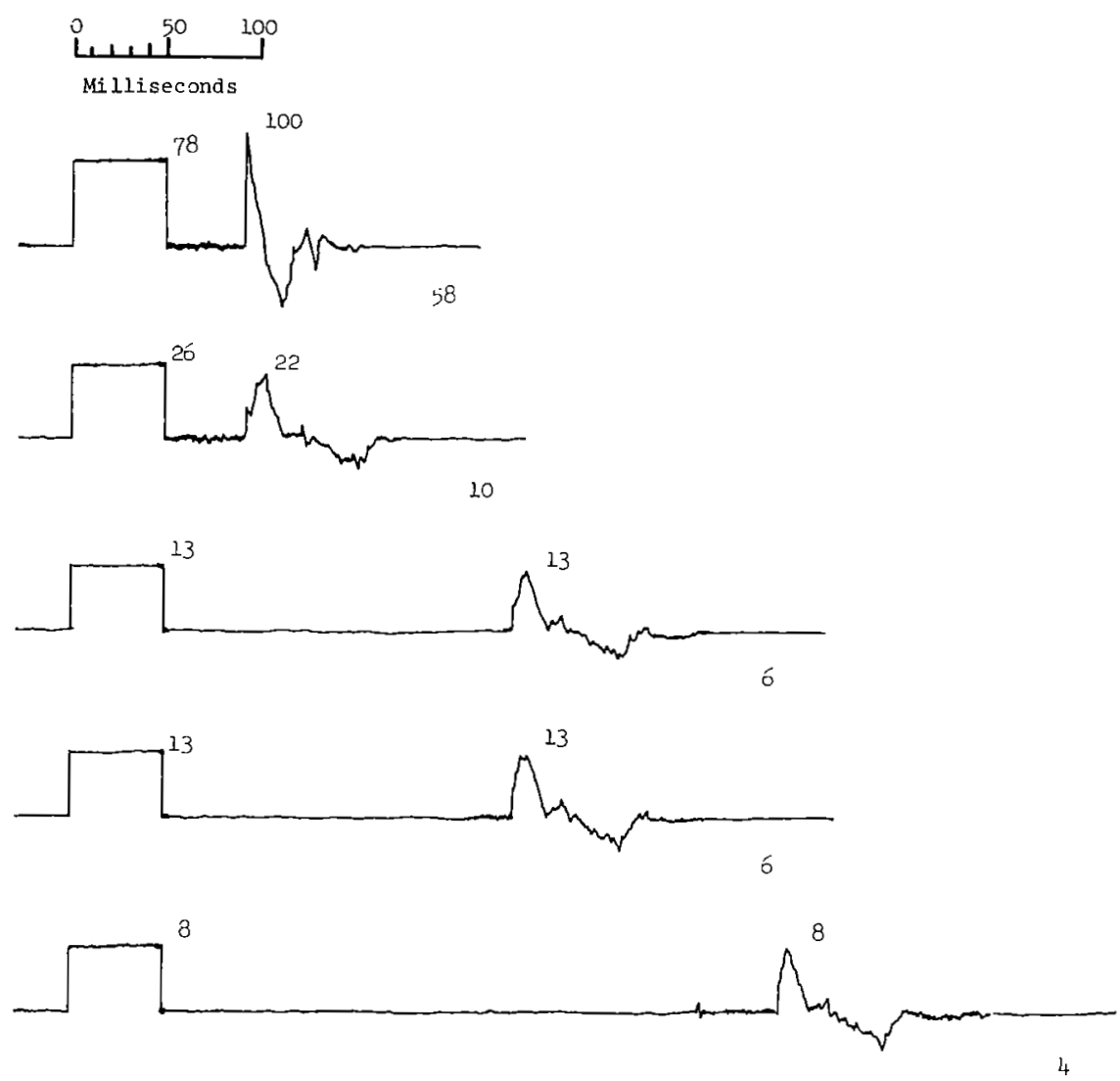

E
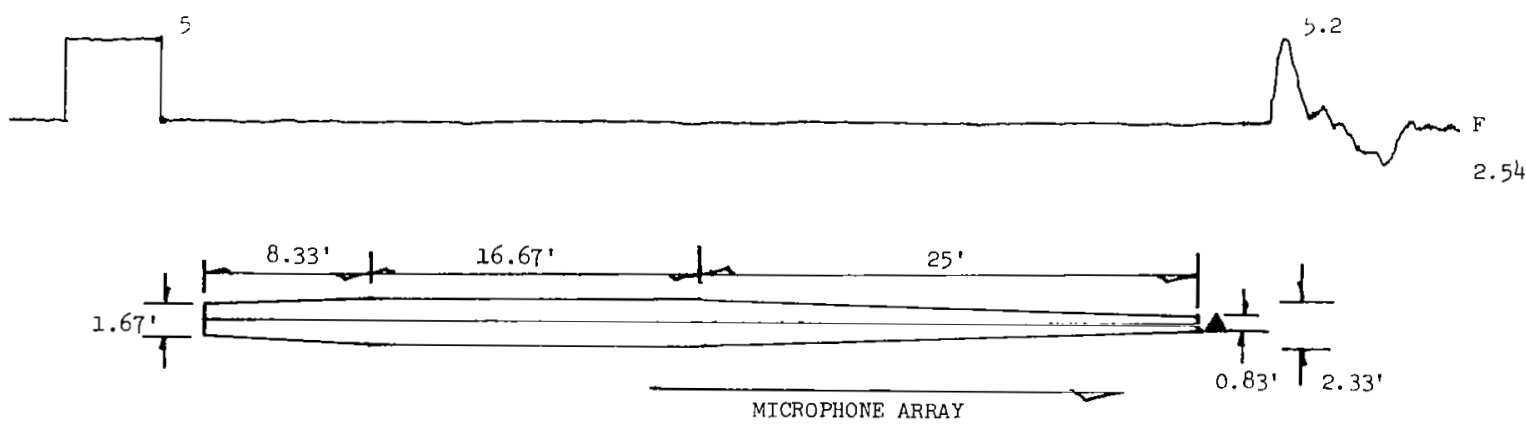

Figure 105 SBS-108 

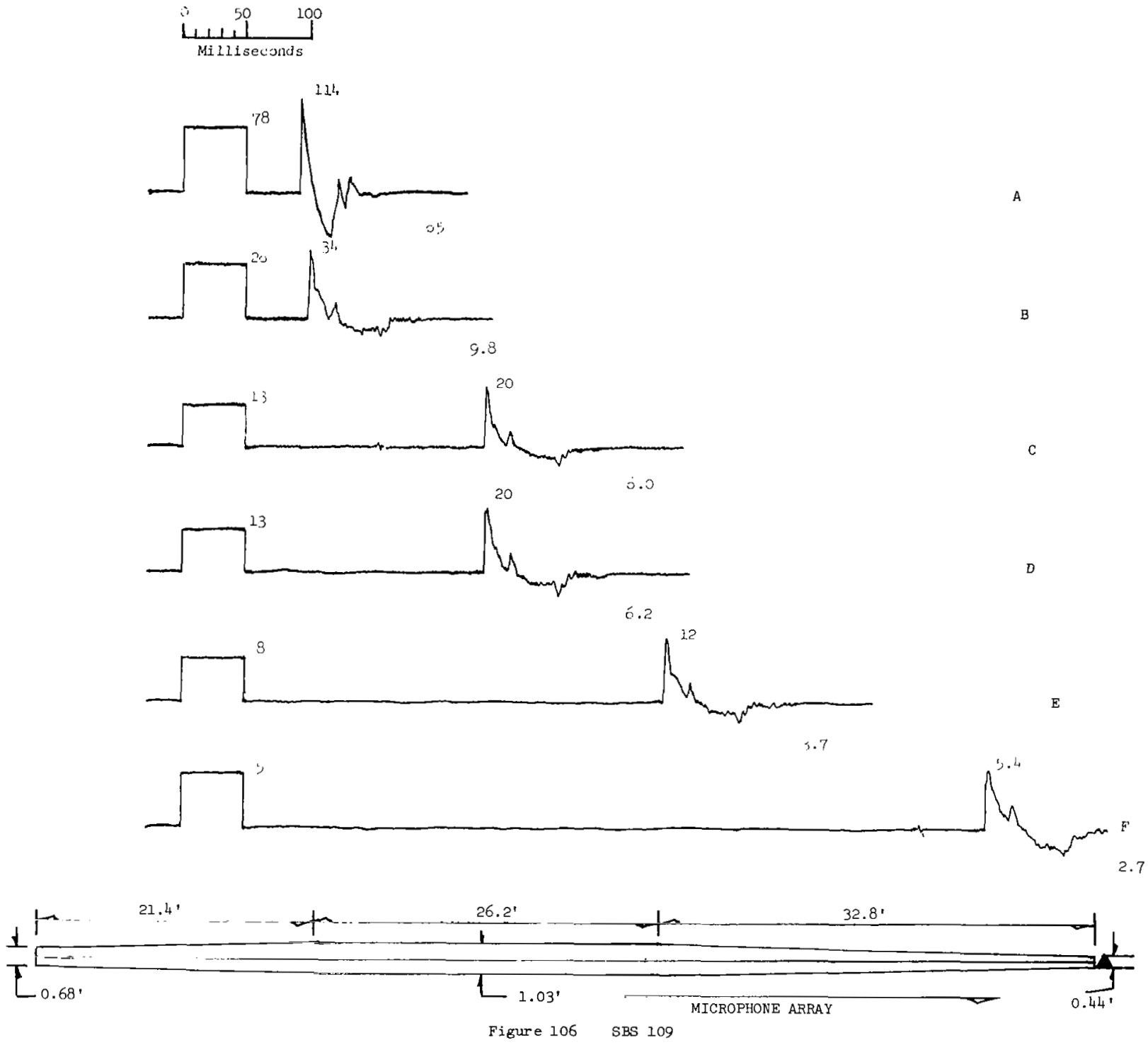


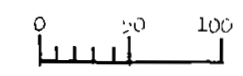

Millisecorits
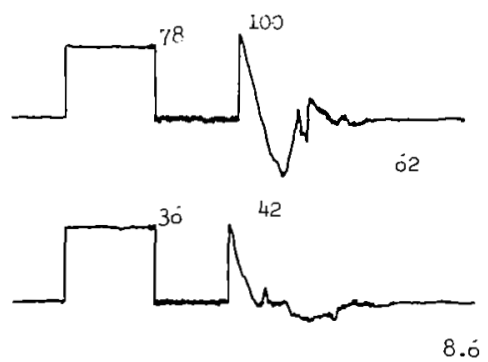

B
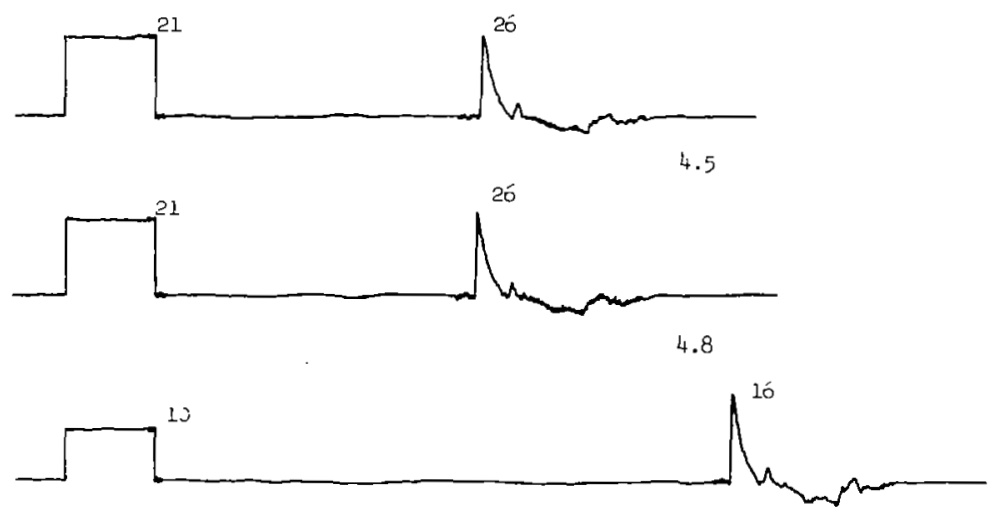

E
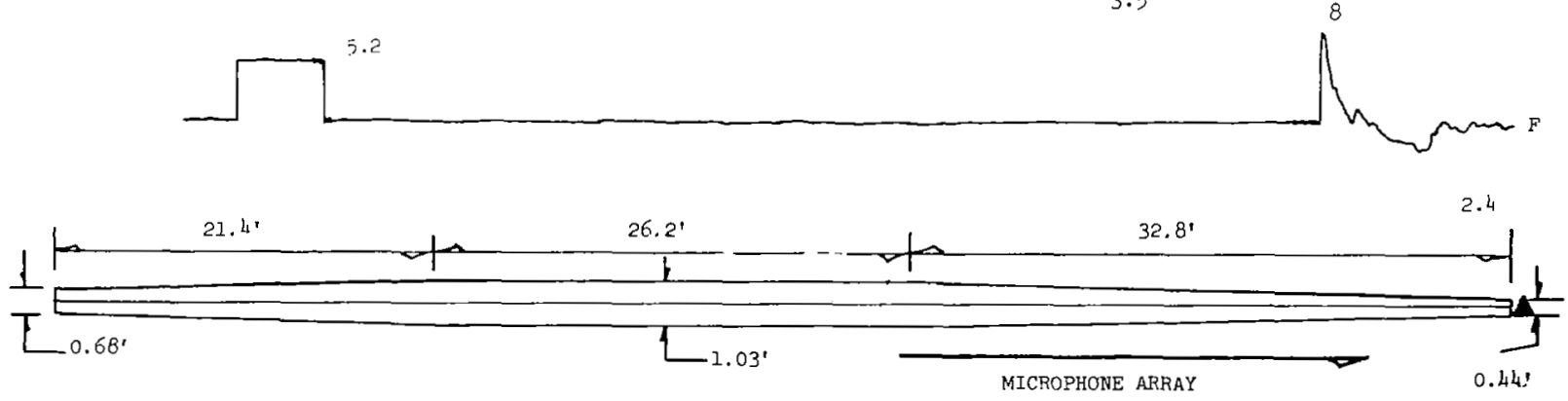

Figure 107 SBS-110 

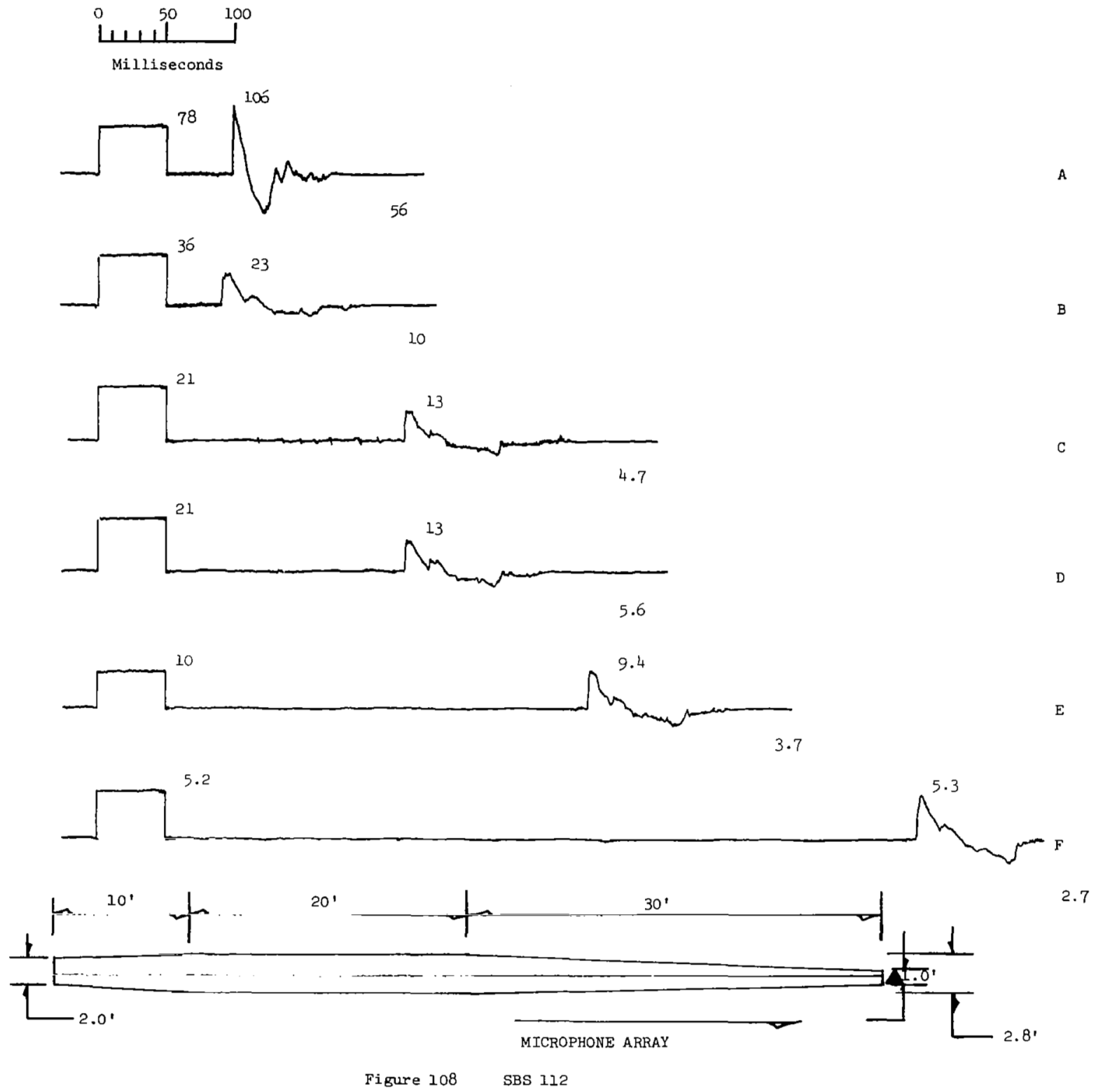